\title{
SB 252
}

.S5 

$\left(x^{y}=3\right.$

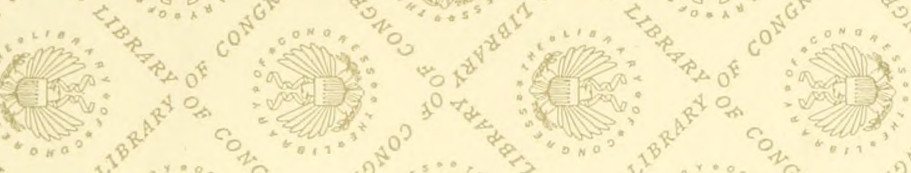

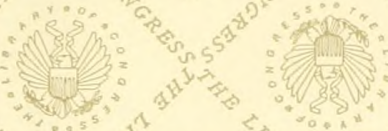

$5^{5 x_{3}}=x+10$

ant?

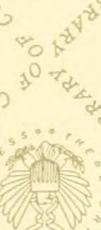

(1)

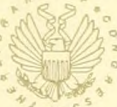

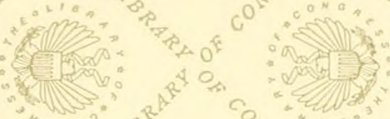

ins

$3^{30} x^{4}:$

年

(1)

$c^{+10}$

a

(fenzo

(n)

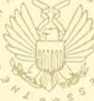

$\frac{2}{2}$

ats

- 10

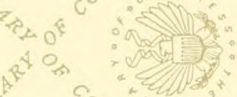
21
स० 



\section{I G E S T}$$
\text { -n- }
$$ \\ COTTON BALE-TIES \\ UNITED STATES PATENTS, \\ $-\mathrm{T} 0-$}

JANUARY 1st, 1877,

ENGLISH PATENTS,

JAIUATEY 1st, 1876.

L. W. SINSABAUGH and T. C. TIPTON. 


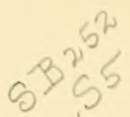

Entered according to Act of Congress, in the year 1877,

By L. W. Sinsabaugh \& T. C. Tipton,

In the office of the Librarian of Congress, Washington, District of Columbia.

In exch,

D, of 0. Pub. Lib.

L 7 ing 


\section{PREFACE.}

This work has been prepared solely for persons interested in the subject treated, and it is hoped that attorneys, inventors and manufacturers of Cotton BaleTies will find it serviceable to them. We have included in this digest all patents granted by the United States on this subject up to January 1st, 1877, in which a drawing of each and every figure, claims, whether original or reissue, dates of extensions, and disclaimers are given. A brief description of each English Patent, together with the drawings, up to January 1st, 1876 ; except where the same device is patented in the United States, in such cases reference is made to the number of the United States patent, and the page on which the drawing may be found. The patents are arranged numerically and chronologically, with name and residence of patentee.

The alphabetical index refers to the claim or brief page, where reference to the page on which the drawing will be found is made.

\section{W. SINSABAUGH,} T. C. TIPTON.

Washington, D. C. 



\section{Digest of U. S. Patents--Cotton Bale-Ties.}

SIMMONS \& RAQUET,-Nov. 7th, 1809.

The invention consists in securing baled substances by metallie bands placed in grooves in the press, and the ends secured (when the band is of flat sheet metal) by riveting the ends together, and when of wire or rod iron, hooks are formed on the ends, and after being hooked together the ends are twisted by pinchers.

[Drawing, page 1.]

JAMES M. TALBOT.-No. 1,790, Sept. 14, 1840.

Claim.-1. Constructing the key-band with a mortice plate $\mathrm{C}$, in combination with the tongue $T$, and wedge $K$, the whole being constructed substantially as herein set forth.

[Drawing, page 1.]

D. McCOMB, of Memphis, Tenn., No. 15,142, June 17, 1856; extended June 17, 1870. Reissued July 16, 1872, No. 4,993.

Claim.-1. I claim the peculiar formation of the link, as exhibited in figures 2 and 3, which forms a secure means of keeping the hooked ends of the hoop together, and has a guard which keeps it to its place, is easy of application in putting on, and may be removed at pleasure without mutilation. (Patented in England May 8, 1856, No. 1,089.)

[Drawing, page 1.]

MARY ANN McCOMB, Miemphis, Tenn., administratrix of the estate of DAVID McCOMB, deceased, No. 4.993, July 16, 1872. Reissue of Patent No. 15,142, dated June 17, 1856 ; extended seven years.

Combination of a slotted link, with the ends of metallic hoops or bands bent into hook form for the purpose of securing compressed bales of cotton and like compressible material.

Claim.-1. A slotted link, in combina. tion with the hooked ends of metallie ties, for the purpose of keeping them in place and assisting in preventing the opening of the hooks with the expansive force of the bales.

2. The method of baling cotton and like material by means of a slotted link or tieplate and metallic ties having their ends bent into hooked form and held in position by said link and the expansive force of the bale when released from pressure.

[Drawing, page 1.]

MARY ANN McCOMB, Memphis, Tenn., administratrix of DAVID McCOMB, deceased, No. 5,616, October 21, 1873.-Reissue of Patent No. 15,142, dated June 17, 1856; extended seven years; l'eissue No. 4,993, dated July 16, 1872. Application filed April 28, 1873.

Claim.-1. In combination with the hooked ends of metallic ties, a slotted link for the purpose of keeping said ends in position, and assisting to prevent the opening of the hooks by the expansive foree of the bale, substantially as specified.

2. The method of baling cotton or other like material by means of a slotted link or tie-plate and metallic ties having their ends bent into hook form, aud held in position by said link and the expansive force of the bale, substantially as is shown.

3. The method of baling cotton or other like material by means of metallic ties having their ends of hooked form, substantially as described, so as to permit of their being united by a sidewise motion, as set forth.

[Drawing, page 2.]

0. A. BROAD, of Louisville, Ky., No. 17,485, June 9th, 1857.

Claim.-1. A metallic hoop or band whose ends are nnited by the bows or curves $a, a$, slide $B$, and pin $C$, as herein set forth and described.

[Drawing, page 2.]

C. P. S. WARDELL, of Lake Village, N. H., No. 17,536, June 9, 1857.

Claim.--1. The combination of the hasps $\mathbf{D}$, having a bridge or bar $\mathbf{K}$, at the outer end of its slot, arranged as described, with the oblong button $e$, the two to operate together substantially in the manner and for the purpose specified.

[Drawing, page 2.] 
CHARLES J, PROVOST, of Sardis, Alabama, No. 18,299. September 29, 1857,

Claim.-1. So forming the slide, that its ends may be stuck down behind the bow or bend of the locks, and thus not only prevented from separating, but also holding the slide to the lock, substantially as herein set forth.

[Drawing, page 2.]

WM. MINOR, of Houma, La., No. 18,514, October $27,1857$.

Claim.-1. Securing the ends of metal bale hoops together by forming loops or eyes in the ends of said hoops, by cut. tiug parallel slits (b) through them, and bending outward the intervening portions $\left(b^{1}\right)$, the loops overlopping each other as the ends of the hoops are overlapped, and a transverse wedge or key $(c)$ passed through the loop, substantially as shown and described.

Drawing, page 3.]

\section{J. R. SPEER, of Vaux Hall, England, No.18,779,} December 1, 1857,

Claim.-1. The use of a hollow clasp or fastening for metallic bands, of the shape shown in the drawings, through which the ends of the hoops are passed in opposite directions, and the projecting extremities bent over the clasp and inserted into an aperture in the middle of the clasp, in the manner before described.

[Drawing, page 3,]

\section{J. R. SPEER.}

("Additional improvement" on above patent. March 23, 1858, No. 195.)

Claim.-1. I elaim bending the ends of the clasp across the aperture $b$ and $c$, so as to present an opening in the clasp for the insertion of the bent ends of the bands at right angles, or nearly so, to the direction in which the bands are inserted in the clasp, in the manner and for the purposes described.

[Drawing, page 3.]

\section{J. R. SPEER.}

(Additional Improvement on above patent, No. 18,779 Dec. 1st, 1857.)

No. 207, Oct. 26th, 1858.

Claim.-1. I claim the use of a clasp for metallic bands, constructed as hereinbefore described, having a single aperture only for the insertion of the hooked ends of the band, the plate of iron of which it is formed being bent across the aperture so as to present a sufficient opening for the ready insertion of the hooked ends of the bands, in the manner hereinbefore described.

[Drawing, page 3.]

\section{J. R. SPEER.}

Re-issue of above patent (No. 18,779, Dec. 1st, 1857.)

Feb. 19th, 1867 No. 2,491.

Claim.-1. A clasp provided with an aperture or apertures, and so bent across said aperture or apertures as to present an opening or openings for the easy insertion of the ends of the bands or hoops, and form an efficient clasp for securing the ends of the band or hoop, substantially as herein described, and for the purpose set forth.

[Drawing, page 3.]

JOHN MCMURTRY, of Lexington, Ky., No. 19,437, Feb. 23, 1858.

Claim.-1. Splitting one end of a eotton bale hoop so that it may be contracted or expanded in width as may be required, in order to effect the locking of the hoop, around the bale without slack, substantially as set forth.

Claim.-2. The combination of the slit and shouldered end of the cotton bale hoop, with the slotted end in the manner described, and for the purpose set forth.

[Drawing, page 4.]

F. C00K, of New Orleans, La., No. 19,490, March 2, 1858. Extended March 2, 1872.

A disclaimer was filed Feb. 1, 1872, disclaiming the 1st claim.

Claim.-1. The frietion clasp or buekle for attaching the ends of iron ties, or hoops for fastening cotton bales and other packages, so that the ties are prevented slipping by the friction against a certain portion of the buckle.

Claim.-2. I also claim the looping of the ends of iron ties or hoops for bales into a bnckle, by the form of which they are prevented slipping by friction when the strain of the expansion of the bale comes on the ties: the ends of the hoops or ties not being attached together in any way, the connection being formed by a distinct buckle or friction clasp. 
Claim.-3. Also, I claim the herein described slot, eut through one bar of clasp, which enables the end of the tie or hoop to be slipped sidewise molerneath the bar in clamp, so as to effect the fustening with greater rapidity than by passing the end of the tie through endwise.

[Drawing, page 4.]

D. G. OLMSTEAD, of Vicksburg, Miss., No. 19,709, March 23, 1858.

Claim.-1. The clasp $\mathrm{A}$, and the wedge $\mathrm{C}$, arranged and operating in combination with the band $B$, with its bent extremities $a, a$, substantially in the manner and for the purpose herein specified.

[Drawing, page 4.]

P. C. INGERSOLL, of Green Point, N. Y., No. 20,311, May 18, 1858.

Claim.-The button B, piroted to the plate $\mathrm{A}$, provided with openings $a, \alpha$, the button $\mathbf{B}$ being provided with recesses $c$ at its ends, and the whole arranged as and for the purpose specified.

[Drawing, page 5.]

JOHN P. MANNY, of Rockford, Illinois, No. 20,809 , July 6,1858 .

Claim.-The use of a short band cut in suitable lengths for separate bundles placed in proper position by lıand, and automatically passed around the bundle and fastened by the expansion of the bundle when re. leased, substantially in the mauner set forth. [Drawing, page 5.]

WM. FIELD, of Providence, R. I., No. 21,190, Aug. 17, 1858.

Claim.-1. Arranging the band over the clasp, and the ends of the band which are bent under to form the loops by which the band is connected with the clasp. so that the ends lay above the clasp, and the band covers and protects both of these ends and also the clasp, substantially as described.

Claim.-2. Connecting the looped ends of the band with the clasp by means of a double key or its equivalent, arrauged substantially as described, so that the turning of the key prevents the loop from slipping as described.

Claim.-3. Arranging the key or keys on the under side of the band and clasp, for the purpose described.

[Drawing, page 5.]
J. C. PLANT, of Macon, Ga., No. 21,272, Aug. $24,1858$.

Claim. The bale-tie or lock maue open at one edge and both ends, so that the band may be inserted in it edgewise, in the manner substantially as described.

[Drawing, page 6.]

JOHN AGNEW, of Columbia, S. C., No. 21,305, Aug. 31, 1858.

Clain. The socket $A$, provided with the double taper opening $a$, in connection with the loops $b, b$, at the ends B, B, of the hoops, substantially as and for the purposes set forth.

[Drawing, page 6.]

G. W. PENNISTON, of North Vernon, Ind., No. 21,360, Aug. 31, 1858.

The construction of my hoop tightener and holder, Figure 1, in connection with doors $D, D$, and arms $B, B$, and lever $A$, constructed as described, or any other construction substantially the same, and which will produce the same result.

[Drawing, page 6.]

A. C. RICHARD, of Newton, Conn., No. 21,517, Sept. 14, 1858.

Claim. The use of three rings, $\mathrm{A}$, and $\mathrm{C}$ $\mathrm{C}$, in combination with the hoop B, as a cheap and convenient cotton bale hoop, substantially as described.

[Drawing, page 6.]

A. C. RICHARD, of Newton, Conn., No. 21,848, Oct. 19, 1858.

Claim. The use of frame $a$ and ring $b$ in combination with the band $c$, substantially as described.

[Drawing, page 7.]

E. A. JEFFERY, of Corning, N. Y., No. 22,869, Dec. 21, 1858.

Claim. A hook-lock composed of a shell or socket $\mathbf{A}$, and a taper pin B, made as herein shown and described.

[Drawing, page 7.]

G, W. PENNISTON, of Mt. Vernon, Ind., No. 22,823, Feb. 1, 1859.

Claim. The tie $\mathbf{A}$, or friction $\mathrm{key}$, constructed as described, with convex inner bearings, 1 and 2, Figure 3, when constructed and operated in the manner and for the purposes specified.

[Drawing, page 7 .] 
H. KNOWLES, of New York City, No, 23.0943 March 1, 1859.

The method substantially as above described, of fistening tine ends of a metallic strap or hoop by passing each end of the strap or hoop through a slot in a metallic plite, one eloe of which slot is former? with a lowe lip on the outer face, bencling the end of the strap or lioop over and ontside of such lip and hammering or clinching down both the end of the strap and the lip, that the strap or hoop may be clasped or held irrespective of the body which is to be strapped or hooped, substantially as describilial.

[I)rawing, jage 7. .

P. C. INGERSOLL, of Green Point, N. $\mathbf{Y}$, No. 23,249, March 15, 1859.

Claim. 'The loops A, and key B, fitted together, and applied to the hoop, substantially as and for the purpose set forth.

[Drawing page 8]

C. WARNER, of New York, N. Y., No. 23,281, March 15, 1859.

Chim. The coustruction of a clasp of any material or dimensions substantially of the form deseribed, and illnstrated by the accompanying drawings, with two wedge shaped projecting tongues $b, b$, placed in the position, titted with sleeves, and protected by sides as mentioned.

[Drawing, page 8.]

GE0. BRODIE, of Plum Bayon, Ark., No. 23,291, March 22, 1859; Extended March 22, 1873.

Claim.-1. I claim forming the connecting links like those shown in figures 4,5 , and 6 .

Claim.-2. I claim bending one or both ends of the hoop or band, as shown in figures 11 and 12, around the outer ends of the connecting link thereby strengthening the ends of the link, preventing it turning or getting out of place, and the tie from untying.

Claim. - 3. I also elaim making metallic hoops for binding bales with a tie on each side of the bale for the uses and purposes before expressed.

Grim.-4. I alaim using strips of cloth or palper, or other suitable material under the metallic ho(y)s, as shown in figmeses 16 ) and 17 , for the purpose described, substantially as herein set forth.

[Drawlng, page 8.]
GE0. BRODIE, of Little Trock, Ark., Reissue of Patent, No. 23,291, March 22, 1859. No. 3,405, April 27, 1809.

Clum.-.1 'The bale tie formed by passing the bent ends or loops of the hoop $\boldsymbol{\Lambda}$, into the link $\mathrm{B}$, and holdine then there by means of pins $\mathrm{C}, \mathrm{C}$, passing through them and over the sides of the link, in the manner herein described, and shown in figures 1 and 3.

Cluim.-2. 'The bale-tie formed by passing the loops of the hoop $A$, into one or more recesses in the liuk 13 , through a slit or opening in the side, and holding said loops in the recesses by placing pins $\mathrm{C}$, within them and thus give such extension to the loops as to prevent their being withdrawn from the recesses while the pins remain in place, in the manner herein deseribed, and as shown in figmes 4 and 5 .

Claim.-3. The connceting link of a baletic having slit or opening in its side or end through which the hoop can be introduced into the link, as herein describer, aud as represented in Figures $6,7,13$ and 14 .

[Drawing, parge 9.]

G. BRODIE, of Little Rock, Ark. Reissue of Patent No. 23,291, March 22, 1859, No. 5,333 of March 25, 1873.

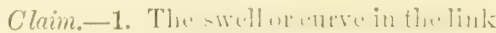
for the purpose of facilitating the introduction of the bands with their inserted pins, substantially as described.

l'laim. -2. The double lap of the band. as shown in Figures 11 and 12 , in combination with a metallic liuk.

Claim.-3. The combination of an open slot for introducing the band sidewise, with the link, luaving a single rectangrular opening for holding both ends of a metallic band, and the band.

Claim.-4. An open slotted link, when combined with metallic bands, the ends of which are turned under the link and held in position by the expansion of the bale.

Claim.-5. The methor of baling cotton with metallic bands and of taking up the slrek of the band by bencling the sime at

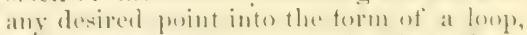

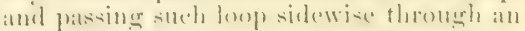

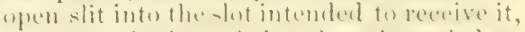
and over the bar of the clats interdere to hisld it.

[Drawlng, page 9.] 
R. LEWIS, of Charleston, S. C., No. 23,474, April 5, 1859.

Cluime. In the device, plates $\mathbf{A}, \mathbf{B}$, with slots $c, d$, projections $\mathbf{E}$, E, opening $f$, legs $g, q$, and shonkters $h, h$, in combination, constructer, mnited and operated, in the inanner substautially as described and for the purpose set forth.

[Draving, page 9.]

R. LEWIS, of Charleston S. C., No. 23,475, April 5, 1859.

C'rim. The plates $\mathrm{A}, \mathrm{B}$, opening $\mathrm{E}$, projections $f, f$, shoulders $c, c$, and $d, d$, in combination, constructed, united and operated, in the manner substantially as described and tor the purpose set forth.

[Drawing, page 9 .]

C. G. WELLS, of Galveston, Texas, No. 23,518. April 5, 1859.

Claim. The applieation of the washer $C$. and the mode of fastening the end of the band with it, as mentioned above, and thus expediting the operation of baling and conpressing bales of cotton or merchandise, and retaining them securely in their compressed form.

[Drawing, page 10.]

G. J. WIDRIG. of Memphis, Tenn., No. 23,632. April 12, 1859.

Clum. 'The particular improvement which constitutes my said invention and wlich I claim as laving been originally and first invented by me is, the combination of the sides $\mathrm{A}$, having slots or grooves $e$, with the bar $B$, for the purpose of fastening cotton bales or other similar substances by bringing the last end $f$, over the bar $B$, substantially as described and for the purpose specitied.

[Drasiug, page 10.]

JHARLES NEAMES, of New Orleans, Ia., No. 23, 777. April 26, 1859.

Clum. 'The arrangement and combination of two jaws II aud 1, hinged together at $L$, by means of hinge pin $\mathrm{L}^{1}$, as and for the jurpose described.

[Drawing, page 10.]

J. NUTTALL, of New Orleans, La., No. 23,940 May 10, 1859.

Clam. The combination of the plate $s$, and movable clasp (c) when made nse of $j n$ contining the hooks $a$ and $b$, as a fistening for iron ties for cotton bales, when made and arranged the same, or substantially as has been set forth.

[Drawing page 10.].
E. GARRETT, of New Orleans, La., No. 24,112. May 24, 1859.

Clum. The combination of the two plates $a$ and $c$, when made and arranged as, of substantially as has been sot forth, to torm a tie for iron bands for baling cotton or for similar purposes.

[Drawing, page 11.]

E. DAVIDSON, of Batesville, Ark., No. 24,995. Aug. 9, 1859.

Forning the socket of two parts to admit of the same being opened to receive the bent or doubled and lapped ends of the bale hoop, and closed to secure the ends of the hoop together, substantially as and for the purpose specitied.

[Drawing, page 11.]

H. KNOWLES, of New York, N. Y., No. 25,125 Aug. 16, 1859.

Claim. The method of securing straps by means of a roller, substantially such as iescriber in combination with the werlgeformed mortice of the sleeve which receives the strap, substantially as described.' Patented in England, Aug. 17, 1866, No 2117. [Drawing, page I1.]

W. BOYD, of New Orleans, Ta., No. 25,240, Aug. 30, 1859.

Cluim. I claim in combination with the splits the use of a key having wings at each end to form the lock to the tie, when mide and arranged as and for the purpose set forth.

[Drawing, page 11]

C. W. PYLE, of Galveston, Tex., No. 25,584, Sept. 27, 1859.

Claim. A plate constructed with a short open slot, a long closed slot, and a turued down lip or flange, substantially as described and for the purpose set forth.

[Drawing, rage 12.]

J. T, BUTLER, of Natchez, Miss., No. 26,087, Nov. 15, 1859.

Chim. The combination of the buckle frame A, when made without any opening in the border of it with the hook $\mathrm{C} \mathrm{C}^{\prime}-$ when the latter are received through the former and beld in place by the pressure of the bale against them, substautially as descrilied.

[0rawing, page 12.] 
A. H. HOOK, of Now York, No, 26,434. Dce. 13. 1859 .

C'luim. 'The outer enripper $a$, and nail $c$, for finstening the endis of bale and other straps, coustructed substantially as and for the purpose set forth.

[1) rawiug, page 12.]

D. HUGHES, of Rochester, N. Y., No. 26,435. Dec. 13, 1859.

Claim. The case or box $\Lambda$, having slots $a$ a, in two opposite sides, and provided with a clamp or juw B, alranged substantially as and for the purpose set forth.

[Drawing, page 12.]

C. W. WAILEY, of Lexington, Ky., No. 27,660. March 27, 1860.

The lues A, in combination with the spaces $b$, formed at the extges of the hoop, and extending any required distance from the euds, so as to unite and form a tie, sub. stantially as set forth.

[I) rawing, page 13.]

J. McMURTRY, of Fayette, Co., Ky., No. 27,866. April 10,1880.

Cluim.-1. 'The bending of the ends of metal hoops or bales substantially as deseribed above, for the purpose of making the fastening of the ends of sane, as shown in the accompanying drawings for the purpose set forth.

[1rawing, page 13.]

JOHN MCMURTRY, of Fayette Co., Ky., No. 5,457. June 17, 1873. Reissue of patent No. 27,866, dated April 10, 1860.

Claim.-1. The attachment of the ends of metallic bands by locking the same together, and bending the surplus ends beneath the borly of the bands, as shown.

2. Uniting the encls of iron bands for balcing purposes, by attacliug the same towether by hooks formed on one or both of suid bands without the interposition of n link or buekle.

3. A tic, formed by booking or looping the ends of metallic bunds into each other without the interposition of a link.

[1rawing, page 13.]

JAMES AIKEN, of Natchez, Miss., No. 28,044. May $1,1860$.

Claim.-1. The formation of the bent plate with the holes to receive the hoop, and also the form of the rivet catches as aforesind, with the mode of fistening the hoop to the plate.

[1) rawing, page 13.]
W. STEWART, of Natchez, Miss., No. 28,110. May 1, 1860.

'The tie or mode of fastening iron hoops on bales (of cotton or other compresed material) by means of a link or links, and sermated or notched edges of the hoop, as represented in the accompanying drawings. [1)rawing, page 14.]

C. H. DUBS, of Natchez, Miss., No. 28,164. May 8, 1860.

'The combination of the three prongse, $c, f$, with the hoop end $B$, and the plate $C$, as and for the purpose shown and described. [Drawing, nage 14.]

W. S. LAUGHBOROUGH, of Rochester, N. Y., No. 28,187. May 8, 1860.

Clam. The ennstruetion of iron ties, substantially as and for the purpose specified. [Drawlng, page 14.]

A. P. MERRILL, of Natchez, Miss., No. 28,392. May 22, 1860.

Claim. The combination of the romnded out notehes in the end of the strap, band or hoop, and the pyramidal shaped opening in the buckle, for the purpose of forming a lock or fistening to the hoops of eotton and other bales, and when construeted to operate together substantially as herein described.

[Drawing, nage 14.]

C. C. BIER, of New Orleans, La., No. 28,825 . June 26, 1860.

Claim. The particular novel mote of makiug an iroutie for the purpose of securly fastening of cotton-bales or other baled goods, as herein described, using for the mannficture of the same any metal suitable for the furpose.

[Dritwing, page 15.]

Z. W. \& E. D. LEE, of Blakely, Ga., No. $28,391$. July 3, 1860.

The tie-plate $\mathrm{C}, \mathrm{D}$, constructed, applied, and operating, as herein described for the purpose set firth.

[urawing, page 15.

T. McINTIRE, of Franklin Furnace, Ohio, No. 29,185. July 17, 1860 .

Cluim. The article of manufacture herein deseribed, to wit, a stiff metal tie-plate for cotton-bule hoops, mate with two 'I' slots in it, a tratusverse stop bar $\mathrm{C}$, between the slots, and two vertical squareshoulders $a, a$, 
at the outer termination of the slots, and below the under side of the bar $\mathrm{C}$, for use in combination with a cotton-bale hoop which has ' $\mathrm{T}$ shaped ends, in the manner and for the purpose heren described.

[Drawing, page 15.]

J. W. EVANS, of New York City, N. Y., No. 29,683. Aug. 21, 1860.

The application and use of a metal piece $A$, bent in the shape of the letter $S$, and operating on the hoop in the manner and for the purpose substantially as described. [Drawing page 15.]

H. A. R0E, of Madison, Ohio, No. 29,824. Aug. $28,1860$.

The arrangement and combination in the manner shown and described of the plate G, eccentric II, and bolt F, with the slotted arm E, yoke $\mathrm{D}$, guides $c$, c, and plate $\mathrm{A}$, for the purpose set forth.

[Draving, page 16.]

\section{P. DAVEY, of Portsmouth, Ohio, No. 30,126.} Sept. 25, 1860.

I clain the manner herein described of tastening the ends of an iron tie, by means of elevations $a^{1}$, fitting into the corresponding depressions a, when used in combination with a keeper $B$, or its equivalent, all substantially as and for the purpose specified.

[Drawing, page 16.]

R. W. FENWICK, of Washington, D. C., No 30,133. Sept. 25, 1860.

The fistening substantially as hercin de. scribed for metallic bands for cotton-bales. [Drdwing, page 16.]

J. J. McCOMB, of New Orleans, La., No. 31,252. Jan. 29, 1861.

Forming the link or tie with an oblong aperture, one end of which is arrow shaped or rather presents two sides of equilateral triangle; the design of this arrow-shaped end being, not only to force the hoop or bend of the hoop over the slot, which is done with unerring precision when the bale expands after being released from the pressure, but also to secure an equal bearing upon the separate parts of the slotted side of the tie.

English Patent No.361 of Feb. 11, 1862. [Drawing, page 16.]

CHAS. HUGHES, of New Orleans, La., No. 31,319. Feb. 5, 1861.

A hook-lock button made in the peculiar manner shown and described.

[Draving, page 17.]
C. WILSON, of Brooklyn, New York, No. 31,505. Feb. 19, 1861.

'The arrangement of the windlass $\mathrm{C}$, and attached hollow cone D, with the sliding cone F, weighted lever I, fork G, collar C, and shaft $B$, in the manner and for the purposes shown and described.

[brawiing, page 17.]

0. C. EVANS, of New York, N. Y., No. $81,848$. March 26, 1861.

T'lue combination of slots $s s$ in the plate $A$, with the angular tongues $t t t$, more or less as herein described and for the purposes set forth.

[Drawing, page 17.]

G. N. BEARD, of St. Louis, Mo., No. 32,818. July 16, 1861.

The shape and proportions of the cleat $c$, with respect to the loop-hole $d$, substantially as clescribed for the purpose specitied.

English 1'atent No. 1208 of April 28, 1866.

[Drawing, page 17.]

G. N. BEARD, of St. Louis, Mo., Reissue of No. 32,818 . July 16,1861, No. 2,548, April $9,1867$.

Claim.-1. The shape and proportion of the cleat device A, with respect to the loopholes B, subszautially as herein set forth.

Claim.-2. The fixed combination of a double hooked cleat, having prongs or engaging points of unequal length, with one end of a metallic band having an elongated aperture in its other end, when the length of satid aperture is less than the united diameter of the shank of said cleat and length of its longer prong, all substantially in the manner and for the purpose herein set forth.

[Drawing, page 18.]

T, W. REILLY, of New Orleans, La., No. 40,983. December 15, 1863.

The buckle $\mathrm{A}$, with tongues $d d$, and center pieces $c$, as finlly represented in the drawing.

[Drawing, nage 18.]

\section{E. V. FASSMAN, of New Orleans, La., No. 47,288. April 18, 1865.}

The plate A, provided with slots B B, and ridges or projections $b b$, at one or hoth sides of the plate, and with slits $a$, to form a new and improved cotton-bale tie or hoop as set forth.

English Patent No. 3,361 of Dec. 28, 1865.

[Drawing, page 18.] 
E. A. FIELD, of Sidney, Me, No. 50,025. Nov. 14,1805 .

Clum.-1. The bale hoop strainer composed of the holding-bar 13 , the lever $A$, the passage $b$, and the jaw e, arranged and applied together substantially as deseribed.

Clam.-2. Also the combination of the eushioning block $d$, the lever $A$, the passage $b$, and the jaw es and the holding-bar 13, the whole being arranged to operate substantially in the manner and for the purnose specified.

[Drawing, paige 18.]

F. QUANT, of Painesville, Ohio, No. 51,214 Nov. $28,1865$.

Claim. A hook-lock constructed with a longitndinal narrow aperture $\mathrm{A}$, and an enlarged transverse aperture B, substantially as herein shown, in combination with the pin or nail $\mathrm{D}$, operating as explained for the purpose set forth.

[Drawing, page 19.]

WM. I. CARROLL, of Natchez, Miss., No, 52,137. January 23, 1866.

Chim. The derices or fastenings $d$, and E, constructed and arranged as herein described and for the purpose herein set forth. [Drawing, page 19.]

J. F. MILLIGAN, of St. Louis, MEo., No. 53,230. March 13, 1866.

Claim. 'The button $a$, with its head set obliquely to the plane of the hoop, and with an oblique flange $d$, operating in the mantrer and for the purpose herein deserilumel.

Euglish patent No. 981, of March 23, 1868.

[Drawing, page 19.]

I. H. MERRITT, of Cincinnati, Ohio, No. 53,851. April 10, 1866.

Clam. 'The combination of the band $\mathrm{A}$, and key $\mathrm{C}$, when so arranged that the separate lugs of the single key shall detain the respective ends of the baud, substan. tially as described and represented.

[Orawing, page 19.]

IAMES B00TH, of St. Louis, Mo., No. 54,675 May 15, 1866.

Claim. An improved cotton-bale tie $\mathbf{A}$, constructed with three hooks $a^{2}, a^{2}, a^{3}$, and combined with the ends 13 and $C$ of the hoop, substantially in the manner deseribed and for the purpose set forth.

[Deawing, page 20]
R. S. ADAMS, of Loyd, N. Y., No. 54,810. May $15,1888$.

Claim.-1. An improved machine formed by eombiuing a paip of srippers B, constructed as describer, with each other, with the cog-wheel C, ratehet-wheel E, pawl F, and with the frame $\mathrm{A}$, in which they are placed.

Clam. -2. The rombination of the punch $G$, construeted and operating substantially as described, with the machine for the purpose set forth.

[Drawing, pare 20.]

W. ONIONS, of St. Louis, Mo., No. 55,353. June 5, 1866.

Claim.-1. The head C, having the hook upon one side, substantially as and for the purnose deseribed.

Claim. - 2. I also claim forming the head C, plate E, and rivet $\alpha$, of one and the same piece, as and for the purpose specifierl.

[Drawing, jage 20.]

T. McINTIRE, of Portsmouth, Ohio, No. 57,945. Sept. 11, 1866.

Claim. A new article of manuficture, viz., iron hoops for cotton-bales, cut to the required length and having a clasp or buckle constructed substantially as deseribed, per nanently attached by a rivet at one end, so as to form a hinged joint, the whole being covered by a protecting corering of paint or varuish, substantially as described.

[Drnwing, page 20.]

T. B. BUNTING, of New York,N. Y., No. 58,018. Sept. 11, 1866.

Claim. I do not claim a slotted frame, nor projecting tongues, but what I do claim is, the rolled eiges $c$, of the slofted frame, substantially as described for the purpose specitiesl.

[Drawing, page 21.]

J. McMURTRY, of Lexington, Ky., No. 58,445. October 2, 1866.

The hoop-iron enton-bale tie $A$, ennstructed and operating in the manner and for the purposes herein set forth.

[1 rawing, page 21.]

JOHN MCMURTRY, of Lexington, Ky., No. 5,617. O3:obэr 21, 1873. Reissue of patent No. 58,445, dated October 2, 1868.

Clrim.-1. A bale tie formed by the attachment of one end of a metallic band or 
strip) to the other by looping it into or onto, or engaging it with the same, the end thus engaged with the other being confined in position by the expansive force of the bale.

Clerm.-2. A metallic bale-band having one end formed into a plain or lialf-twist loop for the reception or interlocking of the other, substantially as hereinbefore described.

[Drawing, page 2t.]

A. BARBARIN, of New Orleans, La., No. 58,574. October 9, 1866.

The herein described derice for fastening metallic bands, the same consisting of a segmental plate recessed so as to have a C shape, construeted and arranged to operate as set forth, so that the partial rotation of the plate shall effect the release or loosening of the band, substantially in the man. ner lrerein specified. $1866^{\circ}$.

English Patent No. «,790, October 29,

[Drawing, nage 21.]

C. W. WAILEY, of New Orleans, La., No. 58,698. October 9, 1866.

The metallic tie or buckle $\mathrm{A}$, when constructed as described for the purpose set forth.

1866.

English Patent No. 2,535, October 3,

[Dratring, page 22.]

G. W. WAILEY, of New Orleans, La. Reissue of No, 58,698. October 9, 1866. Reissue No. 2,496. February 19, 1867.

The wronght or malleable iron self-fas. tening buckle or tie $\mathrm{A}$, when prorided with curved projecting lips $\mathrm{B}, \mathrm{B}^{2}$, and openings $\mathrm{C}, \mathrm{C}^{1}$, and otherwise constructed as described, for the purpose set forth.

[Drawing, page 2.]

G. N. BEARD, of St. Louis, Mo., No. 58,760. October 16, 1866.

A hoop-lock formed with a rectangular slot $a^{1}$, connecting with and forming a part of curved slots $a^{2}, a^{3}$, substantially in the manner and for the purpose herein set forth. [Drawing, jage 22.]

Z. W. LEE, of Blakely, Ga., No. 58,844. October $16,1866$.

The metallic band $B$, having the bend $b$, at one end and the loop $b^{x}$, at the other end, and applied and substantially in the manner and for the purpose described.

English Patent No. 175, of Jan. 23, 1867. [Drawing, page 2w?.]
J. C. LEE, of Gonzales, Tex. Reissue of patent No. 58,844. October 16, 1866. Re. issue No. 2,449. January 8, 1867.

The metallic baud $B$, having the bend $b$, at one end, and applied substantially in the manner for the purpose described.

[Drawing, page 23.]

J. H. GRIDLEY, of Washington, D, C., No. 59,007. October 23, 1866.

C'laim.-1. A cotton bale or other tic, so constructed that the fastening is made by the ectges of said tie, in connection with corresponding flange on the opposite end of the tie, or on a separate plate, haring said thanges on it, sulstantially as described.

Claim.--2. The plate B, having flanges $d$, cast or otherwise formed on its ed ges, in combination with the ends of the tie when said ends are cut in dovetail form, substantially as described.

Clrim.-3. The plate B, having flanges $b$, on its edges, and lips $a$, as described in combination with the tie having a dovetail, and with notehes cut in the erlges of said dovetail, substantially as described.

[Drawing, page 23.]

\section{G. A, SEAVER, of New Orleans, La., No. 59,141. October 23, 1866.}

Making the inner sides of the link with a curved or angular form, substantially as described, for the purpose of holding the band by indenting its edges in addition to the transverse bending when it luas been forced into position.

[Drawing, page 23.]

C. SWETT, of Vicksburg, Miss., No. $59,144$. October 23, 1866.

Claim. My improved fastening block for uniting the ends of metallic bands when said bands are made to embrace completed bales of cotton or other equivalent substance, substantially as herein set forth.

[Dratwing. page 23.]

C. SWETT, of Vicksburg, Miss., No. 4,896 . May 7, 1872. Reissue of patent No. 59,144. October 23, 1866.

Clam.-1. The method of tying or fastening the free ends of metallic bands around bales of cotton and similar elastic material, by passing such free ends, while the bale is muder pressure, through a slotted link or tie-plate, substantially in the manner specified, so that the inner fold or lap, of the band ends will be held up aud pressed firmly against the under side or surfaces of 
the link or loop, by the force exereised in the expansion of the cotton when released from pressure.

Claim.-2. 'The slotted link in combination with the ends of metallic cotton ties, when constructed substantially as deseribed, to be held in position by the expansive force of the bale, substantially as described.

[J)rawing, lage 24.]

\section{J. J. McCOMB, of Liverpool, Eng., No. 59,151.} October 23, 1860.

Claim.-1. 'The peculiar form of the selfacting nipping-ties or metal band lock, for connecting the ends of metal bands, surrounding cotton or other bales, as hereinbefore described, and set forth, and forming the slots or holeg through the same in an oblique direction, and also forming the holes or slots on one end a little narrower than the wilth of the metal band, by forming the sicle or sides at an angle, substantially in the manner and for the purpose hereinbefore described and set forth.

Claim.-2. And lastly: The improved construction of grapple, jointed to and operated by a hand lever having jointed prongs, substantially in the manner and for the purpose hereinbefore described and set forfl.

brawing, page 24.

\section{J. J. McCOMB, of Liverpool, Eng., No. 59,152. October 23, 1866.}

'The peculiar manner of folding the metal bands, as hereinbefore described and illustrated in Figures 1 and 2, substantially in the manner and for the purposes hereinbefore deseribed and set forth,

[Trawing, page 24,]

M. A. TARLETON, of New Orleans, La., No. 69,293. October 30, 1866.

Clam. The tie or buckle $A$, when constructed and operating as herein described for the purpose set forth.

[10rawing, page 25.]

W. ONIONS, of St. Louis, Mo., No. 59,443 November 6, 1886.

Cluim. The bar C, secured to nne end of the bale hoop, and having central tongue piece $\mathrm{D}$, and hooks $\mathrm{E}$ and $\mathrm{F}$, in combination with the notches $a$ a, and opening $b$, in the other end of the bale hoop, substantially as described, and for the purpose specified.

[ I) raw Ing, page 25.]
JOHN F. MILLIGAN, of St. Louis, Mo, Nio. 59,512. November 6, 1866.

C'lam. A tic-plate B, provided with pointed retaining projection or stop $b$, when combined with an oblique slot ", to receive and secure the free end of the hoop, sub. stantially as and for the purpose herein described.

[Drawins, page 25.]

J. W HEDENBERG, of Chicago, Ill., No. 60,187. December 4, 1866.

Claim. A cotton tie, with one or more keys $\mathrm{C}$, so made and arranged as to requile a lateral movement to rlasp and to unelasp it, constructed and operating in the manner herein described.

[Drawing, page 26.]

R. G. LATTING, of New Orleans, La., No:,60,528. December 18, 1866.

Claim.-1. A buckle arranged with two loops $d, g$, constructed as described, with an angular ridge $c$, formed by the depression of the center of the plate, as and for the purpose described.

Claim.-2. I also clain the hook $h$ or its equivalent, for strenthening the open loop $g$.

[Drawing, page 26.]

R. G. LATTING, of New Orleans, La., No. 61,217. January 15, 1867.

Claim.-1. The toothed ridge $\mathrm{G}, 7$, as and for the purpose described.

Claim.-2. The shoulder $h$, in the bar of the loon $\mathrm{C}$, as and for the purpose deseribed.

Claim.-3. The arehed central bar G, substantially as described and represented.

English Patent No. 1880 of June 27, 1867.

[1)rawing, page 26.$]$

H. FASSMAN, of New Orleans, La., No. 61,527. January 29, 1867.

Claim. A hoop-lock constructed in the shape of a hook and of that form, with legs $a, b$, of different lengths, and a short curve or neck $c$, and with or without a shoulder $d$, substantially as and for the purpose set forth.

English I'atent No. 320 of Feb. 1, 1866 , [Lrawing. page 26.]

H. FASSMAN, of New Orleans, La., No. 61,727. February 5, 1867.

Cluim. 'T'he bale-tie buckle constructed with an opening in one loop, with cham- 
fered coiners $a, b$, and with a ridge or $\mid J$ ridges $c c$, on one or both sides, substantially as and for the purpose described.

English Patent No. 1,162, Apr. 20, 1867. [Drawing, page 27.]

1. REESE, of Pittsburg, Penna., No. 61,868 . February 5, 1867.

Claim.-1. The loop $c$, constructed and attached, substantially as described, to one end of a metallic loop, and of snfticient size to admit the opposite end of such hoop, so that when sucli opposite end is passed through and folded back in either of the forms described, it will be held in place either by outward pressure of the bale or by sleeres $n, n^{1}$, one or more.

Claim.-2. Compressing the folded end of a hoop, at or near the point of folding by the joint action of the loop $c$, and bale, or of the loop $c$ and sleeve n, for the purpose of preventing the slipping of the hoop at the point of fastening, substantially as described.

Claim.-3. The sleeves $n, n^{2}$, of a metallic hoop in combination with the loop $c$, for the purpose of fastening bale hoops, substantially in the manner described.

[Drawing, nage $2 \pi$.]

J. KNIGHT, of Louisville, Ky., No. 62,040. February 12, 1867.

Claim. Forming a bale-tie loop A, with turned edges $a, a$, and one diagonal and one square end, arranged and applied for sceuring the ends of a hoop in the manner herein describeri.

Fnglish Patent No.2,726, Oct. 22, 1866. [Drawing, page 27.]

J. REINECKER, of New Orleans, La., No. 62,069. February 12, 1867.

Claim. The plate B, provided with semicirculat openings $a$, and the opening $e$, with inclined sides $d$, presentiug two sharp edges or angles to the straps, substantially as de. scribed and for the purpose specified.

[Drawing, page 27.]

H. FASSMAN, of New Orleans, La., No. 62,188. February 19, 1867.

Claim. A plate $\mathrm{A}$, having slot or opening $b$, provided with serrated or toothed sides to receive the end $\mathrm{C}$ of the hoop and prevent the slipping or withdrawing of $\mathrm{C}$ from $b$, substantially as shown and described.

English Patent No. 858, March 25, 1867. [Drawing, page 3s.]
J. REESE, of Pittsburg, Penna., No. 62,365. Feb. 26, 1867.

Claim. The combination of the $\mathrm{T}$, head $c$, and slots $a, a$, in a hoop or tie for cotton bales, with a movable arm $b$, or strap $b^{1}$, to which the button is attached, so constructed, and arranged, as that when the tie is fastened, the head of the lutton shall lie across the slot, substantially as and for the purpose described.

[Drawing, page 28.]

R. DILLON, of New York, N. Y., No. 62,400. Feb. 26, 1867.

Claim. The combination of plate $\mathbf{B}$, with cross-piece $d$, and wings $e, e$, in combination with the pin $b$, substantially and for the purpose described.

[Drawing, page 28.]

J. W. PETTY, of New Orleans, La., No. 62,560 . March 5, 1867.

Claim. The combination of two ends of an iron band when used for banding cotton when provided with the openings, $a, b$, substantially as described for the purpose set forth.

[1)rawing, page 28.]

J0S. W. PETTY, of New Orleans, La., No. 7,360. Oct. 24, 1867. Reissue of patent No. 52,560, dated March 5, 1867.

Claim.-1. A bale-tie provided near each evd with an oblique or inolined hookingslot, adapted for hooking or clasping around a bale.

Claim.-2. In a bale-tie, an inclined hooking-slot, communicating with the outer edge of the bale-tie band, for the purpose set forth.

Claim. -3. The combination of the ends A B, of an iron band, provided with slots $a a^{1}$ and $b b^{1}$, substantially as set forth.

Claim.-4. In an iron bale-tie having slots in its sides that serve as hooks or clasps, the square inner end $c$ of said slots, substantially as shown, and for the purpose set fortb.

[Drawing, page 29.]

B. COLEMAN, of Louisville, Ky., No. 62,610 . March 5, 1867.

Claim. 'The rectangular tie plate $\mathbf{A}$, having the square and diagonal side slot a, when applied to bale hoops for securing the euds arranged substantially as herein described.

[Urawing, page 29.] 
GE0. RICKER, of Covington, Ky., No. 62,777 . March 12, 1807.

Chim. The plate with slot $\mathbf{B}$, having an. grulat projections $\mathrm{C}$, ore above and the other below the plate, on opposite sides of the same slot, substantially as represented and rleseribed.

[Drawing, wage 25.]

D. M. SECKLER, of Cineinnati, Ohio, No. 63,105. March 19, 1867.

Cluim.-1. 'The arrangement of buckle $A$, constructed with notched slot 4,5 , and the loop B, adipted and proportioned to engago with the buckle, substantially as clescribed and represented.

Claim. -2. I claim the loop B, for attachment to one end of the hoop, and adapted to lock within a buckle or equivalent drvice on the other end of the hoop.

[Drawing, page 29.]

0. MACDANIEL, of New York, N. Y., No. 63,166. March 26, 1867.

'The combination of a wire bale-tie fastened with hooks and eyes, substantially as herein described.

English Patent No. 751, March 15, 1867. [Drawing, page 30 .]

\section{S. 0, RIDER, of New York, N. Y., No. 63,563. April 2, 1867.}

The key or pin c, constructed with an angular tooth or rib $c$, in combination with the loop $a^{\prime}$, and slot $c^{\prime}$, arranged at the op. posite ends of the tie or baud, substantially as herein set forth and for the purpose specified.

[Drawing, page 30.]

W. F. BUCKELEW, of Shreveport, La., No. 83,849 . April 16, 1867.

The point $A, b$, and $a$, in combination with the point $c$, and the bend $B$ and $C$, as and for the purpose set forth.

[Drawing, page 30. ]

M. F. MAURY, of Liverpool, Eng., No. 64,018 . April 23, 1867.

Claim. The tie herein described and shown upon the drawings, when the same is used to connect the ands of wire or wire rope that is employed in baling cotton or like material, substantially in the manner set forth.

[Drawing, page 30.$]$
S. ROGERS, of Pittsburg, Penna., No. B4,255. April 30, 1837.

Clum.-1. 'The loop $c$, with the rigid arm $c^{1}$, when construeted substintially as and for the purposes above set forth.

Chrm.-2. The loop c, either with or withont the rigid arm $e^{\prime}$, in combination with the corrugated or ridged strap end $a$, of a metallic hoop, coustructed substantially as and for the purposes above set forth.

Clam.-3. 'The rigid arm $c^{1}$, in combination with the slot $e$, and the folrled end $d$, of a metallic hoop, construeted substantially as and for the purposes above set forth.

[1)rawing, page 31.$]$

W. ONIONS, of St. Louis, Mo., No. 64,696. May $14,1867$.

Chim. The metallic block A, in combination with the wedge shaped metal piece $B$, secured to the bale hoop end C, arranged and operating substantially as and for the purpose set forth.

[Drawing, page 31.]

W. F. MAURRY, of New Orleans, La., No.65,102. May 28, 1867.

Claim. The plate $\boldsymbol{A}$, when provided with the folding flanches $a, a^{b}$, and shomlelers $b$, as $b^{1}$, described for the purpose set forth.

Euglish Patent No. 52, of Jan. 7, 1868. [Drawing, page 31.]

H. LAMPSON, of London, Eng., No. 65,239. May 28, 1867.

Claim. Securing the ends of the band $a$ together by passing the end $a^{1}$ through the metal loop $b$, and turning the same back upon the inside of the said band, the opposite end $a^{2}$, passing through the loop $b^{1}$ and thromgh the loop $b$, and inserted again in the loop $b^{2}$, and the latter slipped up toward the loop $b$, when all are arranged and operating substantially as herein shown and deseribed.

[Drawing, page 31.]

J. ADAMS, of New Orleans, La., No. 65,850 . June 18, 1867.

Clam.-1. 'The mortice $\mathrm{C}$, in the berl of the machine to armit the tie buekle or fastening, and to aceomplish its adjustment to the hoop by the same motion which bends the hoop.

Claim.-2. 'The spring $\mathrm{G}$, as set forth above. 
Claim.-3. The indentation or oval shape in the handle at the point $I$, and at the points II, H, to form the bend over and under the spring $G$, substantially as described and represented.

[Drawing, page 32. ]

A. BARBARIN, of New Orleans, La., No. 66,065. June 25, 1867.

The device $\mathbf{A}$, when constructed as herein described for the purpose set forth.

[Drawing, page 32.]

ARTHUR BARBARIN, of New Orleans, La., No. 7,388. Nov. 7, 1876. Reissue of patent No. 66 085, dated June 25, 1867.

Claim.-1. A wire bale-tie, having a loop at one or both ends, made by turning back the end of the wire to the body of the tie and twisting the two parts together for the purpose of giving greater strength to the loop, as berein suecitied.

Claim.-2. The fastening device $A$, by means of which the two loops of a wire bale-tie are firmly connected together, substantially as and for the purpose herein specified.

Claim. - 3. The combination of a readymade wire bale-tie, provided with loops formed by twisting the two parts of the wire together, as herein described, with a fastening device, by means of which the two loops are firmly counected, substantially as and for the purpose herein specified.

[Drawing, page 32.]

P. C. INGERSOLL, of Green Point, N. Y., No. 66,087.-June 25, 1867.

The elamp links or grippers B C, in combination with each other and with the lever R A, substantially as herein set forth, for the purpose specified.

[Drawiog, page 32.]

E. B. BISH0P, of New Orleans, La., No. 67,098. July $23,1867$.

The projecting lips $\mathrm{C} \mathrm{C}$, cut as described at their junction with the plate, the whole being constructed as described for the purpose set fortl.

[Drawing, page 33.]

C. ULMER, of Mobile, Ala., No.67,231. July $30,1867$.

'The wituin described buckle or' tie, prorided with opening $\mathrm{D}$, shot $e$ and toothed comers $c$ c c c , substantially as and for the purpose set forth.

[Drawing, page 33.]
J. F. MILLIGAN, of St. Louis, Mo., No. 67,334. July $30,1867$.

The piece A, provicled with notehes $b$ and $b^{1}$, the corners thereof being acute, and sluaped in the crescent form of cross section as herein described, and when furthermore arranged with central rail $a^{1}$ of diminished thickness, substantially as and for the purpose set forth.

English Patent No. 972 of 1868.

[Drawing, rage 33.]

G. N. BEARD, of St. Louis, Mo., No. 67,707. Aug, 13, 1867.

Claim. The tie piece $A$ having a countersunk eavity $a^{2}$ and two diverging mortices $a a^{1}$, when applied to and combined with the baling band $\mathbf{B} \mathbf{B}^{1}$, substantially as deseribed and set forth.

English Patent No. 1358; May 8, 1867.

[Drawing, page 33.]

L. LITTLEJOHN, of New York City, N. Y., No. 67,777. August 13, 1867.

Claim. The double-headed pin $\mathrm{F}$, working longitudinally through the eye $\mathrm{D}$ in the arm B, of the yoke snpported in position to receive the bands by means of the inner lower edge of the eye and its outer upper edge, and adapted to fit into the loop E of the yoke, as herein set forth for the purpose specified.

[Drawing, page 34,]

A. BARBARIN, of New Orleans, Iu., No. 68,148. Aug. 27, 1867.

Claim. A ball A, when provided with two encircling grooves $a$ and $b$, substantially as herein described, for the purpose set forth. [Drawing, nage 34.]

A. BARBARIN, of New Orleans, La., No. 88,149. Aug. 27, 1867.

Claim. A ring A when constructed as herein described, and shown upon the drawings, and used to fasten the ends of iron rope or wire in banding cotton or other bales, substantialiy in the manner herein set forth. [Drawing, page 34.$]$

M. D. CHECK, of Clarenden, Ark., No. 68,167. Aug. 27, 1867.

Claim.-1. A cotton bale-tie constructed in two parts with lapping ends provided with perforations in the one side and hooks on the other, substantially as shown and described. 
Claim.-2. The bars G and II, cylindrical upon the surfice around which the hoon passes in combination with the parts of a cotton bale-tie, as shown and described.

Claim.-3. A cotton bale-tie constructed with lapping ends fitted as shown, and provided with bars G II, slits I I, perforations F I, and hooks E E, for the purpose set forth.

[1) rawing, page 34.]

\section{S. J. MITCHELL, of St. Louis, Mo., No. 68,225.} Aug. 27, 1867.

Claim. A belt tightener consisting of the sliding rollers $\mathrm{C} C$, roller frame $\vec{B}$, windlass $\mathrm{D}$, and cords or chains $g$ g, applied to a frame $A$, and operating substantially as described.

[Drawing, page 35.]

N. T. EDSON, of New Orleans, La., No. 68.859. Sept. 17, 1867.

Claim.-1. So constructing and provid. ing with sharp projecting points the bar $A$, that it will grasp and hold the hoop, substantially as and for the purposes specified.

Claim.-2. Also so constructing and providing with sharp projecting points the bars $\vec{B}$, substantially as and for the purposes specitied.

[Drawing, page 35.]

\section{J. F. MILLIGAN, of St. Louis, Mo., No. 69,113} Sept. 24, 1867.

Claim. The tie piece formed of the parts $A$ and $\mathbf{A}^{1}$, having the mortices $a$ and $a^{1}$, respectively and being joined by a central rail $a^{2}$, in the manner set forth when combined with and acting upon the band ends $B$ and $B^{1}$, substantially as and for the purpose described.

[1rawing, page 35.]

C. J. PAINE, of Barnesville, Ohio, No. 69,120. Sept. 24, 1867.

Cluim. The device Figure 1, constructed with the wedge shaped projection $\mathrm{C}$, and wedge shaped aperture B, substantially as shown and employed as a tie by using two of such devices inverted and reversed to each other as explained in combination with the hoop or band D, as and for the purpose specitied.

[Drawing, wage 35. ]

J. W. TRUMAN, of Macon, Ga., No. 69,274. Sept. 24, 1867.

Claim. 'The flexible tie $\mathbf{A}$, constructed as described, its ends a a, extending the entire width of one sirle over-lapping each other and forming a side of double thickness, their points $d$, turned at right angles with the sides $a$, the latter adapted to be pressed together by the strap $B$, as herein shown and described for the purpose specified.

[Urawing, page :36.]

SAMUEL MORDEN, of Newton, Mass., No, 69,826. October 15, 1867.

An implement for hooping boxes in which the lever $A$, and bar $B$, are combined with the yoke $c$, substantially in the manner and for the purpose herein shown and described.

[I)rawing, page 36.]

J. L. SHEPPARD, of Charleston, S. C., No. 69,849. October 15, 1867.

A tie or lock for metal bale-hoops composed of a metal plate perforated as shown at $a$, provided with loop $b$, slots $a^{1} a^{1}$, and bent portion of the plate $\mathrm{C}$, to admit of attachment of the ends of the hoop as shown, and the turning up or down of the tie or lock while one end of the hoop is passed through its loop $b$, and drawing up or down of the tie or lock parallel with the side of the bale, under the expansion of the same, when relieved of the pressure, substantially as set forth.

[Drawing, page 36.$]$

C. W. WAILEY, of New Orleans, La., No. 69,870, October 15, 1867.

Claim.-1. Construting a cotton baletie with a projecting lip $C$, and roller $G$, substantially as described.

Chim.-2. Constructing a cotton baletie with a projecting lip $\mathrm{C}$, and curved ridge $\mathrm{D}$, substantially as described.

Claim.-3. Constructing a cotton baletie with a projecting lip $\mathrm{C}$, roller $\mathrm{G}$, and curved ridge $\mathrm{D}$, when the sane are atranged substantially as described and for the purpose set forth.

Clam.-4. Securing a cotton bale-tie having a curved projecting lip to the hook by means of roller $G$, loop $H$, and rivet $I$, when the same are so combined as to form a hinged joint, substantially as descrubed. [1)rawing, juge 36.]

R. H. LECKY, of Allegheny City, Penna., No. 70,230. October 29, 1867.

Claim. A clasp for bands or hoops used for baling cottun, said clasp consisting of piece $x$, provided with opehings $\mathrm{C} \mathrm{D}$, and $e$ and $a$, 
projection $\mathrm{B}$, constructed, arranged and operating substantially as herein described and for the purpose set forth.

[Drawiug, page 37.]

\section{J. D. VAN BENTHUYSEN, of New Orleans, La.,} No. 70,295 . Oct. $29,1867$.

Clnim. Construeting a bale-tie with a triangular opening as shown, when the diagonal side thereof is beveled, substantially as deseribed and for the purpose set forth.

[Drawing, page 37.]

H. B. MERRITT, of St. Louis, Mo, No. 70,452. Nov. $5,1867$.

Claim. A tie piece A A, when constructed, substantially as described and set forth. [Drawing, page 37.]

\section{J. N. BARNUM, of New Orleans, La., No, 70,503.} Nov. 5, 1867.

Claim. The device herein described, and as shown upon the drawings, when provided with the two over-lapping semi-annular grooves or curved supporting points $\mathbf{A ~ A}{ }^{\prime}$, as described, when constructed as described and used for fastening the ends of wire rope or of common untwisted wire that is employed for banding cotton bales, as set forth.

[Drawing, page 37.]

J. K. SPEAR, of P1ttsburgh, Pa., No. 71,338 . Nov. 26, 1867.

Claim. -1. A clasp for baling cotton, said clasp being provided with contracted apertures of the form herein described, and bent in the manner and for the purpose set forth.

Claim.-2. In combination with the above, bands made of semi-oval iron and in detached sections, as herein described and for the purpose set forth.

[Drawing, page 38.]

J. H. FRALEY, of New Orleans, La., No. 71,867. Dec. 10, 1867.

Claim. - 1. The combination of the buckles $A$ and $B$, when they are cousstructed and united as described, with the ends of the hoop iron when bent into the form of hooks, as and for the pirpose set forth.

[Drawing. page 38.]

C. MUDGE, of New Orleans, La., 73,026. Jan. 7 th, 1868.

Claim. 'The making of the two additional openings or holes $\mathbf{A}$, in cotton-ties, design- ed for use in connection with hoop-iron, so that the same may be used with equal ease for fastening together the ends of wire-rope or wire, as herein described.

[Drawing, page 38.]

\section{L, PHILLIPS, of Washington County, Miss.,} 73,034. Jan. 7th, 1868.

Claim 1. The device herein described, consisting of the central bar A, when provided with the wings $B, B^{1}$, in which, at the points $a, a^{1}$, are groves to receive the bands; a longitudinal opening for the ends of the bands, and holds $d, d^{1}$, as and for the purpose herein set forth.

[Drawing, page 38.]

T. GUYOL, of New Orleans, La, 73,713. Jan. 28 th, 1868.

Claim 1. In connection with a copper or other suitable wire, for encireling and fusten. ing bales of cotton or other baled material; it metalic sacldle $A$, with. its brace $c$, constructed and operating to hold the two ends of the wires, substantially as herein described and represented.

[Drawing, page 39.]

\section{A. C. FLETCHER, New York, N. Y., No, 73,791, Jan. 28, 1868,}

Claim.-1. A bale fastener composed of a plate $A$, provided with an opening $a$ and a slot or slots $d$, one or both of the latter having arches $c$ at their sides for use in connection with a pin or nail, or pins or nails $D$, to secure the bent or doubled end or ends of the baling hoops or wires, substantially as specified.

[Drawing, page 39.]

\section{J. B. DUNN, of Petersburg, Va., No. 74,059.} Feb. 4, 1868.

Claim.-1. The improved bale tie $A$, formed with the slot $B$ at one end, and a lateral slit or open slot at the other end, said open slit or slot having a shoulder $a^{3}$ at its outer end, and having its inmer side struck or bent downward, formiug a curved lip $a^{2}$, substantially as herein shown and described, and for the purpose set forth.

English Patent 56, Jan. 7, 1868. [Drawing, uage 39.]

\section{A. C. FLETCHER, New York, N. Y., No. 74,070.} Feb. 4, 1868.

Claim.-1. The plate $\mathbf{A}$, having an aperture $c$ e d, lateral side openings $f^{\prime} f^{\prime}$, opening $g$ and lip $h$, for operation in connection 
with a rope or equivalent material, substantially as set forth.

[Drawing, page 39. .

H. FASSMAN, of New Orleans, La, No. 75,140. March 3, 1868.

Claim. The cotton bale-tie composed of the plate $A$, having the slots $a$, between which is a strengthening ridge $d$, on one or both sides of the plate, and having its ends strengthened by stout ridges $b b$, cast upon the plate substantially in the manner and for the purpose described.

[Drawing, page 40.]

J. W. HEDENBERG, of Chicago, III., No. 75,267. March 10, 1868 .

Claim. A cotton-tie buckle, made and constructed substantially in the manner described.

[Drawing, page 40.]

\section{W. TROWBRIDGE, of New Orleans, La., No.} 75,319. March 10, 1868.

Claim. 'The device herein described, to wit: a section or piece of wire, so formed as to be provided with the loop or eye $\mathrm{C}$, and the hooks $B$ and $B^{\prime}$, as herein described for the purpose set forth.

[Drawing, page 40.]

W. TROWBRIDGE, of New Orleans, La. Reissue of No. 75,319. March 10, 1868. Reissue of No. 3,337. March 23, 1869.

Claim. The device herein described, to wit: a section or piece of wire, so formed as to be provided with a loop or eye $\mathrm{C}$, with the two ends into hook-form, substantially as herein described for the purpose set forth. [Drawing, page 40.]

\section{E. S. ROBERTS, of Columbus, Ga., No. 75,461.} March 10, 1888.

Claim. The cotton bale-tie, constructed as described, and consisting of the open box $\mathrm{B}$, provided near each end with a trassserse removable pin b, around which the hoop $\mathrm{A}$ passes, the extremities of said hoop, after passing around the pins, being bent back between the bale and the hoop, in which position they are held by the outward pressure of the bale, all arranged as described for the purpose specilied.

[urawing, page 41 .

J. L. SHEPPARD, of Charlestcn, S, C., No. 75,705. March 17, 1868.

Claim. 'The cottou bale-tie abore describer, consisting of the ring $a, a ; a^{1}, a^{1}$, having the sides $a, a$, straight and parellel, and the silles $a^{1}, a^{t}$, curved ; the centre opening being of such a form as to enable the hoop to be inserted over the ents $a^{1}, a^{1}$, and turned so as to rest upon the sides $a, a$; when such ring is used in connection with an arm $B$, between which and the nearest side $a$, is an open recess $c$; all the said parts being construeted and arranged substantially in the manner and for the purpose specified.

[Drawing, page 41.]

J. W. BARNUM, of Now Orleans, La., 76,141. March 31, 1868.

Claim. The device herein described, to wit, the plate $A$, when provided at its ends with cylindrical supports $\mathbf{B}, \mathrm{B}^{1}$, the opening $\mathrm{C}$, between said supports, and tongues $\mathrm{D}, \mathrm{D})^{\prime}$, for the strengthening of the supports $B, B^{1}$, as and for the purpose set forth.

[Drawing, page 41.]

J. W. BARNUM, of New Orleans, No. 76,142. March 31, 1868.

Claim. The device herein described, consisting of the two supporting curred surtaces $\mathrm{A}, \mathrm{B}$, the projecting arm $\mathrm{C}$, provided with the head or shoulder $D$, the whole being constructed as deseribed, and constituting a new article of manutacture for the purpose set forth.

[D rawing, page 41.]

J. W. BARNUM, of New Orleans, La., No. 76,143. March 31, 1868.

Claim. The combination of the bars $A$ $\mathrm{A}^{1}$, when provided with the notehes $a a^{\text {? }}$ with the eylinder $B$ or its equivalent, as shown in Figure 3, substantially as herein described for the purpose set forth.

[Drawing. page 42.]

J. W. BARNUM, of New Orleans, La., No. 76,144 . March 31, 1868.

Clnim. The half cylinters A A ${ }^{1}$, when placed in relation to each other, as herein deseribed, and secured in position by the plates $\mathrm{B} \mathrm{B}^{1}$, when the latter are verforated, so as to reeeive the key $\mathrm{C}$ at one of their ends, as herein deseribed for the purpose set forth.

[Irawing, page 42.]

J. W. BARNUM, of Now Orleans, La., No. 76,145. March 31, 1868.

Claim. 'The cylinder A when provided witt: the aperture $\mathrm{B}$, the flanches $\mathrm{C} \mathrm{C}^{\prime}$ in which 
are holes $\mathbf{E} \mathbf{E}^{1}$ for the reception of the bolt or key F', the whole being construeted and operating as described, for the purpose set forth.

[I]rawing, yage 42.]

3. W. BARNUM, of New Orleans, La., No. 76,146. March 31, 1868.

Claim. The cylinder A when provided with the two projecting plates $\mathrm{BB}^{1}$ in which are cut the notelies $\mathrm{C}$, as herein described, for the purpose set forth.

[Drawing, page 42.]

H. W. OLIVER, Jr., of Pittsburgh, Pa., No. 76,238 March 31, 1868.

Clain. The hand $\mathrm{A}$, bent around the head of the bolt $\mathrm{B}$, as indicated at $x$, said band being used in combination with the bolt B, and nut $\mathrm{C}$, constructed, alranged and operating substantially as herein described and for the purpose set forth.

[Drawing, rage 43.]

S. H. GOOCH, of Cheraw, S. C., No. 77,277. April 28, 1868.

Claim. The plate A, constructed with the depressions $a$. $a$, the bars $c c^{1} c^{2}$, the tongues $m n$, and the slots $\mathrm{B} \mathrm{C} \mathrm{C}$, the latter slot being constructed with the recesses $e e^{1}$, having the inclined edges $i i^{2}$, and the whole apparatus operating substantially in the manner and for the purposes set forth. [Drawing, page 43.]

G. A. SEAVER, of New York, N. X., No. 77,770. May 12, 1068.

Claim. The construction of the tie or fastening, substantially as described.

[Drawing, page 43.]

J. A. SHONE, of Holly Springs, Miss., No. 81,018. Aug. 11, 1868.

Claim. The bale-tie formed upon the band $A$, by notching one of the ends upou the under side at $c$, and prassing the same through a diagonal slot $e$, formed in the folded opposite end, as lierein shown and describerl.

[Trawing, page 43.]

W. M. IRVINE, of Montgomery Ala., No. 81,374. August 25, 1868.

Claim. Reinforeing one end of the plate $B$, and confining the cuds of the strap or band, in the manner herein set forth and shown.

[Drawing, page 41.
J. TINGLY, of Philadelphia, Pa., No. 81,843. Sept. 1, 1868.

Claim.-1. The plate $\mathrm{G}$, of a shape to fit the side of the vessel, having a projection $f$, and secured to one end of a band, a screw rod at the other cnd, of which jasses through the projection $f$, as and for the purpose described.

Claim. -2. The said hand with serew rod at one end, and projection at the other, in combination with a handled nut $\mathrm{E}$, arranged to conform, or nearly conform, to the shape of the ressel to which the band is applied, as set forth.

Claim.-3. The slot $m$, in the band D, for the purpose specified.

[Drawing, page 4t.]

J. S. CARSON, of Brook Haven, Miss., No. 87,541. March 9, 1869.

Clam. A bale-tie formed of a plate $x$, of sheet-iron, having the loops $\mathrm{A}, \mathrm{B}, \mathrm{C}, \mathrm{D}, \mathrm{F}, f$, and $G$, and latch $I, h, h^{i}$, the whole being formed and arranged substantially as set forth.

[Drawing, page 44.]

JOHN S. CARSON, of Brook Haven, Miss., No. 6,468. June 1, 1875. Reissue of patent No. 87,541, dated March 9, 1869.

Claim.-1. In a metallic tie for baling purposes, a hook attached to the tie for the 1) urpose of completing the counection between the ends of the same, and thereby preventing the release of the bale.

Claim.-2. The combination, in a netalic tie for baling purposes, of a laud passing around the bale, a link to connect the two ends of the band, having an opening, through which the looped end of the band may be passed, and a hook secured to some portion of the tie, and so adjusted that it may engage the loop of the free end of the bund after it has been passed through the opening in the link, and thereby prevent the withdiawal of the band.

[Drawing, page 44.]

W. M. MORRIS, of Washington Co., Miss., No. 88,727. April 6, 1869.

Claim. 'The buckle $\mathbf{A}$, when provided with the slut $\mathrm{B}$, the triangular lug $\mathrm{D}$, and the projections $i$ and $j$, and otherwise constructed substantially as herein described. [Drawing, rage 45.]

B, W. FIELD, of Ferrisburg, Vt., No. 89,136. April 20, 1869.

Claim. 'I'he arrangement of the handle 
$\Lambda, a^{1}$, pivoted lever $B$, and the notehed and forkerl claws $b^{1}, a^{2}$, as herein deseribed and for the purpose specitied.

[Drawing, page 45.]

J. S. WALLIS, of New Orleans, La., No. 89,612 May 4, 1869.

Claim. The buckle A, when constructed of plate-iron, one side being thicker than the other, and having two slots B B eleft $\mathrm{C}$, as and for the purpose herein describe. English Patent No. 2,863. Oct. 2, 1869. [1)raning, page 45.]

G. N. BEARD, of St. Louis, Mo., No. 89,844 . May 11, 1869.

Claim. The tongue lever B . $\mathrm{B}^{1}$, in combination with the buckle $A$, so sbaped as when drawn down by the band $\mathrm{C}$ to cause the end $\mathrm{C}^{1}$ of the band to bend abont the end rail $\mathrm{A}^{1}$, forming by the counter pressure of the compressed bale an $\mathrm{S}$ shaped curve, substantially as herein described. [Drawing, page 45.]

E. T. MAINWARING, of Tipton, England, $90,781$. June 1, 1869.

Claim. The bale-tie consisting of the rectangular slotted plate $\mathrm{C}$, having one or more extended slides $\mathrm{E}$, and applied to the deflected portion of the hoop $A$, in the manner described, and secured thereto by the clip or clips D, as herein set forth, for the purpose specified.

English Patent 326.1868.

[Drawing, page 46.]

J. B. MCDONALD, of Louisville, Ky., No. 91,034 . June 8, 1869.

Claim. The link $\mathrm{H}$ for cotton bale-ties, when its parallel side bars $\mathrm{G}$ are enlarged to form convex inner bearing surfaces for the hoop, and their outer edges hollowed out parallel to each other at $\mathrm{F} \mathrm{F}$, to form projecting angles over which the hoop is bent by the expansion of the bale, as herein shown and described.

[1)rawing, page 46.]

J. CROOKES, of St. Louis, Mo., No. 91,091. June 8, 1869.

Claim. The locking piece $\mathrm{B}$ arranged with ear pieces $B^{2}$ and riveted to the end $\Lambda^{1}$ when combined with the joint rivet $\mathrm{C}$ and the end A, substantially as herein set forth.

[Drawing, page $4 \dot{0}$.
T. C. OAKMAN, of Paterson, N. J., No. 91,361. June $15,1869$.

Clam. The bale-tie ol tastening consisting of a cam lever A, provided with the journals $B$ flattened on one side and having their bearings If in the angles of the bent side-bars of the frame $C$, all eunstructed and operating as set forth.

[I) rawing, page 46.]

WM. RIDDLE, of Lark Hill Lane, England, No. 93,555. August 10, 1869.

Claim. The combination of the flat band, having its ends formed into loops withont slitting, with a spear inserted through the loops, as described.

1865.

English Putent 628 of Mareh 6th,

[Drawing, page 47.]

M. TILDESLEY, of Willenhall, England, No. 95,851. October 12, 1869.

Claim. The double tie, clip or fastening obtained by the combination of the two parts $a$ when construeted and applied to each other and to the surrounding band, as herein specified.

English Patent 2,214, July 21, 1869.

[Drawing, page 47.]

J. WHEELOCK, of San Francisco, Cal., No. 96.521. November 2, 1869.

Claim. The bale-tie lock composed of the slide $\mathbf{M}$, with its interior Hange or shonlder $\mathrm{L}$, in combination with the band or strap having the folded end $\Lambda$ and donble-lapped and curved end $B$, when said parts are construeted, arranged and applied together in the manner and for the purpose herein shown and deseribed.

[Drawing, page 47.]

F. M. LOTTRIDGE, of Portland, Indiana, No. 97,784. December 14, 1869.

Claim.-1. The combination of shatt $A$ $A^{1}$, hook $A^{2}$, ratchet-wheel $A^{3}$, pawl $a$, spring $a^{1}$, crank $B^{1}$ and cross-arm $\mathrm{C}$, with pulley $c$ and $c^{1} c^{1}$, all arranged to operate substantially as described.

Claim.--2. In combination with the abore, the cut $\mathrm{C}^{3}$ on the upper side of the cross-arm $\mathrm{C}$ with reference to the band or rope and the pulleys $c^{1} c^{l}$, substantially as shown and described.

[1)rawing, page 47.] 
W. M. SMITH, of Augusta, Ga., No. 97,977. Dec. 14, 1869.

Claim. An improvement upon rectangular cotton bile-ties with $\mathrm{V}$ or $\mathrm{X}$ shaped slots, said improvement consisting in striking off the interior point or angle $a$, while the point or angle $a^{1}$, is left entire, for the ready and secure adjustment of the loop band D, as herein shown and described. [Draving, page 48.]

E. S. LENOX, of New Brighton, N. Y., No. 98,169. Dec. 21, 1869.

Claim. A wire bale-band formed at one end into the loop $B$, with its recess $b$, and at the other with the cross-head $\mathrm{C}$, when said parts are constructed, combined and operated as and for the purpose herein set forth.

English Patent No. 16, January 3d, 1870. [Drawing, page 48.]

E. S. LENOX, of New York, N. Y., No. 7,026 of April 4, 1876. Reissue of Patent $\mathbf{N}$. 93,169, dated Dec. 21, 1869.

Clarm. 1.-A wire bale-band and tie of one piece of flexible wire, having the loop B at one end, and having the other end bent back and twisted upon itself, so that the doubled wire can be passed through the loop.

Claim.-2. A wire bale-tie, consisting of a loop on one end of the bale-band and a double wire catch upon the other, of wire, of the same size as, or continuous with, the bale-band wire, substantially as shown and described.

Clam.-3. A wire bale-tie in which the catch is bent forward, so as to brace and support itself upon the loop end of the wire, instead of merely curving back upon itself in ordinary hoop form.

Claim.-4. A wire bale-tie in which the part of the catch which is directly upposed to the strain tending to separate the wires is supported or braced upou the loop end of the wire.

Claim.-5. A wire bale-tie in which that end of the wire forming the catch $e e c$ is bent or doubled upon itself, substantially as shown and described.

Claim.-6. A wire bale-tie in which that part of the wire forming the catch or hook $e e c$ is bent upon itself, and curved so as to support or brace itself, substantially as shown and described.

Claim.-7. A wire bale-band and tie, consisting of a single piece of flexible wire having a loop, B, at one end, and having the other end bent back and twisted upon itself when the doubled end of the wire is passed through the loop $\mathrm{B}$.

[Drawing, page 43.]

E. S. LENOX, of New York, N. Y., No. 7,027 of April 4, 1876. Reissue of Patent No. 98,169 , dated Dec. 21,1869 .

Claim. A wire bale-tie, consisting of the elliptical wire loop, at one end, and at the other end having an eye, with a permanently attached cross-piece of rigid metal passing through said eye, substantially as shown and described.

[Drawing, page 48.]

J. W. ROGAN, of Memphis, Tenn., No. 99,239. Jan. 25, 1870.

Clrim. The buckle A, provided with the break $J$, and with the tongue $\mathrm{E}$, having shoulders $g$, in combination with the hoops $\mathrm{C}$ and $\mathrm{C}^{1}$, the latter having a $\mathrm{T}$, slot or aperture, all arranged as set forth and shown.

[Drawing, page 49.]

W. M. SMITH, of Augusta, Ga., No. 99,964. Feb. $15,1870$.

Claim.-1. The improved cotton bale-tie consisting of pieces A A A A, with its oblong angular hole D D D D, V shaped notches $\mathrm{G} \mathrm{G}$, depressed incisions $\mathrm{C} \mathrm{C}$, and shoulders E E, substantially as and for the purposes herein set forth.

Claim. -2. The combination of the pieces A A A A, with the piece $H$ II H II, having the upper corners rounded as shown, and the hole I I, substantially as and for the purposes herein set forth.

Claim.-3. The band B, when provided with the curved end $R$, and attached to the plates $\mathrm{A} \mathrm{A} \mathrm{A} \mathrm{A,} \mathrm{and} \mathrm{H} \mathrm{H} \mathrm{H} \mathrm{H}$, substan. tially as and for the purposes herein set forth.

[Orawing, page 49.]

F. R. HUNT, of Leavenworth, Kan., No.100,897. March 15, 1870.

Claim. A band for securing packages consisting of the parts $A$ and $B$, the part A, being provided with the slots $1,2,3,4$, \&c., bars $a, b, c$, \&c., as shown and described, and for the purpose set forth.

[Drawing, page 49.]

W. CHAMBERS, of New Orleans, La., No. 105,. 172. July 12, 1870.

Claim. The combination of a cleft $\mathrm{C}$, in 
a cotton balc-tic or buckle having two slots I3, $3^{1}$, with two expanded bearing surfaces D D', for the two ends of a metallie band, when the said bearing surfaces are produeed in the manner herein deseribed.

[1) rawing, rage 49.]

\section{W. A. JORDAN, of New Orleans, La., No.106,098.} August 28, 1870.

Claim. The buckle $\Lambda$, when made of plate-iron, having smooth surfaces, and provided with a slot $\mathrm{D}$, and a slot $\mathrm{E}$, into the linter of which a clett a enters, when said slors and clefts are forned, as herein described for the purpose set forth.

[Drawing. page 50.]

W. A. JORDAN, of New Orleans, La., No.107,058. Sept. 6, 1870

Claim. 'I'he cotton bale-tie $\mathrm{A}$, wheu provided with a central opening $\mathbf{B}$, that is formed as herein described and shown on the drawing, a slit $\mathrm{D}$, lugs $a a^{1}$, and re. cesses $b b^{1}$, for the purpose set forth.

[Drawing, lage 50 ]

M. R. CLARK, of Columbia, S. C., No. 108,450. Oct. $18,1870$.

Claim. The main loop a, provided with the rail $a^{1}$, and combined with the lever $b$, provided with the plates $c c^{1}$, and rail $c$, in the manner and for the purpose specified. [I rawing, page 50.]

\section{E. P, JONES, of Sun-Flower Co., Miss., No} 108,600. Oct. $25,1870$.

Claim.-1. The employment in a bale-tie of the converging slanting eleft $\mathrm{C}$, when the same is so formed that its narrowest point of entrance shall be at its inner end, substantially as shown and described and for the purpose set forth.

Claim.-2. The improved bale-tie herein shown and described consisting of the reetangular metallic plate A, provided with triangular openings $\mathrm{B} \mathrm{B}^{1}$, placed in reverse position as shown, the diagonal brace $D$, and inwardly etrving and slanting cleft $\mathrm{C}$, when constructed, combined and arratuged for operation in the manner specified and set forth.

1870 .

English Patent No. 2,273. August 17,

[Urawing, page 50.]

J. F. MIiLIGAN, of St. Louis, Mo., No. 109,748 Nov. 29, 1870.

Claim. In a tie-plate $\mathrm{A}$, substantially of this form, the improved entering space here shown, composed of the transverse slot $a$, and diagonal slot $a^{1}$, for the purpose set forth.

[Drawing, jage 51.]

W. CHAMBERS, of New Orleans, La., No. 109,804. Dec, 6, 1870.

Claim. 'The tie $\Lambda$, when provided with slots formed as shown at $\mathrm{B}$ and $\mathrm{C}$, and a slit D, entering the slot $\mathrm{C}$, in such a manner is to prodnce the point $\mathrm{J}$, as herein deseribed for the purpose set forth.

[Dratving, page 51.]

S. MCFERRAN, of Philadelphia, No. 110,255. December 20, 1870.

Clain.-1. The shield $\mathrm{K}$, arranged and operating in relation to the tightening serew II, substantially in the manner and for the purpose above described.

Claim.-2. The combination of the shield $K$ with the stud $G$, whereby the ends of the strap $\mathrm{D}$ are held in position, substantially as above set forth.

[Drawing page 51.]

G. N. BEARD, of St. Louis, Mo., No. 110,539. December 27, 1870.

Claim. The combination, in the bale-tie A, herein described of the rectangular slot a, with the end bars $\mathrm{B} \mathrm{B}^{\prime}$, provided with the curved lips $c c^{1}$, and central entering slot $a$, and the strengthening-rib or projection 1 , when all these parts are constructed and armuged as shown and described, for the purpose set forth.

[Drawing page 51.]

J. E. PERKINS, of San Francisco, Cal, No. 112,375. March 7, 1871.

Claim. A bale-tie A, having the folding lids $a$ and $d$, in combination with an upen rectangular link $c$, and the loop $f$, when construeterl and operated, substantially as herein described,

[Drawing nage 5\%.]

J. HOLMES \& J.C. H. SLACK, of Manchester, England, No. 113,518. A pril 4, 1871.

Claim. The combination (on the ends of i a cotton bale-tie) of the projections $a b$, with the intermediate projections $c d$, respectively and independently operating as and tor the purpose described.

English P'atent 1097, April 19, 1866.

[1)rawing nuse 5:2.] 
F. WATKINS, of London Works, Birmingham, England, No. 114,236. A pril 25, 1871.

Claim. In combination with the hoop A $B$, provided at its free end, with the loop $a$, the hook plate $\mathrm{C}$, leaving the curved projection $d$, slot $c$, and inclined opening $e$, all constructed as described, and for the purpose specifier.

[Drawing page 52.]

M. MARTIN, of Scharlotte, N. C., No. 114,581, May 9, 1871.

Claim. The rack-bar $\mathrm{A}$, lever $\mathrm{B}$ G, lugged side C F, weighted pawls D E H, slotted arms I J L $\mathrm{N}$, and eccentric levers $\mathrm{K} K$, all combined as described to operate in the manner specified.

[Drawing page 52.]

W. J. CARROLL, of Natehez, Miss., No. 114,760. May 16, 1871.

Cluim. The cotton bale-cleat D, herein described, provided with the steps $a b$, and the curved hook $\mathrm{E}$. in conbluation with the band $A$, and slot $B$, when constructel and arranged as sliown for the puryose set forth.

[D1awing page 53 ]

W. J. CARROLL, of Natchez, Miss., No. 5,912. June 16, 1874. Reissue of Patent No. 114,760. May 16, 1871.

Claim.-1. 'The cleat D, having steps $a$ and $b b^{\prime}$, curved or hooked projection $\mathbf{E}$, passing through a slot in the opposite end of the band, as described, the square heel, $c$, placed at a right angle to the under surface of the band, substantially as and for the purpose set forth.

Claim.-2. The cleat D, herein described, provided with the steps $a$ and $b b^{\prime}$, the curved or hooked projection $\mathrm{E}$, and the square heel $c$, placed at a right angle to the under surface of and in combination with the slotted band $A$, constructed as shown, and for the purpose set forth.

[Drawing page 53.]

W. J. CARROLL, of Natchez, Miss., No. 6,043. Sept. 8, 1874. Reissue of Reissue Patent No, 5,912. June 16, 1874.

Claim.-1. In combination with the slotted bale-band, a cleat provided with an extension or toe at its forward end projecting beyond the end of the band to which it is attached, and reaching upward, so as when locked to rest against the under side of the other end of the band, substantially as describerl.
Clam.-2. In combination with the slotted bale band, a cleat extending beyond the end of the band and having a forwardly projecting and upwardly-extending tive and a square heel, substantially as described.

[Dsaiving page 53.]

\section{J.M. McCLINTOCK \& J. CUMBERLAND, of New} Orleans, La., No, 115,225. May 23, 1871.

Claim. The buckle A, provided with a single central opening or slot $\mathrm{B}$, when the same is used for fastening the ends of metallic bands together aromud cotton bales, in the manner substantially as herein deseriber.

[Drawing, page 53.]

JAMES R. MCCLINTOCK, of Mobile, Ala., No. 5,404. May 13, 1873. Reissue of Patent No. 115,225. May 23, 1871.

Claim.-The buckle A provided with a central opening or slot $B$, when the same is used for fastening the ends of metallic bands together around cotton bales, in the manner substantially as herein described. [Drawing, page 54.]

JAMES R. McCLINTOCK, of Mobile, Ala., No. 5,919. June 16, 1874. Reissue of Reissue Patent No. 5,404. May 13, 1873.

Claim.-The buckle $\mathbf{A}$, provided with a central opening or slot $\mathrm{B}$, when the same is used for fastening the ends of metallic bands together around cotton bales, in the manner substantially as herein described. [Drawing, page 54.]

S. BRETT, of New York, N. Y., No. 115,692. June 6, 1871 .

Claim. The wire bale-tie constructed as described with the eye B upon one end, and the hook $\mathrm{C}$ upon the opposite end, and applied to a bale in the mamner herein set forth and shown.

1871.

English Patent 2,151 of August 15th, [Drawing, page 51.]

G. BRODIE, of Plum Bayou, Ark.,No. 116,925. July 11, 1871.

Claim. A tie for cotton bales and other aualogous uses, having brads or $^{*}$ nibs $a a$, and a slot $c$, in combination with intervening nibs which taper toward the side in which the said slot is construeted, in the manner and for the purpose herein describerl.

English Patent 1,764 of July 6th 1871. [Drawing, page 54.] 
C. G. JOHNSON, of Now Orleans, La., No. 116,964. July 11, 1871.

Clrim?. The eotton bale-tie herein described, provider with the elosed slot $l^{\text {; }}$, anct open slot $\mathrm{C}$, haviug the projections $c$ and $c$, and the strengthening bar $\mathrm{D}$, when all are constructed aud arranged as shown for the purpose set forth.

Drawing, lage 5ij.]

\section{J. J. PEITON, of Washington, D. C., No. 117,-} 202. July 18, 1871.

Claim. The improved tie herein described and shown, constructed substantially as and for the jurpose set forth.

[1)raw li:g, mage 55.]

S. LEWIS, of Rochester, New York, No. 118.252. Aug. 22, 1871.

Cleim. In a hoop lock substantially as herein described the angular seats $y$, at the base of the interlocking tongue, for the purpose set forth.

[Drawing. page 55.]

S. MATHERS, of New Braunfels, Texas, No. 118,254. Aug. 22, 1871.

Clam. The improved cotton tie stretcher herein described, consisting of the bent bar $\Lambda$, having hook $a^{1}$, at one end, and slot at the other, the lever $\mathbf{B}$ having jaw $b^{1}$, in combination with the adjustable arm $\mathrm{C}$, with jaw $c^{3}$, all construeted and operating substantially as and for the purpose set forth.

[Urawing, page 5i.].

\section{J. L. SHEPPARD, of Charleston, S. C., No. 118, 286. Aug. 22, 1871}

Clain. The bale-tie herein described having the curved lips $A$ and $B$, rectangular slot $\mathrm{C}$, and transverse slit de, constructed and arranged substantially as and for the purpose set forth.

[Drawing, page 5i.]

R. T, YARDLEY, of Baltimore, Md., No. 119,213. Scpt. 29, 1871.

Clam. The construetion of tootherl hooks having the form substantially the sime as that described in this specification.

[Drawing, page 56.]

J S, DAVIS, of Louisville, Ky., No, 120,045 Oct. 17, 1871.

Claim. The combination with the band D, of the keys $\mathrm{C} \mathrm{C}$, and the buckle herein deseribed, having eurved side bars $\Lambda \Lambda$, and cross bars 13 B, the latter urovicled with lips $b^{\prime} b^{\prime}$, when all are constructed and arranged as and for the purpose specified.

[Drawing, page 5aj.]

J.F. RUSLIN, of Lawrenceville, Pa., No. 120,104. Oct. 17, 1871.

Claim. The lever D, provided with the hook shaped fulcruned end $\mathrm{E}$, and having its free end made in spiral form as shown, to adopt it to be tueked nurler the band and hold itself in position, as set forth.

[1) rawing, page 50.]

J. DOWNES, of Handsworth, England, No. 120,727. Nov. 7, 1871.

Claim. As a new article of manufacture a folking metallic band for baling cotton and like purposes, constructed as herein described, consisting of two or more sections of hoop iron hinged torether, substantially as shown and set forth, to allow of said sections being folded that together for transportation.

[1 rawing, 1rage 57.]

M. N. COE, of Madison Parish, La., No. 121,7b8. December 12, 1871.

Clam. The combination of the hanclle $B$, hinged arm $F$, stock $G$, for holding the type-block, spring $\mathbf{A}$, and the beveled and dart shaped tongue $\mathrm{C}$, all constructed and arranged to operate substantially as described.

[Drawing, mge 57.]

F. G. BROWN, of Brenham, Tex., No. 121,988. Dec, 19, 1871.

Claim. 'The bale-tie buckle herein rescriber consisting of the plate $\Lambda$, provided with the openinges $f g$, elefts 00 , and slot $h$, constructed and arranged to operate substantially as specified.

(1)rasviug, page 57.)

\section{J. T. BUTLER, of New Orleans, La., No.122,583,} Jan. 9, 1872 .

Claim. The buckle or tic A, having an inclined slit $b$, ent at an angle with the plane of the buckle, substantially as described and shown, and for the purpose set forth.

English Patent 3,264, Dec. 2d, 1871.

[Drawing, ]age 5s.]

J. C. ColT, of Cheraw, S. C, No. 122,813. Jan. $16,1872$.

Clam,-1. 'The bale-tie herein described, composed of hook-and-eye frames $\mathrm{B}$ C pro- 
viderl with flanges $b \quad b c e$ and liook $b$, respectively, constructed as and for the purpose set forth.

Claim.-2. In combination with a bale-tie constructed ats herein described, the lever D having mougs $d d$, graples $d^{1} d l^{1}$, and guides $d^{2} d^{2}$, and as for the prurpose set forth.

Claim.-3. The method of eompressing and fistening a bale of cotton and other substances of like nature by means of the hook-and-eye frames B C and lever D, all constructed and arranged to operate as specified.

[Drawing, page 53.]

W. PARSONS, of Palmyra, N. Y.. No. 122,907. Jan. 23, 1872.

Claim. The hook A, formed with the curved seat $f$, piroted to and in combination with the ccentric lever B, having the curved open look d, all constructed, arransed, and operatiug in connection with the band $\mathrm{C}$, in the manner described. (Drawing, page 58.)

G. BRODIE, of Jefferson Co., Ark., No. 123,228. Jan. 30, 1872.

Clrim. The cotton-tie stretcher herein described, consisting of the hand-lever $\mathrm{A}$, hinged bav $B$, piroted jaw $C$ with flat end $\mathrm{C}^{2}$, and jaw $\mathrm{D}$ having slot d at one end and lip E at the other, when constructed for operation as shown, and for the purpose set fortl.

(Drawing, nage 58)

L. J. ANDERSON, of Water Valley, Miss., No. 123,374. Feb. 6, 1872.

Claim. 'The lever A, arm A B, eceentrics D D, and gripers E E, or their equivalents, all arranged substantially as specified. (Drawing, nage 59)

G. W. ADAMS, of New Orleans, La., No. 123,853. Feb. 20, 1872.

Clum. The bale-tic $\mathrm{A}$, lerein described, having the slots $\mathrm{C} \mathrm{C}$, tongue $\mathrm{D}$, and cleft $B$, constructed and arrangerl substantially as shorn, and for the purpose set forth.

(D)rawing, page 59)

G. BRODIE, of Plum Bayou, Ark:, No. 123,976. Feb. 27, 1872.

Claim. The improved bale-tie hercin described, cousisting of the staple $a$, provided with the eye $g$, and hinged perforated link or tie-plate $e$, constructed and applied substantially in the manner described as shown. (Drawing, page 59.)
J. L. SHEPPARD, of Charleston S. C., No. 124,090. Feb. 27, 1872.

Claim. The improved tie herein described and sliown, consisting of the plate $\mathbf{X}$, provided with a rectangular slot, $b$, and the opening $a$, having the lip $d$, recessed handseat $e \hat{e}$, curved projection or shoulder $f$, and the entering slot or cleft $c$, all constructed aud arranged for operation substantially in the manner and for the purpose set forth. [Drawing page 59.]

L. DODGE, of Waterford, N. Y., No. 125,031. March 26, 1872.

Claim. As a new article of manufacture, a bale of hay, straw, or similar substance, marle substantially as herein shown and deseriber.

[Drawing page 60.]

D. L. MILLER, of Madison, N. J., No. 125,474. April 9, 1872.

Claim. In combination with the looper ends of the bale-band $A$, the overreaching lever B, provided with end hooks $f$ and $d$ and intervening eye $b$, all constructed and operating in the manner described and shown, and for the purpose set forth. [Drawing page 60.]

B. W. COLLIER, of Oxord, Miss., No. 125,721. April 16, 1872.

Clam.-1. The improved cotton-baling herein described, the same being formed of wire-cloth, as set forth.

Claim.-2. The coarser wires $\alpha^{\prime}$ woven into the wire baling-cloth A to furnish a means for securing said cloth upon the bale, substantially as herein shown and described.

Claim.-3. The liooks or buckles B, in combination with the coarser wires $a^{\prime}$ and wire-cloth $\mathrm{A}$, substantially as herein shown and described, and for the purpose set forth. [Drawing page 60.]

C. BROWN, of New York, N. Y., No.126,515. May 7, 1872.

Claim. The wire bale-tie fastening hercin shown, consisting of the straight end $a$, aud the double-eyed or looped end $b$, when combined for operation, substantially in the manner described.

[Drawing page 60.]

W. McNABB, of Clapton, England, No. 126,645. May 14, 1872.

Claim. In combination with the folded, beut-over, or hooked ends of a metallie 
band, I elitim the tie A, when provided with a solid back $\mathbf{B}$, open slots $\mathrm{C}$, and central tougue or plate D, all constructed, consbined, and arranged to operate in the inan. ner deseribed and showli, and for the purpose set forth.

[Drawing. page bi.]

E. A. FRANKLIN, of Brenham, Texas, No. 128,687. May 14, 1872.

Claim. The tie-plate $\Lambda$ herein described, provided with the slots $\mathrm{C}$ and $\mathrm{C}^{\prime}$ and zigzas or transversely-shouldered enteringcleft E, construeted and operating in the manner and for the purpose specified.

[Drawing, page 61.]

H. C. BABCOCK, of Hartford, Conn., No. 128,454. July 2, 1872.

Claim. A bale of manure formed and pressed into layers, and with or without handles embedded, substantially as set forth. [10rawing, page 61.]

E. S. LEN0X, of New York, N. Y., No. 128,803. July $9,1872$.

Claim.-1. A wire bale-band fastening formed of the link $a b c$, in combination with the eyes $d d^{\prime}$ of the band, all construeted and operating substantially as herein set forth.

Claim.-2. In a wire bale-band fastening formed of a section of wire, the ends of which are bent toward each other in the same lateral direction, I claim the curved ends $b$ and $c$ bent at the angle described relatively to the straight portion $a$, substantially as shown and described, and for the purposes set forth.

[1) rawing, nage 61.]

H. T, MINOR, Jr, of Savannah, Ga., No. 129,157. July 16, 1872.

Claim. The tic-plate A provided with a central opening, B, having its end or ends formed by the inclines $b^{2} b^{2}$, in connection with the oblique slot or entering-cleft C, all constructed and arranged substantially ats deseribed, and for the purposes set forth.

[Drawing, page $6:$ ]

C. SWETT, of Copiah Co., Miss., No. 129,188. July 16,1872

Clrim. 'The base-plate $\Lambda$, provided with Hanged elbow-plates $\mathbf{B} \mathrm{J}^{1}$, lips $6 b^{2}$, and reecss $y$, the said flanged elbow-plates being folded over toward each other, in the manner specified to constitute a clasp or tic, substantially of the form shown in Figs. 2 and If if the drawing, for the purpose set forth. (Drawing, page 62.$)$
C. SWETT, of Copiah Co., Miss., No. 129,187. July 16, 1872.

Claim. 'T'he tie-plate $\Lambda$, having the lips B B on the orposite edges thereof, the whole being construeted and arranged as described and shown, to secure a fastening for the bands around bales of cotton, \&c., substantially as set forth.

Drawing, vage 62 .

C. SWETT, of Copiah Co., Miss., No. 129,188. July 16, 1872.

Cluim. The tie-plate herein shown and deseribed, consisting of the sections $\Lambda \quad B$ folded over or bent in the form represented in Fig. 3 of the drawing, and having the slot $\mathrm{C}$ in the section $\mathrm{B}$, substantially as and for the purpose described.

[Drawing, page 6.2.]

C. SWETT, of Coprah Co., Miss., No. 129,189. July 16, 1872.

Chim. The plate $B$, having recesses $A$ and projections or shoulders $b$, said plate being folded over, as represented by Figs. 2 and 3 of the drawing, all constructed and operated substantially as lescribed to form a fastening for metallic bands around bales of cotton and like material.

[Drawing, page 6i3.]

C. SWETT, of Copiah Co., Miss., No. 129,190. July 16, 1872.

Claim. 'The tie-plate $\mathrm{A}$, having double or reverse inclined lips $\mathrm{B} \mathrm{B}^{\prime}$ on the opposite or upper and lower surfaces of said plate, the whole being constructed and arl'anged substantially as described to provide a fastening for the band or hoop around the bale.

[Drawing, nage 63.]

C. SWETT, of Copiah Co., Miss., No. 129,191. July 16, 1872.

Claim. The tie-plate $\Lambda$ having the lips $B$ $\mathrm{B}^{\prime}$ on the opposite edges, as represented and shown in Fig. 1 of the drawng, and constructed and arranged as clecribed to form a fistening for the ends of metallic ties around bales of cotton and like material, substautialiy as set forth. [Drawing, page 63.]

J. C. ColT, of Cheraw, S. C., No. 129,715. July 23,1872 .

Claim. 'The straining lever D, when provided with the beveled guide-ways $d^{2}$, formed upon the curved branches of said lever, in combination with inclined notehes 
in the flanges of the eye C, substantially as herein described and shown, and for the purpose set forth.

[Drawing, page 63.]

\section{J. F. MILLIGAN, of St, Louis, Mo. No. 129,851.} July 23, 1872.

Claim. The bale-tie, constructed as herein described, consisting of the plate B having its ends $\mathrm{A} C$ folded over as shown, and provided with the bent lips or flanges a c, substantially as and for the purpose set forth.

[Drawing, page 64.]

E. J. BEARD, of St. Louis, Mo., No. 129,917. July $30,1872$.

Claim.-1. A sleeve-coupling A, formed with flanges $a a^{2}$ and openings $a^{2}$, substantially as set forth.

Clam.-2. The combination of the coupbands, as and for the purpose set forth.

$\operatorname{ling} \mathbf{A}$, forned as described, with metallic

Eng. Prov. Spec., No. 1,706; June 5, 1872 .

[Drawing, page 64.]

\section{G. BRODIE, of Jefferson Co., Ark., No. 129,925. July $30,1872$.}

Claim. As a new article of manufacture, the buckle or tie $\mathbf{A}$, provided with a center opening $\mathrm{A}^{1}$, transverse slots $a$ a near its ends and semi-cylindrical bars B B and C $\mathrm{C}$ on its upper and lower faces, all constructed and relatively arranged for operation in the manner specified, in connection with the band or hoop ends $\mathrm{D}$, attached and secured as shown and described, for the purpose set forth.

(Drawing, page 6t.)

\section{J. L HAIGH, of New York, N. Y., No. 130,218. A.ug. 6, 1872.}

Claim. An improved wire bale-band, A, provided with an eye $B$, at one end, and with a hook, C, haviug an eye, D, formed in its base at the other end to adapt it to receive the eye $\mathrm{B}$ and enable the said eye $\mathrm{B}$ to be passed over the said hook $\mathrm{C}$ from beneath, substantially as herein shown and described, and for the purpose set forth.

[Drawing, page 64.]

R. S. G00DGION, of Goodgion's Factory, S. C., No. 130,293. Aug. 6, 1872.

Claim. The tie-plate $\mathbf{A}$, formed in wedge shape, as shown, and provided with trans- verse slot $B C$, in combination with the band-ends D E, when arranged and operated substantially in the manner and for the purpose set forth. [Drawing, page 65.]

D. McCOMB, of Memphis, Tenn., No. 130.519. Aug. 13, 1872.

Claim. The improved method of connecting together the ends of wire for baling and other purposes, by means of a hookand-eye formed on each of said ends, and combined for operation substantially as shown and described.

[Drawing, page 65.]

D. S. SKINNER, of Providence, R. I., No. 131,573. Sept. 24, 1872.

Claim. The double planes A B, and the form in which they are bent or folded together to form parallel planes, as arranged in reference to each other, and the bracketed or angular forms or edges $\mathrm{E} \mathrm{F}^{\prime} \mathrm{G}$ of the plane $A$, and recess $C$, substantially as herein described, and for the purpose specifierl.

[Drawing, page 65.]

N. S. WALKER, of Liverpool, England, No. 132,223. Oct. 15, 1872 .

Claim. The within-described bale-tie, formed of one piece of metal, having a continuous frame or body extending quite around the tongue, the free-ended tongue $b$, with a detent $b^{1}$, to receive one end of the band, and the closed slot $a$ to receive the other end, all arranged as and for the purposes herein set forth.

Euglish Patent 1,653 May 31st, 1872.

[Drawing, page 65.]

L. ARNOLD, of Galveston, Texas, No. 133,349. Nov. 26, 1872.

Claim. As a new article of maunfacture, the bale-tie $\mathbf{A}$, provided with the ordinary slot $\mathrm{E}$, and with the tongue or bar $\mathrm{H}$ having the projection $I$, and the shorter loopholding tongue $\mathrm{G}$, as specified.

[Drawiug, page 66.]

F. C00K, of New Orleans, La., No. 133, 112. Nov. 26, 1872.

Claim. A metallic cotton bale-tie composed of the webs $N$, flanges $A$, and lips or stops B, as and for the purpose described and represented.

[Drawing, page 66.] 
R. S. SAYRE, of Stilesborough, Ga., No. 133,803. Dec. 10, 1872.

Claim. The lever A, with the slotted swinging plate lis attached thereto, and the slotted hook-plate II, all eoustrueted substantially as, and for the purposes described. [Drawing, jage fi6.]

\section{H. A. HOUSE, of Bridgeport, Conn., No. 133,-} 858. Dec. 10, 1872.

Claim. The device $a b$, substantially as described, for securing bundles or parcels. [3rawing page, 66.]

J. W. GURLEY, of Petersburg, Va., No. 134,052. Dec. 17, 1872.

Claim. 'The combination of the box $\mathrm{A}$ having a tapering recess with the wedge $B$ haring the head $b$ and beel $b^{\prime}$, substantially as described.

(Drawing, page 67.)

F. C00K, of New Orleans, La., No. 135,526. Feb. 4, 1873.

Chim. 'The openings between the bars $\mathrm{C}$ and D made by spliting off the bars $C$ from the bar's $D$ without loss of metal, and the lips turned on the edges of the said bars for the purpose of enlarging the openings, and thus makiug more easy the introduction of the bent ends of the bands.

[Drawing, page 67.]

P. K. DEDERICK, of Albany, N. Y., No. 135,700. Feb. 11, 1873.

Claim.-1. A bale-tie, consisting of a metal plate having one point of connection common to both ends of the band, and a projection of one or both ends from the point of connection along and over the taut portions of the band, adapted to secure the end of the band to be tied between said projection and the band, substantially as specified.

Claim.-2. 'The mode of securing a wire band to the tie by passing the end of the band to be tied through a hole in the tieplate or around it, and then between a projection of said plate along the band and the said band, sulbstantially in the manner deseriberl.

[Drawing, page 6i.]

M. QUIN, of Galveston, Texas, No. 135,938. Feb. 18, 1873.

Claim. The buckle, as constructed, in combination with the notched baud, substantially as described.

[10raving :page 67.]
A. J. G0ING, of Clinton, La., No.137,301, A pril 1, 1873.

Claim. 'I'he within-described bale-tie, consisting of the strip $\mathbf{A}$, laving one or mole tongues, $b$, at each end, with a slot, $a$, on each side of each tongue, substantially as shown and described, and for the purposes herein set fortl.

[1rawing, page $6 s$.

A. J, GolNG, of Clinton, La., No. 5,553, Aug. 26, 1873. Reissue of Patent No. 137,301. April 26, 1873.

Claim. A bale-tie, constructed with slots B and tongues D formed on opposice sides thereof, so that its ends may be locked together, substantially as shown and described.

[1) rawing, page 68.]

1. W. HEDENBERG, of Chicago, I11., No. 137,549. April 8, 1873.

Clrim. A plate, A, constructed with the raised loop, $B$, notch $\mathrm{E}$, and prong $\mathrm{F}$, in the form described, and combined with a suitable strap, G II, to form a bale, as set forth.

[Drawing, page 68.]

W. C. RAMSAY, of Wadesborough, N. C., No. 137,570. April 8, 1873.

Claim. As an improvement in bale-ties, the loop B having pointed projections $i t$ arranged to operate with the band $A$, bent substantially as and for the purpose specified.

[Drawing, page 68.]

F. Co0K, of New Orleans, Ia., No. 138,479. May 6, 1873.

Cluim. 'The cotton-tie fastening as shown and deseribed, having a detached loop or loops, D, secured to the end of the band, for the purpose specified.

[Drawing, page 69.]

F. C00K, of New Orleans, La, No. 138,480. May 6, 1873.

Claim. 'I'he cotton-tie, cunstructed as shown and described, having the loop D at right angles with the body of the band and the bend $\mathbf{E}$ in a double thickness of the band.

[Drawing, mage 69.]

F. COOK, of New Orleans, La., No. 138,481. May $6,1873$.

Claim. The sliding loop $\mathrm{A}$, substantially as shown and described.

[1)rawing, lage 69.] 
F. CooK, of New Orleans, La., No. 138,482 May 6, 1873.

Claim. A clasp for cotton-bale ties, having two pairs of raised lips, C C, recessed for the reception of the bent ends of the bands, and so made, with relation to the body of the clasp, as that said ends shall pass between the lips and body of the clasp, as and for the purpose described and remresented.

[Drawing, page 69.]

F. COOK, of New Orleans, La. No. 138,483. May 6, 1873.

Claim.-1. The cotton-tie link made with the planes of the band seats at an angle with each other, having a fold and twist iu the middle.

Chim.--2. The end flanges, made at an angle with the plane of the baud-seat, for the purpose shown, and substautially as described.

Claim.-3. The combination of the angular band-seats with end flunges and looped ends of metallic bands for bales.

[Drawing, lige 70.]

F. C0OK, of New Oxleans, La., No. 138,484. May 6, 1873.

Claim. The construction of the cottontie, as shown and described, without a buckle or link.

[Drawing, page 70.]

W. D. FIELD, of Providence, $\mathbf{R}, \mathbf{I}$, No. $138,492$. May 6, 1873.

Claim.-1. A cotton-tie formed from a single plate, and having the slot and two hollow projecting arms, $B$ and $B^{\prime}$, as described, for the purposes specified.

Clam.-2. The cross-bar $\mathrm{E}$ in combination with the hollow projecting arms $B$ and $B^{\prime}$, the whole arranged and operating in the manner substantially as described.

[Drawing, page 70 .

\section{E, P. JONES, of Shell Mound, Miss. No. 139,675. June 10, 1873.}

Claim.-1. The bale-tie $\mathrm{A}$, having a continuous and uncut wa!l, slots or openiugs $\mathrm{B} \mathrm{B}^{\prime}$, and the tongue $\mathrm{C}$, having its outer section turned down so as to leave a shoulder or flange bearing; $c$, and an opening $c^{\prime}$, either with or without the wall $A^{4}$ being bulged, the whole being so constructed and relatively armanged that the tongue shall extend on such a plane with the side walls $\mathrm{A}^{2} \mathrm{~A}^{3}$ of the tie that the lateral slipping of the band off the tongue shall be prevented by said walls, and without any section of the same being cut away so as to provide bearing-flunges for that purpose, substantially as described.

Claim.-2. The bale-tie A having slots or openings $\mathrm{B} \mathrm{B}^{\prime}$, and the tongue $\mathrm{C}$ having shoulders or projections $c b$, either with or witlout the wall $A^{4}$ being bulged, the whole being so constructed, combined, and arrauged as to permit of the fastening and retention of the band, substantially as deseribed.

Claim,-3. The bale-tie $\mathbf{A}$, having a projection, $a^{\prime}$, on its wall, as shown, slots or openings $\mathrm{B} \mathrm{B}^{\prime}$, and the tongue $\mathrm{C}$, having shoulder's or projections $c b$, either with or without the walls $A^{4}$ being bulged, the whole being so constructed, combined, and arranged as to operate substantially as described, as and for the purpose specified. [Drawing. page 70.]

A. S. ARMSTRONG, of New Orleans, La., No. 139,754. June 10, 1873.

Claim. 'The buckle or bale-tie herein shown and described, for the purposes specified.

[Drawing, page 71.$]$

F, COOK, of New Orleans, La., No. 139,777. June 10,1873

Claim.-1. The buckle having a single mortise and open slot, when surrounded by an outer rim, $E$, for the purpose specified, forming therewith a new and improved buckle.

Claim.-2. The buckle having in combination, the fingers D D split off and pressed out from its body, with the single central mortise $A$, the open slot $C$, the stops or lips $\mathrm{G}$, and the outer rim-plate $\mathrm{E}$ with the looped encls of metallic bands. substantially as described.

[Drawing, page 71.]

W. D. FIELD, of Providence, R. I., No. 140,024. June 17, 1873.

Claim.-1. A bale-tie composed of two hook-pieces, A A, pivoted together and arranged relatively to each other, substantially as described.

Claim.-2. A bale-tie composed of the hook-piece A pivoted to a slotted link-piece, E, substantially as described.

[Drawing, page 71.]

F. C00K, of New Orleans, La., No. 140,246, June 24, 1873.

Claim. A cotton tie buckle with one 
mortise and two leversed tongues split off from the outer bars 1).

[Drawing, page 71.]

W. C. STIFF, of Birmingham, England, No. 140,556. July 1, 1873.

Clam. A loop or eye for bands or hoops for baling cotton or other substances, substantially such as herein described and illustrated in Figs. 7, 14, 15, 16 of the accompanying drawing, said Joop or eye being formed from a portion of the band, or from a separate piece, bent and fashioned in the mamner shown and set forth.

English Patent No. 1,544 of April 28th, 1873.

[Drawing, page 72.]

R. W. COBB, of Helena, Ark., No. 140,575. July 8, 1873.

Claim. A cotton bale-tie, consisting of the buckle and the slotted plate or keeper, combined with the hoop, as and for the purpo:es described.

[Drawing, page 72.]

F. COOK, of New Orleans, La., No. 140,766. July 15, 1873.

Claim.-1. The cotton tie made as shown and described on the band or on a separate piece riveted on.

Claim.-2. The side cut or notch in the band to receive the looped end sidewise.

Claim.-3. The notched edge, so arranged that when the looped end enters it the looped end laps over a double thickness of the band and holds the bent end in position by the expansive force of the bale.

Claim.-4. The raised lip $J$ in the band. [Drawing, page 72.

E. J. BEARD, of St. Louis, Mo., No. $140,873$. July 15, 1873.

Claim. The bale-tie, formed by looping one end of the band into the recess $a$ eut in the edge near the other end of the band, and locked by rivet $a^{2}$ near the recess, and rivet $a^{1}$ at the extreme end, substantially as shown arid described.

tDrawing, page 73 .

F. M. LOGUE, of Satartia, Miss., No. 141,447. Aug. 5, 1873 .

Claim. The lever $\mathrm{A}$ and arm $\mathrm{C}$, when forked and notched as shown, and combined with the crank B, as herein described, and for the purpose specified.

[Drawing, page 73.]
W. CRONE, of Galveston, Texas, No.141,494. Aug. 5, 1873.

Claim. The S-shaped bav A B B, and the cross-bars E, combined with the band $D$ in the manner and for the purpose deseribed.

[Drawing, page 73.]

L. D0TY, of Frankfort, I11., No. 141,630. Aug. $12,1873$.

Claim. The combination of the levers $e$ and $v$, pawl $s$, and forked point $i$, collstructed, operating and arranged as and for the purpose set forth.

[Drawing, page 73.]

G. L. LAUGHLAND, of New York, N. Y., No. 141,879. Aug. 19, 1873.

Claim.-1. A wire tie for baling liay and similar substance, composer of a bright or unannealed wire band, the ends of which are upset, riveted or enlarged at opposite ends of a holler, coustructed and operating substantially as herein deseribed and for the purpose set forth.

Claim.-2. As a new article of manufacture for baling hay, wires or wire rods cut into suitable lengths, and their ends upset or enlarged, and ready to be united to holders without twisting, as described and represented.

English Patent No. 2,734; Sept. 13. 1872 .

[0rawing, nage 71.$]$

F. C00K, of New Orleans, La., No. 142,001. Aug. 19, 1873.

Claim. - 1. The bale-tie constructed sub. stantially as shown and described.

Claim. - 2. The combination of the double notches in the straight band with the looped band end and a strengtheningplate riveted on said straight end.

Claim.-3. A bale-tie constructed so that when the looped end of the band enters a side noteh in the straight end the bent end of the loop enters simultaneously a second side notch and is locked by pressure against the straight band, or by the strengtheningplate riveted on it.

[Drnwing, page 74.]

W. J, ORR, of Charlotte, N. C., No. 142,505. Sept. 2, 1873.

Claim. A metal-strap bale-tic having the eye-piece $\mathrm{D} d$ set to one side of the strap $\Lambda$, open nearly the width of the strap in front of face $d^{1}$, and having the inclined $d^{2}$, 
in combination with the loop $\mathrm{C}$, as and for the purpose described.

[10riwing. page 74.]

H. D. STARR, of Texana, Texas, No, 142,527. Sept. 2, 1873.

Claim. A pair of tie-plates, each consisting of a eatch bar $d$ and $a$, strap-bar $e$ conneeted at their ends by side-bar's \%, surrounding a slot $b$, and having extending from the catch-bar on opposite sides a tougue or hook $c$ adapted to engage with the catch-bar of the opposite plate forming a double lock, as shown and described.

[Drawing, phge 7t.]

F. COOK, of New Orleans, La., No. 142,772. Sept. 16, 1873.

Claim.-1. The cotton-tie made as shown and deseribed, or its equivalent.

Clum. - 2. The plate E, having the stop II and an oftset or thicker part, through which the rivets $K$ pass.

Claim.-3. The plate E attached to the straight end of the band, and so made as to admit the bent end of the loop of the band between the hook-piece of plate $\mathrm{E}$ and the straight, end of the band, to pre. vent the bent end of the loop drawing out by the strain of the expansion of the bale. [Drawing, page 75.]

0. K. McCLEAN, of New Orleans, Ia., No. 142,802. Sept. 16, 1873.

Claim.-1. The bale tie-plate A F B made in the form as shown and described.

Claim. -2. The bale-tie plate constructed as shown, having the guard $\mathbf{A}$ and projections, the latter forming space $B$, substantially as described.

[Drawing, page 75.]

J. McMURTRY, of Lexington, Ky., No. 142,803. Sept, 16, 1873.

Claim. The ends A B, having the square notches $d$ and downwardly-projecting flaps $c$ formed in their edges at each side of the notch $d$, so that when the ends are brought together both ends and flaps will come upon the under side of the tie next to the bale, substantially as shown and described. [Drawing, rage 75. ]

G. BRODIE, of Plum Bayou, Ark., No. 142,894. Sept. $16,1873$.

Claim. The method of securing and identifying bales of cotton and like material, and providing against the possible loss or detachment of the marks of identity, except by disruption of the bale, by means of metallic bands and tie-plates hoving the names and eharacters indicating owuership, quality, weight, \&c., indelibly stamped upon the said bands and plates, or either of them, substantially as described.

[Drawing, page 75.$]$

\section{T. CROMER, of Galveston, Texas, No. 143,124.} Sept. 23, 1873.

Claim. The plate A, provided with slotted projections $a$, when combined, as deserilied, with the indented band.

[Drawing, page 70. .]

F. C0OK, of New Orleans, La., No. 142,223. Sept. 30, 1873.

Gaim.-1. A cotton-bale tie, made of band metal curled around one end of the band and riveted thereto, and standing off from the band far enough to admit, between itself and the band, the other or bent end of the band, substantially as clescribecl.

Claim.-2. In combination with a baleband, the eurled fastener E, secured to operate substantially in the manner and for the purpose set forth.

[Drawing, page 76.$]$

G. N. BEARD, of St. Louis, Mo., No. 143,319. Sept. 30, 1873.

Claim.-1. The tie-plate consisting of a thick back, $A$, provided with a sidle flange, $a$, lock-projection $\mathrm{F}$, and a horn, $\mathrm{G}$, so much thimner than the back $\mathrm{A}$ as to allow a thickness of the band between the horn and the end $B$ of the band when attached to the latter, substantially as set forth.

Claim.-2. The combination of band-end $\mathrm{B}$ and plate or tie-piece consisting of a back, A $a$, projection $\mathrm{F}$, horn $\mathrm{G} g$, and rivets or studs D E, all substantially as and for the purpose set forth.

[Drawing, page 76 ]

J. M. GOLDSMITH, of Boston, Mass., No. 143. 343. Sept. 30, 1873.

Claim. The fastening $\mathrm{B}$ having Ings $b \quad b$, beveled, as shown, to form the dovetailed space $\mathrm{C}$ of uniform width, and riveted to the band $A$, in combination with the notches a a upon said band, substantially as epecified.

[Drawing, page 76.]

B. KIMBALL, of St. Louis, Mo., No. 143,911. Oct. $21,1873$.

Claim. The combination of the plate $\mathbf{A}$, having a slot, $b$, and ears $a a^{\prime}$, hoop D, pro- 
vided with one or more tongues, $\mathrm{F}$, eonstrueted for joint operation, substantially as and for the purpose shown and sperified.

[Drawing, page 77.]

\section{A. G. BUFORD, of Water Valley, Miss., No.144,-} 502. Nov. 11, 1873.

Claim. The cotton bale-tie consisting of the side-tapered bars $\mathrm{A} A$, cross-bars $B \mathrm{~B}^{\prime}$, and the remorable wedge-shajed eross-bar $\mathrm{C}$, constructed substantially as shown and described.

[Drawing, page 77.]

T. D. LEONARD, of Waco, Texas, No. 144,776. Nov. 18, 1873.

Claim. The mortiser lever A provided with roller $\mathrm{B}$, recess $a$, and dogs $\mathrm{D} \mathrm{D}$, in combination with the double rachet bar $\mathrm{C}$, with oftset $d$ and cam-lever $G$, and the stirrup $f$, all constructed and arranged substantially as and for the purposes herein set forth.

[Drawing, page 77.]

F. QUARLES, of Waco, Texas, No. 144,793. Nov. 18, 1873.

Claim. The cotton-bale tie consisting of the wedge-shaped plate, having oblique slot on one side and a perforation at one end, in combination with a wire band, one end of which is secured within the perforation and the other adapted for looping in the slot, substantially as specified. [Drawing page 77. ]

L. CARTER, of Huntsville, Ala., No, 145,091. Dec. 2, 1873.

Claim. The combination of the halved or shouldered wedge $J$ with the clip A C and block E, secured to the end $B$ of the band, as shown and described, whereby the end $\mathrm{F}$ is bent and secured, as specified. [Drawing, page 78.]

G. N. BEARD, of St. Louis, Mo., No. 145,273. Dec. 9, 1873.

Claim. The bale-tie or fastening having a stiff back $A$, horn $B$, ear or ears $C D$, and band ends $E$ and $f$, the former end lying directly beneath the whole width of the latter, and holding it in place without aid from the cotton.

[Drawing, nago 7s.]

J. MCCLEAN, of Now Orleans, La., No. 145,357. Dec. $9,1873$.

Claim. In a bale-tie forming machine the combination of the angular shaping-erlge
II, the holder I, and the two hinged bending-levers $F$ and $K$ for shaping and bend. ing the end of a balc-tic, substantially as described and represented. [Drawing, 1ages $78,79$. .]

D. S. SKINNER, of Providence, R. I., No. 145,536. Dec. 18, 1873.

Claim. The bridge E, in connection with the ribs or abutments D D, and in combination with the bars $F G$, plane $A$, and abutment $\mathrm{B}$, with its projection $\mathrm{C}$, constructed substantially as herein set forth, and for the parpose specified.

[Drawing, page 79.]

\section{F. COOK, of New Orleans, La., No. 145,847.} Dec. 23, 1873.

Claim. A bale-tic or fastening, composed of a hook or band piece II, having a long solid riveting-strip $G$, rolled upon it, by which it is riveted to a single or double thickness of the band, and a recess $K$, to receive and retain the bent end of the band, which is slipped laterally over it, as described and represented.

[Drawing, page 79.]

L. WEIL, of New York, N. Y., No. 146,037. Dec. 30, 1873.

Claim. The end B C of the bale-band, having a series of rectangular slots $\Lambda$, with their lips D, in combination with the key E, substantially as shown and described.

[Drawiog, page 79.]

J. W. HEDENBERG, of Chicago, Ill., No. 146,529. Jan. 20, 1874.

Clarm. The buckle-plate A, provided with the bars $I I \mathrm{G} I$, in combination with the looped plate J B, constructed substantially as and for the purpose set forth.

[Drawing, page 80. .]

W. A. JORDAN, of New Orleans, La., No. 140,911. Jan. 27, 1874 .

Glaim. A bale tie consisting of a plate $A$, having slots $b b^{\prime}$, sleere $B$, and a band or hoop, the looped end of which is elinehed over the sleeve 13 , and the free end passed through the slot $b^{\prime}$ from the under side, and secured in the said sleeve, substantially as aud for the purpose set forth.

English l'atent No, 4,208 of December 221,1873 .

[Drawing, nage 80.] 
0. R. MCCLEAN, of New Orleans, La. No. 147,015. Feb. 3, 1874.

Claim. The loops secured to the bands, and the mode of bending and securing the said band to the loops as described, for the purpose set forth.

(Drawing, nage 80.)

C. DRISCOLL, of New Orleans, La., No. 147,049. Feb. 3, 1874.

Claim. The loop A, having the end riveted to one end of the band, the other end being secured within said loop, as shown and deseribed.

(Drawing, page 80.)

\section{H. SCHNELLE, of St. Louis, Mo., No. 147,179.} Feb. 3, 1874.

Clam. The combination of the side bar B, horn G, and bar D, all arranged in one plane, the inclined bars E F, beneath said plane, to hold the free ends of the lap, and the side bar $\mathrm{C} c$, curved or depressed opposite said horm, all as herein described, for the purpose specified.

(Drawing, page 81.)

\section{J. W. HEDENBERG, of Chicago, Ill., No. 147,262.} Feb. 10, 1874.

Claim.-1. The loop plates A B, constructed as set forth, in combination with a continuous strap-iron. E D, when the plate $\mathrm{B}$ is arranged to swing to one side, as set forth.

Claim.-2. The sliding loop C, combined with the end D of the strap, and the loopplates A B, as and for the purpose set forth. [Drawing, page 81.]

J. E. LEA, of Summit, Miss., No. 147,276. Feb. 10,1874 .

Claim. The cotton bale-tie A, having one end made with a shoulder $b$, and catch $\_$, and the other end with a loop $d$, the whole constructed and fastened substantially as and for the purpose set forth.

[Drawing, wage 81.]

H. ESTES, of St. Louis, Mo.-Case B, No. 147,380. Feb. 10, 1874,

"Claim. The tie formed of a sleeve, C, riveted to the band end A and stud $c$, in com. bination with the notebed end $B \quad b$, substantially as set forth.

[Urawing, page 81 .]
H. ESTES, of St. Louis, Mo.-Case B. No. 147,381. Feb. 10, 1874.

Claim.-1. The bale-tie, having an oblique slot, C, and adapted to elutch the band edgewise, in the manner substantially as explained.

Claim.-2. The tie-piece A, formed with projecting part $B$, slot $C e c^{1}$, and aperture $\mathrm{E}$, substantially as set forth.

[Drawing, page 82.]

R. FELL, Jr., of Helena, Ala., No. 147,757. Feb. $24,1874$.

Claim. The combination of the twisted band $\mathrm{A}$, provided with the loop $\mathrm{B}$, end $c$, and keeper $d$, all operating as described.

[Drawing, page 82.]

\section{E, J, BEARD, of St. Louis, Mo., No. 147,811. Feb.} $24,1874$.

Claim. The bale-tie or fastening formed with three prongs, A B and C, with or without the additional prong $\mathrm{G}$, for the purpose of holding or tying the looped ends $\mathrm{E} F$ with their laps $e f$, in the manner substantially as set forth.

[Drawing, page 82.]

E. W. WHITEMAN, of Bayou Sara, La., No. 147,883. Feb. 24, 1874.

Claim. An improved bale-tic A, made with a hole $a^{x}$ in one end, loops or bends $a^{2}$ upon its other end, and with a tongue $a^{3}$, in its middle part, to adapt it to be used with a wire $B$, substantially as herein shown and described.

[Drawing, page 82.]

W. S. DAVIS, of Galveston, Texas, No. 147,911. Feb. 24, 1874.

Claim. A guard for wire bale-ties, consisting of a strip sheet or plate metal having eyes or loops to receive the tie, and arranged between the tie and the bale substantially as and for the purpose shown and described.

[Drawing, page 83.]

J. R. KENNEDY, of Tuscaloosa, Ala, No. 148.068. March 3, 1874.

Claim. The combination of the link $\mathbf{A}$, having the ends bent, with the band or hoop having the oblong holes or perforations $a$ at one end, and several perforations $b$ at the other end, within which the link A is hooked, thereby making the fastening substantially as deseribed.

[Drawing, page 83.] 
W. S, DAVIS, of Galveston, Texas.-Case B. No. 148,423. March 10, 1874 .

Claim. A bale-tic fustening constructed with an elongated slot b, at its rear end, and terminating at its front end in a hook, in the mamner as herein shown, so that the engraing point of the hook and of the slot will be in line with each other and the ends of the band, as set forth.

[Drawing, page 83.]

1. M. GOLDSMITH, of Boston, Mass., No. 148,444. March 10, 1874

Claim.-1. 'The box A, constructed with an extension, $a$, beyond its largest end, to which one end of the hoop or band $B$ is permanently secured, as set forth.

Claim.-2. 'The arresting shonlder or al utment $c$ on the bottom of the box $A$, constituting part of the band $B$, in combination with a box, $\mathrm{A}$, of werlge-shape interiorly, and which has its band secured to the base-extension $a$, as substantially describerl.

[Drawing, page 83.]

\section{F. M. LOGUE, of Satartia, Miss., No. 148,890} March 24, 1874.

Cluim. The buckle formed of the parts $a$ and $b$, constructed as described, in combination with a bale-band, substantially as and for the purpose set forth.

[Drawing page 84.]

A. J. NELLIS, of Pittsburg, Pa., No, 149,144. March 31, 1874.

Claim. The combination of the bale-band, having one end looped and the hook C, riveted thereto with the closed buckle $a$, substantially as specified.

[Drawing page 84.]

J. G. ANGEL, of New Orleans, La., No. 149,424. April 7, 1874.

Claim. A band-iron bale-tie having slots $\mathrm{C}$, near one end. and at the other an arrowhead having the rear of its sides obtuseangled and re-enforeed at the neek by a strip, $\mathrm{B}$, which is bent orer the end of the arrow-head, as and for the purpose specified.

[1 rawing, page 81.]

\section{A. A. GOLDSMITH, of Charleston, S. C., No.149,-} 468. April 7, 1874.

Claim. The bale-tie deseribed, consisting of a wedge, tapered and shonldered as deseribed, and permanentiy secured to the bale-band in combination with the loop $\mathrm{A}$, as set forth.

[Drawins, 1rage 81 .]
T. F. SHERRILL, of Wadesborough, N. C., 149,531. April 7, 1874.

Clum. The open ring $\mathrm{C}$, laving the tapering overlapping ends $a$ a with notehes $b$ $b$, in combination with the band $A$ and its loops $\mathrm{B}$ B, substantially as and for the purposes herein set forth.

[Drawing, page 85.]

J. L. RANDOLPH, of Martinsburg, W. Va., No. 149,605. April 14. 1874.

Claim. The buckle described, consisting of three parallel bars with intervening slots and two transverse bar's, in combination with the band and key, as described.

[Drawing, page 85.]

A. J. NELLIS, of Pittsburg, Pa., No. 149,949. April 21, 1874.

Claim. The tic-buckle c, hatving the slots $a a$, the bearing-sides $a^{1}$ of the slots being at an angle to the euds $b \quad b$ of the buckle, to form an excess or increased width of metal at the inmer or closed ends of the slots, substantially as and for the purpose described.

[Drawing, page 85.]

E. H. STAFFORD, of Kernersville, N. C., No. 150,096. April 21, 1874.

Claim. 'The box B, provided with an interior horizontal slot, the upper surfuce of which slot is on a straight line, and the bottom and sides made fluring from a central point outward, in combination with the strap $\Lambda$, with interlocking hooks $a$, as shown and described.

[Drawing, page 85.]

A. B. HAGAMAN, of Jackson, La., No. 150,238. April 28, 1874.

Claim. The bale-band provided with projections $\mathrm{C}$, located on opposite sides, the slits B D, and an intermediate slit or notch, $\mathrm{E}$, as shown, and for the purpose set forth. [Drawing page 86.]

J. H. LANE, of Waco, Texas, No. 150,240. April 28, 1874.

Claim. Whe tie or bickle A, provided with end hooks $\mathrm{C}$ and one or nore hookis, $\mathbf{E}$, located intermediately of t'ie ends of the tie, as shown and described.

[1)rawing page S6.]

1. W. PARISH, of McFarland's. Va., No. 150,885. May $12,1874$.

Claim. A tie for cotton bales and otlicr 
analogous purposes, consisting of the links $A A^{\prime}$, the lever $\mathrm{C}$, and the slides and baleband, combined in the manner described. [Drawing, page 86. .]

F. L. BATES, of Winona, Miss., No. 15],000. May 19, 1874.

Claim. The bale-band tie, A, having two end-spurred legs, B B, plain-faced on top, and with sharp corners subjacently and in front, as shown and deseribed, so that the end of the band will be presented from slip ping, however great may be the strain or jars to which it may be subjected.

[Dratving, page sti.]

J. J. HIGINS, of Rock Hill, S. C., No. 151,120. May 19, 1874.

Claim. A bale-hoop or binder having its ends twisted in the form of an auger, substantially as and for the purposes specified. (Drawing, page 87.)

A. S. ARMSTRONG, of New Orleans, La., No. 151.191. May 26, 1874.

Claim.-1. A bale-tie constructed with a slot $\mathrm{B}$, and lapped end $\mathrm{C} \mathrm{C}^{11}$, as deseribed. Claim.-2. In comlination with the folded ends of the bale-bands, a slotted bale-tie with lapped ends, as and for the purpose specified.

(Drawing, wage 87.)

\section{E. GRANT, of Savannah, Ga., No. 151,281. May} $26,1874$.

Clain. A bale or packing-baud having on one side near its end, a series of U-shaped notches or recesses for interlocking with the opposite end of said band, having one or more corresponding notehes or recesses, and otherwise constructed substantially as herein shown and described.

(Drawing, page 87.)

J. K. FLICKINGER, of Seven Mile, Ohio, No. 151,483. June 2, 1874.

Clam. The combination of the closed frame $a$, provided with serrations $g$ and slots $b \quad b c c$, tongue $d$ and detents, substantially as and for the purpose described.

[Drawing, page 8\%.]

W. S. DAVIS, of Galveston, Texas.-Case A. No. 151,572. June 2, 1874.

Claim. The open hook B, laving the narrow neck portion $\alpha$, with its tlattened and tapering or inclined shank portion d and hook portion $b$, constructed as herein shown, for the purpose specitied.

[Drawing, page 89.]
G. B. FORD, of Waterford, Miss., No. 151,770. June 9, 1874.

Claim. The tie-block A, with the two perforations $a a$, in combination with the band-wire $B$, substantially as and for the purpose herein specified.

[Drawing, page 88.]

G. BRODIE, of Plum Bayou, Ark., No. 121,831. June 9, 1874.

Claim. The plate $\mathrm{A}$, having its surface cut as shown, and its center piece $B$ and sirles $\mathrm{B}^{1} \mathrm{~B}^{1}$ bulged in opposite directions, key C, and the hooked or looped ends of the band $\mathrm{D}$, when the whole are combined and arranged to constitute a bale-tie fastening, substantially as described.

[Drawing, page 85.]

J. T. MANGHAM, of Rainey's Creek, Texas, No. 152,138. June 16,1874.

Claim. An open-slotted plate or tie A, having an outwardly-flaring opening $a$, and the slot through which is terminated by round endsee, iu combination with a hoop or band $\mathrm{C}$, which, in cross-section, is flat on one side and couvex on the interior surface, substantially as and for the purpose set forth.

[Drawing, page 88.]

A. A. GOLDSMITH, of Charleston, S. C., No. 152,362. June 23, 1874.

Claim. The buckle $\mathrm{A}$, having a slot $a$, with its walls $a^{\prime} a^{\prime \prime}$ inclined downsard and toward each other, in cumbination with the binder $\mathrm{B}$, having a straight end $b^{\prime}$, and a bent end $b$, substantially as specitied. [Drawing page 89.]

G. W. SCOTT, of Savannah, Ga., No. 152,424. June 23, 1874.

Claim. A hook or catch formed by notching, folding, and refolding band-iron at such angles as to form, when conuected with the other end of the band or tie, a complete selt-fastening bale-tie-the hook or eatch formed upon one end of the band or tie, or out of a separate piece, and riveted to the band, substantially as described.

[Drawing, yage 8y.]

J. M. GOLDSMITH, of Boston, Mass., No. 152,480. June 30, 1874.

Claim. In a bale-tie, the slotted plate B, having an inclined slot $b$, and constructed with ridges $c$ and $d$ on the front upper lip and rear lower lip of the said slot, in com- 
bination with a binder $B$, rigidly attached to the said plate, so that the line of strain shall be in a direction with the length of the plate.

[I rawing page 89.]

W. C. BANKS, of Como Depot, Miss., No. 152,823. July $7,1874$.

Claim. 'The conbination of band $\mathbf{A}$ and buckle $B$, the former crimped near one end, and the latter having the tongue $b^{1}$ bent below the plane of side pieces $b^{3} b^{3}$, as and for the purpose described.

[Drawing yage 89.]

A. BALDWIN, of New York, N. Y., No, 153,035. July 14, 1874.

Claim. The combination of the independent caps, adapted for application to the top and bottom surfaces of the bale, with the independent intermediate securing devices in their various forms, substantialily as deseritied.

[Drawing, page 90.]

W. COOPER, of Tyler, Tox., No. 153,317. July $21,1874$.

Claim. As a new article of manufacture a cotton bale-tie constructed as described, with the wedge-shaped bolt $B$ and wedge. shaped slot $\mathrm{C}$ for locking the tie, substantially as set forth.

Eng. P. P. No. 4,041; Nov. 24, 1874.

[Drawing, page 90.]

\section{Y. F. WRIGHT, of Jamestown, Ga, No. 153,469.} July 28, 1874

Claim. The bale-tic herein deseribed con. sisting of the plate $\Lambda$, provided with the mortise $a$ and beveled slot $b$, having rombled end and notches $x$ in the inner edges, substantially as and for the purpose herein set forth.

[Drawing, page 90.]

\section{J. G. BATTELLE, of Memphis, Tenn., No. 153,- 656. Aug, 4, 1874.}

Claim. In a cotton bale-tie, the loop formed by bending the hoop twice at right angles with itself, as shown at $a$ and $b$, and forming the outer part thereof in a plane perpendicular to the hoop, as shown at $c$, as and for the purposes described.

[Drawing, rage 90.]

W. CRONE and T, CROMER, of Galveston, Tex., No. 153,689. Aug. 4, 1874.

Claim. The eyc-piece having an aperture for the reception of the hook, and openings for the reception of the end of the strap $n$ and for the purposes described.

[Drawing, prage 91. ]

A. A. GOLDSMITH, of Charleston, s. C., No. 153,820. Aug. 4, 1874.

Claim. In a bale-tie the welge $\mathbf{B}$, having a beveled shoulder $b$ upon its lower surfice, and a shoulder $b^{\prime}$ upon its upper inclined surface, and having its smaller end $b^{2}$ bent downward, in combination with a baleband and the taperingly-slotted and bereled buckle $A$, substantially as specrfied.

[Drawing, page 91.]

W. S, DAVIS, of Galveston, Tex., No. 154,229. Aug. 18. 1874.

Claim.-1. The plate A, provided with a slot $a$, and raised loop $b$, in combination with the tongue $\mathrm{B}$, provided with a neek $c$, and head $d$, substartially as and for the purpose herein described.

Claim.-2. The tongue $\mathrm{B}$, riveted to the loop $\mathrm{C}$, and provided with a head $d$, and neck $c$, in combination with the plate $A$, provided with a slot $a$, which at some part of its length is of less width than the head $d$, and with a loop or eye for the hoop $\mathrm{C}$ to pass through, substantially as and for the purpose herein specified.

Claim.-3. The offiset $e$ in the neck of the tongue $\mathrm{B}$, in combination with the slot a in the plate $\boldsymbol{\Lambda}$, substantially as and for the purpose herein set forth.

[Drawing, nage 91.]

R. D. McILWAINE, of Petersburg, Va., No. 154,267. Aug. 18, 1874.

Claim. The bale-tic formed by lonping the ends $c$ c of the hoop upon the opposite ends of the donble-headed bolt $a$, with their contiguons edges $d d$ in the center and their onter edges e e braced by the inner faces of the bolt-head $b b$, as shown and de. scribed.

[Drawing, page 91.]

J. D. HUSBANDS, Jr., of St. Louis, Mo., No. 154, 797. Sept. 8, 1874.

Claim.-1. A bale-tic or packing band, having one end divided, so as to form two members ol straps, or a double band at said end, which are adapted to be passed through a suitable eye or loop in the other end of the packing-band or tie, and the two tied or fastened together.

Claim.-2. A bale-tic or packing band having each end slotted and divided, forming two members or straps at each end, 
the members or straps of one end being formed into an eye or loop, into which the members of the other inay be interlocked.

Claim.-3. A bale-tie or packing band constructed with divided ends, so that the ends may be brought together and tied or fastened antomatically at each successive compression of the bale, substantially as described.

[Drawing, page 92.]

W. R. LENARD, Waco, Tex., No. 154,799. Sept. $8,1874$.

Claim. In a bale-tie the plate $\mathrm{A}$, consisting of an end and two equal sides $a a^{\prime}$, of a rectangle, and the plate $A^{\prime}$ of similar construction, pivoted the one to the other at the middle of the length of the leverage sides $a b$, and held elosed by the expansion of the baled mass, to form a rectangular clasp without edge-hooks, substantially as specified.

[Drawing, page 92.]

W. M. SMITH, of Augusta, Ga., No. 154,920. Sept. 8, 1874.

Claim. A metal plate A, provided with two loops $\mathrm{B} \mathrm{B}$, one above the other, at or near opposite edges of the plate, as shown and described.

[Drawing, page 92.]

O. D. WOODBURY and E. C. WOODBURY. of New York, N. Y., No. 154,998. Sept. 15, 1874.

Claim. The cotton bale-tie formed of two parts $A$ and $B$, each turned over in the middle to form a right angle, one end.in each part turned back to form a loop, both parts to interlock in the manner as and for the purpose described.

[Drawing, nage 92.]

A. A. GOLDSMITH, of Charleston, S. C., No. 155,234. Sept. 22, 1374.

Claim. In a bale-tie, the curved wedge $\mathrm{C}$, having upon its thick end the cylindrical enlargement D, and upon its other extremity a downwardly-bent barbed griping part E, substantially as specified.

[Drawing, page 93.]

W. H. TILLERY, of st. Helena Parish, La., No. 155,271. Sept. 22, 1874.

Claim. 'I'he band A, provided with notches on both sides of each end, having the hooks $a^{1}$ and the inclines $a$, all constructed as shown and described, for the purpose specified.

[Drawing, page 93.]
A. A. SZAB0, of Houston, Tex., No. 155,344. Sept. 22, 1874.

Claim. The combination, with block B, having two transverse holes, $b$, and grooves $b^{\prime}$, of the wire $\mathbf{A}$, having ends $a$ a passed through said holes, and then bent down as well as forward into the grooves, as and for the purpose specified.

[Drawing, page 93 ]

J. BOISSEAU, of Shreveport, La., No. 155,413. Sept. 29, 1874.

Claim.-1. In a balc-tie, the combination, with the hooked end $b^{\prime}$ of a binder and the sleeve $\mathrm{A}$, of the locking-key $\mathrm{C}$, substantially as specified.

Claim.-2. The sleeve $\mathbf{A}$, hooks $b b^{\prime}$ of the binder $\mathrm{B}$, and locking-key $\mathrm{C}$, combined and arranged substantially as set forth.

[Drawing, page 93.]

J. COLLEY, of New Orleans, La., No. 155,423. Sept. 29, 1874.

Claim. The notched-plate $\mathrm{A}$, rivets $\mathrm{C} \mathrm{D}$, and slotted and notebed loolt E, combined and arranged to form a bale-tie, substantially as specitied.

[Drawing, page 94.]

J. ADAMS, of New Orleans, La., No. 155,848 . Oct. $13,1874$.

Claim. The band-union herein described, having a uwion-piece held in one end of the band by cutting a tongue therein, within which the key is inserted and held, in the manner and for the purposes substantially as described.

[Drawing, pinge 94]

J. ADAMS, of New Orleans, La., No. 155,849. Oct. $13,1874$.

Claim.-1. 'I'he key consisting of the head and bolt formed transversely to each other.

Claim.-2. The mode of securing the band to the key by holding the head of the key within the slotted and bent part of one end, and inserting the bolt of the key within its seat in the other end of the band. [Drawing, yage 91]

A. A. GOLDSMITH, of Charleston, S. C., No. 155,867. Oct. $13,1874$.

Claim.-1. The combination, with a binder, $A$, and the 'T-shaped plate $B$ rigidly secured thereto, of the plate $\mathrm{C}$ having lateral hooks $c c^{\prime}$, a slot, $a^{\prime}$, and an upwardly-bent end $a$, substantially as specified. 
Cluim-2. 'The plate C, having hooks $c c^{\prime}$, a slot, $a^{\prime}$, and an upwardly-bent end, $a$, substautially as specified.

[Drawing page Uf.]

G. W. SCOTT, of Savannah, Ga., No. 155,981. Oct. 13,1874 .

Claim.-1. The bale-tic, consisting of a doubled or folded strip or band of metal, eut or notched and lapped into a hook, the parts of which clasp and embrace one end of the packing-band, and are secured there to by means of a high-headed rivet, or otherwise, substantially as described.

Claim.-2. In a cotton bale or other tie, the strip or band of single or doubled iron, cut ol notched, and lapped to form a hook or eatch, shaped so as to permit the loose or folded end of the tie to pass over the hook part and rest between it and the back part.

Claim.-3. In combination with the packing-band and hook or lock, the rivet, serew, or bolt, with a high or bossed head placed opposite the projection of the hook for controlling the movenient of the folded end of the packing-band, and preventing the sane from becoming unlocked, as hereiu deseribed.

[Drawing lige 95.]

G. W. SC0TT, of Savannah, Ga., No. 155,982. Oct. 13, 1874.

Claim.-1. 'The lock or buckle $\mathrm{C}$ made of band, malieable, or cast-iron, and notched so as to form a hook to secure and hold the folded end of the hook $B$ of the packingband, and turned so as to hold the other end, substantially as herein described.

Claim.-2. The lock or buckle C, with both ends turned out and secured to onc end of the packing-band by means of the loop on the end of the same secured by rivets, substantially as herein shown and deseribed.

Cluim.-3. In combination with the packing-band and loek or tie, the riset, bolt, or serew $\mathrm{N}$, with its enlarged boss or head for confining the hook $B$ in place when the parts are locked, substantially as herein de-.r.riluel.

[Trawing page 95.]

M. T. BROWN, of Tyler, Texas, No. 156,013. Oct. 20, 1874.

Clam. A bale-tie fastening ennsisting of the shank $d$, riveted projection $e$, at one end and projection $i$ at the other, and hook por- tion $c$, attached by the neck $c^{\prime}$, in combination with the tie cuds $\mathbf{A} \mathbf{A}^{\prime}$, slotted as described, substantially as set forth. [Drawing, page 45 .]

\section{R. TERRELL, of New Orleans, La., No. 156,262.} Oct. $27,1874$.

Claim. 'The notches a $a^{\prime}$, sc., hooks $b$ l', \&e., and projecting guards or shields $c c^{\prime}$, Sc., formed at the erlges and center of the opposite sections of a netallic band, the whole being constructed, combined, and arranged to provide a means of fastening and protecting the ends of said band, substantially as described.

English Patent No. 4,344, December 17, 1874.

[Drawing page 95.]

\section{R. TERRELL, of New Orleans, La., No. 156,263.} Oct. 27, 1874.

Claim. A cotton-tie fastening for metallic bands, by turuing one end of the band back parallel with itself, so as to provide a double thickness of material, and then folding or bending the same in succession, as shown as Figs. 2, 3 , and 4 , thereby forming a loop whose bearing-surface is on a line and at right angles with the main section of the body of the band and the oblate hook $A$ on the opposite end of the band, the whole being combined and arringed to secure the band around the bale, substantially as described.

[Drawing page 9 i.].]

\section{H. B. JONES, of Burton, Texas, No. 156,292.} Oct. 27.1874.

Claim. The key, consisting essentially of the head $\mathrm{C}$, a short shank, and a radiallyprojecting bit $\mathrm{D}$, having sharp corners to clutch the fibers of the bale, in combination with the key-hole slots in the ends of the hoop, all constructed and arranged substantially as and for the purpose described. (Drawing, page 96.)

\section{R. MONTFORT, of Butler, Ga., No. 156,400.} Nov. 3, 1874.

Clam. In a bale-tie, the buckle $\mathbf{A}$, having the stuck-up tongue $a$, the downwardlybent heel $d$, and the hook $\mathrm{C}$, for the purpose of attuching the wire to the buckle, as shown and described.

[Drawing, page ki.]

W. S. DAVIS, of Galveston, Texas, No. 158,548. Nov. 3, 1874.

Clexim.-1. 'The tie-plate A, provided 
with the slot $a$, for receiving the end of the hoop, and with the locking-slot $b c$ and arched bar $d$, substantially as and for the purpose herein described.

Cluim.-2. 'The tongue B, constructed of a double thickness of metal, as described, and provided with a head $e$, and neck $f$, said neck being formed with an off'set, and the whole constructed substantially as herein shown and set forth.

[Driwing, page 9i.]

W. S. DAVIS, of Galveston, Texas, No. 156,547. Nov. 3, 1874.

Claim. The tongue $\mathrm{B}$, provided with a head $c$, and neck $f$, the latter having an oftset, as deseribed, in combination with the tie-plate $A$ having a 'T-shaped slot, substan. tially as set forth, whereby the head $c$ is made to impinge on the turned-in or endlapped portion $g$ at the other end of the hoop, as and for the purposes herein set forth.

[Drawing, page 9\%.]

A. A. SZAB0, of Houston, Texas, INo. 156,827. Nov. 10, 1874.

Claim. The block B, for holding the ends of bale-wire $A$, having an open crossslats $b^{\prime}$, on each side, leading to the inner aperture $b$ as well as cramping-grooves running longitudinally from the latter to the ends of block, as aud for the purpose describel.

[1)rawing, yage 97.]

G. N. BEARD, of St. Louis, Mo., No. 156,752. Nov. 10, 1874.

Claim. 'The cleat B, having the notched straight bearing $b^{1} b^{2}$, the notched heel $b^{3} b^{4}$, and a quadrangular or rectangular shank $b$, said cleat being riveted parallel to the band, in combination with the shouldered slot $c c^{1} c^{2} c^{3} c^{4} c^{5}$, having its portion $c^{4}$ parallel with the band, substantially as set forth.

[Drawing, nage 97.]

G. N. BEARD, of St. Louis, Mo., No. 156,753. Nov, 10, 1874.

Clam. The combination of the honkplate $C$, having a hook $c$, flaring backwardly, and round stud $\mathrm{B}$ on the end $A$, and round eyes E on the end D of the band, all constructed and operating substantially as set forth.

[Drawing, page 97.]
G. N. BEARD, of St. Louis, Mio., No. 156,754. Nov. 10, 1874.

Claim. The button or cleat B, having a straight bearing $l^{2}$, parallel with the ends of the band, and a bulging projection $b^{3}$, on the heel, substantially as and for the purpose set forth.

[Drawing, page 98.]

A. ALLAN \& J. BURNS, of Liverpool, England, No. 156,965 . Nov. 17, 1874 .

Claim. A cotton bale-tie having a button-like inner head $a$, a round stem $b$, rising from the inner head, and commecting it with the outer head c, projecting at right angles from the stem b, all combined substantially as specifiel.

English Patent, No. 543, August 7, 1874. [Drawing, page 93.]

\section{H. G. HUTCHISON, of Pittsburg, Pa.; No. 157,-} 005. Nov. 17, 1874.

Claim.-1. The independent bale-tie or key B, provided with the jaw or look I) $d$ and lip or lng $\mathrm{E}$ at one enrl, and the jaw $\mathrm{C}$, with its lips $c c^{1}$ at the other, substantially as and for the purposes set forth.

Claim.-2. The combination with the hoop or band $A$, provided with the slots $a a^{1} a^{2}, \& c_{0}$, of the removable and independent key B; the whole ennstructed and adapted to operate substantially as and in the manner shown.

[Drawing, page 9S.]

J. N. SMITH, of Jersey City, N. J., No. 157,032. Nov. 17, 1874.

Claim. The bale-band A, provided with solid interlocking ends $\mathrm{B}$ D and confiningwings $\mathrm{C} \mathrm{C}$, substantially as and for the purposes hereinbefore set forth.

[Drawing, page 98.]

S. J. LEACH, of Tuscaloosa, Ala., No. 157.206. Nov. 24, 1874.

Claim. - 1. The plate $\mathbf{A}$, having notched or serrated flanges $\mathrm{D}$, combined with the hoop, having notched edges, as rescribed. Claim.-2. The loop $\mathrm{F}$, combined with the plate $A$ and notehed Hanges D, substantially as specified.

[Drawing, nage 99.]

\section{J. L. REESE, of Galveston, Texas, No. 157,223.} Nov. 24, 1874.

Claim. The bale-tie consisting of the spaced transverse slits $b b^{\prime}$ and the longitudinal slit $c^{\prime}$, eut through one broadened and re-enforced end of a metallic binder, 
and the hook $h$ of the other end thereof', arlapted for use substantially als specified.

[1)ruwitg, page y9.]

C. A. WARD, of Owego, N. Y., No. 157,303 . Dec. 1, 1874.

Clam. A bale-tie consisting of the wire $\Delta$, twisted at each end into a loop, the smaller of said loops holding the long link B, substantially as and for the purposes set forth.

[Drawing, nage y9.]

J. N. SMITH, of Jersey City, N. J., No. 157,354, Dec. 1, 1874.

Clnim. The combination of the shears $b e$, the dies $f h$, and punches $g g^{\prime} i i^{\prime}$, and the dies G II, the whole forming a single machine or tool, whereby a strap may be rapidly prepared, fitted and tied on the bale without removing either it or the tool, substantially in the manner hereinabove set forth.

[Drawing, page 90.]

J. N. SMITH, of Jersey City, N. J., No. 157,940. Dec. 22, 1874.

Claim. A bale-tie made by cutting and pressing up out of the body of the metal strap tongues or elasps $a$ a on one or both ends of the said strap, which tongues or clasps are inserted into openings formed in the other end of the said strap, and closed down around the edges of the said openings, substantially as hereinabove set forth.

[Drawing, page 100.]

R. M. TAYLOR, of Memphis, Tenn., No. 158,145. Dec. 22, 1874.

Claim. A wire bale-tie provided at one side with an opening for the inward passage of the doubled ends of a band, and having one or both of its ends turned downerd in a line perpendicular to the plane of said tie, substantially as and for the purpose specified.

[Drawing, page 100.]

G. W. CAIN, of Tyler, Texas, No. 158,243. Dec. $29,1874$.

Claim. In a bale-tie the flaring end C, provided with shoulders $a^{\prime \prime} a^{\prime \prime}$, in combination with the end $B$, provided with turned-downed grooved ears $c c$, substantially as described and for the purpose set forth.

[Irawing, page 100 ]
M. D. COPELAND, of Providence, IR. I., No. 158,683. Jan. 12, 1875.

C'reim.-1. 'The combination of the baleband, having elliptio slots at the ends, with the bolt, as and for the purpose set forth.

Claim.-2. A tie-bolt with neck under the head, for the purpose fully specified.

[Drawing, rage 100.]

J. W. PHILLIP, of Humboldt, Texas, No. 158,733. Jan. 12, 1875

Claim. The wire bale-tic having a hook $B$, and a single or double coil c, formed upon the same strand, in combination with the tic end, passed round the base of the coil, and a clamping locking pin $\mathrm{E}$, driven through said coil above the bent tie end, substantially as and for the purpose set forth.

[Drawing, page 101.]

E. FLINN \& R. G. WIER, of Mobile, Ala., No. 158,836. Jan. 19, 1875.

Claim. A balc-tie link described, the same consisting of a single piece of stift wire $A$, bent into the form of a parallelogram, and the two evds of the wire secured together at one corner by coiling the projecting end of the wire at the shorter side $a^{\prime}$ of the link around the projecting end of the wire at the longer side $a^{\prime \prime}$ of the same, for the purposes specified.

[Drawing, page 101 ]

A. 0. SCHULTZ, of Memphis, Tenn., No. 158,985. Jan. $19,1875$.

Claim. As an improvement in cottonangers, an auger constructed with symmetrically-fluted cross-section, extending along blades and teeth from stem to tapering point, substantially in the manner specified and set forth.

[Drawing, page 101.]

J. B. ARRANTS, of Society Hill, S. C., No. 159,OBO. Jan. 26, 1875.

Claim. 'T'he block or plate $\mathrm{A}$, having grooves D and E, attached to part $B$ nf the hoop, in combination with loop $\mathrm{F}$, having part $G$ of the hoop connected to it, all substantially as specified.

[1) rawing, rage 101.]

A. A. GOLDSMITH, of Charleston, S. C., No. 159,089. Jan. 26, 1875.

Claim.-1. In a bale-tie, the combination with the plate $\Lambda$, having slot $a$, and slotted projecting lug $b$, of the slotted plate $B$, hav. 
ing the double-barbed cateh $f$, and shouldcred projection $e^{2}$, substantially as specitied.

Cleim.-2. The plate A, having slot $a$ to receive the free end of the bale-strap, and the slot $c$ in its down ward projection $b$, substantially as described, for the purpose specified.

[1) rawing, nage 102.]

W. ILER, of Shreveport, La., No. 159,098. Jan. $26,1875$.

Claim.-1. The swinging clamp B, having right-angled arm $\mathrm{D}$, and pivoted to one side of a lever, $A$, having an obligne-erdged lower end, as and for the purpose deseribed.

Cluim.--2. The combination, with bar $G$, of the lower lip $J$ and superposed cam I, as and for the purpose specified.

[Drawing, page 102.]

S. H. GILMAN, of New Orleans, La., No. 159,258. Feb. 2, 1875.

Clam.-1. The combination of a hoop having a solid end with a tie made in the form of a flattened tube, both erlges of which taper from top to bottom, and with one side flat, while the opposite side is concave on a line tapering from top to bottom, all substantially as and for the purpose described.

Clam.-2. A hoop for baling purposes, with the extreme head of the wedge ou its end wider than any other part, substantially as described, and for the purposes set forth.

Clam.-3. A tic for uniting the two ends of bale-hoops, constructed in the form of a section of a thattened tapering tube, tapering in its tube on straight lines from one end to the other on its two erlges and on its bottom side, and concare on a corresponding taper line on the uppèr or top side, all substantially as described, and for the purpose set forth.

[Drawing, nage 102.]

H. B. JONES, of Burton, Texas, No. 159,268. Feb. 2, 1875.

Claim. As a new article of manufacture, the detachable cleat-tie herein described, consisting of the base-block $\mathrm{C}$, having the shoulders $c$, shank $\mathrm{D}$, and segmental cleat $\mathrm{E} \mathrm{F}$, substantially as and for the purpose specified.

[Drawing, page 102.]

A. BALDWIN, of New York, N. Y.. No. 159,378. Feb. 2, 1875.

Clain.-1. The described method of applying the fastening devices to cotton or other bales, consisting, broadly, in the employment of the power used to compress the bale to apply the covering parts of the fistening devices thereto, substantially as deseribed.

Claim. -2. A press-platen adapted for operation as a die, substantially as described, for the purpose of shaping the fastening devices to the bale, and holding the same in proper position to be secured.

Claim.-3. The platens described, provicled with beveled or rounded-edged blocks or bars, $a$ a, as described.

Claim.-4. The combination of the smoothfaced platens with the bars or blocks $a$, and means for adjusting them, substantially as described.

[Drarwing, page 103.)

1. L. REESE, of Galveston, Texas, No. 159,449 . Feb. 2, 1875.

Clain.-1. The bale-tie $a$, having a broadened end, $b$, slot $c$, and slit $d$, forming strip $f$, whether the same be used as shown on F'ig. 1, or folded as shown on Figs. 2 and 4, substantially as specified.

Claim. -2. In a bale-tie, the loop $c$, formed on one end of a binder, the open-ended slot $c$, and strip $f$ on the broadened end of the binder, substantially as specified.

[Drawing, page 103.]

J. T. SMITH, of Richmond, Va., No. 159,463. Feb. 2, 1875.

Clam. The double-hook tie $\mathrm{A}$, having central top opening, $a$, and $V$-shaped recesses $b$, substantially as and for the purposes lierein set forth.

[Drawing, page 103.]

J. THAYER, of New Orleans, La., No. 159,531. Feb. 9, 1875.

Clain. The bale-tie consisting of the band A, having the L-shaped and outward-bulging-lips B punched into each end thereof, and adapted to be locked together, substantially as specitied.

[Drawing, page 103.]

\section{A. J. NELLIS, of Pittsburg, Pa., No. 159,703.} Feb. 9, 1875 .

Claim. The table $\mathrm{A}$, having a central trough, B, provided with the incline $b$ and wipers $b^{2} b^{2}$, substantially as and for the purpose specified.

[Drawing, page 104.] 
A. J. NELLIS, of Pittsburg, Pa., No. 159,704. Feb. 9, 1875.

Clam.-1. In combination with a baleband and slotted buckle, an eye-headed rivetand $\mathbf{U}$ or similar shaped locking levice, substantially as specified.

Claim.-2. In combination with a baleband and slotted buckle, an eye-headed rivet, saicl eye or slot being elongated, and a U or similar shaped locking device, one end of which is of an oval or similar form having different diameters, one of which exceeds the smaller diameter of the riveteye, substantially as set forth.

Claim.-3. In combination with a baleband and its slotted buckle, an eye-headed rivet and a $\mathbf{U}$ or similar shaped locking device, said locking device being providen with a shonlder or projection upou the end which engages the baud-loop.

[Drawing, rage 104.]

A. A. GOLCSMITH, of Charleston, S. C., No. 159,815. Feb. 16, 1875.

Claim.-1. In a bale-tie, the combination, with plate B, rigidly secured upon one end of a binder $A$, having rectangular slots $a a^{\prime}$, and a bar $b^{\prime}$, struek down below the level of its plate, of the plate $\mathrm{C}$, adjustably applied upon the other end of the said binder, and having slot $c$, tongue $d$, with upturned look $e$, and stop $i$, substantially as specified.

Clam.-2 The plate $\mathrm{C}$, having slot $c$ and tongued, with upturned hook $e$ and stop or shoulder $i$, when adapted for use substantially as specified.

Claim.-3. The plate B, having slots $a a^{\prime}$, separated by bar $b$, and a front bar $b^{\prime}$, struck down below its level, as specified, and for the purpose set forth.

[Drawing, mage 104.]

W. A. JORDAN, of New Orleans, La., No. 160, 331. Narch 2, 1875.

Claim.-1. The buckle $\mathrm{A}^{2}$, provided with the slots $a$ and $b$ and the angular extension $\Lambda^{1}$, substantially as described, and for the purpose set forth.

Claim.-2. 'The buckle $\mathrm{A}^{2}$, provided with the slots $a$ and $b$ and the angular cxtension $A^{\prime}$, having the projections $b^{1}$ and $b^{2}$, substan tially as and for the purpose set forth.

[Drawtug, Irage 104.

\section{G. N. OSG00D, of Savannah, Ga., No. 160,345} March 2, 1875.

Clam. A cotton bale-tie of hoop metal, onc end having half-mortises cut into its elges to coincide with ents made into the elges of the ather end, forming tenoms to be bent around through the half-nortises when lapper, locking them rogether, substantially ats herein set forth.

[1rrawing, ]nge 105.]

R. TERRELL, of New Orleans, La., No. 181.074. March 23, 1875.

Claim. A cotton bale-tie consisting of the base-plate $\Lambda$, having a bar $B$, cast with or folded over the same, and the projecting section $D$ of the plate $\Lambda$, having the relation to the plate $B$ slown, whereby the lower seetion of the hook of which the plate $B$ provides the bearing slatl, when fastened, extend along said plate $D$, imyinging against the same, as stated, and the shield $\mathrm{C}$ running the whole wistl of the base-plate $A$, and curred at its outer section, as shown, so as to provide a lateral opening for the insertion of the hook on the fiee end of the band, and a bearingshoulder to retain the same in position when fastened, substantially as and for the purposes specified.

[Irawing page, 105.]

R. TERRELL, of New Orleans, La., No. 161,177. March 23, 1875.

Claim. The bale-tie herein described, consisting of the plate $A$, provided with bars $b b^{\prime}$, sirles $a a^{\prime}$, and cleats or hooks $c c^{\prime}$, as described, and for the purposes sperified.

(Drawing, page 105.)

R. TERRELL, of New Orleans, La., No, 161,178, March 23, 1875.

Claim. A bale-tie consisting of two sections, $A$ and $B$, the former provided with a raised bar $a$, and tongue $c$, and the latter with raised bar $a$ and slot $b$, as described, and for the purposes specified.

[1)rawing, page 105.]

\section{J. H. HARDMAN, of Allegheny, Pa., No. 161,409.} March 30, 1875.

Claim. 'T'he tongue $e c$ and reverse tongue

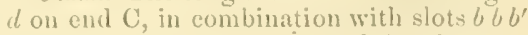
in end $B$, substantially ins and for the purposes deseribed.

[1)rawing, mage 106.]

H. B. JONES, of Burton, Texas, No.101,416. March $30,1875$.

Clam.-1. As a new article of m:unfacture, the buckle herein described, consisting of the base or bar $B$ and the two 
projecting horns $\mathrm{C} \mathrm{C}^{\prime}$, curving towal each other from said base, substantially as and for the purpose specitied.

Claim.-2. The combination of the buckle herein deseribed, with a band or hoop, A, notehed in the manner shown, as and for the purpose specitied.

[Driwing, jage 100.]

J. W. PHILIP, of Humboldt, Tenn, No. 161'819. April 6, 1875.

Cluim. The wire bale-tie, having the coil $c$ at the end, in combination with the link $l$, to hold the tie end, and be itself secured in place by the turned-up eud $e$, as shown and described.

[Drawing, page 106.]

M. T. BROWN, of Tyler, Texas, No. 162,023. April 13, 1875.

Claim. A bale-tie fastening consisting of the locking device $\mathrm{D}$, riveted projection $e$ at one end, and key-bit projection $c$ at the other, in combination with the tie ends $A$ $\mathrm{A}^{\prime}$, slotted as described, substantially as set forth.

[Drawing, nage 106.]

J. M. GOLDSMITH, of Boston, Mass., No. 162,054. April 13, 1875.

Claim.-1. In a bale-tie, the combination, with a strap-iron binder having a trapezoidal end, $e$, of the plate $\mathrm{A}$, having slot $a$, recess $b$, and lateral lugs $c$, substantially as specified.

Claim.-2. The buckle-plate $\mathrm{A}$, having a rearwardly inclined slot, $a$, recess $b$, and lugs $c$, adapted for use substantially as and for the purpose specitied.

[Drawing, page 107.]

J. W. DEY0, of Baton Rouge, La., No. 162,354. April 20, 1875.

Cluim. The tie-plate $\mathrm{A}$, having an oblong central opening, and which is divided by an oblique tongue, $\mathrm{B}$, into two slots, $\mathrm{C}$ $D^{\prime}$, and having bearing-walls $C^{\prime} D^{\prime}$, the bearing-surfuce of the latter being formed so as to provide a beveled edge, $d$, and the lower section of the tongue being also beveled, as shown at $b$, and having its bearing projecting beyond the vertical line of the bearing of the edge $d$, so as to operate substantially as described, as and for the purpose specified.

[Drawing, page 107.]
J. J. HOLLOMAN, of Humboldt, Tenn, No.162,654. April 27, 1875.

Claim. The combination, with a wire having horizontal hook $B$ on une end, and at an angle thereto, on the other end, a vertical hook, C, of the grooved plate D D', having hole $d^{3}$, as and for the purpose tescribed.

[Drawing, page 107.]

D. E. McGARRAH, of Rosemond, Ill., No, 162,672. April 27, 1875.

Claim. The band-tightener having toe L, helve or handle $\mathrm{C}$, opening $\mathrm{E}$, and clamping eccentire roller $\mathrm{F}$, all combined and constructed substantially as and for the purpose set forth.

[1)rawing, page 107.]

G. W. SCOTT, of Savaniah, Ga., No. 162,699. April 27, 1875.

Claim.-1. A bale-tie fastening formed of a double plate, open at one side and both encls, and provided with a laterally-extended base portiou, carrying al stop-pin or stud, substantially as described.

Claim.-2. A plate of metal constructed so as to form a rounded hack and sides, about in parallelism, one of the sides being of a width greater than the other, and having an oblique end, upon which is placed a shouldered stud or high-lieaded rivet, to permanently secure one end of the band to the plate, and prevent lateral displacement of the free end of the band when sprung into positiou, substantially as described.

Claim.-3. In combination with the double plate, a stud or stop formed and placed so as to secure one end of the band permanently to the plate without affecting the strength of the band, and to securely hold the other end after it has been sprung into position.

[Drawing, page 108.]

0. R. McCLEAN, of New Orleans, La., No. 162,844. May 4, 1875.

Claim.-1. In a cotton-bale tie, a tie plate riveted to and laterally projectiug from a folded end of the bale-band, in combiuation with said bale-band, the end thereof being notched and folded, as shown, so as to provide a bearing for the looped free end of the bale-band, to enable its being held in position independently of the expansive force of the bale, substantially as specified.

Claim.-2. A band-seat, onc-balf of which is on the folded end of the bale-band, and 
the other balf on the tie-plate, the arrangement heing such ats to canse the looped fiee a end of the hand, when placed in position, to bear equally on the tie plate and baleband, as herein set forth.

[Drawing, lage 10\%.]

\section{J. B. ARRANTS, of Society Hill, No. 163,133.} May 11, 1875.

Claim. In a bale.tie, the liuk B, having widened bar $b$, and vibrating in a loop, $a$, of a strap-iron binder, in combination with the U-shiped plate C, having slots d, substantially as specitied.

[1) rawing, page 10s.]

\section{J. BEASLEY, of Petersburg, Va., No. 163,138. May 11, 1875.}

Claim. A bale-tie or buekle made in two pieces, $\mathrm{A} \Lambda$, joined together by a rivet, and capable of opening at one end to snch extent that the hoop or loop may pass vertically into the opening, and the two ends of said pieces brought together to form a bar through the loop, these ends being kept in position by the other loop being drawn into the narrower space between the opposite ends, as specified.

[Drawing, page 108.]

W. L. ROSE, of Wadesborough, N. C., No. 163,331. May 18, 1875.

Claim. The double lever, cross-riveted in the center, opening from both ends to receive the loops.

[Drawing, pase 509 ]

W. A.JORDAN, of New Orleans, La., No. 163,380. May 18, 1875.

Claim. A bale-tie, from the raised portion of which lips extend forward over the band-seat, as and for the purposes set forth. [11rawing, page 109.]

J. W. PHILIP, of Humboldt, Tenn., No. 163,522. May 18, 1875.

Claim. A cotton bale-tie consisting of the plate $a$, having the slots $b c e$, as described, in combination with the wire $g$, looped and interlocked or crossed at $e$ with each other on the muler side of the plate, whereby the strain is divectly upon the wire hoop instead of the plate, as specified. [1)rawing, lrage 10!.]

J. M. GOLDSMITH, of Boston, Mass., No. 163 649. May 25, 1875.

C'laim.-1. In a bale-tie, the plate $\Lambda$, having rectingular slot $a$, oblong slot $b$, with its lateral and end bars overhanging a recess $r^{\circ}$, and lugs upon its under side, adapted for the use substantially as specified.

Cluim.-2. The buckle-plate $\mathrm{A}$, having slots $a b$, an overhanging ledge and lugs, in combination with the notehed end of a strap-iron binder, substantially as specified. [1) rawing, wages 109 and 110.]

J. W. PHILIP, of Humboldt, Tenn., No. 163,803. May 25, 1875.

Claim. The wire bale-tie having the coil c near one end, and passing the other end through it before it is brought into the clasp $d$ at the end of the coiled end of the wire for final fastening, as shown and.desireiluel.

[Drawing, page 110.]

J. N. SMITH, of Jersey City, N. J., No. 163,815. May 25, 1875.

C'laim. The bale-band having notehes or slots formed in it, as described, in combination with the elip or clasp, applied as set forth, to form a bale-tie, substantially as and for the purpose set forth.

[Drawing, page 110.]

E. D. CHADICK, of Denison, Texas, No. 164,142. June 8, 1875.

Claim. A bale-tie consisting of the tubnlar $\mathbf{T}$ shaped buckle $A$, in combination with wire band, as described.

(Drawing, jage 110.)

J. M. GOLDSMITH, of Boston, Mass., No. 164, 164. June 8, 1875.

Claim.-1. In a bale-tie, the combination, with a binder $B$, having notehes $i$ in one end and spaced notches $j$ in the other, of the plate $A$, having slots $a b$, with retaining-lugs $e e^{\prime}$ over bars $d$ and a recess $r$, uncler the body of the plate, substantially as specified.

Claim.-2. The plate $A$ having slots $a b$, $\operatorname{lugs} c e$, and recess $r$, adapted for use, substantially as specitied.

[Drawing, page 111.]

J. M. GOLDSMITH, of Boston, Mass., No. 164,165. June 8, 1875.

Cluim. 'The bale-tag consisting of the oblong plate $A$, having slots $b$ and tongues $a$, alapted for use substantially as specified. [Drawing pase 111 ] 
H. K. DU BOSE \& E. W. CHARLES, Jr., of Camden, S. C., No. 164,817. June 22, 1875.

The combination of tongueless buckle $B$ and fastener D, having two cross-slots. obliqued toward each other, with a flexible bale-band, as and for the purpose specified. [Drawing, page 111.]

A. EICHHOLZ, of St. Louis, Mo., No. 164,821. June 22, 1875.

Claim. 'The buckle part formed to have a coupling bar $\mathrm{A}^{\prime}$ with $\operatorname{lug} a$ and the $\mathbf{V}$-shaped edge $d$, in combination with the complement buckle part formed to have the opening $b$, slot $b^{1}$, and edge $c$, all coustructed to form a bale-tie or buckle, as heruin shown and set forth.

[Drawing, page 111.]

J. H. HARDMAN, of Allegheny, Penn., No. 164,835. June 22, 1875.

Claim. In a bale-tie buckle having an end bar $a$, and a middle bar $b$, with the end at side $d$ free, the bar $c$ having one end attached to the side $d$ and the other end free, substantially as and for the purposes described.

[Drawing, page 112.]

W. P. ELLIOTT, of Wilmington, N. C., No. 165081. June 29,1875 :

Claim. A wire bale-tie constructed approximately the form of a figure 8 , with crossed central portions, and ends bent inward, so that they will be drawn over the band by the effect of its orn draft or pressure, as explained.

[Drawing, nage 112.]

J. L. SHEPPARD, of Charleston, S. C., No. 165374. July 6, 1875.

Claim. -1. The combination of a revolping roller, pivoted concentrically, with the other smaller roller, journaled ecceutrically in movable bearings, substantially as and for the purpose described.

Claim.-2. The combination of the roller $A$, the smaller rollers $\mathrm{E}$, the spring $\mathrm{Z}$, and the lever $G$, substantially as and for the purpose described.

[Drawing, page 112.]

P. R. DAWSON, of Brenham, Tex., No. 165,407. July 13, 1875.

Claim. 'The cotton bale-tie, consisting of the hook $A$, provided at one end thereof with the elongated apertures B, and at the other end thereof with the transverse aper- ture $\mathrm{C}$, the $\operatorname{lng} \mathrm{K}$ on the imner side of the hoop, and the $\operatorname{lng} \mathrm{D}$, one side of which is inclined or cut away to allow the end of the hoop to freely pass, combined together as and for the purposes described.

[Drawing, page 112.]

W. GREET, of Mooresville, Ala.. No. 165,996. July 27, 1875.

Claim. The combination of the plate $B$, provided with the recesses $b^{1} b^{2}$, and the slots $b^{3} b^{4}$, and the hook $\mathrm{C}$ with each other, to adapt the tie to be used with a bale-band A, substantially as herein shown and described.

[Drawing, page 113.]

H. ESTES, of St. Louis, Mo., No. 166,085. July $27,1875$.

Claim. The combination of the band end A, with the serpentine tie or lock piece $\mathrm{C}$, provided with finger $c^{\prime}$ and head $D$, the latter having recess $d^{1}$ and projection or shoul. der $d^{2}$, and secured by rivet or stud $d$, all substantially as set forth.

(Drawing, page 113.)

S. SULLIVAN, of Savannah, Ga., No. 166,158 July 27, 1875.

Claim. A device for securing samplepatches to cotton bales, consisting of a hook or fastening-clamp adapted to hold the corners of the same, and secure them to the outer covering of the bale, substautially as described.

(Drawing, page 113.)

H. J. WRIGHT, of Society Hill, S. C., No. 166,326. Aug. 3, 1875.

Claim. The bale-tie or buckle, composed of the plate $\mathrm{A}$, having slot $\mathrm{C}$ and the end cross-bar D in a different plane from the part to which the band is riveted, and the plate $H$, having slot I to receive the fiee end of the band, and tenon $\mathrm{E}$, to adapt it for locking with plate $\mathrm{A}$, as shown and deseribed.

(Drawing, page 113.)

H. Z. YOUNG, of Vicksburg, Miss., No. 166,491. Aug. 10, 1875.

Claim.-1. In a bale-tie clamp or stretcher, the vibrating arm $F$, combined with the main lever $\mathrm{D}$, its pivot-pin $f$ being arranged in slots $g$ of the said lever, substantially as and for the purpose specified.

Claim.-2. The combination, with lever $\mathrm{D}$ and the arm $\mathrm{F}$, endwise movable with 
relation thereto, of the trigger $\mathrm{G}$, arranged within the said lever, and adjustable pin $p$ on arms $\mathbf{F}$, substantially as specified.

Claim.-3. In a bale-tie clamp, the trigger $\mathrm{G}$, eomsisting of parts $j j$, linged together and adapted to Hex downwardly, as and for the purpose specified.

[Drawing, page i1.]

\section{H. B. JONES, of Galveston, Tex., No. 166,614.} Aug. 10, 1875.

Claim. As a new article of manufucture, the bale-tie herein described, consisting of the bate of bar B, having a perforated furtjecting tongue $\mathrm{B}^{\prime}$, a short projection or catch C, curved and beveled as described, and a long projection or eatch $\mathrm{C}^{\prime}$, bent at right angles and beveled on its under surface, substantially as and for the purpose specifiel.

[Drawing, lage 114.]

\section{J. M. SEYMOUR, of Newark, N. J., No. 166,640.}

\section{Aug. 10, 1875.}

Claim. The process heretofore described of applying flexible bands to materials to be baled, and which eonsists in lapping the ends of the band, after it has been passed around the bale, over upon each other, and then, by any suitable device, taking up the slack of the band by tolding a patt of the baud over upon a contignous part thereof,

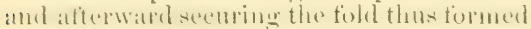
in any efticient manner.

[Drawing, page 114.]

\section{A. A. SZAB0, of Houston, Texas, No, 166,652. Aug. 10, 1875.}

Cherm. The improved bale-tie block A, with laterally-open slot $B \quad b$, and crampinggrooves $\mathrm{C}$, having the hole $\mathrm{D}$, extending from a point near one end of slot B laterally or transversely through the block, as and for the purpose specitied.

[Drawing, mage 114.]

\section{M. ALBERTSON, of Now London, Conn., No.} 166,677. Aug, 17, 1875.

(7rim.-1. I bale-tie firmed ly a single pieces or loleck of motal, havinge tope and bettom batte "h, and provided with two

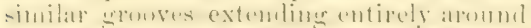
it, fint the reception of the ends of the laturde, these grooves being at an angle with each other, and crossing upon opposite sides of the tie, substantially as herein shown and deseriberl.

Caim.-2. A bale-tie having grooves which eross or intersect ench other at a common point, C, said grooves being of a greater depth at the point $\mathrm{C}$ than at any other portion of the same, $\mathrm{su}$ as to better contain the two wires erossing each other at this point, substantially as described.

Claim.-3. A bale-tie formed with two intersecting grooves, and provided with a spur, D, substantially as and for the puryose specitied.

[Drawing, page 115.]

W. H. WALKER, of Charleston, S. C., No. 167,960. Sept. 21, 1875.

Claim. The improved bale-tie buekle herein dencribed, the sitme being ents-truteted of a plate, $A$, having central closed slot $B$, and the bent arms $\mathrm{E} F$, the latter projecting from diagonally-opposite comers of said plate, and in opposite directions, as shown and described, tor the purpose specitied.

[Drawing, page 115]

T. H. MURPHY, of New Orleans, La., No. 168,518. Oct. 5, 1875.

Claim. The button $c$, provided with an obtuse-angled lieel, the inclined side of which extends firom the point of intersection between the said button and the hoop to which it is attached to the inner side of the button, in combloination with the hoop ends, as and for the purpose describul.

(1) ratwiug, pate 11 :

R. STEWART, of Barnesville, N. Y., No. 169,493. Nov. 2, 1875.

Claim. The hook $\mathrm{A}$, having a brace, $\mathrm{B}$, which constitutes an eye, which receives aud secures the eye C, substantially as specitied.

[Drawing, page 115.]

C. BROWN, of New York, N. Y., No, 169,518. Nov. 2, 1875 ,

Claim. The combination of the longituilinal and sepalmater slats C (" with the

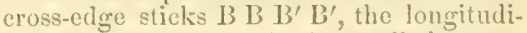

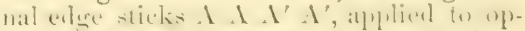
pusite sides of the bate, and the limeling

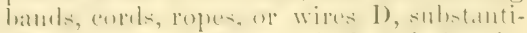
ally as shown and dererilned, and tor the purposes herein set tisth.

[Lriw itus. 1abce 11.

C. H. CHASE, of New Orleans, La., No. 169,521. Nov. 2, 1875.

Claim. 'The enff' $\mathrm{I}^{1}$, with projecting guides or lugs 6 and 7 , elongation $\mathrm{B}$, rounded corners $a$, rivet 5 , and wedge 8 , all construct- 
ed and arranged substantially as described, and for the purposes specified,

[Drawing, page 116.]

\section{S. N. DRAKE, of Galveston, Texas, No. 169,789.} Nov. 9, 1875.

Claim. The bale-tie having the shonlder A near each end of the hoop and on a line with the slots $\mathrm{C}$, whereby each face of the slots rests against the eorresponding shoulder of the opposite end, the ends being on inside, forming a double lock and brace, as specified, and for the purpose set forth.

[Drawing, page 116.]

\section{J. P. RADLEY, of Albany, N. Y., No. 169,020.} Nov. 16, 1875.

Cluim. The button $\mathrm{F}$, constructed of mal. leable metal, with projecting lips $a a$ and $c$ $c$, separated by a double or duplex shank or neck, $x z$, having projections $v v$ between the recess of said duplex shank or neck, in combination with the grasping-loop E, permanently secured to the said button, and the detachable loop $\mathrm{D}$, capable of receiving the lip end $a$ of said button at a point remote from the end of said detachable loop, substantially as described.

[Drawing, page 116.]

\section{H. CHASE, of New Orleans, La., No. 170,} 054. Nov. 16, 1875.

Claim. The lever $\mathrm{H}$, bars $\mathrm{F}$ and $\mathrm{G}$, in combination with the brackets D and rod $\mathrm{E}$, the whole being constructed and arranged substantially as described, and for the purposes specified.

[Drawing, page 117.]

C. H. CHASE, of New Orleans, La., No. 7,260 of Aug. 15, 1876. Reissue of No. 170,054. Nov. 16, 1875.

Claim.-1. The combination of the platen $a$, brackets $\mathrm{D} \mathrm{D}$, and double-acting lever $\mathrm{H}$, the latter having its fulcrum in a rod or cross-piece, uniting the brackets D $D$, substantially as and for the purpose herein shown and specified.

Claim.-2. The combination of the double-acting lever $H$, having a series of perforations, with a fulerum-pin resting in brackets D D, projecting from the platen $a$ of a cotton or other press, whereby the fulcrum or bearing of said lever may be changed to change the amount of leverage to be applied, substantially as and for the purpose hereinbefore set forth.

Claim.-3. The combination of the 12 double-acting lever $\mathrm{H}$, bar $\mathrm{F}$, having cluteh or roose-neck $\mathrm{P}$, and bar $\mathrm{G}$, having the pins L M, substantially an and for the purpose herein shown and specified.

Claim.-4. The combination of the doubl e-acting lever $\boldsymbol{H}$, laving the nipperjaws $\mathrm{L}$ ' $\mathrm{T}$, with the force-bair $\mathrm{F}$, having clutch or goose-neck I', substantially as and for the purpose herein shown and specified.

Claim.-5. The combination of the lever $\mathrm{H}$, having a fixed jaw ' $\mathrm{T}$, with the lonse jaw $\mathrm{L}$, pivoted at $\mathrm{Y}$, and having the guidepiece M, substantially as and for the purpose herein shown and specified.

[Dratving, page 117.]

J. Z. STOCKER, of Charleston. S. C., No. 170,411. Nov. 23, 1875.

Claim.-1. The combination of the claw $\mathrm{H}$ and catch $\mathrm{E}$ with the lever $\mathrm{A}$ and rigid bar, as and for the purpose specified.

Claim.-2. The lever A, suspended by a cord, having a counter-weight, in combination with the strap $\mathrm{F}$, extensible rod $J$, and claw $\mathrm{H}$, as and for the purpose specified.

Claim.-3. The slotted wedge L, provided with serrated can M, having a slot $m$, in combination with a sliding rod $\mathrm{N}$, as and for the purpose specified.

[Drawing, page 118 ]

T. H. MURPHY, of New Orleans, La., No. 170,446. Nov. 30, 1875.

Claim. The mode of tightening bands on bales by means of slots on each end of the band, and a lever notehed on opposite sides, inserted with its slots on said band, and constructed in the manner described. [Drawing, page 118.]

A. N. POWELL, of Alvarado, Tex., No. 170,589. Nov. 30, 1875.

Cluim. A pair of hooks $h h^{2}$, attached to the respective ends of a hoop-iron band $B$, so as to project on opposite sides at the extremities of the same, in combination with the slots $s s^{2}$ behind the respective hooks in bot' ends of the bands, substantially as herein shown and described, for the purposes set forth. [Drawing, page 118.]

E. O. SCHARTAN \& J. H. GARDNER, of New Orleans, La., No. 170,597. Nov. 30, 1875

Claim.-1. The slotted coiler D, substantially as described. 
Chim.-2. The combination of the champinc-lever B with the coiler I), substuntially ats described.

Claim.-3. The enneave gage E, combinced with the coiler D, substantially as described.

[Drawing page 11 s and 119.]

L. I. BODENHAMER, of Kernersville, N. C., No. 170,932. Dec. 14, 1875.

Claim.-1. In a hale-tie, a hinged fastener $c$, provided with the tongue $c^{1}$, aud supported by the lugs $b^{2}$, so that as the free end of the band is drawn through the tie, it will antomatically eatch in the holes provided in said end, and seeure the band to the bale.

Chrim.-2. The lacer $d$, constructed with the prongs $d^{\prime} d^{t}$, and provided with the rod $d^{2}$, having the hook $d^{3}$, for the purpose specified.

[Drawing, page 119.]

\section{P. K. DEGERICK, of Albany, N. Y., No. 171,215. Dec. 21, 1875.}

Claim. A wire-band or tie constructed with a loop or eye at one end, and a double point or locking end at the other, substantially as deseribed, and shown in Fig 2. [Drawing page 119.]

\section{R. MONTFORT, of Butlor, Ga., No. 171,302.} Dec. $21,1875$.

Claim,-1. 'The bale-tie buckle $A$, having lozenge-shaped slot $a$, and downwardlybent lips $b$, having slot $C$, substantially as specified.

Claim.-2. In combination with wire binder $\mathrm{B}$ the buckle-plate $\mathrm{A}$, having slot $a$, downwardly-bent ends $b$, and slors, substautially as and for the purpose specified. [Drawing lage 119.]

S. H. GILMAN, of New Orleans, La., No. 171,560. Dec. 28, 1875.

Claim.-1. 'T'he jaws $\mathrm{L}, \mathrm{M}$ and $\mathbf{J} \mathrm{J}^{\prime}$ which, by the operation of the lever $f$ are simultaneonsly moved apart or together, substantially as and for the purposes set forth.

Claim.-2. The sliding plates II and I, interlocked so as to form mutial and firm guides for perpendicular motion, construeted and operiting substantially as and for the purposes described.

Claim.-3. The sliding plates $\mathrm{H}$ and $\mathrm{I}$, and flanges $h^{\prime} i^{\prime}$, whereby the operating crank-plate $G$ and the connecting-rods of are inclosed, and prevent any lateral move- ment of the same, substantially as hereinbefore set forth.

Claim.-4. The jaws I and M, constructed with variant diameters, and arranged and operating as set forth.

Claim.-5. The plate $I I$, provided with the fixed jaw $J$, the movable jaw $J^{\prime}$, and the lever-cam $K$, combined and operating substantially as set forth.

Claim.-6. The shoe $\mathrm{O}$, having the flange 0 , in combination with the lever 1 , substantially as and for the purposes set forth.

Cluim.-7. The traveling and swinging frame E, earying a band-tightening machine, and supported and guided on the shaft D, substantially as and for the purposes set forth.

Olaim. -8 . The vertically-movable shoe $O$, having tlanges $o$, in combination with the upper jaws L M, for the purpose of preventing the band from slipping on the bale while the said jaws are being released, as herein set forth.

Claim.-9. A band-tightening and locking machine composed of a traveling frame $\mathrm{E}$, the eccentric operating-plate $\mathrm{G}$, the slidiug plates $\mathrm{H}$ and $\mathrm{I}$, the jaws $\mathrm{L}$ M and $\mathrm{J}$ $J^{\prime}$, the shoe $O$, and lever $P$, constructed and operated as and for the purposes set forth.

[Drawing, page 120.]

\section{S. H. GILMAN, of New Orleans, La., No. 171,-} 659. Jan. 4, 1876.

Claim.-1. A machine having two pairs of jaws to seize and operate upon the two tied ends of cotton-bands, substantially as deseribed.

Claim.-2. The upper jars $\mathrm{C} \mathrm{C}$, with au incline $c$, on the under sides of their rear ends, substantially as described.

Claim.-3. The elbowed links G F G F, substantially as and for the purpose deseriiberl.

Claim.-4. The combination of the pairs of jaws with the elbowed links $G \mathrm{~F}$, conneeting-rod $I$, and lever $J$, substantially as deseriberl.

[Drawing, page 120.]

\section{S. H. GILMAN, of Now Orleans, Iar., No. 171,660.} Jan. 4, 1876.

Claim.-1. A hand-tool for cutting and punching cotton-bale bands and other analogous uses, comprising a punch and die, a pair of shear-blades, mechanism for actuating one of said shear-blades, and the punch 
or dic, and a handle for conveniently applying and holding said tool to its work, substantially as described.

Claim.-2. The combination of the shearblade B, punch-stock $\mathrm{C}$, and handles $\mathrm{Q}$, with the novable frame $\mathrm{A}$, bed $\mathrm{D}$, shearblade $\mathrm{E}$, and punch-die $f$, substantially as and for the purpose described.

Claim.-3. The combination, in a portable hand-tool, or a device consisting of a shear-blade and a punch and punch-stock, either integral or permanently united, with a device consisting of a shear.blade and punch-die, also integral or permanently united, mechanism for actuating one of said devices so as to cause it to cut and punch a piece of metal presented to it, and a liandle for conveniently presenting and holding the combined device to the plate to be operated on, substantially as described.

Claim.-4. The combination of the shearing and punching devices, the handle, the eccentric, and the crank, substantially as and for the purpuses described.

[Drawing, page 120.]

G. GALE, of Barnerville, N. Y., No. 172,417. Jan. 18, 1876.

Claim. 'The bale-tie, as described, consisting of the barb $a$, in the form of tigure 4 , on one end of the hoop and a loop on the other, addapted for application substantially as specified.

[Drawing, page 121.]

D. H. MATHIAS, of Albany, N. Y., No. 172,330. Jan. 18, 1876.

Claim. A bale-tie, having on one end the loop $\mathrm{L}$, and on the other end the hook II and brace $h$, made continuous with said hook, and extending forward, and inclined downward, when combined to operate substantially as described.

[Drawing, page 121.]

C. R. HERRON, of Savannah, Ga., No. 172,434, Jan. 18, 1876,

Clrim. A buckle formed of a single piece of metal, cut and bent substantially as shown and described.

[Drawing, page 121.]

V. F. P. ALEXANDER, of Greenville, Miss., No. 172, 683. Jan. 25, 1876.

Claim. The bale-tie herein described, consisting of the plate or buckle B, having slots $a b$, combined with the $\mathbf{T}$-button $\mathrm{C}$ and bale-band $\mathbf{A}$, substantially as set forth. [Drawing, page 121.]
T. BAILEY, of San Francisco, Cal., No. 172,947. Feb. 1, 1876.

Claim. A closed bale-tie link, composed of malleable cast-iron, and provided with a rectangular opening, and with rounded ribs and convex webs at its sides, substantially as described.

[Drawing, page 122.]

BURROW \& NICHOLS, of Norfolk. Va. No. 172,845. Feb. 1, 1876.

Claim. The cotton-bale tie $\mathrm{A}$, provided with an arm, $a$, elongated beyond the main portion of the tie, in combination with the band having its ends $B$ and $C$ bent and fas. tened, as shown and clescribed.

[Drawing, page 122.]

R. S. STENTON, of Cincinnati, Ohio, No. 172,897. Feb. 1, 1876.

Claim. The button B, tapered at both ends and undereut at opposite sides, in cornbination with the band, having corresponding slots with the button, substantially as and for the purpose described.

[Drawing, page 122.]

\section{J. C. RIEThMULleR, of Allegheny, Pa., No.} 172,936. Feb. 1, 1876.

Claim. In combination with the slotted bale-band and detachable locking device, an open ring or detachable washer, for retaining the locking device, substantially as specified.

[Drawing, page 122.]

\section{J, C. RIETHMMULLER, of Allegheny, Pa., No.} 172,937. Feb. 1, 1876.

Claim.-1. In combination with a slotted bale-band and its locking device, a check, having a slot which crosses that of the baleband when the parts are in position to lock a bale.

Claim.-2. A check for bale-bands, having a constricted portion or neck and but. tou to engage with a slot in the bale-band.

Claim.-3. In combination with a slotted bale-band, a check provided with a neck or constricted portion to engage with the slot of the bale-band.

Claim.-4. In combination with the locking device of a bale-band, a check secured or held by the locking device, substantially as and for the purpose specified.

[Drawing, page 123.]

S. H. GILMAN, of New Orleans, La., No, 173,118. Feb, 8, 1876.

Claim.-1. The cotton-bale-tie cam B, 
and its slant formed with it, in combination with the flanged plate $\Lambda$ and $\Lambda^{\prime} \Lambda^{\prime}$, one of

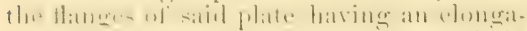

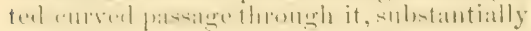
as and for the purpose described.

Cl-im.-2. The combination of the flangcol plate $\Lambda$ and $\Lambda^{\prime} \Lambda^{\prime}$, made with a concave surface, $a$, and the cam and its shaft, substantially as and for the purpose deseribed. [Drawing, pare 12:3.]

S. H. GILMAN, of New Orleans, La., No. 173,119. Feb. 8, 1876.

Claim.-1. The buckle-frame A, having cylindrical bearings $\mathrm{B} \mathrm{B}^{\prime}$, in comlination with the (:im C', having a transverse semieylindrical groove, $c$, and a surfuce, $\mathrm{D}$, substantially as and for the purpose described.

Claim.-2. The buekle-frame $\mathrm{A}$, having the cylindrical bearings $B B^{\prime}$, in which are depressions $b b^{\prime}$, in combination with a cam, C, having a luy, $d$, formerl on it, substantially as and for the purpose set forth.

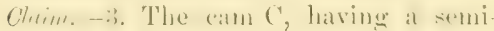
circular bearing, $c$, and ling $d$, and the camsurface D, substantially as and for the purposes set forth.

[Drawing, page 123.]

J. NOBLIT, of Philadelphia, Pa., No. 173,328, Feb. 8, 1876.

Claim.-1. A bale-tic composed of two like and equal parts, $\Lambda$ and $\mathbf{A}$, having their corresponding joining edges beveled, so that, when united at one end by the loose rivet $v$, it may be closed at the other, and helhl togrollew by a certain amomut of foree, resulting from the pressure of the beveled edges against each other, substantially as ateil tor the purpere deseribed.

('Him.-... A balegtie emprosed of two like and menal parts, $\Lambda$ and $\Lambda$, lowing their

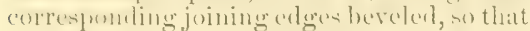
when united by the loose rivet $v$ at one end, it may be clnsed at the other, and become practically a closed buckle, of four sides of equil strength and thickness, without waste of materiul in its construction, substantially as shown and described.

[Drawing lage 123.]

J. N. BRANDENBURG, of Fort Motte, S. C., No. 173,527. Feb. 15, 1876.

Cleim. The bale-tie $\Lambda$, provided with the

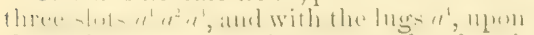
the ends of its side edges, next the slot $a^{1}$, substantially as herein shown and described. [Drawing, page 124.]
W. S. DAVIS, of Galveston; Texas, No. 173,597. Fob. 15, 1870.

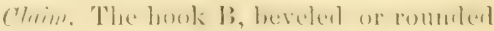
at the [ront end of its loot $/$, and provident with a nose, $i$, at the rear of said root, in combination with the spread and flattened shank C, and otherwise construeted and proportioned, in relation to the mortise $b$, substantially as described.

[1rawing, page 124]

S, CALLANAN, of Castleton, N. Y., No. 173,843. Feb. 22, 1876,

Claim. The improved bale-tic, consisting of the ring $a$. formed on the wire $b$, bent as at $d$, and the hook $f$ of wire $e$, bent as at $i$, substantially as specified.

[Drawing, page 121.]

G. MOULTON, of Cloveland, Ohio, No. 173,737. Feb. 22, 1876,

Claim. A bale-tic or lock constructed substantially ar-herein decoriberl, and fir the purpose specified.

[Drawing, page 12t.]

\section{J. A. BOSTWICK, of New York, N. Y., No. 174,- 109. Feb. 29, 1876.}

Claim. The bale-tie made with the perforated plate $b$, slipping upon the open parallel ends of the staple-shaped body $a$, substantially as set forth.

[Drawing, page 125.]

J. R. HORTON, of St. Louis, Mo., No. 174,217. Feb. 29, 1876 .

Claim. The bale-band provided with the

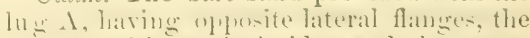
stud I, with rertieal sides, and the corresponding slot I) and hole E, having the form shomm, as and for the formose specified.

[Drawing, page 125.]

\section{H. MATHIAS, of Albany, N. Y., No. 174,082.} Feb. 29, 1876.

Claim.-1. In a tie, the buckle end A, comprised by the loop $\mathrm{C}$, neek $u$, and tongue D, when combined to operate substantially

in the nianner set forth.

Claim.-2. The loop $\mathrm{E}$ of end $\mathrm{B}$, in combination with loop $\mathrm{C}$ and tongue $\mathrm{D}$, extend-

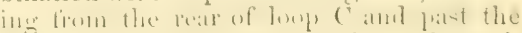
front of the same, for operation substantially as set forth.

[Drawing, ]age 125.] 
J. L. SHEPPARD, of Charleston, S. C., No. 174,580. Mareh 7, 1876.

Claim.-1. In combination with a press box, having channel $G$ in its hed, the lever $A$, and the arm $\mathrm{E}$, pivoted thereto and carrying band-clamping jaws, substantially as shown and described.

Cleim.-2. The combination with lever $A$, arm $\mathrm{E}$, and jaws $\mathrm{F} \mathrm{F}$, of springs arranged within the channel $G$, and bent downward at their free outer ends, as shown and described.

Claim.-3. The friction plates I I, extending downward on the frout of the pressbox to facilitate the movement of the bandtightening device, as set forth.

Clain.-4. The lever $A$, bent at an obtuse angle, and pivoted to bracket $\mathrm{C}$, as shown, and the band-clamping device pivoted thereto, near said angle, said parts being combined and arranged on the side of the press-box, as set forth, whereby the lever is adipted for self-locking to hold the band.

[Drawing page 125.]

\section{P. SLATTERY, of Charleston, S. C., No.174,707. March 14, 1878.}

Claim. In a bale-buckle or tie, as constructed, the shoulder or off'set $i$, on the outer side of the lip, for the insertion of the forked lever C, substantially as and for the purpose specified.

[Drawing page 126.]

\section{J.S. \& C. R. HERRON, of Savannah, Ga., No.} 174,730. March 14, 1876.

Claim. As an improvement in band-ties, the combination of a band end, having closed L-shaped slot, with the opposite band end, being provided with recesses or notches at alternate sides, the distance of two alternating notches being equal to the Jength of the L-shaped slot, substantially in the manner and for the purpose set fortb. [Drawing page 126.]

W. CARSON, of St. Louis, Mo., No. 175,334. March 28, 1876.

Claim. The part $\mathrm{A}$, having the noteh or open slot $\mathrm{E}$, and sockets or hooks $\mathrm{G}$, in combination with the part $B$, having lateral projections $J$ and tongue $I$, as shown and described, whereby said parts are adiaj,ed to be disengaged, in the manner set forth.

[Drawing, page 120.]
J. THAYER, of New Orleans, La., No. 175,546. March 28, 1876.

Claim. The buckle having the lugs $\& c$, the shoe or pocket $d$, Figis. 1 and 3 , and the flange upon the wedge, substantially as described and for the purposes set forth.

[Drawing, page 126.]

A. KIMLER, of Howe's Cave, N. X., No. 175,711. April 4, 1876,

Claim. The baling-wire $\mathbf{A}$, formed with the eye or loop B, at one end, and at the other end with eye or loop C and hooks D, as and for the purpose set forth.

[Drawing, page 127 ]

\section{R. C. LUDLOW, of'St. Louis, Mo., No. 175,720.} April, 4, 1876.

Claim.-1. 'The bale-tie herein described, consisting of the flat body $\mathrm{A}$, provided at one end with prongs $\mathrm{C} \mathrm{C}$, having inwardly-projecting points $a a$, and the T-shaped head $\mathrm{B}$, provided with holes at the other end at right angles or parallel with the body $A$, substantially as described and for the purpose set forth.

Claim.-2. A bale-tie having prongs terminated by inwardly-projecting points at one end of its body, and a T-shaped head $\mathrm{B}$, at its opposite end, the opening between the prongs corresponding exactly in size and shape with the head, whercby the tie may be punched from a bar withont any loss of metal, substantially as described. [Drawing, rage 127.]

A. B. RAMSEY, of Trenton, Tenn., No. 175,752. April 4, 1876.

Claim.-1. The wire bale-tie consisting of the loops $a a^{\prime}$, linked together as described, and held against casual detachment by twisting the ends $b b^{\prime}$, of the wire around each other, substantially as specified.

Claim.- A wire bale-binder, having the ends looped, as at $a a^{\prime}$, and extensions $b b^{\prime}$, at right angles with the length of the binder, und adapted to be twisted together and tucked under said binder, as specified.

[Drawing, page 127.]

S. D. PURDY, of Cleveland, Ohio, TNo. 176,049. April 11, 1876.

Claim. The herein described bale-tie, consisting of the two ends of the wire $\mathbf{A} \mathbf{A}$, twisted together and locking them, substantially in the manner and for the purpose specified.

[Drawing, page 127.] 
W. ROGERS, of Now Orleans, La., No. 176,355. April 18, 1870.

Claim.-1. 'The combination, with the platen of a cotton-juess, of a group of baleticrs, substantially as specified, constituting one antomatic tying mechanism for simultaneonsly tying all the bands of the bale.

Cham.-2. In a bale-tier the combination, substantially as specified, of the holdfist, the stretcher, and the doubler.

Claim.-3. 'The combination, substantially as specified, of the stretcher and the sherirs.

[1)rawing, page 128.]

\section{G. S. FRANCE, of Cobleskill, N. Y., No. 176,613. April 25, 1876.}

Claim.-1. The combiuation, with the ends of a bale tie, of the hooks ]) D and loops C C, substantially as and for the purposes set forth.

Claim.-2. As an improved article of manufucture, a bale-tic, each end of which is provided with a loop D, and the hook C, with a partial twist between the respective loops and hooks, substantially as and for the purposes set forth.

[Drawing, prage 129.]

\section{G. S. FRANCE, of Cobleskill, N. Y., No.176,014} April 25, 1876.

Claim.-1. 'The combination, with the ends of a bale-tie, of hooks C, and loops D, substantially as and for the purposes set forth.

Clain.--2. A bale-tic as an improved article of manufacture, having interlocking ends C D, constructed substantially as and for the purpose set forth.

[Drawing, page 129.]

\section{P. K. DEDERICK, of Albany, N. Y., No. 177,221.} May 9, 1876.

Clam,-1. 'The bending-disks $\mathrm{A}$, having the shoulders $a^{\prime}$ and adapted to rotate on the posts $\mathrm{C}$, substantially as described, for the purpose specified.

Claim.-2. 'The bending.disks A, in combination with the stop $\mathrm{D}$, and cutting-jars E E, substantially as described, for the purpose specified.

Claim.-3. The rotating hook $\mathrm{F}$, in combination with the clamping-jaws $\mathrm{G} G$, substantially as described.

Claim.-4. The bifureated hook II, combined with the clamping-jaws $G^{\prime} G^{\prime}$, substantially as described.

[Drawing, page 1.2.]

\section{P. K. DEDERICK, of Albany, N. Y., No. 177,222. May $9,1876$.}

Claim. A wire-tic constructed with a loop or eye at one end, and a point or lockingend at the other, of larger wire, twisted or otherwise attached to the body of the tie, for the purpose specified.

[1rawing, page 12\%.]

J. M. GOLDSMITH, of Boston, Mass., No. 177,330. May $16,1876$.

Claim.-1. In a bale-tie the buckle $\mathbf{A}$, having slots $b b^{\prime}$ sunken bar's $a c$, guideways $e$, and notches $n$, adapted for use substantially as specified.

Claim.-2. The binder B, having a transverse lock-piece $f$, in combination with a slotted buckle, having inclined ways $e$, and notches $n$, substantially as specitied.

Claim.-3. The lock-piece $f$, riveted to the end of a binder, B, and projecting beyoud the lateral edges of the same, substantially as and for the purpose specified.

(1)rawing, page 12y.)

J. McMURTRY, of Lexington, Ky., No. 177,650. May 23, 1876.

Claim. 'The buckle for cotton-bale ties; consisting of the two parts $a d$, which are constructed and made to hook together, stantially as shown and described, and for the purpose set forth.

(Drawing, nage 130.)

J. MCMURTRY, of Lexington, Ky., No. 177,651. May 23, 1876.

Claim.-1. As a cotton-bale tie, the band $a$, having two or more inclined slots cut in its edge or edges, substantially as showu.

Claim.-2. The band a, laving an in. creased thickness along its center, substantially as described.

Clam.-3. The band $a$, having the inclined slots $d$ and thickness $c$, substantially as and for the purpose described.

Claim.-4. The basd $a$, having inclined slots that are widest at their mouths, and having the depressed lips 2, substantially as shown and described.

(1)rnwing, page 130.)

I. N. BRIGGS, of Colymans, N. Y., No. 177,683 . May 23, 1876.

Claim. The wire balc-tic $\mathbf{A}$, constructed with an open hook, B, at each of its ends, for the purpose of interlocking the ends 
together, in the manner and for the purpose herein specified.

[Drawing, page 130.]

J. L. RANDO_PH, of Martinsburg, W. Va., No. 177,957. May $30,1876$.

Glaim. The rolled and longitudinally. grooved plates, provided with central and side openings, both said plates being used to form a single buckle, substantially as described.

[Drawing page 130.]

H. W. PUTNAM, of Bennington, Vt., No. 178,027. May 30, 1876.

Claim.-1. In a machine for bending and twisting wire, the combination of a bending-arm, a stud around which the wire is bent, a holding-jaw, to retain the wire as the two parts lie side by side, and a revolvirg jaw that twists the wire together, substantially as set forth.

Claim.-2. In the wire bending machine, the bending-arm $r$, with a forked end 15, for bending the wire and lholding the two parts of such wire while it is being twisted, in combination with the jaw $h$, and gearing for revolving the same, to form the loop, substantialiy as set forth.

Claim.-3. In the wire-twisting machine, the stud $u$ upon the arm $r$, placed eccentric to the shaft upon which the arm swings, relieving the strain upon the loop as the arrn swings, in combination with gearing for turning such arm thereby back from the twisted loop, as set forth.

Claim.-4. The combination with the arm $r$, of the pinion $s$, spring-pawl 12, actuating-lever 1 , and jaw $h$, substantially as set forth.

Claim.-5. The shear $c^{\prime}$ and feeding-rollers $b^{2} b^{3}$, in combination with the segmental gearing $b$, and the holding and twisting jaws, and gearing connecting the parts, substantially as specified, to feed, cut off; and twist the wire, as set forth.

Claim.-6. The notehed guide-wheels $d$, moved progressively by a ratehet and pawl, in combination with the bending and twisting jaws, substantially as specitied, for bending the loop and twisting the wire.

Claim.-7. The combination, in a wire. bending machine, of the guide-wheels $d$, for carrying the wire, with two sets of bending and twisting jairs for simultaneously bendung both ends of the wire, and then twisting the wire together, as set forth.

Claim.-8. The die 22, in combination with the bending die $r^{2}$, die 23 , and loopforming mechanism, to bend such loop into a hook after it has been twisted, as set forth.

Clain.-29. The three-pronged die $2^{2}$, in combination with the sliding die 22 and actuating mechanism, substautially as set forth.

Claim.-10. The wedge $l^{5}$ and its actuating-lever $l^{6}$ in combination with the sliding die 22 , dies 23 and $l^{1}$, substantially as set forth.

Claim.-11. The combination with the sliding die 22 and stationary die 23 , of the die $l^{\prime}$, and shoulders 29, that press the die 22 downward to form the curved end of the hook, as set forth.

Claim.-12. The sliding die 22, with the projection 30, to allow the same to drop after it is drawn back, in combination with the dies $l^{1}$ and 23 , and bender ${ }^{3}$, that press the twisted wire toward the point of the hook, as set forth.

Claim.-13. The combination, with the revolving jaw $h$, and mechanism for twisting the wire, of a stop to hold the twisting. jaw in the position of rest, substantially, as set forth.

Claim.-14. The bending die $r^{3}$, made as a fork at the end, to draw the wires of the loop together and bend the same, in combination with the dies that bend the wire into the hook, substantially as set forth.

Claim.-15. The holding die $v^{1}$, made as a fork, to draw the parts of the wire together, in combination with the stationary rest $v$, substantially as set forth.

Cleim.-16. In a wire-bending machine, the combination of two bending and twisting jaws with their actuating devices and adjustable beds for adapting the machine to different lengths of wires, and simultaneously operating at both ends of wires, as set forth.

[Drawing, page 131.]

\section{G. D. JEWETT, of Oakland, Cal., No. 178,15B. May 30, 1876.}

Claim. The bale-band having the loop $\mathbf{A}$, the slip-band $\mathrm{D}$, and the point-band $\mathrm{C}$, or their equivalents, when constructed and arranged substantially in the manner and for the purposes set forth.

[Drawing, page 131.]

\section{J. H. SNYDER, of Richmond, Va., No. 178,198. May 30, 1876.}

Claim. The within-described bale tie, consisting of the plate $A$, having the parallel slots $a a^{\prime}$, inclined angular slots $b b$, 
tongne $d$, and lips e e, and stanued, substantially as and for the purposes herein set forth.

[ I)rowing, jage 132.]

W. S. DAVIS, of Galveston, Texas, No. 178,418. June 6, 1870.

Cluim. The hook $\mathrm{B}$, provirled with a flattened shank C, forming the enlarged head $d$, the said hook being construeted at the forward end with the front bent end or root $h$, and rearwardly projecting nose $i$, arranged at the back end of the face $g$ of the hook for operation in connection with the nortises $b$ in the bale-band, substantially as described.

[Drawing, page 132.]

W. S. DAVIS, of Galveston, Texas, No. 7,252.

Aug. 8, 1876. Reissue of No, 178,418.

June 6, 1878.

Claim. The single hook $\mathrm{B}$, having its face o constructed to dip or incline downwarily or in and in ward direction relative to the planes of the overlapping end portions of the band from the end $i$ of the nose of said hook to the root $/$ thereof, for operation in comnection with the mortises $b$ in the bale-band, substantially as described.

[Drawing sage 13:.]

\section{S. PALMATIER, of Catskill, N. Y., No, 178,665.} June 13, 1876.

Clam. The wire bale-tie having the rounded end of the loop a bent upwards to freely admit the connecting twisted end $b$, substantially as and for the purpose set forth.

[1)rawing, page:132.]

\section{B. K. FOWLER, of New York, N. Y., No. 178,-} 754. June 13, 1876.

Claim. In a wire-band for bales, the cross-bar B, pivoted in the loop a, provided upon the one end $\mathrm{A}$, of the band, in combination with the outwardly-turned loop $c$ on the other end $C$, of the said band, the same constructed and combined substantially as and for the purpose herein set fortl?.

[Drawing page 133.]

A. A. GoLdSMITH, of Charleston, S. C., No. 178,762. June 13, 1876.

Claim. 'The W-shaped plate A, having lug $i$ and cross-bars $i^{\prime}$, resprectively, on its central and end-bars, substantially as speeifiel.

[Drawing, rage 133.]
B. HEMPSTEAD, of Littlo Rock, Ark., No, 178,77 1. Junc, 13, 1876.

Claim.-1. The bale-tie fustener consist. ing of a stiff' plate, $\mathbf{A}$, having a trinsierse slot, D, at one end, and a button, B, at the other, provided with a long extension, $b$, and a short extension, $b^{\prime}$, as and for the purpose described.

Clam. - 2. The bale-tie consisting of the plate $\mathrm{A}$, having transverse slot $\mathrm{D}$ and button $B$, provided with long extension $b$ and short extension $b^{\prime}$, in combination with the bale-band passed through slot D, and beut around the same at one end, and having a slot, C, at the other, adlapted to receive the button, as and for the purpose described.

[Drawing, page 133.]

\section{R. C. LUDLOW, of St. Louis, Mo., No. 179,578. July 4, 1876.}

Claim. The manuficture of a donble se. ries of bale-ties from a single strip of sheet metal of a given width, without waste of material, as shown, said bale-ties having outwarlly-projecting extensions $a^{1} a^{1}$, for the purpose set forth.

[Drawing, page 133.]

\section{B. A. RAMSEY, of Tronton, Tenn., No. 179,604. July 4, 1876.}

Claim. A wire bale-tie, consisting of the upset loop $a c$ and the loop $d$, in combination with the separate bow or bent key e, substantially as herein set forth.

[Drawing, page 134.]

\section{W. B. HAYDEN, of Columbus, Ohio, No. 179,654. July 11, 1876.}

Claim. The loop C, formed with crossbars $a, b$, and $c$, constructed and arranged as deseribed, in combination with the band or hoop provided with transverse strengthening and retaining ribs on its under surface, substantially as described.

[Drawing, page 134.]

\section{R. DE GRAY, of New Orleans, La., No. $179,841$. July 18, 1876.}

Claim.-1. T'he buckle-plate made with the guard-tooth or lip $\Lambda$, and slot or opening $\bar{D}$ s, in combination with the band or hoop, substantially as described.

Claim.-2. The buckle-plate made with the slot or opening D E, holding-teeth or lips B and C, and guard-lip or tooth A, in combination with the band or hoop having holes through it, substantially as described. [Wrawing page 134.] 
J. A. DRAKE, of New Orleans, La., No. 179,848. July 18, 1876.

Claim.-1. The perforated twisting.cylinder $\mathrm{B}$, having its forward section ennically contrated and terminating in a narrow delivery-tube, the whole constructed and arranged to operate, substantially as described.

Claim.-2. The twisting perforated cylinder $\mathrm{B}$, and the grooved-face rollers $f^{\prime} f^{\prime}$, the same being combined and arranged to operate substintially as described.

Claim.-.3. The twisting cylinder B, rollers $f f^{\prime}$, corrugated roller $K$, and weighted frame $h$, the whole being combined and arrangerl to operate substantially as described. [Dratwings, pages 134 and 135 ]

J. A. DRAKE, of New Orleans, La., No. 179,849. July 18, 1876.

Claim.-1. As a new article of manufacture, a bale of cotton formed from a continuons strand or strands of loosely-twisted cotton wound or coiled around a shaft or axle, substantially as described.

Claim,-2. The method herein described of baling and packing cotton, which consists in loosely twisting the cotton to secure a continuity of its tibers, and in then wind. ing or coiliug the same around an axle or shaft, substantially as described.

[Drawing, page 135.]

J. M. SEYMOUR, of Newark, N.J., No. 179,872. July $18,1876$.

Claim.-1. A buckle provided with two straining-bars, a lever-arm, and a fasteningbar, constructed and arranged to operate substantially as and for the purpose described.

Claim.-2. A buckle provided with two straining-bars and a lever-arm, constructed aud arranged to operate substantially as and for the purpose set forth.

Claim.-3. A buckle provided with two straining-bars and a lever-arm, when one or both of the straining-bars are provided with projections to retain the band in position upon the bar or bars, substantially as set forth.

[Drawing, page 13ß.]

\section{J. H. SNYDER, of Richmond, Va., No, 180,388. July 25, 1876,}

Claim.-1. 'I'he bale-tie herein described, consisting of the plate $\Lambda$, formed with the raised part $B$, and the raised tongues $C D$, of unequal length, substantially as and for the purposes herein set forth.
Cluim,-2. The plate A, formed with the raised part $\mathrm{B}$, the long raised tongue $\mathrm{C}$, having ineline or curve $a b$ on its inner edge, and the short raised tongue D, substantially as and for the purpose herein set forth.

[Urawing, page ]36.]

\section{S. D. PURDY, of Cleveland, Ohio, No. 180,788.}

\section{Aug. 8, 1876.}

Claim. The above-rlescribed device, consisting of the frame $A$, having arms $G H I$, the shaft F, having the groove J. eomnected with the slots $\mathrm{K}$ and the bevel-gears $\mathrm{E} I$, the shaft $\mathrm{C}$, and crank D, all constructed, combined, and operating substantially as and for the purpose specitied.

[Drawing, page 136.]

D. C. LOWBER, of Liverpool, England, No. 180,897. Aug. 8, 1876.

Chim.-1. A soldered-wire bale-tie formed with the eye $\mathrm{A} \mathrm{A}^{1} \mathrm{~A}^{2}$ soldered, as and for the purposes herein specified.

Claim. -2. The process herein described of forming a loop and securing the same, consisting in folding the bale-tie back upon itself, and dipping in solder, substantially as specified.

[Drawing, nage 196.]

D. OLMSTEAD, of Minneapolis, Minn., No. 180,910. Aug. 8, 1876.

Claim.-1. The herein-rlescribed lock or fastening for bands, bale-ties, ste., consisting of one or more angular slits and tongues $e$, formed in each end of the band, substantially as shown and deseribed.

Claim.-2. A band having the angular slits and tongues, $e$, formed by cutting or punching the slits in the solis body of the band at each end, as set forth.

Claim.-3. The herein-described morle or method of locking or fastening the ends of bands by means of the tongues $e$, and the angular slits whereby the tongues of both parts are made to engage against the solid metal at their ends, as set forth.

[Dratving, page 137.]

\section{J. THAYER, of New Orleans, La., No. 181,020.} Aug. 15, 1876.

Claim.-1. In bale-band-tightening machines, the combination, with the handlever and pushing-bar, of a pulling-bar, provided with a hook or claw adapted to engage-the buckle, said pulling-bar being connected to said pushing-bar by a movable joint, substantially as set forth. 
Cluim,-2. In balc-band-tighening machince, the combination of the pushing bar to with a suide-piece or gruiding-edge of the platen, snitably arranged to direet and steady the pusling-bar while the strain is being applied by the operators, substantially : is set forth.

Clum.-3. The cominination, with the hand-lever, of a spring supported by a crosbar, said spring serving to keep the hand- $t$ lever elevated in proper position to apply the band to the clamp on the end of said hamd-lever preparatory to applying the strain, substantially as set forth.

Clam.-4. In band-tiglitening machines, the arrangement of the strain-developing parts, whereby both ends of the band are made to receive the tightening foree, and both ends yield to such force in substantially an equal degree, substantially as and for the purpose described.

Claim.-5. The combination, with the pushing-bar and jointed pulling elaw-bar, of a spring to elevate the claw-bar, substan tially as and for the purpose deseribed.

Claim.-6. The combination, with the pushing-bar and lever, of a segment of a circle, notcher on its outer edge, used, in connection with the lock and eateh, for the purpose of holding all the strain that may be exerted upon the hoop or band by the downwal pressure upon the lever at the point attuined, relieving the operator, and allowing him free use of himself to adjust and drive the werlge into the buckle, thereby securing the ends of the band, substantially as set forth.

Claim.-7. The combination of the slot or mortise in the lever, which is a guide for the free end of the segmental strip, also the manner of attaching the segmental strip to the pushing-bar, substantially as set forth.

Claim.-8. The combination devices, as shown and describerl, consisting of the pushing-bar and pulling-bar, in connection with the guide-strip, clatrs, and griping de. vice, springs for lifting the lever and pulling-bar, the notched segmental strip, the mammer of attaching to pusbing-bar, the slot in lever-guide for free end of segmen. tal strip, the catching deriee, together with spiral spring and trigger, for compressing cotton, substantially as and for the purpose describerl.

[10rawing, page 137.]

R. DE GRAY, of New Orleans, La., No. 181,052. Aug. 15, 1870.

Claim.-1. In a band-tightening machine, the shaft $\mathrm{E}$, having slots $e^{1}$ and ratehet-teeth $\epsilon^{2}$, construeted and operating substantially as set forth.

Claim.--2. In a band-tightening machine, the buckle-bar II, having grooves II' and $^{\prime}$ notches $h^{4}$ for the purpose of drawing tight the buckle ends of the balc-bands, sabstantially as set forth.

Cluim. - 3. In a band-tightening machine, the sliding bearings D, whereby the upper and lower band-tiglitening apparatus are supported, substantially as and tor the pur. pose set forth.

Claim.-4. In a band-tightening machine, the plate $K$, operating substantially as set forth.

Claim.-5. The shaft E and the slidingbearings $D$, substantially as set forth.

Claim.-6. The enmbination of the bucklebar $\mathrm{H}$ and the cams $\mathrm{F}^{\prime \prime}$, substantially as set forth.

Claim.-7. The combination of shaft $\mathbf{E}$, the buckle-bar $\mathrm{H}$, and the bearings $\mathrm{J}$, substantially as described.

Claim.-8. The shaft E, the buckle-bar II, and the sliding-plate $K$, combined and operating substantially as set forth.

Clam.-9. 'The combination of the plate $K$ and the levers L, substantially as and for the purpose set forth.

Claim.-10. The buckle-bar II and the weighted levers I, constructed aud operating substantially as set forth.

[Drawing, page 137.]

\section{P. F, KING, of St. Louis, Mo., No. 181,183.} Aug. 15, 1876.

Claim.-1. A wire fastening, consisting of the body part $a^{2}$, having projecting ends a $a^{3}$, their bearing-pointe at $a^{3} a^{4} a^{5}$, all constructed to operate in the manner and for the purpose set forth.

Claim.-2. The combination of a wire fastening, consisting of the body part $a^{2}$, its ends $a a^{1}$, bearing $a^{3} a^{4}$, locking-point $a^{5}$, with slotted band-ends, as and for the purposes set forth.

[1)rawing, page 138.]

W. WILKINSON, of Charleston, S. C., No. 181,385. Aug. 22, 1876.

Claim. A balc-tic consisting of the quadrangular metal $A$, having one free end straight, and subjacently crossing the other, while the latter is provided with a hook at its end, substantially as aud for the purpose specified.

[Drawing, page 135.] 
T. BUNKER, of Cuero, Tex., No, 181,818. Sept. $5,1876$.

Chim. An improved bale-tie buckle, consisting of the half-ring bars $\mathrm{A} \mathrm{B}$, having small half-ring hooks formed upon their ends, securing the ends of a bale-band, substantially as shown and described.

[Drawing. page 138.]

T. C. KNOWLES \& J. P. DERDEN, of Vienna, La., No. 181,949. Sept. 5, 1876.

Claim. A bale-hoop tightener consisting of notched lever $\mathrm{F}$, having forked claw $G$, and hook $H$, having yoke $J$, substantially as and for the purose specitied.

[Drawing, nage 13s.]

H. MILLINGAR, of Pittsburg, Pa., No, 182,031. Sept. 12, 1876.

Claim. A hoop-iron haring its overlapping end A B provided with inclined slots $a$ in each edge, runuing from the edge at an angle of forty-five degrees inward, forming lips $b$, which are pressed so as to stand beyond, but paralled with, the plaue of the batind.

[Drawing, page 139.]

F. G. WHEELER, of New York, N. Y., No. 182,339. Sept. 19, 1876.

Claim.-1. The method describer of treating cotton-bales before and during compression, consisting, essentially, in applying the bands to the bale before it enters the press, and holding them before and during the time of compression by means of independent frames, substantially as deseribed.

Claim.-2. In combination with a bale and securing-bands laid upon the same, an independent removable frame for holding: the bands in place, as described.

Claim.-3. A frame adapted for adjustment to suit-bales of different widtb, substantially as described.

Claim-4. A frame provided with side $p^{\text {lates or bars, hinged thereto, as described. }}$

Claim.-5. An independent frame hav. ing side pieces adapted to hold the bale against lateral expansion, as deseribed.

Claim.-6. A frame having hinged sides and locking-bars, as described.

[Drawing, page 139.]

W. B. HAZELTINE, of Jamestown, N. Y., No. 182,757. Oct. 3,1876 .

Claim. 'T'he bale-tie buckle herein described, consisting of at that piece of metal, bent over upon itself, so as to form two flat and parallel leaves, with straight mubroken edges, with a space between said leaves to accommodate the ends of the bands, substantially as and for the purposes described. [Drawing, page 13\%.]

\section{E. EVANS, of New York, No. 182,810. Oct.}

$3,1876$.

C'laim.-1. The double hook $b^{2} b^{2} b^{3} b^{4}$ on one end of the tie, formed by bending the double wile, as shown, in combination with the loop A on the other end, and adapted to serve together, as and for the purposes herein specified.

Claim.-2. The end $e$, extended past the engaging hook or hooks on the tie, and arranged to be pressed against and into the body of the bale by the tension of the loop $\mathbf{A}$, in combination with the clouble hook and said loop, and its neck a pressing on the outer face of the said end, all substantially as and for the purposes specified. [Drawing, page 139.]

\section{A. W. HESS, of Chicago, Ill., No. 183,053. Oct.} $10,1876$.

Claim. A bale-tie, consisting of a metallic strip fastened by means of tougues and slots cut at one and the same time in the overlap of the ends of the tie, the tongues of the upper lap projecting into the slots of the under lap, and the tongues of both the upper and the under lap being on the inside of the tie when the same is fastened, leaviug the outside thereof free from any projections, substantially as described. [Drawing, page 140.]

\section{KRIEG, of Dallas, Texas, No. 183,058. Oct.} 10, 1876.

Claim.-1. The clasp B with the tongue $\mathrm{E}$, constructed substantially as herein described.

Clcim.-2. The combination of the clasp $B$ with the tongue $\mathrm{E}$, the band $\mathrm{H}$, and the fastening $\mathrm{P}$, substantially as and for the purpose herein set forth.

Claim.-3. The combination of the clasp $B$ with the tongue $\mathrm{E}$, the band $\mathrm{H}$, and the slicling fastening $\mathrm{C}$, substantially as and for the purpose herein set forth.

[Drawing, page 140.]

\section{J. TWEEDALE, of Castleton, N. Y., No. 183,234.} Oct. $10,1876$.

Claim.-1. Catch or double hook C, having eye or loop $\mathrm{C}^{1}$, arms $\mathrm{C}^{2} \mathrm{C}^{3}$, and in- 
wardly and backwarlly turning hooks $c^{1} c^{2}$, substantially as set forth.

Clrim.-2. 'The catch-hook C, the free ends of which are turned in opposite directions, in combination with the loops $\Lambda^{\prime} B^{\prime}$ of the bale-tic wire, substantially as shown and deseribed.

[Drawing, s'age 140.]

\section{S. N. DRAKE, of New Orleans, La., No. 183,382. Oct. $17,1876$.}

Claim.-1. A die A, having raised biting-dange I) and coneavities E E, in combination with a die-surface having a slot $\mathrm{B}^{3}$, and convex heads $\mathrm{F}^{2}$, substantially as and for the purpose set furth.

Claim.-2. The combination of die A, having bar $\mathrm{C}$, oblique bevel $c$, biting-flange $\mathrm{D}$, and concavities $\mathrm{E} E$, with die $\mathrm{B}$, having longitudinally-oblique bevel $b$, slot $B^{3}$, and convex heads $\mathrm{F}^{2}$, substantially as set forth.

Claim.-3. A bale-tie having depressed portion $\mathrm{G}^{\mathrm{t}}$, slot $\mathrm{G}^{3}$, and spuds $\mathrm{G}^{4} \mathrm{G}^{5}$ upon one end, and eorresponding depressed portion $\mathrm{II}^{2}$, slot $\mathrm{H}^{3}$, and spuds $\mathrm{II}^{4} \mathrm{H}^{5}$, on the other end, substantially as aud for the purpose set forth.

Claim.-4. A bale-tie having depressed portion $G^{1}$, oblique bevel $G^{2}$, slot $G^{3}$, and spuds $\mathrm{G}^{4} \mathrm{G}^{5}$ upon one end, and corresponding depressed portion $\mathrm{II}^{1}$, oblique bevel $\mathrm{H}^{2}$, slot $\mathrm{H}^{3}$, and spuds $\mathrm{II}^{4} \mathrm{II}^{5}$ on the other end, substantially as and for the purpose set forth.

[Drawing, page 140.]

\section{A. A, GOLDSMITH, of Charleston, S. C., No. 183,-} 390. Oct. 17, 1876.

Claim.-1. The tie-plate D, having the angular cross-tongue $\mathrm{E}$, rear bar $\mathrm{G}$, depressed at the bend $k$, and guard $F$, separated from said cross-tongue by the angular slit $c$, opening at the front of the plate, and joined to the depressed rear bar $G$, sub. stantially as specified.

Claim.-2. 'The tic-plate haviug the angular cross-tongue E separated by slit-opening at $a$ in front, and bent fasteniug-luga $n$ cut from the material of the plate in rear, substantially as specified.

[Drawing, page 141.]

\section{E. E. PIERCE, of Cuyahoga Falls, Ohio, No} 183,702. Oct. 24, 1876.

Claim.-1. $\Lambda$ hook for a bale-tic or other purpose, constructed of a strip of suitable metal by folding the sides of said strip for a short distance from one end longitudiualIy on a line midway between the edres, bending the metal downwardly into the shape of a hook, and then forcing the sides closely together, suhstantially as described.

Claim.-2. The tongue formel at the onter end of the ere of a bale-tie, capable of being closed inwardly toward the hook to lock it in position, substantially as deseribed.

[Drawing, rage 11t.]

D. T. LEWIS, of Brownsville, Tenn., No. 183,948. Oct. $31,1876$.

Claim. A bale-tie consisting of a solid buckle, formed at one end for attachiment to one end of the strap, and yrovided with a tongue which is cut transversely at or near the middle, so as to leave an inclined passage between the ends, as set forth.

[1)rawing, page 14].]

C. VAN DERZEE, of Albany, N. Y., No, 184,272. Nov. 14, 1870.

Chim.-1. The connecting piece D, having side strands $s$ s terminating with the score-block $c$ at their rear, and with the cleat $e$ projecting inward from the conjoined ends of the said side pieces in front, substantially as and for the purpose set forth.

Claim.-2. The combination, with the connecting piece D, constructed as described, of the loop $\mathrm{C}$, having the angle $z$ turned up from the horizontal portion $z^{\prime}$, and adapted to engage with the cleat $e$ of the said connecting piece, substantially as and for the purpose set forth.

[Urawing, page 141.]

J, W. MACUMBER, of Wilmington, N. C., No. 184,397. Nov. 14, 1876.

Claim,-1. In a balc-tie, the combination of the ends $\mathrm{A} B$, having hooks $\mathrm{C}$ and swells D, substantially as and for the purpose described.

Claim.-2. 'The combination, with the die and punch $\mathrm{E} \mathrm{F}$; for forming the eyeportion of the band, of the die and punch G II, for forming the hooked end of the band, substantially as and for the purpose specified.

[I rawing, jage 14:

C. VAN DERZEE, of Albany, N. Y., No. 184,448. Nov. 14, 1878.

Claim.-1. 'The eccentric E, carrying piu $e$ and brake $d$, in combination with the piroted carrier $\mathrm{B}$, carrying the block $b$ and 
mechanical levice for operating said ecentric, substantially as and for the purpose set fortl..

Claim,-2. The combination, with the vibrating jaw $\mathbf{M}$, of the lever $\mathrm{N}$, carryiug the jaw $s$, substuntially as and for the purpose set forth.

Cluim.-3. The combination, with the lever $\mathrm{N}$, carrying the jaw $s$, operating with the vibrating juw $M$, of the finger-lever $P$, $\operatorname{dog} q$, and catch $r$, substantially as and for the purpose set forth.

Clam.-4. The conbination, with the shaft $\mathrm{L}$, provided with crank $h$, and carrying the vibrating jaw $M$, and the jaw $s$, carried by lever $\mathrm{N}$, of the block $\mathrm{Q}$ and lever $R$, substantially as and for the purpose set forth.

[Drawios, nage 142.]

G. S. FRANCE, of Worcester, Mass,, No. 184,607. Nov. 21, 1876.

Clam.-1. The combination, in a balctie, of the loous C D and hook E, substantially as and for the purposes set forth.

Claim.-2. A bale-tie having two loops at one end, separated by a partial twist, and a hook device at the other end, substantially as and for the purposes set fortl.

Caim.-3. A bale-tie provided with two loops at one end, for engaging the hook device at the other end of the bale-tie. [Drawing, page 142.]

H. H. M00RE, of Vicksburg, Miss., No. 184,650. Nov. 21, 1876.

Claim. A bale-tie constructed is described, and consisting of the band D, provided with a smooth wedge-shaped enlargement E, lying close to the band the whole length of the enlargement, in combination of a slide $B$, having an inside opening to correspond with the angle of the enlargement, and of sufticient width to cover the same, substantially as set forth. [Drawing, page 143.]

\section{H. VICTORY, of Albany, N. Y., No. 184,739 Nov. 28, 1876.}

Claim. The clongated buttons $\mathrm{A}$ and $\mathrm{B}$, having lapering top e, thin rounded ends $a$ and $a^{\prime}$ and $c$ and $c^{\prime}$, the connecting shank or neck $b$, prorided with the flange ol collar $d$, in combination with the loops II and E on the ends of the bale-wire, substantially as shown or as described.

[Drawing, mage 113.]
J, M. POLLARD, of New Orleans, La., No. 184,901. Nov. 28, 1876.

Claim.-1. The combination of a buckle haring central and end cross bars, a fixed or movable lug or its equivalent, and a band having one of its ends bent around one of the end bars, and forming a spring, which operates to hold the free end of the band locked with said lug, substantially as shown and described.

Claim.-2. The combination, with the buckle, constructed of side and end bars, and a central cross-bar provided with a lug, of the band having one or more slots, and held engaged with the said lug by springpressure, as shown and described.

Cleim.-3. The combination, with the central cross-bar $c$ of the buckle, having the lug $e$, of the looped spring end of the band and the slotted end thereof, as shown and described, whereby the said slotted end is held engaged with the lug, as specified.

Claim.-4. The spring end of the band, bent around one of the cross-bars of the buckle, and provided with a depression, forming a shonlder, for holding the parts detachably connected, substantially as shown and described.

[Drawing, page 143.]

\section{E. BOARDMAN, of New York, N. Y., No. 185,070. Dec. 5, 1876.}

Claim.-1. In the baling-tie, a series of bars $\mathrm{B} \mathrm{B}$, located in the band-grooves of the bottom platen and follower, all connected to suitable levers, or equivalent mechanism, and operating simultaneously up and down within the grooves by means of levers, or their equivalents, on the ends of the platen and follower, for the purposes set forth.

Claim.-2. The combination of the platen $A$, with band-grooves $b$, the bars $B$, togglelevers $\mathrm{C}$, connecting-bars $\mathrm{D}, \operatorname{rod} \mathrm{E}$, and lever $G$, substantially as and for the purposes lierein set forth.

[Drawing, nage 143.]

\section{P. C. INGERSOLL, of Brooklyn, N. Y., No. 185, . 106. Dec. 5, 1876.}

Cluim -1. The bale or package described, composed of the compressed fertilizing material $A$, inclosed within broad-strips $B$ C D, of wood, as shown, and as herein specified.

Claim.-2. The fastening-wires $m$, set in the frames B C, adapted to secure the side pieces D, substantially as and for the purposes herein specitied.

[Drawing, page 14t] 
J. C. DU BOIS, of Tuscaloosa, Ala., No.185,304. Dec. 12, 1876.

Claim. A bale-tie consisting of a band whose end $A$ is provided with slots $a$, the end $\mathrm{A}^{\prime}$ with perforntions $a^{\prime} a^{\prime}$, and the wire $B$, made fist to the end $A^{\prime}$, with terminals $b b^{\prime}$, substantially as shown and described. [1)rawing, page 14t.]

G. S. FRANCE, of Cobleskill, N. Y., No. 185,310. Dec. 12, 1870.

Claim.-1. A bale-tie having on one end a $\operatorname{loop} \mathrm{E}$, and ou the other end a hook C, and brace D, substantially as and for the purposes set forth.

Claim.-2. 'The combination, with a baletie hook $\mathrm{C}$, of a downwardly-projecting brace or tongue $\mathrm{D}$, made continuous with said hook, for the purposes stated.

[Urawing, page 14t.]

\section{M. PEARRE, of Galveston, Tex., No. 185,347.} Dec. 12, 1876.

Claim.-1. The gripers $A$ and $B$, arrangerl to be separated or brought together, and having projecting lugs or plates forming a central deep slot for the reception of the bale-tie, and shallower slots for the band, substantially as and for the purpose described.

Claim.-2. The bar C, carrying a griping device at its end, and a guide, in combination with the slide-bar $\mathrm{X}$, having a griping device, and moving in said guide, and the elbow-lever $\mathrm{D}$, having one arm pivoted to the bar $\mathrm{X}$, and moving at its angle upon bar $\mathrm{C}$ by nieans of rollers and keepers, substantially as described.

Cluim.-3. The bar C, curved or inclined at $f$, and carrying socket $a$, and griping device, in combination with the bar $\mathrm{X}$, carrying a griping device, and the elbowlever D, substantially as and for the purpose described.

[Drawing, bage 144.]

W. P. GERLACH, of San Francisco, Cal, No. 185,519. Dec. 19, 1878.

Claim. As a new article of manufacture, the octagonal bale-tie buckle or link, composert of the sides $\mathbf{A} \mathbf{A}$, the ends $\mathbf{A}^{\prime} \mathbf{A}^{\prime}$, and the diagonals $a$ a, uniting the sides and ends, when made with straight angular inner edges and beveled outer sides or faces, substantially as and for the purpose set forth.

[1)rawing, page 145.]

J. R. KENNEDY, of Tuscaloosa, Ala., No. 185,544. Dec. 19, 1876.

Claim. The combination of the link A fastened to the band $\mathbf{B}^{1}$ by inserting the end $a^{1}$ through the hole $\mathrm{D}$, bent inward, and closed against band $\mathrm{B}^{1}$, and the other end of the link A resting through the open slotted recess $\mathrm{C}$, the fastening of the tie then being made to $\mathrm{B}^{2}$ by inserting the end $a^{2}$ into any of the holes $\mathrm{B}^{2}$, dropping the end $a^{1}$ in the next hole, thus forning a lock, substantially as deseribed.

[Drawing, page 145.] 


\section{Digest·of English Patents--Cotton Bale-Ties.}

W. SABATIER, of London, England, No. 2,125. July 4, 1796.

Bales or packages secure 1 by iron links, having eyes in their ends through which iron bolts pass, said links and bolts lying in grooves in boards surrounding the compressed article.

Cane or other suitable article might be substituted for the links and bolts.

[Drawing, page $146^{\circ}$ ]

A. BLAIR, of Bayford, Eng., No. 2,643. Aug. $19,1802$.

Wood, bamboo, cane, or iron hoops for cotton bales, said honps eitler secured by nailing into the cotton through the meeting ends or by clinching the nails on the under sides, or in the case of iron ties, of driving a wedge through a slot in the shank of the rivet on under side of band and riveting down the outer end of shank.

[Urawing, page 1+b.]

J. BRECK, of Newcastle, Under Lyne, Eng., No. 3,089. 1807.

The ends of the bands are turned back upou themselves, makung a kind of wedgeshaped point or end, the ends being then drawn into a collar of wedge shape within; if necessary a wedge may be introduced between the ends and the collar. In this manner ties may be made of short sections of band by connecting several in the above manner.

[Drawing, page 146.]

F. M. A. dez MAUREL, of 3 Newington Terrace, London, Eng., No. 9,087. Sept. 20, 1841.

Buckles having slots through which the ends of bands or straps are passed, from outside inward, and then around and over a bar, and then back under the outer bar. Modificatlons are shown in which a $\mathrm{V}$ slaped bar is employed, around which the end of strap is passed. The holding-bar may have serrated edges if preferred. [Drawing, page 146.]

T. B. DAFT, of Birmingham, Eng., No. 11,554. Feb. 1, 1847.

The ends of india-rubber bands are passed through metal eyes, as at $h$ Fig. 15, and a metallic plate, $r$, slipped over the end and pressed down securely holding the end from slipping out; the two ends are united by a hook which clasps around the free bars of the eyes $h$.

Au open staple is also employed with bands having the ends cernented together, forming eyes into which said staple is inserted.

[Drawing, page 147.]

H. TURCK, of Broad St. Buildings, London, Eng., No.112. Oct. 1, 1852.

Iron hoops coated with zinc or tin to prevent goods from injurious effects of rust from iron bale-ties.

[No drawing.]

E. H. RASCOL, of Catherine st., London. A communication from M. M. CONVENTZ, of Nancy, France, No. 995. May 3, 1854.

A buckle having central openings through which the ends of the bands are inserted, and then turned upward and outward, and a wedge-shaped lug inserted between the ends whereby the pressure of the bale tends to tighten the grip of the wedge upon the ends, and prevents their withdrawal. [Drawing,'page 147.]

A. V. NEWTON, of 66 Chancery Lane, London, Eng. A communication. No. 1,089. May $8,1856$.

The ends of metallic bands are formed into hooks aud engage each other, and a slotted slide is then slid over them to prevent their straightening out under pressure.

U. S. Patent No. 15,142, Juue 17, 1856. [Drawing, page 1.]

\section{W. RIDDLE, of Westbourne Terrace, Barnes.} bury Park, Middlesex Co., Eng., No. 304. Feb. 17, 1858.

The ends of the bands are made hookshape, as at $A$ and $B$, or as at $D$ and $E$, and the ring or slide $C$, passed over the joint, and the ears or projections $a$ and $a^{\prime}$ are knocked down, which prevents slipping of the slide.

[Drawing, page 147.] 
W. RIDDLE, of Westbourne Terrace, Barnes. bury Park, Middlesex Co., Eng., No. 2,339. Oct. 19, 1858.

Inon binds covered to protect bited material, by cotton cloth or other textile fibric saturated with a solution of india-rubber or other gum, or resin, or with paint or other material for closing the pores of the fibrous material.

[No drawings.]

J. BULL, of Port St., Manchester, Eng., No. 1,089. A pril 30, 1859.

The ends of iron hoops are made hookshape, and are passed throngh rectangular openings in a metallic plate; the looks being inward against the baled matter, the pressure thereof will prevent the straightening out of the looks, and thus secure the bands.

[No drawing.]

W. HUGHES, of Manchester, Eng. A communication from C. HUGHES, of New Orleans, La. No. 115. Jan. 17, 1860.

One end of tie has studs, the lieads of which are flattened to prevent coming out, but will allow them to be turned to different positions; other end of band has reetangular holes somewhat larger than head of studs, so as to pass over the same and allow the stud to be turned in the transverse di. rection and extend over the sides of the slot.

[No drawings.]

\section{J. J. McCOMB, of Liverpool, England, No. 361 .} Feb. 11, 1862.

A rectangular metallic plate recessed in the centre, and having one side cut through and having the metal at the cut, bent out of a straight line to permit of the insertion of the hooked ends of the tie or band after which the said bent portions are forced back into line again.

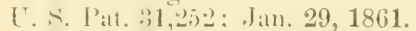

[Drawing, page 16.]

W. RIDDLE, of Gerrard St., Parish of Islington,

Middlesex, Fng., No. 1,376. May 8, 1862.

Loops or hooks are turned in upon eacl. end of the bands and are arranged so ats to match each other on the bale, and a metallic lath or strip is then slipped through them all, and expansion of bale secures them in place. 1868.

Same as Eng. P'at. No. 3,417 of Nov. 10 ,

U. S. I'at. No. 93,555 ; Aug. 10, 1869. [Drawing, uage 4i.]
J. PENDER, of Manchester, Eng., No. 2,531. Scpt. 15, 1862.

Shows machine for making perforations in the bands for the insertion of the rivets.

S, WILSON, of Manchester, England, No, 1,102. May 9, 1863.

In the ends of the batuds are made $\mathrm{V}$ or other shaped recesses and projections which fit into each other, and when brought together are secured by a clip which slips over them.

[Provisional protection. No drawing.]

J. J. McCOMB, of Liverpool, Eng. Partly a communication from D. McCOMB, of Tenn., U. S. A. No. 1.390. June 3, 1863.

Shows press for baling, and also bands.

A plate having two jarallel slots, into one of which is hooked the bent end of the band, and into the other slot is drawn the other end of the band. 'The recoil or stretch causes the plate to tip, and thereby nips the straight end of the band.

[Drawing, rage 147.]

J. HOPKINSON, of Manchester, Eng., No. 1,480. June 13, 1863.

The ends of the bands are corrugated and then laid togetker, and a clip shipped over them to draw and hold them close together. (Machine shown for corrugating the ends.

[Drawing, page 148.]

J. A. TULLESTON, of Manchester, England, No. 1,967. Aug. 10, 1863.

Rivets with elongated learls take into slots in the band, the rivet heads then being turned partially around secure the band. (Machine shown for punching the bands.) [Drawing, jage 14s.]

G. BUDDINGTON \& J. R. HAMPTON, both of Manchester, Eng., No. 2,148. Aug. 31, 1863. -Provisional protection.

The bands have slots near their ends, into which are inserted rivets having one T head and one circular or button head, the $\mathbf{T}$ being passed through the slots and turned half around the button head.

R. VAN HESS, of Manchoster, Eng., No. 3,244. Dec, 23, 1863,

A bar or plate having one or more studs or projections provided with slots in thein 
side secures the perforated ends of the bands, by the slotted studs entering the slots in the bands, and the bands taking into the slots in the studs.

[Drawing, rage 145.]

R. WILSON, of Patricroft, near Manchester, Eng., No. 1,198. May 12, 1864.

The ends of the bands or hoops are bent around longitudinal metal bars which lie next the bale, and the projecting ends of the bands placed next the bale, thereby being prevented from slipping, by the expansion of the bale.

[Drawing, page 148. Drawing also shows machine for bending lands, and, also, presses.]

W. J. DORNING, of Mauchester, Eng., No. 663. March 9, 1865. A communication from E. T. BELLHOUSE, of Egypt.

The meeting ends of the bands are either hook-shaped or corrugated, and when matcher together have a ferrule or clasp slipper over them, and are thus secured. [Drawing, Inge 149.]

J. J, McCOMB, of Liverpool, Eng., No. 2,837. Nov. 3, 1865.

A rectangular piece of metal having two slots for insertion of bands, one slot having two parallel and two oblique sides, and the other slot being cut through in an olilique direction, to form nipping elges. The end of band to be inserted in the slots in the buckle is doubled back upon itself, to enable the band to be turned over in double, so that at the throat of the strap resting on the nip of the buckle, the bund will be two fold, thus avoiding the strap being cut oft or broken by the nipping power of the inner side of buckle.

[Drawing, rage 149.]

W. E, NEWTON, A communication from $E_{1}$. FASSMAN, of New Orleans, La., No. 3,361. Dec. 28, 1865.

A perforated clasp or buckle having side slots, and projecting ribs bearing against bale, one end of the band being hooked into one perforation, and the other end passed down through the other perforation and forward under the ribs or clasp, and nnder and against the loop of the other end of band.

U. S. Patent No. 47,288, April 18, 1865. [Drawing, page 18.]
H. LUCAS, of Livexpool, Eng. A communication from H. FASSMAN, of New Orleans, La., No. 320. Feb. 1, 1866.

A metal plate or tongue, one end of which is a sbank, whose inner side is at light angles to the tongue; on the head of the shank is a small cross-head which is parallel to the tongue face.

The ends of the bands have holes and are slipped over the studs, and the spring of the bale secures them.

U. S. Patent No. 61,527, Jan'y 29, 1867. [Drawing page 20.]

J. HOLMES \& J. C. H. SLACK, both of Manchester, Eng., No. 1,097. April 19, 1866.

The two ends of eacli hoop, when on the bale, arè pressed by a punching mechanism, one edge of the projection on this punch is forced through the ends of the hoop, and the other part of the projection forms only an inclined indentation in the hoop; two or more indentations are made, and when the pressure is relieved the expansion of bale securely holds the band through the indentations.

U. S. Patent No. 113,518, April 11, 1871. [Drawing, page 52.]

E. J. BEARD, of Nicholas Lane, London, Eng. A communication from G, N. BEARD, of St. Louis, Mo., No. 1,208. April 28, 1866.

An elongated catch is riveted to one end of the band, and is inserted into slots in the other end of band, said cateh is longer than the slot and is pressed in at an incliuation, and when in place the two ends of the eatch will overlap the ends of the hole.

U. S. Patent No. 32,818, July 16, 1861. [Drawing, page 17.]

A. V. NEWTON, of 66 Chancery Lane, London, Eng. A communication from H. KNOWLES, of New York City, No. 2,117. Aug. 17, 1866.

A sleeve coupling or collar with a wedgeshaped or tapering mortise through it, in which is a free roller, one end of band is inserted under roller from one side and turned down over edge of collar, and the other end is inserted from other side and laid flat upon top of first placed band.

Expansion of bale tends to draw roller toward narrow throat of mortise, thereby firmly pinching the bands.

U. S. Patent No. 25,125, Aug. 16, 1859. [Drawing page 11] 
S. WOODALL, of Dudley, Worstershire Co., Eng, and J. M. VANWAIKLE, of Lawrence, Pountney Hill, London, Eng., No. 2,345. Sept. 12, 1868 ,

A revolving eatch or button is secured to one end of the band and takes into elongateil slot in other end, and is turned after being inserted in slot. The ends of the bands are kept in contact by a slide or clip slid over them.

[Drawing, page 149.]

M. P. ROBERTSON, of Liverpool, Eng. A communication from C. W. WAILEY, of New Orleans, La., No. 2,535. Oct. 3, 1866.

A flat metal plate having two lips or projections struck up or thrown out from the plane of the side next the bale, a loop on one end of band is then slipped through one of the openings formed by one of the lugs, and the opposite end of the band slipped through the other opening from the top side of plate, and passed forvard under the projecting lugs, which rest against the face of the bale, and any drawing tendency on the baud causes the projections to nip it, and thereby securely hold it.

U.S. Patent No. 58,698, Oct. 9, 1866.

[Drawing, page 22.]

A. V. NEWTON, of 66 Chancery Lane, London. Eng. A communication from R. DILLON, of New York City, No. 2,726. Oct. 22, 1866.

The ends of the bands are connected by a loop and pin, one end of the band being folded over the neck of the loop and the other over the pin which passes through the loop. The bent-over ends lie next the bale.

U. S. Patent No. 62,400, Feb. $20,1867$. [U rawing, page 28. ]

J. H. JOHNSON, of 47 Lincoln In-Fields, Middlesex Co., Eng. A communication from A. BARBARIN, of New Orleans, La., No. 2,790. Oct. 29, 1866.

$\Lambda$ that $\mathrm{C}$, or curve-shaped piece of metal having inclined projection or stop at one or both encls, and in some cases a slot in the lower part of the fastener, conforming to the imner enre of the fastener: "The ends of the band are made into a loop, and slipped over the ends or into the slot of the fastener, sueh ends being secured or not, by a rivet.

U. S. Patent No. 58,574, Oet. 9th, 1866. [Drawing, page 21.]
H. LAMPSON, of Queen St., Cheapside, London, No. 2,991. Nov. 15, 1866.

One end of the band is passed through a sliding loop and then turned back upon itself next the bale; another loop is passed over other end of band and is then passed through the other loop, and turmed back again orer it, and then through the second loop which acts as a capping, and keeps the ends in place.

[Drawing, page 149.]

H. C. LUCAS, of Liverpool, Eng. A communication from S, BOYD, of New Orleans, La., No. 3,234. Dec. 8, 1866.

'T'o one end of the band is riveted two Hat sided stud-picees having overhanging or projecting shoulders pointing in opposite directions, which take into longitudinal slots in the other end of the band.

[Drawing, page 150 ]

S. WILSON, of Manchester, Eng., No. 3,335. Dec. 19, 1866.-Provisional protection.

The ends of the bands are bent backwards so as to make enlarged eyes or loops, which are inserted sidewise into a slotted coupling block provided with holes corresponding to the shape of the eyes or loops of band, but having narrow necks, and the expansion of the bale draws the eyes in bands against the narrow opening in the eyes in the coupling-block and secures them.

[No Drawing.]

A. SHANKS, of 6 Robert St, Adelphi, Westminster, London, No. 3,374. Dec. 22, 1866.

One end of band has holes and the other end has tongues or flaps struck up out of its surface said tongues taking into the holes in other end of band thereby securing them.

[Drawing, page 150.]

W. E. NEWTON, of 66 Chancery Lane, Middlesex Co., Eng. A communication from J. C. LEE, of Blakely, Gà., No. 175. Jan. 23, 1867.

The band is passed around the bale, one end having a loop to assist in drawing it, and the other end is passed over the first coil, and then tucked under the band next the bale, and through expansion of bale held tight.

U. S. Patent No. 58,844, Oct. 16th, 1866. [Drawing, joge :2.; 
נ. D. BULLOCK, of Liverpool, Eng, A communication from C. W. WAILEY, of New Orleans, La., No. 311. Feb. 4, 1867.

An improvement on Patent No. 2,535, Oct. 3d, 1866 , consisting of bending out the projections or tougues, in a curve from the plane of the plate, instead of at an angle as described in the above referred to patent. The buckle also has no angle or edge to at raid or weaken the band at the points where said band bears against the buckle.

U. S. Patent No. 25,698, Oct. 9, 1866.

[Drawing, page 2:.]

A. V. NEWTON, of 66 Chancery Lane, London. A communication from G. N, BEARD, of St. Louis, Mo., No. 630. March 6, 1867.

'The hooked end of the band is inserted in a straight slot in the buckle, and the free end of haud is inserted through an in. clined lateral opening, into a slot parallel to the first, said second slot being extended at its upper end and slightly inclined inward to enable the band to clear the lip formed by the junction of the inclined lateral opening with the lower end of the slot.

[Drawing, page 150.]

A. V. NEWTON, of 66 Chancery Lane, London. A communication from 0. MACDANIEL, of New York City, No, 751. March 15, 1867. -Provisional protection only.

The ends of the bands are bent-hook shape and rest against bale, and are secured together by a wire-stirrup or yoke, having hook-and-eye terminations.

U. S. Patent No. 63,166, March 26, 1867. [1)rawing, page 30.$]$

H. FASSMAN, of New Orlears, La., U. S. A., No. 858. March 25, 1867.

One end of the band is hooked to a buckle having two slots, one having serrated edges, and the opposite end of the band is passed through said serrated slot and under buckle next the bale, and is held by expansion of bale. An iustrument shown for bending end of bale upon buckle, and holding buckle while securing baud therein. U. S. Patent No. 62,188; Feb. 19, 1867. [Drawing, page 28.]

T. H. LUCAS, of Manchester, Eng., No. 1,036. April 6, 1867.

A metal box or elip having a longitudiual slot for the ends of band to pass through, (one lying upou the other, aud a transverse dome-shaped lole for a metal pin or roller to pass through, said pin being a little longer than the width of the band. The expansion of bale causes the pin to roll to one end of the transverse hole, and bind the ends of the band firmly together.

[Drawing, page 150.]

\section{H. FASSMANN, of New Orleans, La., No. 1,162.} April 20, 1867.

One end of band is hooked to buckle, through one of the two slots therein, and the other end is introduced through the other aperture and passed under the centre bar of buckle, which bar has ribs or projections, to grip the said end of the hoop. The last-named aperture may have a slot in its side to facilitate introduction of strap or band.

U. S. Patent No. 61,727; Feb. 5, 1867. [Drawing, page 27.]

W. R. LAKE, of 8 Southampton Buildings, London. A communication from G. N. BEARD, of St. Louis, Mo., No. 1,358. May 8, 1867.

A metal tie piece pierced with two mortices, the lower faces of which are at an angle of abont thirty degrees with the axial line of the tie; one end of band is hooked into one of the mortices, and the other is passed down through the other and back under the first uamed, and securely held by expansion of bale.

U. S. Patent No. 67,707; Aug. 13, 1867. [Drawing, page 35.]

W. R. LAKE, of 8 Southampton Buildings, London. A communication from R. G. LATTING, of New Orleans, La., No. 1,880 . June 27, 1867.

A buckle having two slots, and an obloug central projecting rib with teeth or notches thereon; the band is hooked to the buckle at one end, and the other is passed down through opposite slot back under the toothed rib, and under the first-named hook, and all held by expansion of bale.

U. S. Patent No. 61,217; Jan. 15, 1867. [Drawing, page 26.]

H. C. CALVER, of Manchester, Eng. A communication from E. D, CARVER and G. ASHCROFT, both of Alexandria, Egypt, No. 1,972. July 5, 1867.

The band is turned down upon itself at both ends, and one end has a hutton-headed rivet attached, and the other end is perforated with an elongated slot, to receive the button on other end.

[Drawing, page 151.] 
W. WALKER, of tivorpool, Eng. A communiration from J, T, BUTLER, of Natchez, Miss., No. 3,645. Dec. 23, 1867.

A rectangular or square piece of metal laving a rectangular slot therein, the long waty of slot being in direction of crossing the band. The ends of band are bent into hook shape and inserted through the slot, the bent portion being against the bale; expansion of bale securing band.

[Irnwing, pare 151.]

J. MAURY, of New Orleans, La., U, S, A., No. 52. Jan. 7, 1868.

Securing the ends of wire or wire rope around bates by a peculiar knot or loop tie; also a metal plate having projecting studs or buttons, over which the loop on ends of bale band are placerl.

U. S. Patent No. 65,102; May 28, 1867. (1) rawing, page 15].

J. B. DUNN, of Petersburg, Va., U. S. A., No. 56. Jan. 7, 1868.

A flat metal buckle having a slot in one side, for the looped end of band, and in the other side is struck up a tongue projecting in against the bale; the opposite end of band is passed down through opening made by the struck up part and forward over edge of said part, and rests upon the loop of the other end of band. A slot is cut in one elge of buckle for insertion of the last-placed end of band.

U. S. Patent No. 74,059; Feb. 4, 1868. [Drawing, ]nge 39.]

E. T. MAINWARIN, of Tipton, Suffolk Co., Eng., No. 326. Jan. 30, 1868.

The meeting ends of band are deflecterl from general plane, and are passed throngh a slot in a metal plate, whose thickness is about that of the deflection in the bands, said plate has a shank or shanks cxtending along the surface of the band, over which are slipped slides, which securely retain all in position.

U. S. Patent No. 90,761, June 1, 1869.

[Drawing, nasge 46.]

W. R. LAKE, of 8 Southampton Buildings, London, A communication from J. W. BRANCH and J. CROOKS, both of St. Louis Mo., No. 972. March 23, 1868.

$\Lambda$ curved tie piece or buckle having two slots throngh which pass the band, the under side of buekle is coneave, and the bars against which the bauds infringe have sharp edres, to liold band securely.

U. S. Patent No. 67,334, July 30, 1867. [10rawing, page 33.]
W. R. LAKE, of 8 Southampton Buildings, London. A communication from J. W. BRANCH and J. CR0OKS, of St. Louis, Mo., No. 981. March 23, 1868.

To one end of band is riveted a button having a head which stands in a diagonal line with reference to the axis of the hoop. A cavity in shank of button allows the button to project over the edge of the slot in the upper band.

U. S. Pattent No. 53,230, March 13, 1866. [Drawing, page 19.\}

J. F. HADLAND, of London, Eng. A communication from J. E. SWEET, of Syracuse, N. Y., No. 1,079, March 30, 1868.-Provisional specification.

The ties are secured by a coupling device having at hole for securing one end of wire, and the other end is seenred by pressing it through a similar hole in buckle, or by securing it to prongs or hooks upon birckle.

[No drawing.]

D. C. LOBER, of New Orleans, La., No. $\mathbf{1}, 346$. April 24, 1868.

To one end of a wire bale-tie is securer a hook by a loop, and the other end is also provided with a loop, into which takes the hook attached to first-named end.

[Drawing. mage 151.]

T. BRIGGS, of Manchester, Eng., No. 1,542. May 12, 1868.-Provisional protection.

Each end of baud has two or more longitudinal slits opposite which the onter portions of the band are bent into a convex form, while the center strip is bent concave, or vice versa. When the ends of the band meet, the convex and concave portions fit each other, leaving an open transverse slot through which a securing-key or cotter is driven.

Specifieation enrolled and Patent No. 2,974, Sept. 29, 1868.

[No drawing.]

J. EDMUNSON, of Manchester, Eng., No. 2,838 . Scpt. 15, 1868.

At botle ends of the band are cut and struck-up pieces, forming apertures, said pieces prointing in reverse direction at each end of hand, whereby the projections of each end-take into the eorresponding recesses in other end.

[Drawing, ]age 152.] 
T. BRIGGS, of Manchester, Eng., No. 2,974. Sept. 29, 1868.

Longitudinal slits made in band, and the surfice on each sirle of slits sprung or pressed in opposite directions, the bands being lapped one upon another and a pin inserter through the hinge thus formed. Also shows elongated slots and doubleheaded buttons for securing the end. (See provisional specification to same party, No. 1,542, Miry 12, 1868.)

[Irawing, page 15:-]

W. RIDDLE, of Lark Hall Lane, Surrey Co. Eng., No. 3,417. Nov. 10, 1868.

Substantially the same, as same person.

No. 1,376, May 8, 1862. U. S. Patent Nก. 93,555 .

[Drawing, bage 47.]

W. McNABB, of Cambridge Terrace, London Road, Clapton, Middlesex, London, No. 1,864. June 17, 1869.

Several modifications of clasps, which slip over the ends of the band after they are placed one upon the other. Also clasps nsed when ends of band are made loopshaped. (See drawings.)

[Drawing page 152.]

W. LARMUTH, of Pendleton, Lancashire Co., Eng., No. 2,201. July 21, 1869.-Provisional protection.

'To one end of baud is secured a T-shaped button which takes into a longitndinal slot in other end of band and is then turned partially around, thereby preventing the disconnection of the ends.

[No Drawing.]

M. TILDSLEY, of Willenhall, Staffordshire Co. Eng., No. 2,214. July 21, 1869.

Tro clamps, the counterpart of each other, which slicle into and upon each other are provided with recesses and slots, and are inserted through the turner up ends of the bands, so that the recessed parts face and fit into each other, when the comnection will be complete.

U. S. Patent No. $95,85+$ Oct. 12 th, 1869. [Drawing, page 47.]

J. H. JOHNSON, of 47 Lincoln Inn-Fields, Middlesex Co., Eng. A communication from E. CHRISTIAN, of Egypt, No. 2,663. Sept. $10,1869$.

A plate having two buttons or studs secures the ends of band together by said buttons passing up through round holes in one end of the elongated slots in ends of band, and by expansion of bale, the parallel sides of the slots bear against the shanks of the studs.

Drawing, page 153.]

A. KEEN, of Edgboston, Warwick Co., Eng. A communication from J. S. WALLIS, of New Orleans, La., No. 2,863. Oct. 2, 1869.

A rectangular piece of metal of wedgeshape eross section having two parallel slots, the ends of which extend from near the thin edge of the plate toward the thick edge. In thin edge of plate an opening is made into the slot where is the greatest breadth of metal, said thickness of metal compensating for the opening. 'The ends of the bands are passed through the slots in the buckle.

U. S. Patent No. 89,612 Maly 4th, 1869. [Drawing, prage 45.]

B. B. MILLS, of 35 Southampton Buildings, London. A communication from A. McDOUGALL, of Calcutta, British India, No. 3,535. Dec. 7, 1869.-Provisional protection.

The ends of band are secured by a metal piece, having eyes or loops, and slotted opening, one end of the tie being passed through the slotted opening and bent ovei, the other end being formed into a loop, through which, and also though the eyes or loops of the plate a split-pin is passed to connect all together.

Also a tie-buckle made of round metal bent as above described. Also a buckle of round or other suitable section made to form three sides of a parallelagram as before, but without loops. The ends of the bands are attached to two opposite sides thereof, and to prevent the ends of the buckle parting a strip is passed arouud the ends.

[No Drawing.]

H. WHITTAKER, of Manchester, Eng. and W. BRADBURY, of Prestwick, Lancashire Co., Eng., No. 3,567. Dec. 10, 1869.-Provisional protection.

Slots in the ends of the bands receive a T-shaperl fasiener, made of a piece of metal berit or doubled upon itself, and after being inserted in said slots its two meeting or lower ends are separated or spread apart and flattened down against the band. [No Drawing.] 
W. R. LAKE, of Southnmpton Buildings, London. A communication from E. S. LENOX, of New Brighton, N. Y., No. 16. Jan. 3, 1870.-Provisional protection.

In one end of at wire-band or tie is formed an eve or loop, and on opposite end a $\mathbf{T}$. slapied cross-bead, formed by turning the ends of the wire back upon itself, and twisting the two parts together, and then flattening or conmpressiug the eye thus formed until it assumes a $\mathbf{T}$-form, which is inserted into loop.

U. S. Patent No. 98,169, Dec. 21st, 1869. [Drawing, nage 48.]

W. MCNABB, of 6 Cambridge Terrace, London Road, Clapton, Middlesex Co., Eng., No. 011. March 29, 1870.

Two lougitudiual slits are made at each encl of the band, and the material or each side of the slits is raised or depressed; upon both ends being correspondingly treated and bromght together one above the other, a kunckle joint is secured into which is passed a pin or buckle which secures the ends together.

[Drawiug, page 153 ]

A. V. NEWTON, of 66 Chancery Lane, Middlesex Co., Eng. A communication from E. J. BEARD, of St. Louis, Mo., No. 1,255. May 2, 1870.

A buckle having two slots, one of which has an opening to permit of the insertion of the tree end of the band, both of the bearing surfaces of the buckle having a convex form. A strengthening rib extends across the buckle in rear of the inner ent of the slots.

[Drawing, rage 153.]

D. C. LOWBER, of Church St., Warrington, Lancashire Co., Eng., No. 1,464. May 20, 1870.

An improvement on patent No. 1,3.6; April 2t, 1868 .

In licu of hook in previous case, I use a $\mathbf{T}$ piece formed by making a loop of one end of the wire tie, the two portions of said loop being twisted together, and then flattened or eompressed so the two sides are brought together and at right angles to the cond of tie. At opposite end is formed a loop with a wide and narrow portion, the diameter of large portion being arreater than the length of the $\mathbf{T}$ piece, while the small part, which extends outwardly from the larere portion, receives the $\mathbf{T}$ end, into which it is drawn by the expansion of the bale.

[1)wing, prge 153.]
E. A, 0'BRIEN, of New Orleans, La. A communication from E.P. JONES, of Sun-flower Co., Miss., No. 2,273. Aug. 17, 1870.

A quadraugular tie plate having eross. bar extending from or near one angle to or near the opposite thereof, having two triangular spaees, nne of these spaces being entire and the other having a slit or opening. One end of band is hooked into the entire space, and the other is looper into other space through the slit. Instead of the angular cross-bar it may extend only matially across, or there may be two of such cross-bars inclining the one to the other.

U.S. I'atent No. 108,600 ; Oct. 25, 1870. (Drawing, page 50.)

F. WATKINS, of Southwick, Staffordshire Co, Eng., No. 2,604. Sept. 30, 1870. Provisional protection only.

The ends of the band have a series of opcuings with tonguc-like projections, said projections being the portion which is struck II) out of the openines; and when the euds are brought together the projections in each enter the corresponding open. ings, and the bands are thereby secured when the bale is relieved from pressure. [No drawing.]

T. J. SMITH, of 166 Fleet St., London. (Patent Agent.) A communication from $E_{\text {. }} S$. LENOX, of New York, N. Y., No. 3,260. Dec. 13, 1870. Provisional protection only.

One end of a wire band is twisted to getlier to form an eye or 100p, and the other emrl lias a short piece of wire twisted upon it, so that the two are held together to grive inereased strength; this eml is then bent inte the form of a hook, to engage with the eye or loop at the other end. [No drawing.]

W. C. STIFF, of Birmingham, Eng. A communication from J, S. LENG, of New York, N. Y., No. 231. Jan. 28, 1871 .

A rectangular iron-plate having a slot in which is seemed the hooked end of the band, and in said plate is a rectangular openine in which is formed a tratusversebar which is divided near one end and slightly hent mpwads leaving space in the oprening for the other end of the band to be bent over it, amd pased in orer the bar, on which ina a enred incline is formed so that when the pressure is on the tie, the enrved incline places the band in its proper position and bearing, on the transverse-bar. [1)rawing jage, 15t.] 
H. LINDON, 14 Hampden St. District, Parish of Traumer, Chester Co., Eng., No. 574. March 3, 1871.

One end of band has a movable button in commection with a fixerl stud to bear the principal strain, while the other oud has slots or holes. When buttons are passed through slots they are partially turned. The curls of studs are slightly beveled to facilitate separating the bands when the buttons are turned back for disconnection. [Drawing, page 154.]

J. DOWNS, of Handsworth, Staffordshire, Co., Eng., No. 625, March 9, 1871.

The bandis are made from several short pieces of strap iron which have hinged joints, and can be stored or packed conviently for shipment. The ordinary hinge joint nay be ased for joining the sections.

A tie is used to unite the sections, sain tie having three bars, two outer, and one middle. Thie ends of the pieces are passed around the onter bars and the over-lapping ends riveted down, the said outer bar, constituting the joint-pin. The free ends of band are united by any of the ordinary bale-fastener's. 1871.

U. S. Patent No. 120,727 November 7 th, [Drawing, page 57.]

A. SPARROW, of Liverpool, Lancashire Co., Eng., No. 1502. June 6, 1871. Provisional protection.

From a sheet of hoop or strap.iron is stamper a blank having a centrial portion with curved or inclined sides and a projecting ear un each side, somewhat narrower than the central portion. In this central portion, and between the ears is formed a fong narrow slot, the two sides are then folded or doubled over, whereby the ears are brought opposite each other, but do not quite meet, leaving an aperture between them. One end of band is bent hook shape and inserted in the slot, and other end is bent and inserted in space between the curved or inclined parts of the fastening. As the hoop is drawn tight this end of it will slide down the inclined part agninst the shonlder, and thereby be securely held. [No Drawing.]

E. EDWARDS, of 22 Southampton Buildings, Chancery Lane, London, Fng. A communication from G. BROLIE, of Plum bayou, Jefferson Co., Ark., No. 1,764. July 6, 1871.

A buckle having two parallel ribs around which the ends of the band are bent, one of which ribs las a slot or opening in the centre, these ribs being connected by webs which gradually decrease in thickness from the side of the rib which is not slotted, to the slotted rib, whereby the metal is best distributed for strength and lightness.

U. S. Patent No. 116,925, July 11th, 1871. [Drawing, lage 55]

W. R. LAKE, of HASELTINE, LAKE \& C0, London, Eng. A communication from S. BRETT, of New York, N. Y., No. 2,151. Aug. 15, 1871.

A wire-bale is formed into an eye at one cnd, and a hook at the other, said eye and hook are interlocked by passing the hook upward through the eye until the limb of the hook has passed beyond the eye, I then bring the limb of hook around the shank of eye and springing or passing it forward into the eye so as to interlock the hook and eve together, the bight of the hook surrounding the back of the strands which form the eye, and the eye being arranged over the limb and body of the hook.

U. S. Patent No. 115,962, June 6th, 1871. [Drawing, page 5t.]

W. R. LAKE, of HASELTINE, LAKE \& C0, London, Eng. A communication from J.T. BUTLER, of New Orleans, La., No. 3,264. Dec. $2,1871$.

A tie or buckle of regular rectangular form having the interior portion cut out, and having a narrow diagonal cleft communicating with said opening, through which eleft the band is inserted edgewise eitler before or after it is bent into hookshape.

U. S. Patent No. 122,563, January 9th, 1872.

[Drawing, page 58.]

W. ASHCROFT, of Wolverhampton, Staffordshire, Eng., No. 1,486. May 16, 1872.

A tie or buckle consisting of a square piece of metal having two slots for the passage of the ends of the hoop. The body of tie between the slots is double the thickness of the portion which forms the rim or extremities of the tie, the ends of the band are passed through the slots from the under level surface, and then over the upper elevated surface.

[1)rawing, prage 154.]

N. S. WALKER, of Liverpool, Eng., No. 1,653. May 31, 1872.

A buckle or tie having a slot to secure 
one end of baud, and a "free end tongue" of the width of band, depressed from the borly of the metal, to receive the other looped end of the band.

U. S. l'atent No. 132,223, October 15th, 1872 .

[1)ratwing, palge tis.]

A. V. NEWTON, of 60 Chancery Lane, London, Eng. A communication from E, J. BEARD, of St. Łouis, Mo., No. 1,708. June 5, 1872. -Provisional protection.

A tie consisting of a short flattened tube or sleeve, open at one side, and of greater width than the band, through the side opening of which are inserted the hooked ends of the band. (No drawing.)

U. S. P'atent No. 1£9,917, July 30, 1872. [Drawingivage 64.]

W. R. LAKE, of Haseltine Lake \& Co., Chancery Lane, London, Eng. A communication from J. E. AIKEN, of New Orleans, La., and CHAS, SWETT, of Copiah Co., Miss., No. 2,099. July 11, 1872.

From sheet-metal is ent a plate which may have a single oblong rectangular form with four tongues, two on one edge and two on the other; the two ends of the band to lie side by side and hook over the two edges, and are passed under the tongues, and are securely held by same. The form represented in drawing is preferred. A modifieation consists in making a slot in one side of the plate to receive one end of the band, while the other end is hooked upon the onter edge and retained in place by a thange or lip formed by turning down the end of the plate.

[Orawing, pages 151 and 155.]

W. R. LAKE, of Haseltine, Lake \& Co., Chancery Lane, London, Eng. A communication from GE0. L. LAUGHLAND, of New Orleans, La., No. 2,734. Sept. 13, 1872.

Each end of a wire band has a loop, in one end of which is secured a hook, which is hooked into the other loop and then bent back or closed to prevent its escape.

U. S. Patent No. 141,879, Aug. 19, 1873. [Drawing, page 7t.]

J. J. McCOMB, of Liverpool, Eng. A communication from $F$, COOK, of New Orleans, La., U. S. A., No. 2,942, of 1872.-Provisional protection.

A tie formed with flanges, which prevent the bands when at tension from slipping laterally off the tie. The metal forming the base of tie is made sutheiently long to receive the hooked ends of a band, side by side, and the flanges which run transwersely of the base, and in general at both sicles thereof, serve to resist any diagonal pull of band, and at same time ofter no obstruction to the end way insertion of the tie into the hooks of the band. The flanges may be at the end only, or at the middle of the tie.

[No drawing. ]

W. C. STIFF, of Birmingham, Eng., No. 1,544 . April 28, 1873.

T'he ends of the band are made self-fastening by making a hook at one end by turning the end back tuon itself, and by a transverse loop or lip, with which said hook engages upon the other end of band, said eye being made by bendiug a portion of the band at an angle of 90 degrees, folling the bent part flat upon the other part of the band. The folded part stands at right angles to the band, and from this part the lorp is made, by bending the part standing at right angles to the band, so that it forms at the end of the band at transverse hoop or eye surrounding the end of the band.

U. S. Patent No, 140,556, July 1, 1873. [Drawing, page 72.]

J. J. McCOMB, of Liverpool, Eng. A communication from C. G. JOHNSEN, of New Or. leans, La., No.1,835. May 20, 1873.-Drovisional protection only.

At or near the end or edge of the band, hoop, or sheet tongues are punched. The formation of these tongues produces enresponding openings of montlis, which are so arranged that the tongue at one end of the band or hoop will be inserted in the mouth or opening male at the other end, and viee versil.

[No drawink.]

A. V. NEWTON, 66 Chancery Lane, London, Eng. A communication from E, J. BEARD, of St. Louis, Mo., U. S. A., No. 1,882. May 24, 1873. - Provisional protection only.

The looped ends of the bamls are caused to hook the one on to the other, and become locked together. Thus, for example, the looped enils of the band may catch into a notels cut in one exige of the other end of the band, say at about four or more inclies from the extremity thereot. The noteh may be strengthenes by riveting a short piece into the face of the band, and if desired, this same piece may extend beyoud the edre of the band sufficiently to take the 
loop of the other end of the baurl, and thus dispense with the notehing of the hoopiron. Near the extremity of the noteher end of the band a rivet or button is provided for the edge of the looped end to eatch under.

U. S. Patent No. 140,873, July 15, 1873. [Drawing, page 73.]

N. S. WALKER, of Liverpool, Eng., No. 2,456. July 16, 1873.

A buckle of that metal having a slot near one end, through which one hooked end of ! s. band is inserted, said buckle being in length more than twice the width of the band, and boing turned down at the corners at the end oprposite the slot, to prevent the end of the band, which is hooked around that end of buckle, from slipping oft:

[Drawing, page 155.]

E. P. 10 NES, of Shell Mound, Miss., U. S. A. No. 2,621. Aug. 2, 1873.-Provisional protection only.

The metal tie-plate is formed with slots or openings, separated by a tongue formed on one side of the tie and projecting inward from the same across the tie in the same place, or nearly so, as the-sides, at its disconnected extremity, the erlge of the said tongue is slightly curved or turned down to leave a space or opening between it and the side of the tie just sufficient to permit the introrluction of the loop or hook edgewise. The latter, after being introdueed and passed over the tongue, is so held by the sides of the tie as to prevent its lateral slipping.

U. S. Patent No. 108,600, Oct. 25, 1870. [Drawing, page 50.]

W. R. LAKE, of HASELTINE, LAKE \& C 0 , 8 Southhampton Building, London. A communication from W. A. JORDAN, of New Orleans, La., U. S. A., No. 4,208. December 22, 1873.

A rectangular metal plate is provided with two parallel slots, through which the extreme ends of the bands are made to pass, said ends being passed through a metal sleeve which holds the ends firmly in place.

U. S. Patent No. 146,911, Jan. 27, 1874. [Drawing, page s0-]

ANDREW ALLAN and JOHN BURNS, of Liverpool, Eng., No. 543. Aug. 7, 1874.

A stud or button consisting of an inner head, of button-like or other form, a stem 18 rising from the inner head, and commecting it to the onter head. The onter head extends from the stem at a right angle in one direction, and is caused to pass tlirough elongated apertures in the band in such manner that it points in the direction of the free over-lapping end of the band. To release it the stud is turned a half turn, and the end of the band slipped orer the outer head.

U. S. Patent No. 156,965; Nov.17, 1874. (Drawing, page 98.)

J. B. BRADSHAW, of Clough Hill House, Rotherham, York Co., Eng., No. 872. July 21, 1874.

The bale iron is rolled with ribs on its surfiaces.

[Drawing, page 155.]

J. B. BRADSHAW, of Clough Hill House, Rotherham, York Co., Eng., No. 1,182. July 21, 1874.

Bends are formed in the ends of the tie. The bend at one end is made to lie within the bend at the other end, and over these bends a slotted plate is placed, which is just large enough for the admission of the bends. A metal key or pin is then inserted between the bends and the slotted plate.

Several modifications.

[Drawing, page 155.]

SAMUEL MARSDEN, of Hale, Chester Co., Eng., No. 1,615. May 7, 1874,-Provisional protection.

The two ends are united by means of a pin prased through loops formed in the ends of the bands by parallel slits, the metal on altermate sides of the slit being pressed out of line. The two ends are then placed together, the depressed surface of one adapting itself to the raised portion of the other, thus forming the loops through which the pin is passed. (No drawing.)

W. R. LAKE, of HASELTINE, LAKE \& CO, London, Eng. A communication from S, P. PARMLY and JOHN HUGHES, of New Orleans, La., No. 1,700. May 13, 1874.

One end of band has elongated slots or apertures, and to the other end is riveted a cleat of oblong shape having one end curved or beut downward; steps or shoulders are also formed on the cleat, which, in combination with the hook, hold the band, and lock it firmly after the aperture of the band has been passed orer the cleat.

[No drawing.] 
W. C. STIFF and JOHN SHELDON, of Birmingham, Eng., No. 2,221. June 20, 1874.

Wire of greater diameter than is for the band portion is provided with a hook at nne end and an eye at the other, and the surface between the two is reduced either by rolling or drawing down. WThen hoop iron is used, the ends are heated and formed into hooks by dies or press. The hooks may be strengthened by corrugations formed thereon. The ends of the bands may be doubled before the hooks are formed, to give additional strength. [No drawing.]

\section{J. B. BRADSHAW, of Clough Hill House, Roth-} erham, York Co., Eng., No. 2,329. July 9, 1874.-Provisional protection.

The ends of the bands are inserted into a slotted tabe, and a key is then driven in between the two bands, bending them out. ward away from each other. A slotted bent plate may be used in lieu of a tube. To strengthen hoops at the holes where rivets are used to secure them, longitudinal ridges are rolled, one on each side of the rivet holes. In some cases the hoops are formed with longitudinal grooves over their whole surfice.

[No drawing.]

M. BENSON, of 9 Southampton Buildings, London, Eng. A communication from C. H. COMPTON, of Calcutta, India, No. $3,369$. Oct. 2, 1874.-Provisional protection.

The slotted ends of the bands are secured by a $\mathbf{T}$-shaped fastening, the rertical stem of which is made double, and when passed through the slots one-half of it is turned down on one side and the other half on the other side, and both sides are then hammered flat on the surface of the band. [No drawing.]

P. D. RODDEY, of Tuscaloosa, Ala., U. S. A. A communication from WM. COOPER, of Tyler, Texas, No. 4,041, Nov. 24, 1874. -Provisional protection.

One end of tie has a slot of same size as the bolt which is fixed to the other end of the tie. Said bolt is wedge-shape, having a catch or look at its small encl, and a groove the whole length of each of its sides to almit the thickness of the tie. As soon as the wedge-shape bolt enters the slot, and strain is brought on the tie, the bolt imme. diately locks through its length, the edges of the slot passing into the grooves on the side of the bolt.

U. S. Patent No.153,317; July 21, 1874 . [Drawing, rage 90 ]
W. R. LAKE, of HASELTINE, LAKE \& C0, London, Eng, A communication from RICHARD TERRELL, of New Orleans, La., No. $4,344$. Dec. 17, 1874.

1. On one end of a band is formed a series of notelies and on the opposite end a succession of projecting hooks, all an equal distance apart, so the hooks on one end engage with the edges of the notches on the other end.

2. One end of baud is folded back upon itself for about five inches; this fold is then bent over and at right angles to band; the opposite end is folded into an oblate hook, and is secured to the upper fold of opposite end by slipping the said hook edgewise over the same.

Other modifications shown.

U. S. P'atent No. 156,263; Oct. 27, 1874. [1)rawing, page 96. .]

E. P. ALEXANDER, of 14 Southampton Buildings, London, Eng. A communication from R. BONWELL, and G. HUMPHREYS, of Alexandria, Egypt, No. 196. Jan 19, 1875.

A button for securing slotted-band ends, the shank of button being of square section, and disposed eccentrically to the upper and lower heads, the main portions of which project or overhang respectively to the right and left of the shank, or vice versa. A small lip or projection being left on the sides of the shank opposite to the main projecting portions of the heads.

[Drawing, page 156]

J. LIND, of Liverpool, Eng., No. 457. Feb. 6, 1875.

A detached stud or fastener, consisting of a catch or hook at one side and a square or rectangular head at the other. 'The catch is passed through slots in the ends of the band and the stud is then locked by turning it part way round by a spanner or key which tits the square head.

[Drawing, page 156.]

E. W. HODGETTS, of Moreton-in-the-Marsh, Gloucestershire, Eng., No. 2,807. Aug* 10,1875 .

Wheat or other substance is bound by a cord of cocoa fiber, or suitable material, with knots at one end and a hook formed of wire or flat metal fastened at other end. [No drawing.] 
W. R. LAKE, of HASELTINE, LAKE \& C0, Southamton Buildings, London. A communication from J. M. SEYMOUR, of Newark, N.J. No. 3,318. Sept. 22, 1875.

'The band is secured by passing its ends around two straining-bars of the buckle, said buckle having an arm at right angles to the straining-bars, which acts as a lever to turn the buckle over endwise, and a bar projects laterally from the lever-arm in the direction of the straining-bars, and which, by being slipped under the tightened band, securely fastens the ends of the band.

U. S. Patent No. 166,640, Aug. 10, 1875. [Drawing, page 114.]
T. H. MURPHY, of New Orleans, La., No. 3,596 of 1875 .

One eud of band has oblong or oval slots into which take a key or button secured to opposite end of band, said key being capable of being turned half way round after having been inserted in the slot, thereby preventing its withdrawal until turned back.

U. S. Patent No. 168,518, Oct. 5, 1875. [Drawing, page 115.] 

Sinzmomss:Raquet. Cotsorz Bale Tie

Fitented Nor 7 wess.

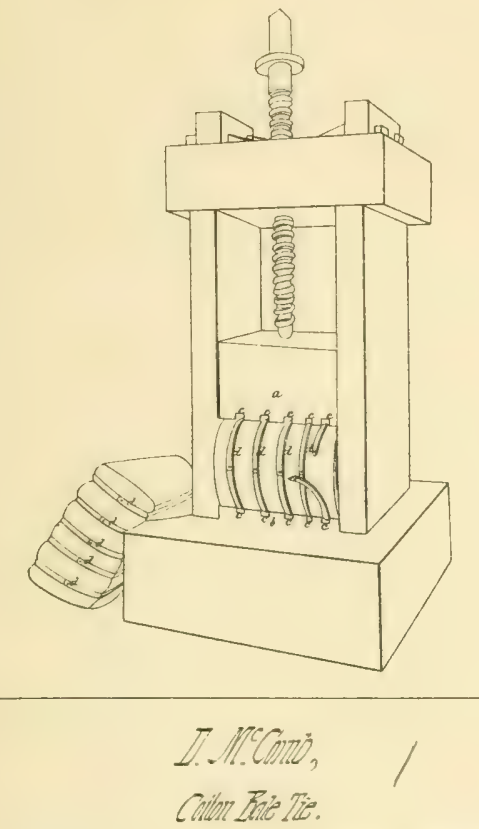

$10,15,14 \%$

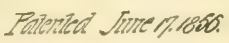
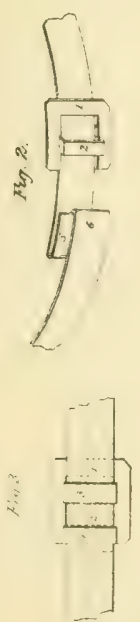

SII. Thito",

Cifon Bale Tie.

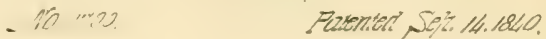
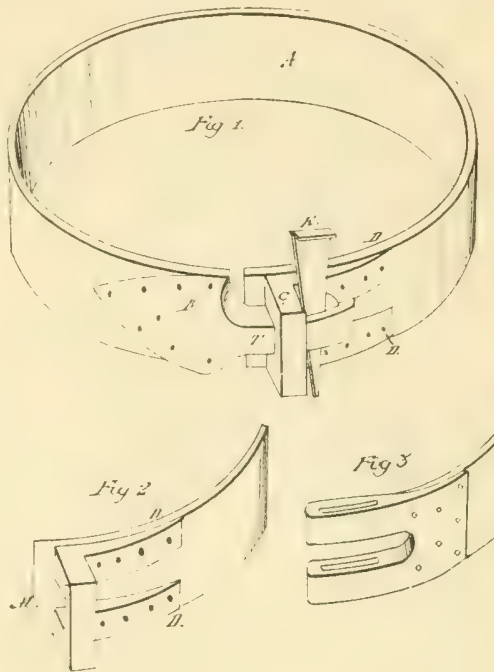

D. McCOMB.

Improvement in the Method of Securing Metalic Ties Around Cotron-Bales. No. 4.993 .

Reiscued July 16,1872 .

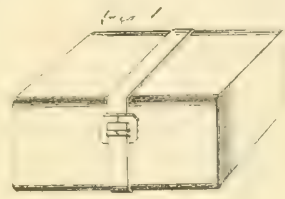

Fig.2.

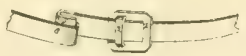

Eig.3.

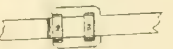

Figit. 


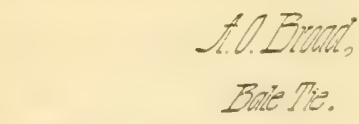

10. 17.485
Faterical Sure 9.185?
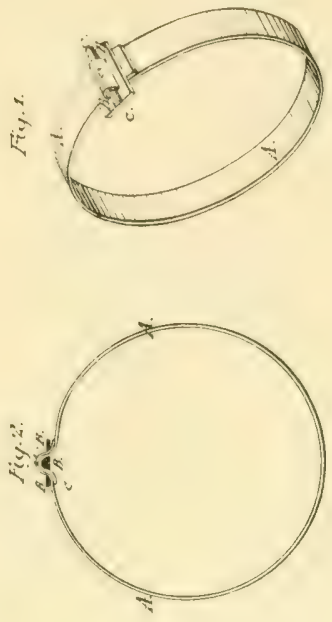

$-10.17 .596$ CPS MENGl".

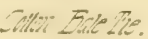

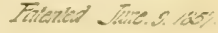
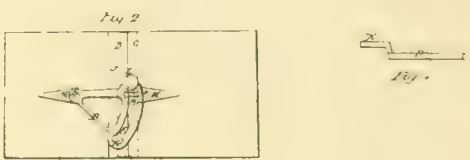

\section{C.J.Provost}

Cotar Bale Tie.

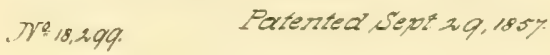
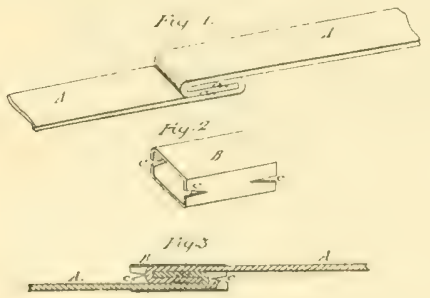

riv, $\therefore$

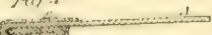

No 5,616 a. Mc COMB, dacd

Balo-Ties.

Relesved Oet. 21, 1873.
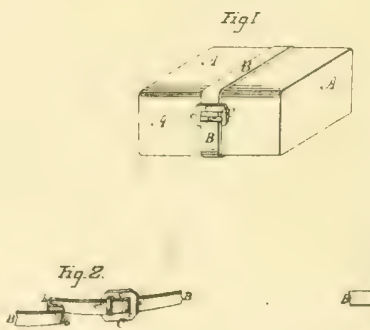

Fig. 3.

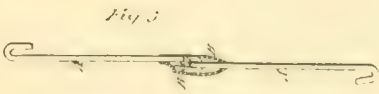



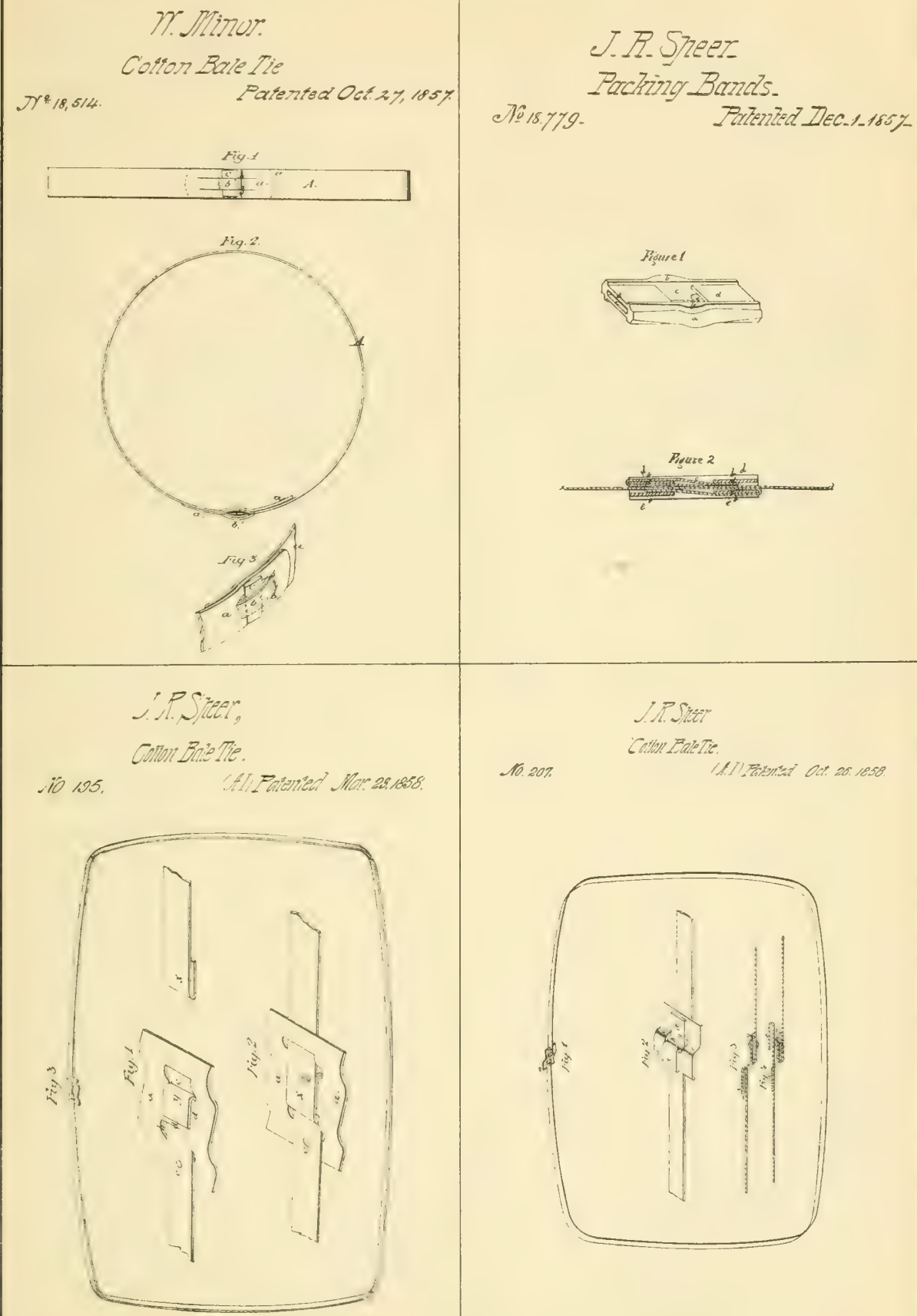


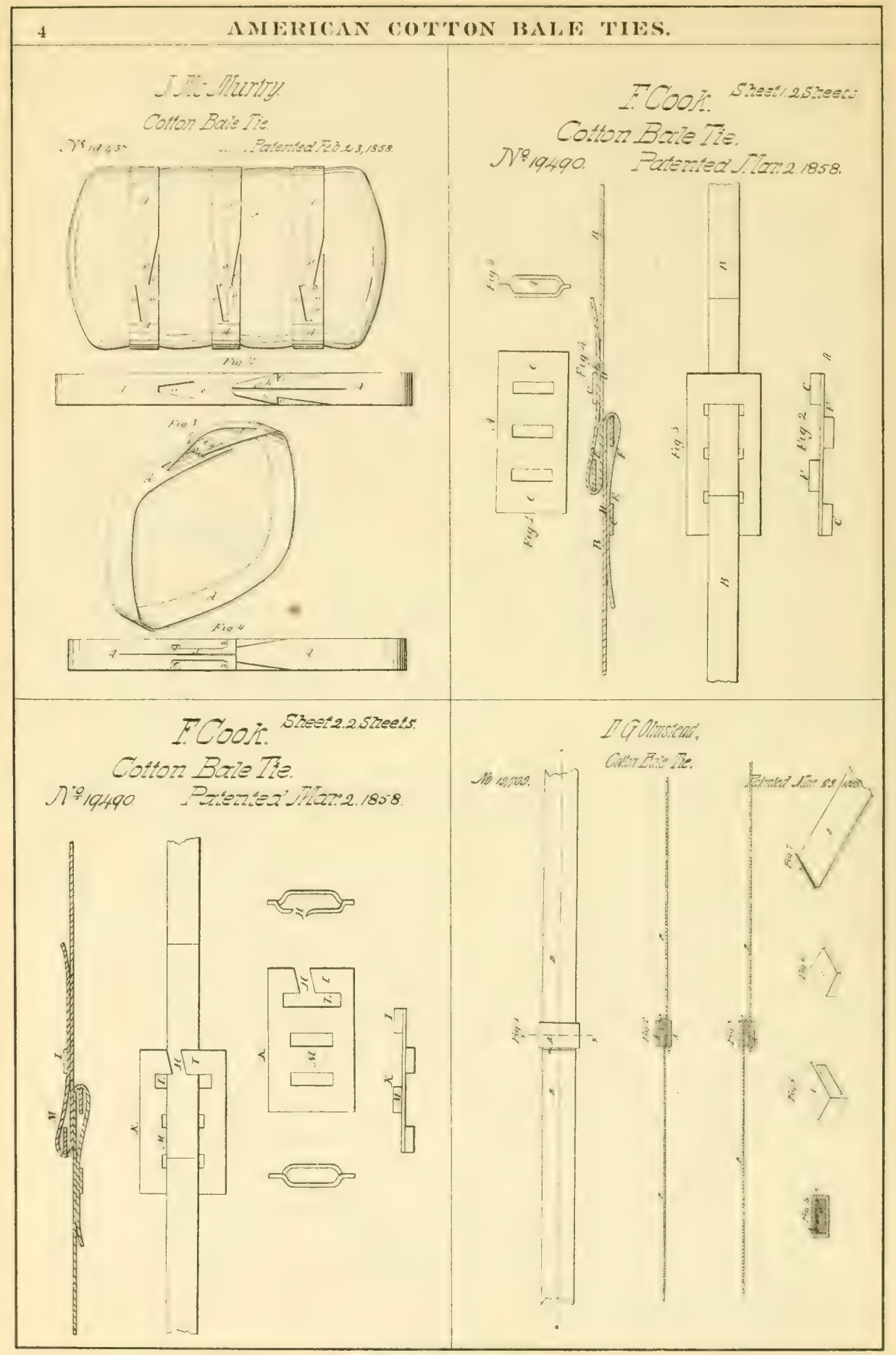


PC. Trocesoll:

Colton Bale Tie

Tro30,311 Patented Thay 18, 1850.
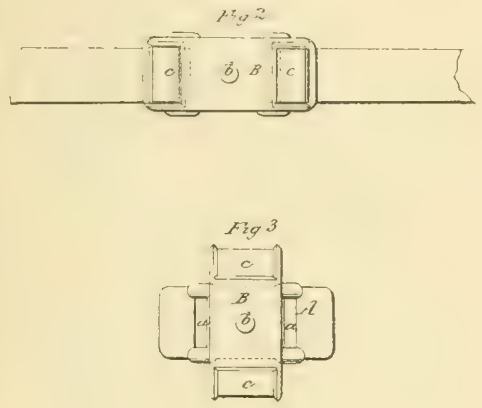

- P-Tarra:

Cottor Bate Tie.

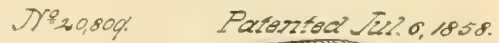

$\Rightarrow$
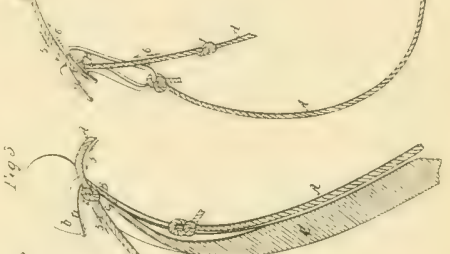

$\sqrt{2}$
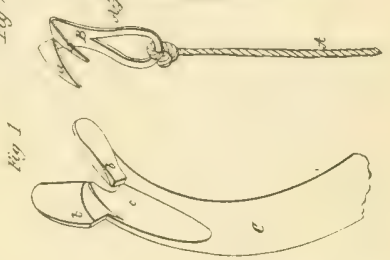

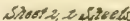

\section{7y. Field.}

Cotton Bale Tis

$\pi \times 21190$

Fatorted fur iy isse.

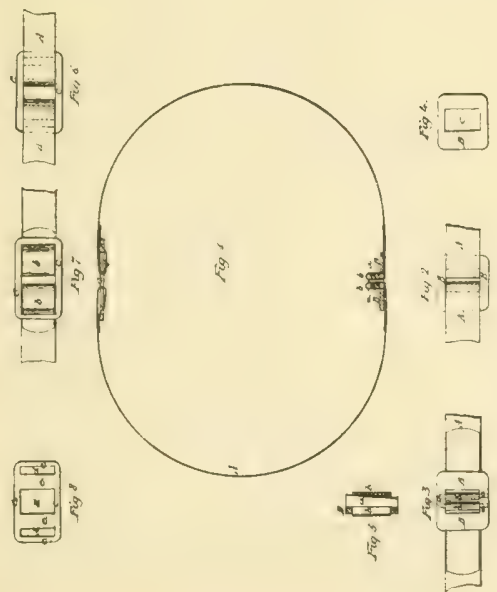

के

$+$

3.
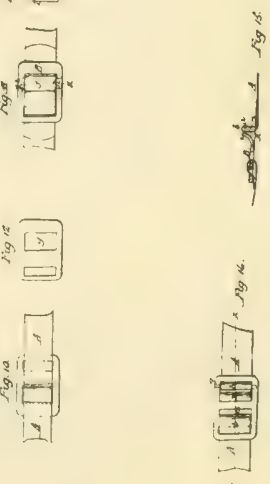


\section{I.C. Plant, \\ Dotor Bale Tie,}

-7P21, 27\%, Faterteci-ing 24, 1958.
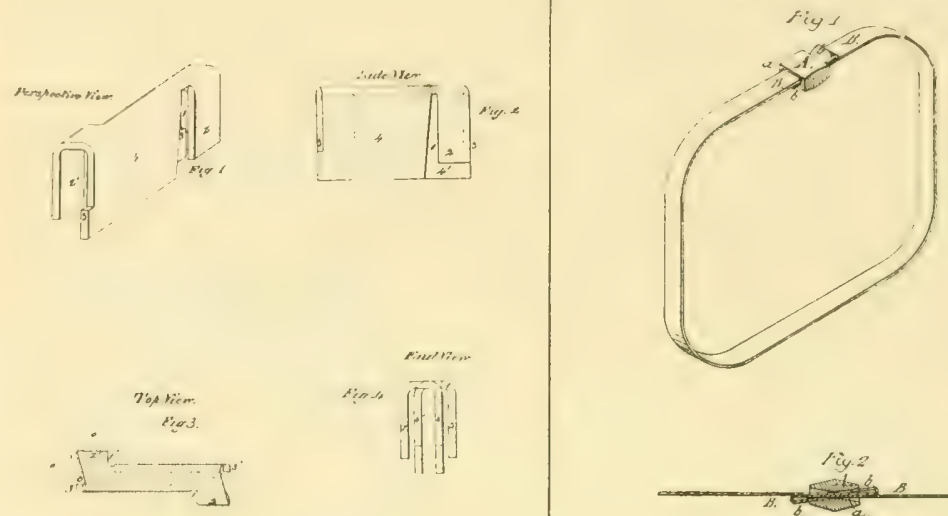

$$
\because \ldots=\ldots . . . . .
$$

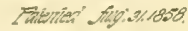

3

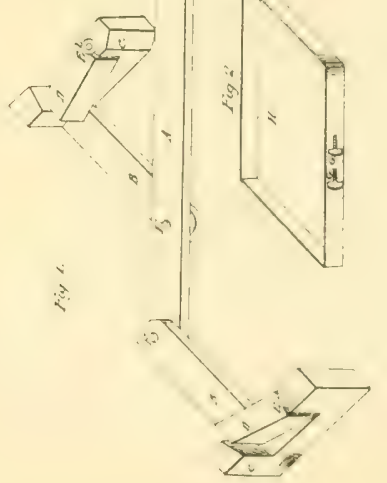

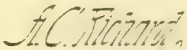

Coltor Bale Tie.

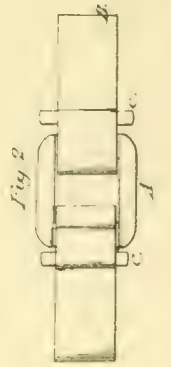



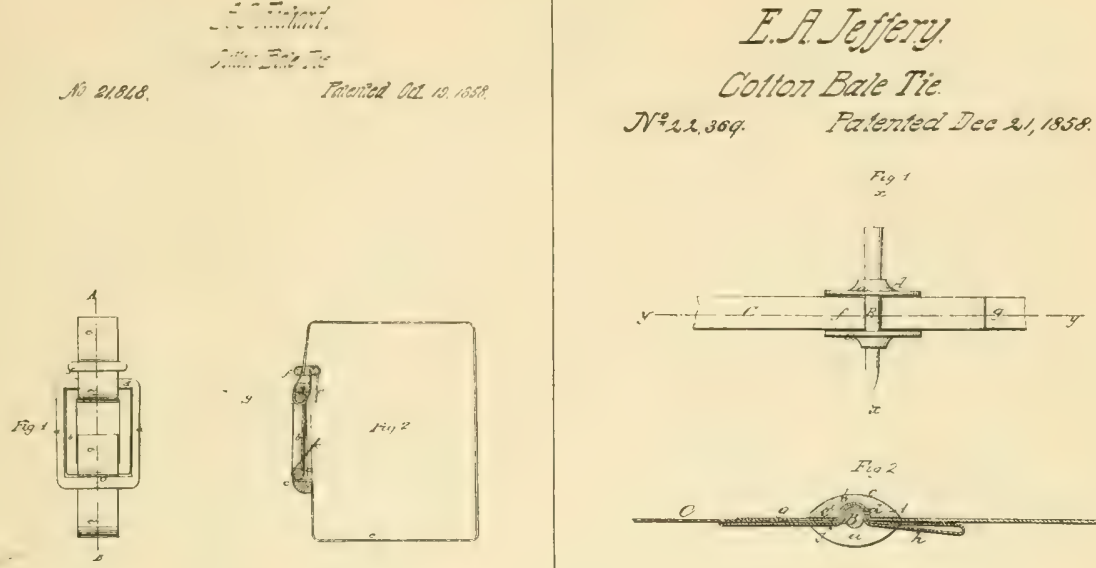

Jigy
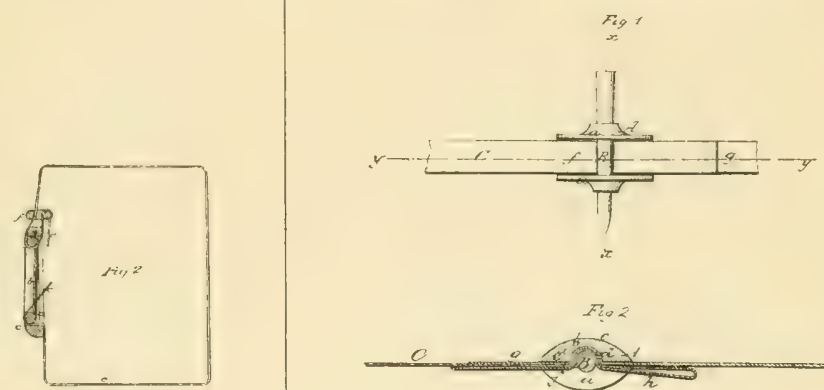

$F: 2$
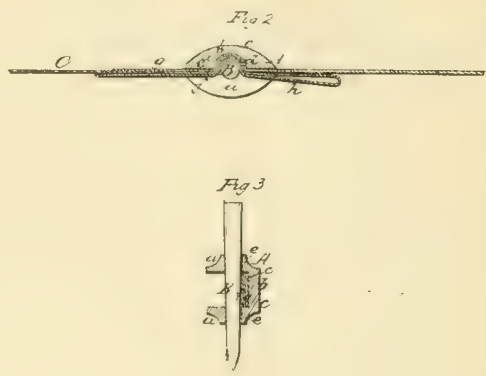

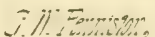

Gurr Büb Tie.

10. 29823.

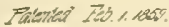

\section{H. Hrowles.}

Cotton Bale Tie.

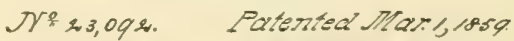
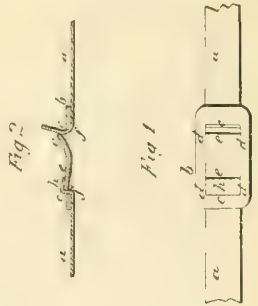

=

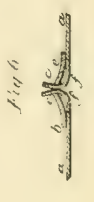




\section{PC Trgersoll.}

Cottor Bale Tie.

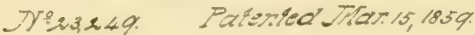
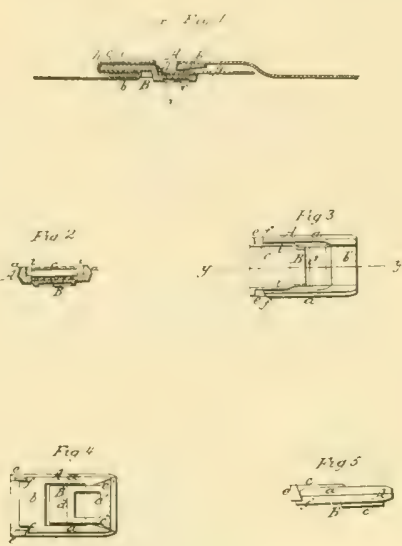

sieet ic:3ecis

$$
\text { G.Brodit }
$$

Cotton Bale Tie

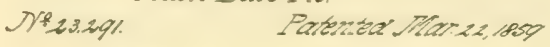
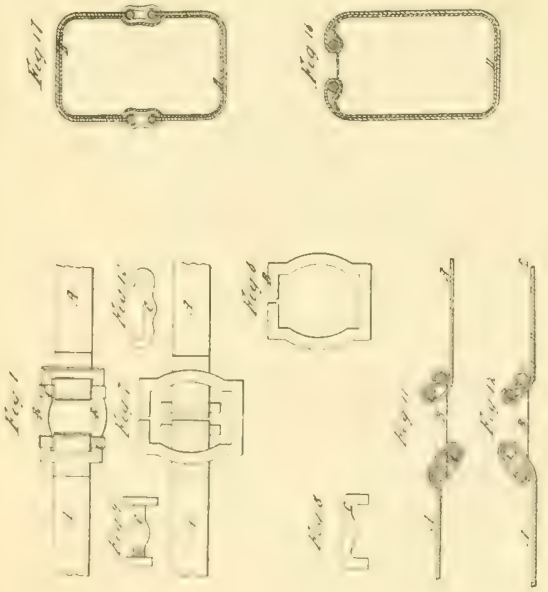

\section{Mantrer:}

Collor Bale Tie.

10. $2928 \%$

Paterier' NGT: 5. 1250?
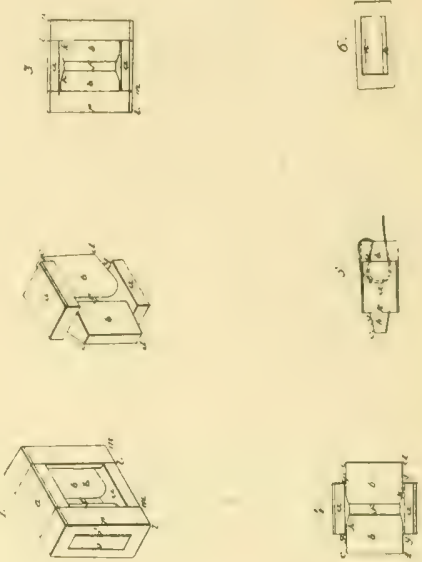

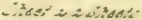

\section{G. Brodie}

Cotton Bale Tie

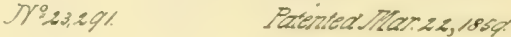

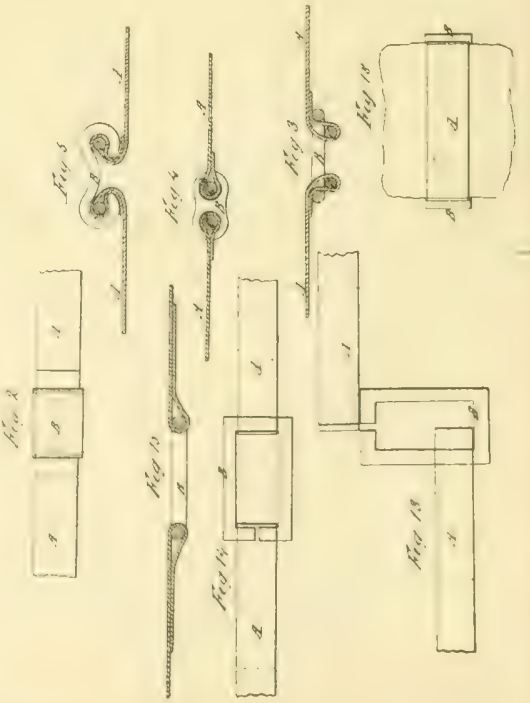



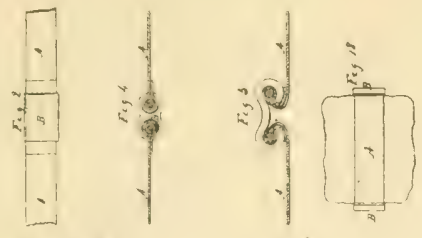

है
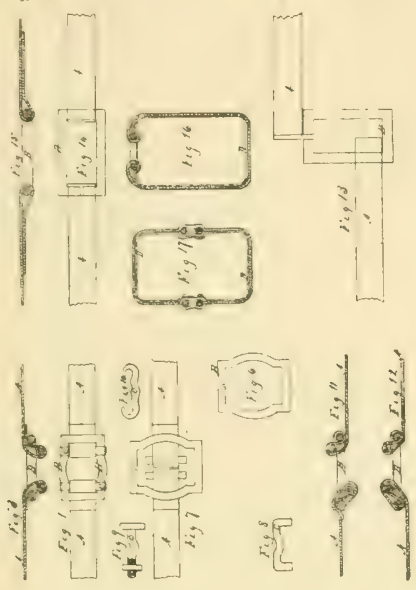

\section{R.Lervis}

Cottor Bate Tie.

Tr:33,444 Patented Fas 5, 1859.

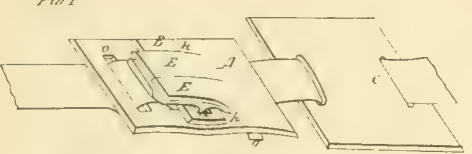

$\operatorname{fig} 2$
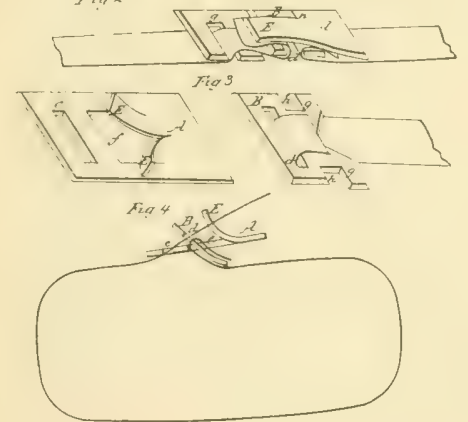

6. BRODIE.

Cotten.Bale Tías.

No. 5,333 .

Relssuod March 25, 1873 .

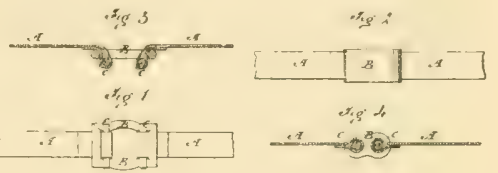

sp.

.xes 5
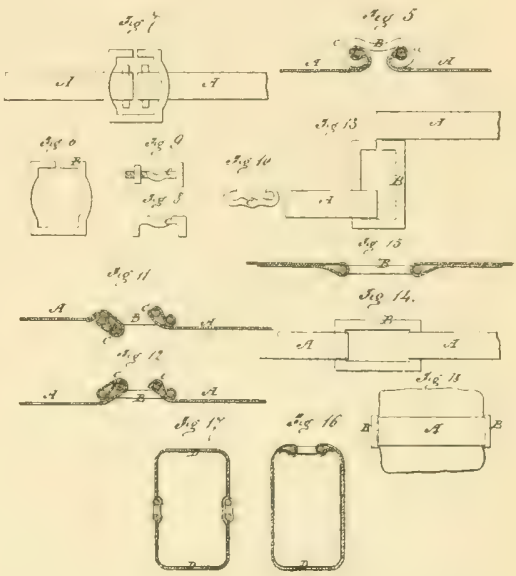

R. LeWIS

Colfor Bale Tie.

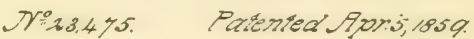

Fig 1
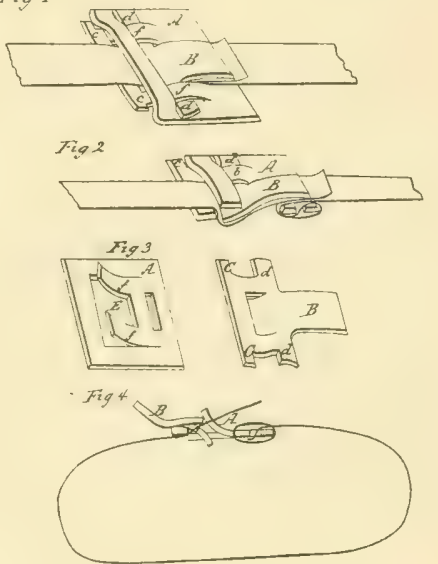
C. Terls,

Colum: Finere.

-in. 29.918
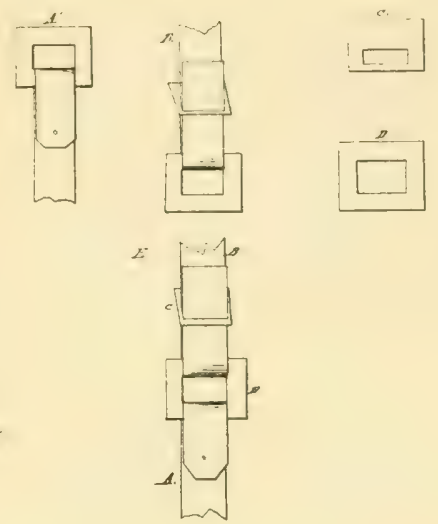

C. Menties,

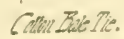

10. $39 \pi 7 \%$

\section{Fintet of 20.1005 .}

rig:

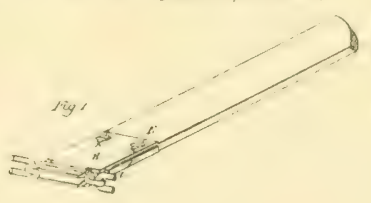

an

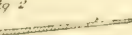

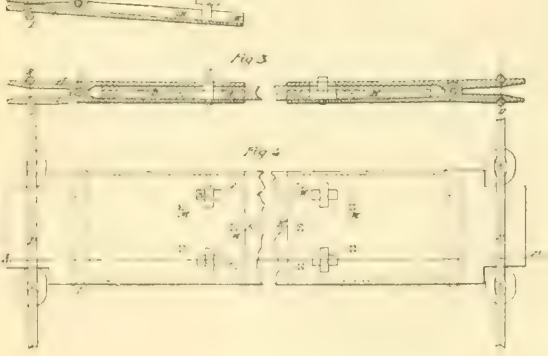

A. Miking,

Gilin Bielie.

Palented this 18. 18:?

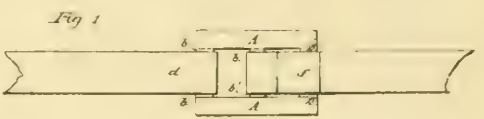

fig 2
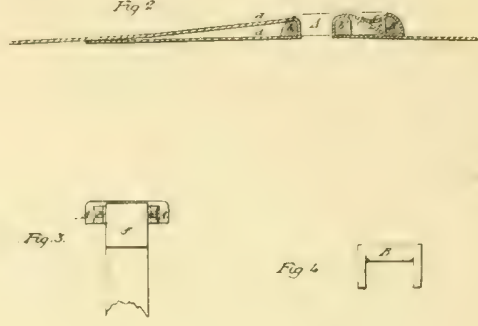

10. 23058

\section{J Jistall}

Cotton Baie Tie.

Tres,940. Fotented Jitay 19,1859.

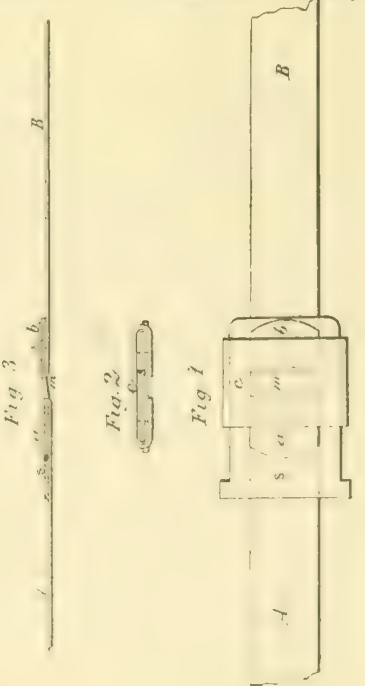




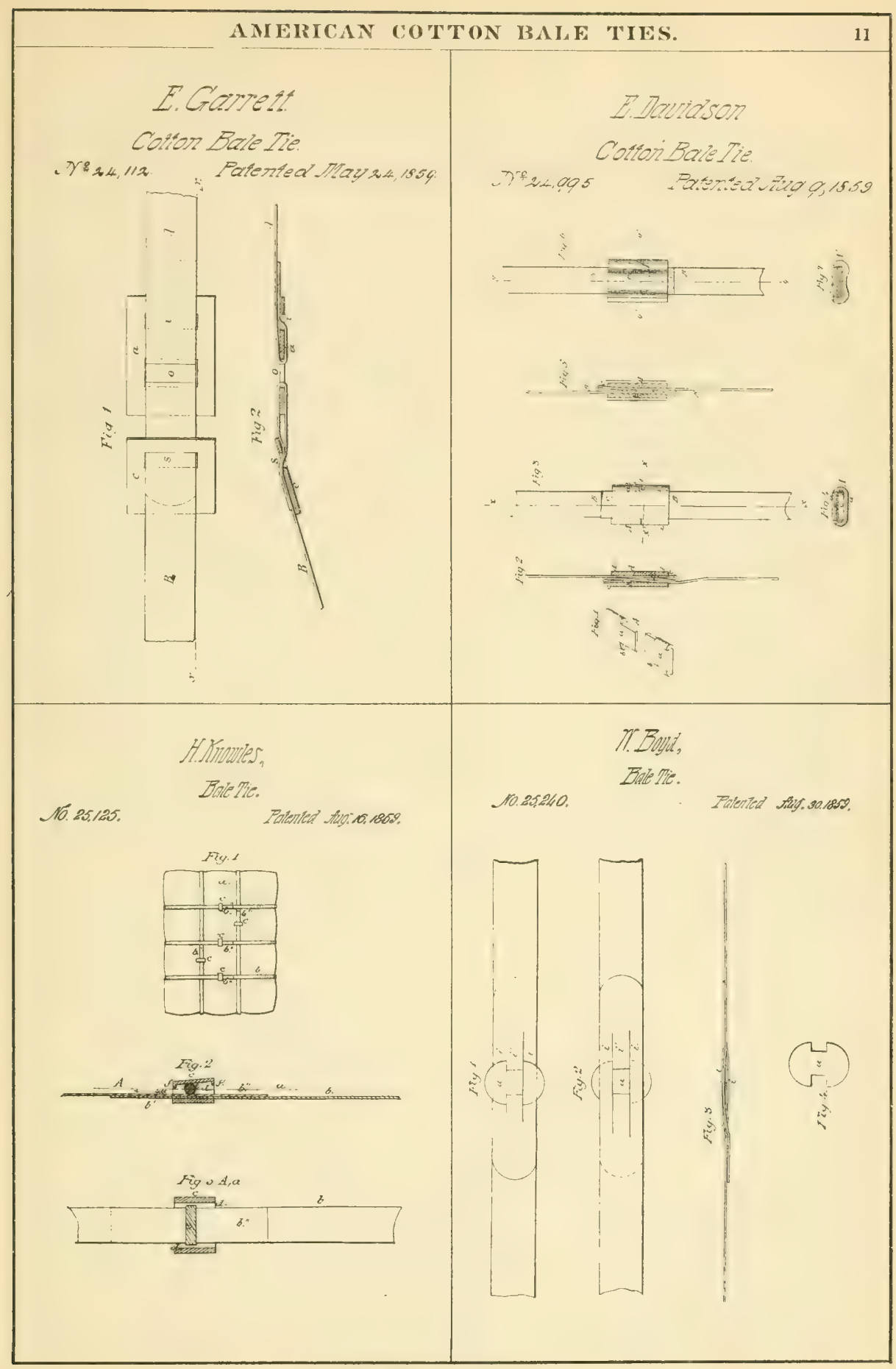



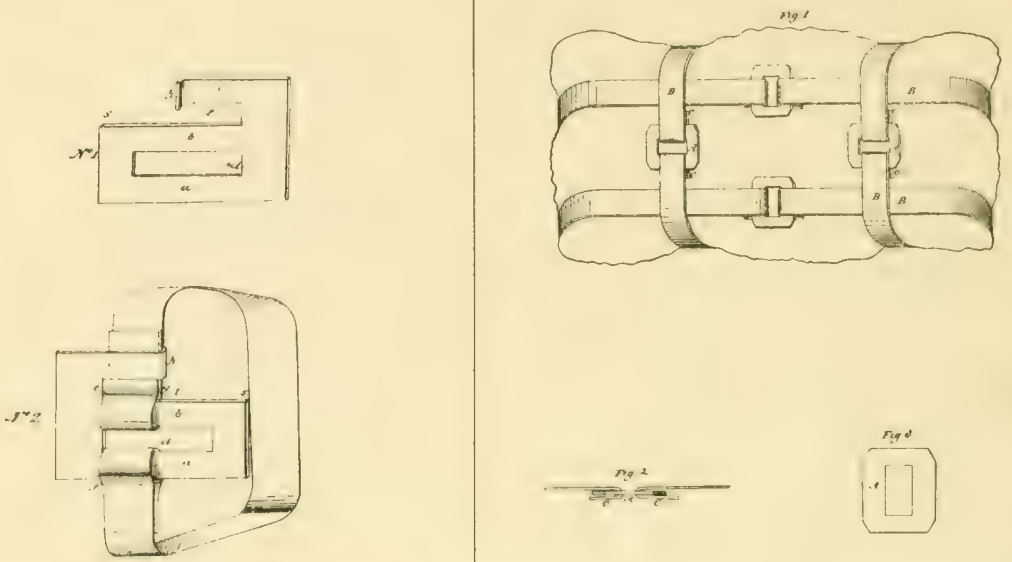

M6 20087

\section{S. T. Butler.}

Cotion Bale Tie.

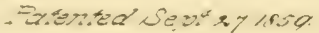

Fiterited Mov: 15. 185s

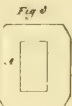

ת. H Hoot

Cotton Bale Tie $\sin 20,434$.

\section{Furastes Colfor Bale Tie.}
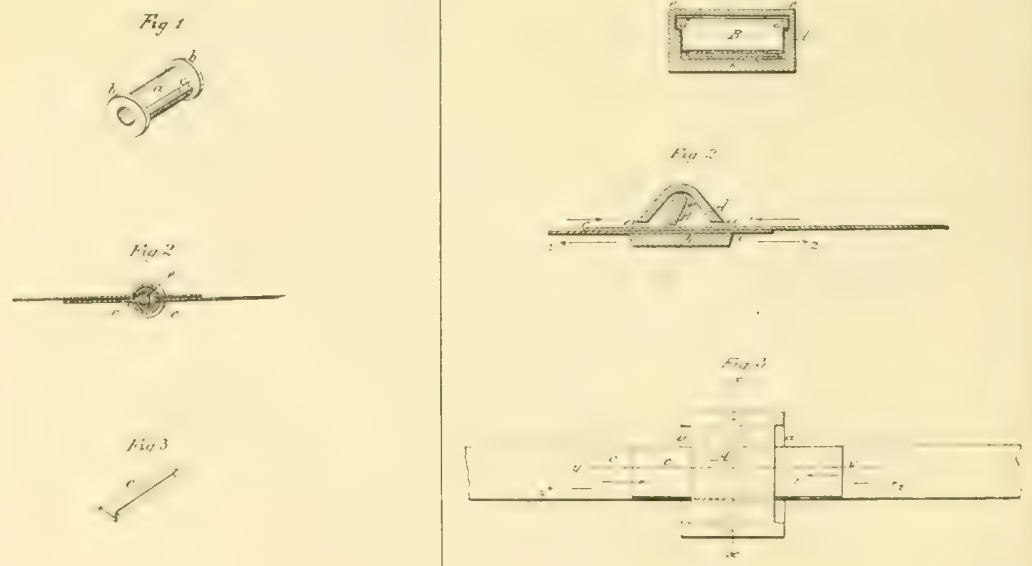
$-7027.000$

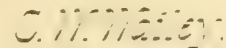

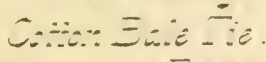
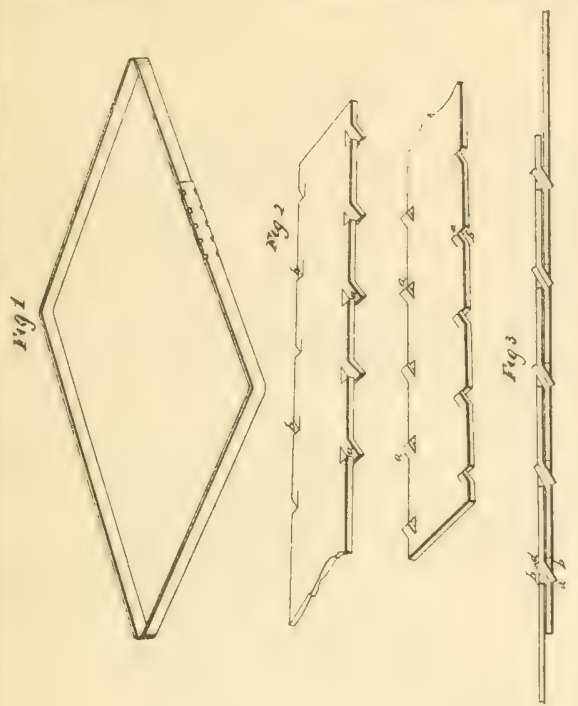

1. MCMURTRY.

Cotton. 8 ale Ties.

No 5.457

Solszued June 17,1873

Fig. 1

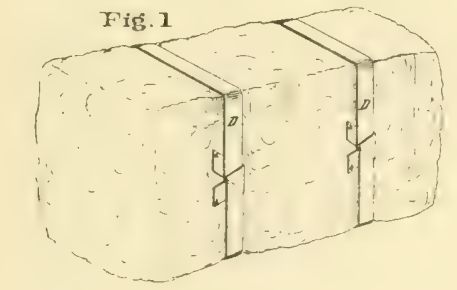

Fig. 2
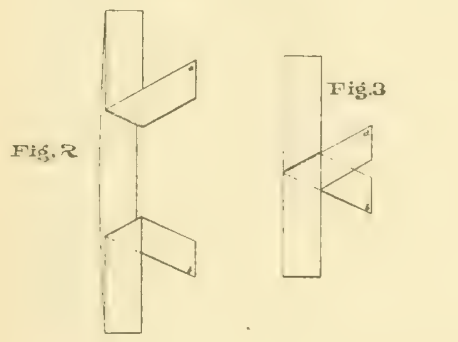

J Jic Jisurty.

Cotton Bate Tie.

Trix\%soo. Patented-Apr: 10, 1800
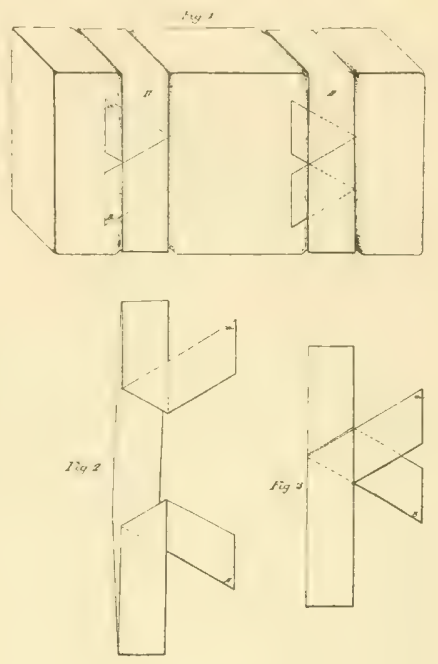

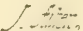

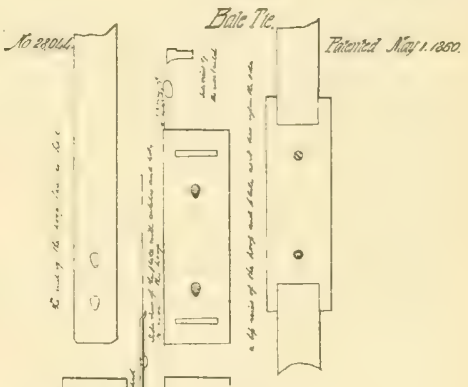


…..........

\section{CHDubs}

Cotton Bale Tie.

Patented May 8, 1800
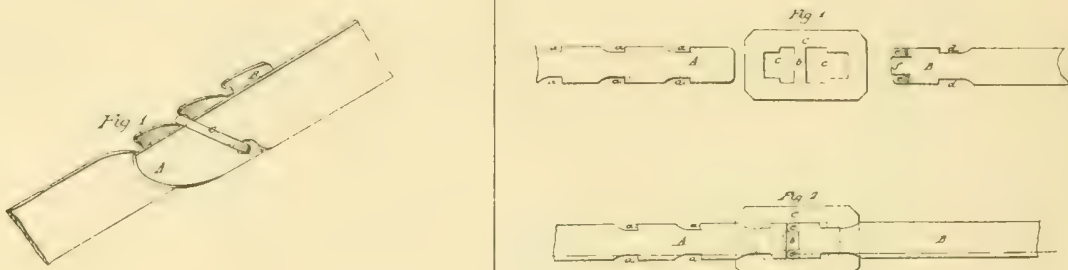

Fig 2

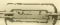

71.S. Loughiborougr:

Cotfon Bale Tie

$7)^{2} 6,18 \%$

Pafented Mays, 1800
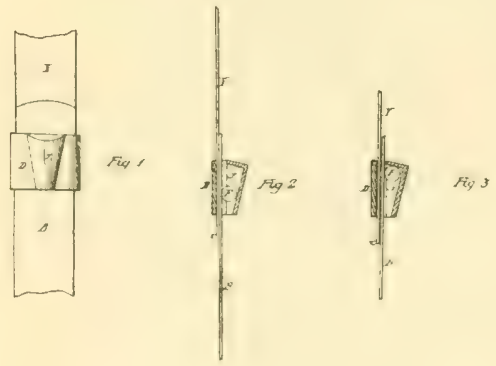

A.P. Nientill S,

Bale Tie.

No. 20392. Palented May 22,18C6. Fin. 2

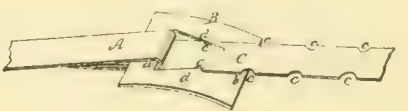

Tiza 2
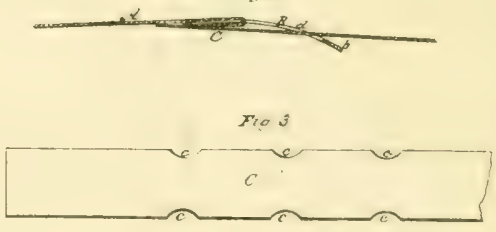

$F \geq 04$

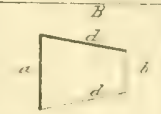




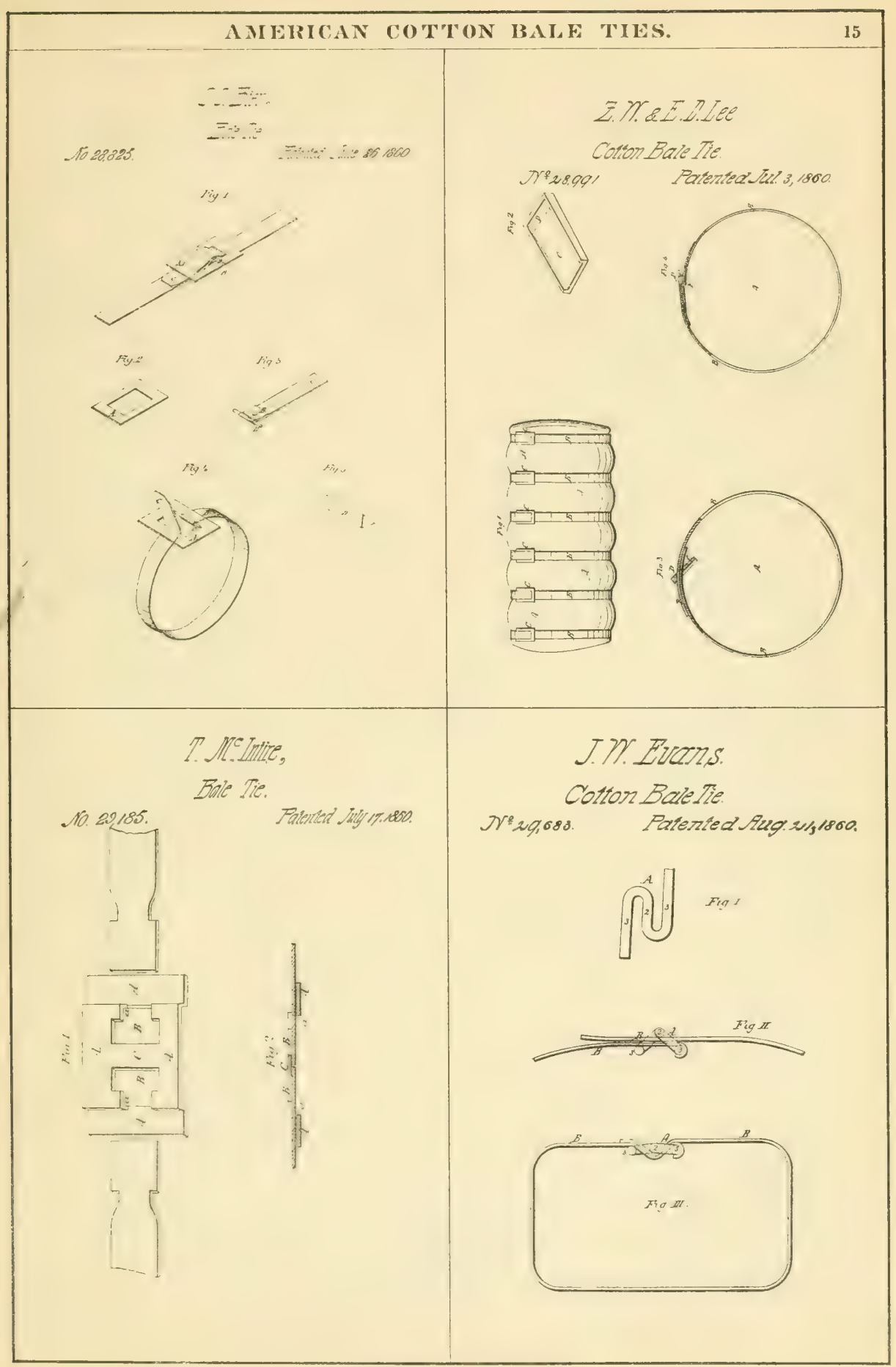




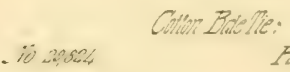

\section{Nos sa180.}

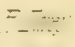

\section{H. STRe,}

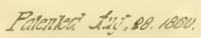
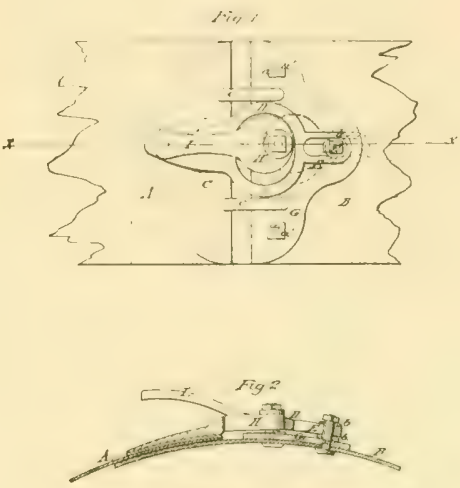

\section{R. Penusict:}

Collon Bale Fie.

Triso, 138 Patentea Sevi25, 1860
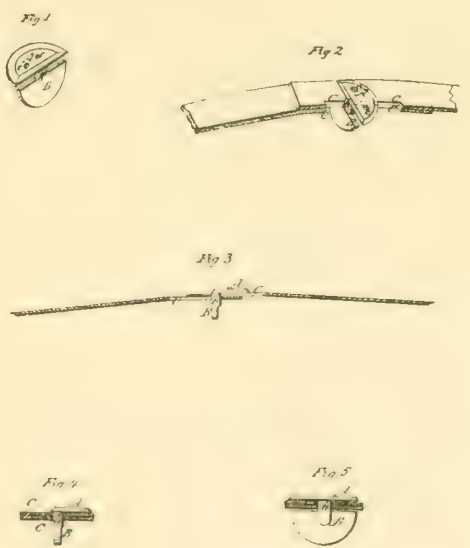
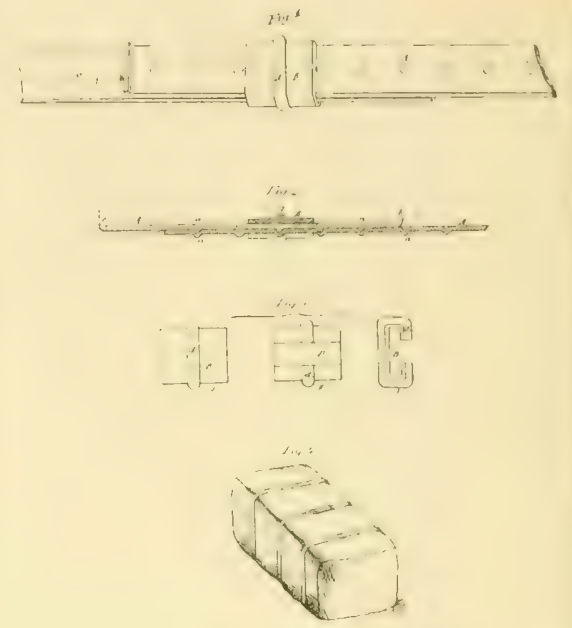

J. Mlec Coms.

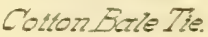

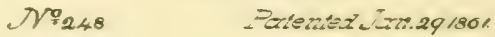
$3 / 252$
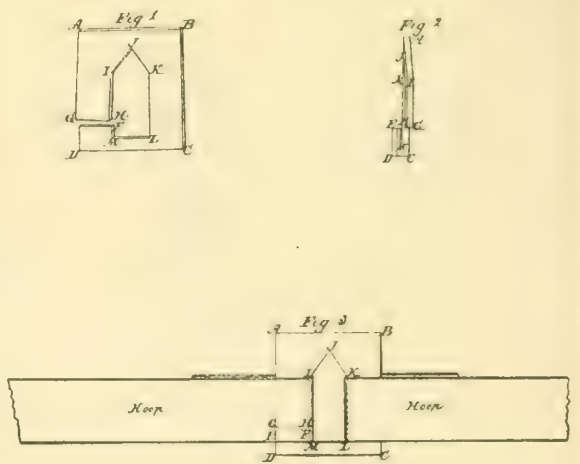


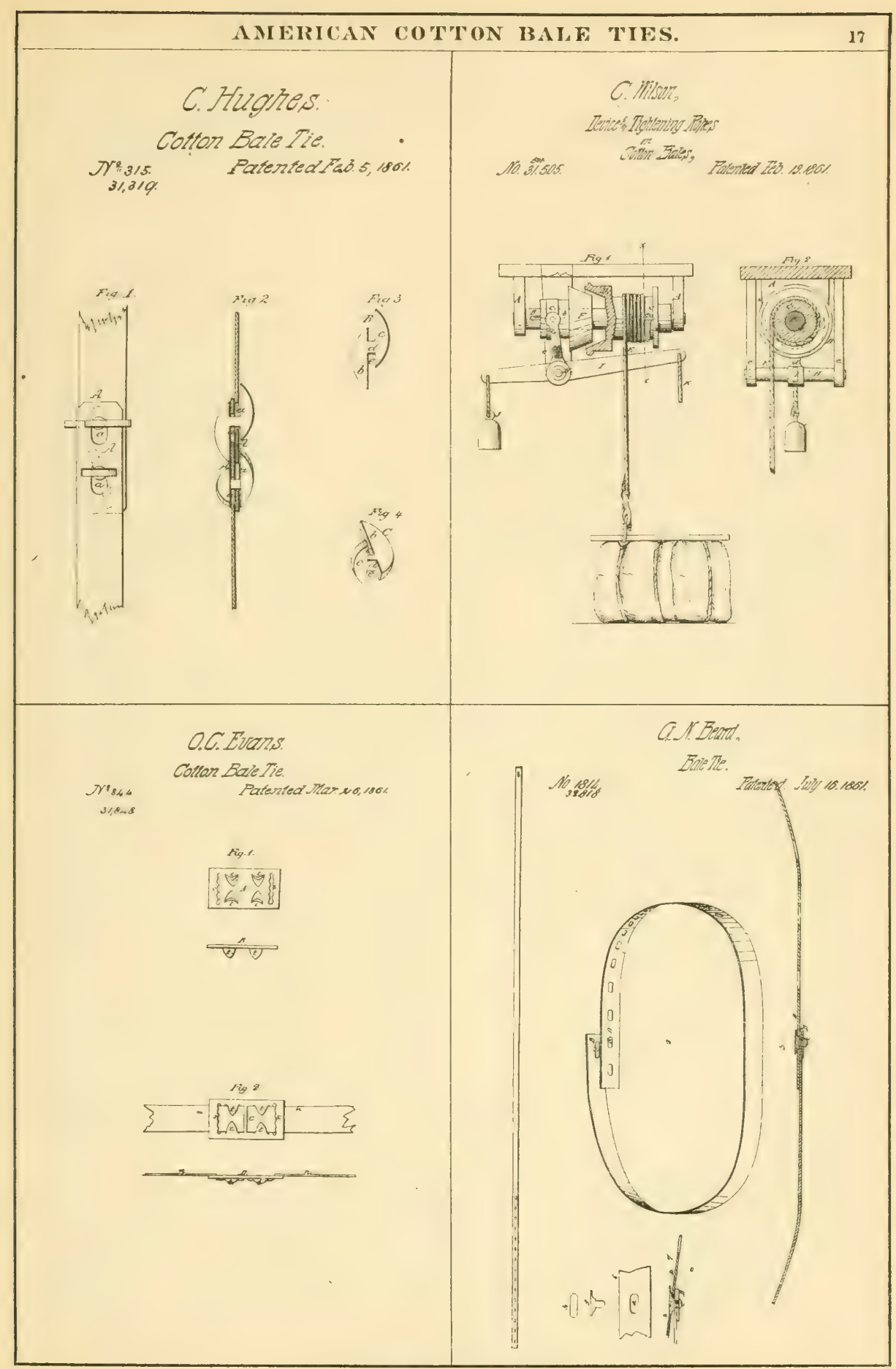




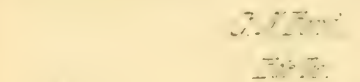

10,3518 Riscent str. 21807
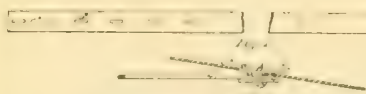

nitis

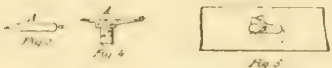

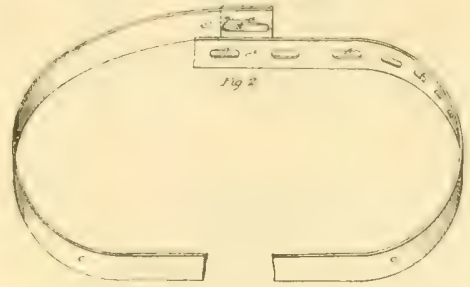

EV V.FSsmann.

Cotton Baie Tie. $\mathrm{J}^{3} 4,288$.

Paterted Par 18, 1805 .

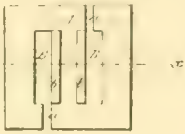

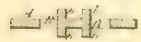

Fin.
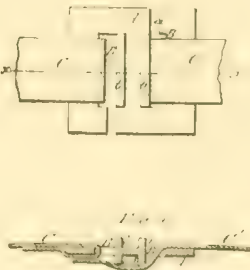

$r m=$
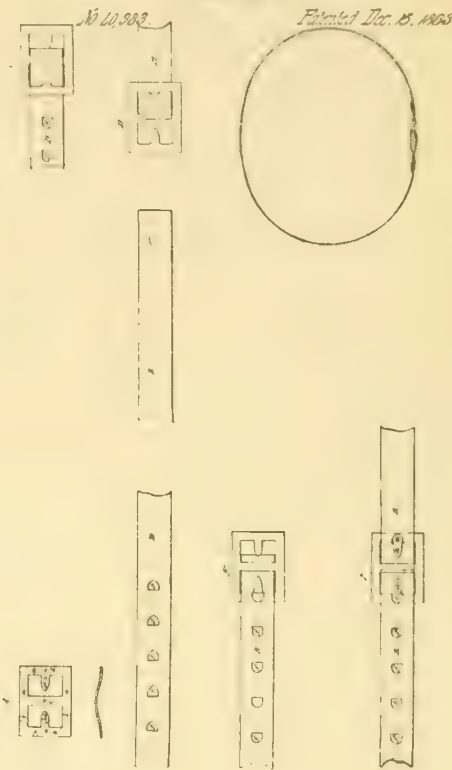


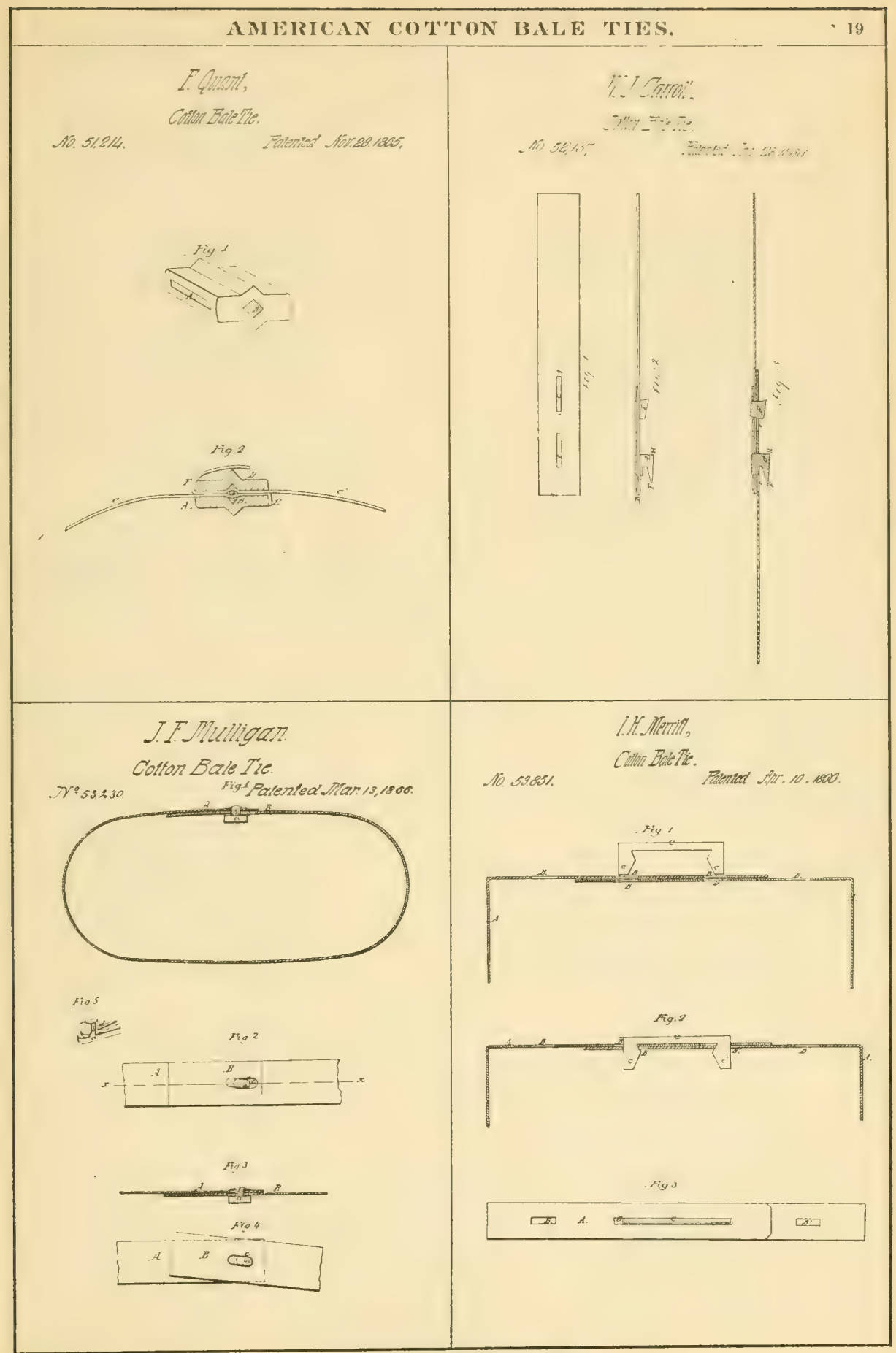




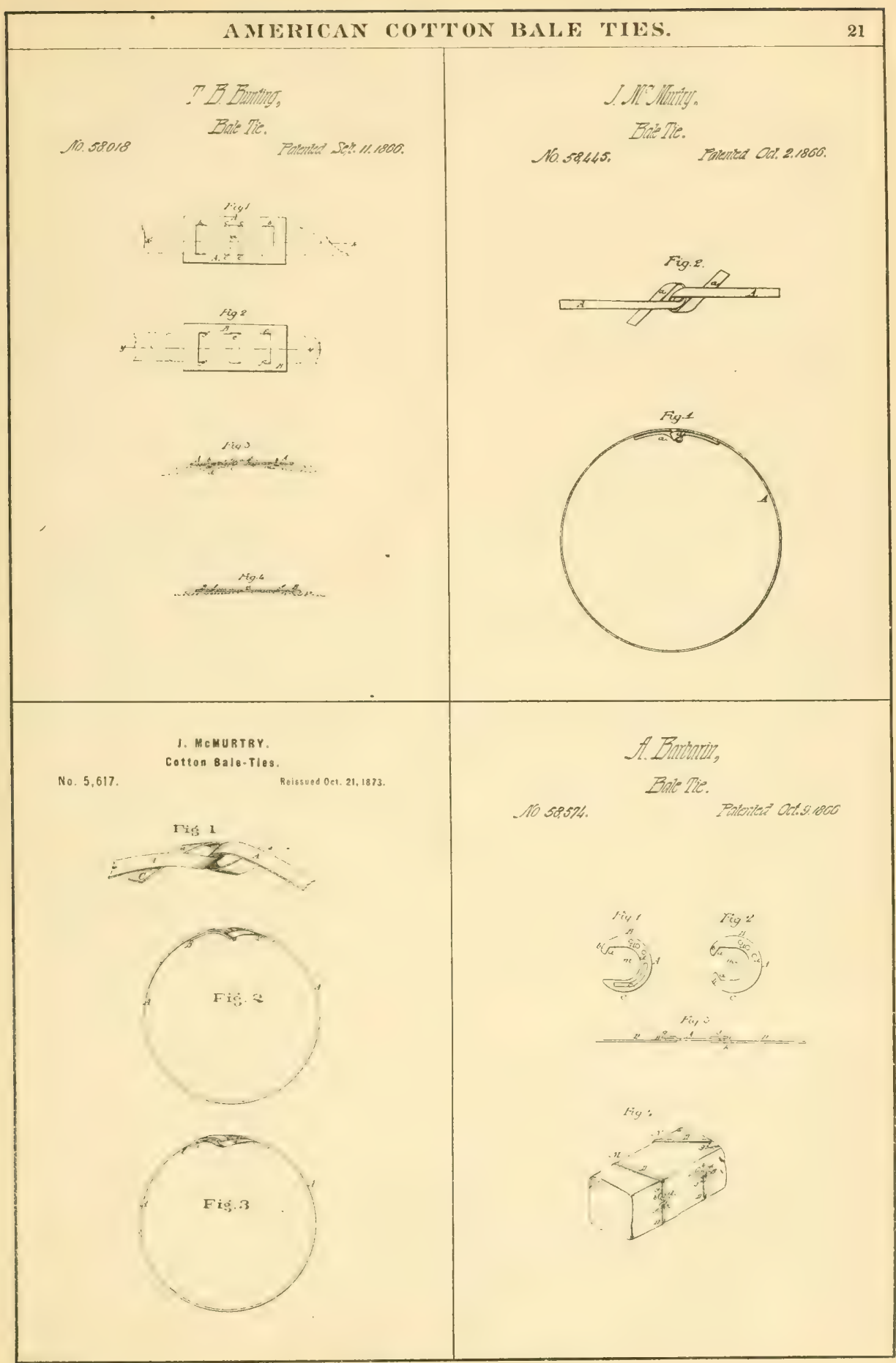


$\therefore-\cdots=$ E............

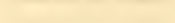

Corlor Bale Re.
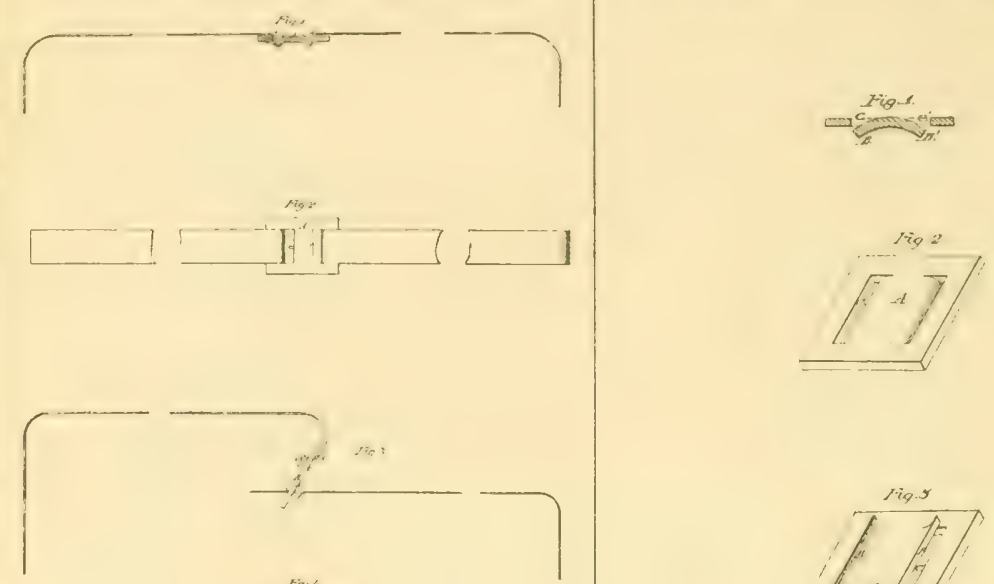

$10.58 \% 0$

\section{Bate Tie. \\ G. Fent,
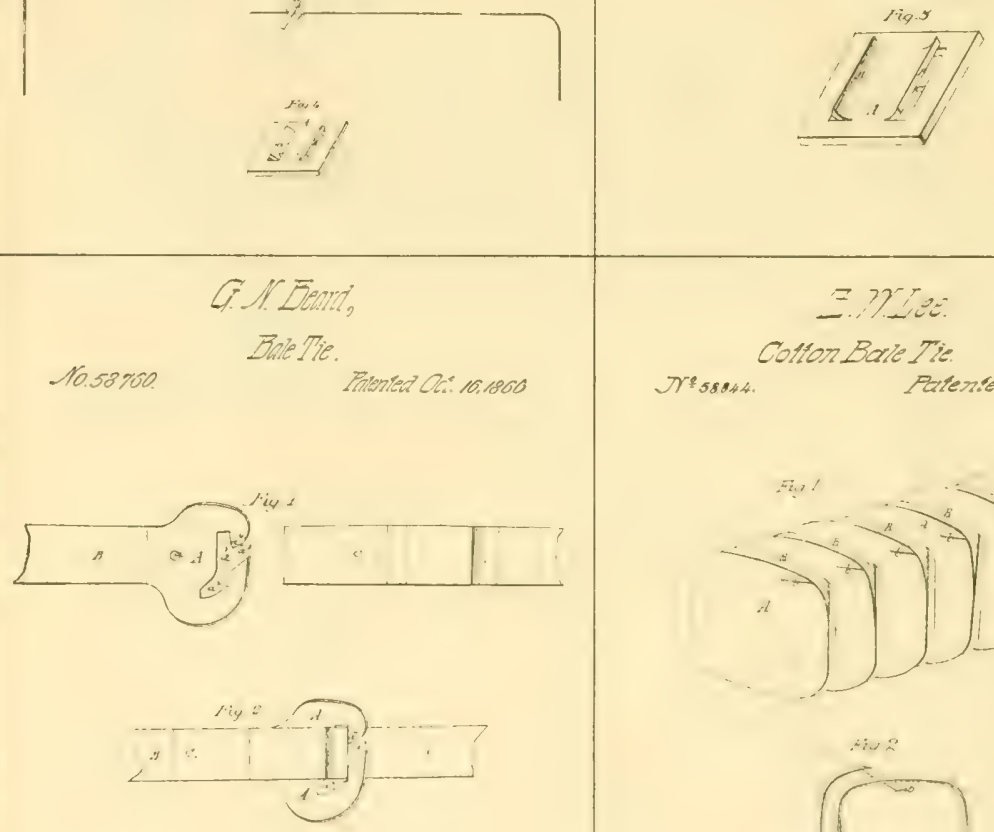

$$
=7720
$$

Colion Barle Tie.

Trissunt. Patented Oet 10.1850.
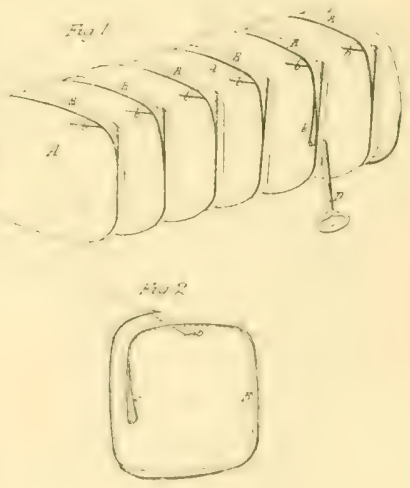


\section{Z.M. Lee \\ Cotton Bale Tie. \\ Tre 2,449. Feissued Nars, 186\%.}
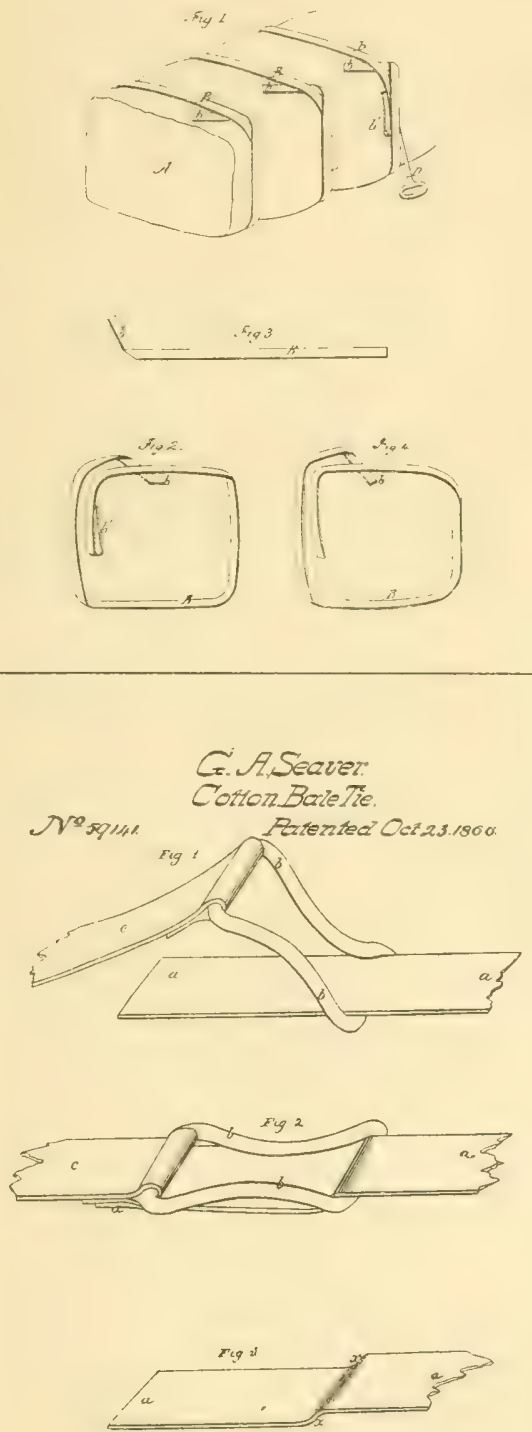

\section{JHGridley.}

Cotton Bale Tie.

Trisq.00\% Faterted Octes, 1800

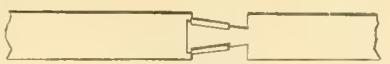

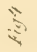

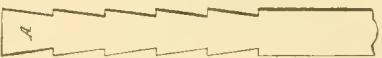

है

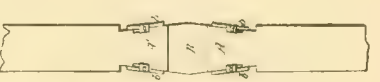

这

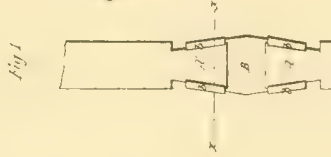

C. Smett,

Bale Tie.

- Ne5q, 144, Patented Oc:233,1866.

$F_{i g} 1$

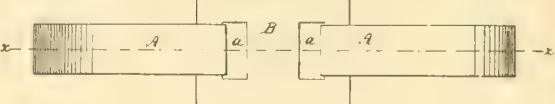

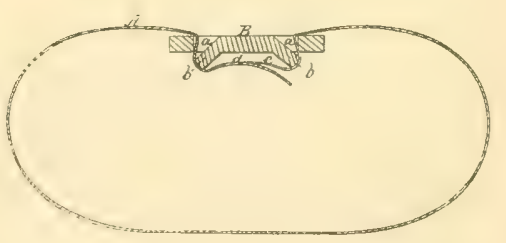


ZHARLES SWETT.

Improvement in Method of Fastening Colton.Bale Ties.

No. 4,896

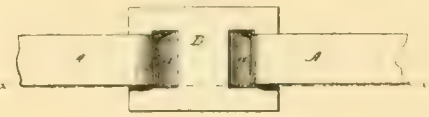

†iุ่
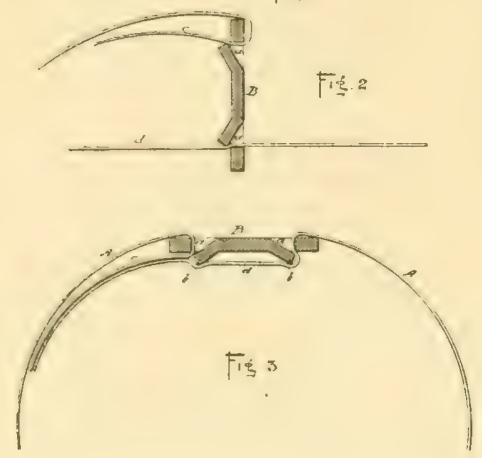

2. Sientis 2

STMComb

LiO $5815 \%$

Ente Tie.

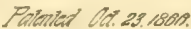
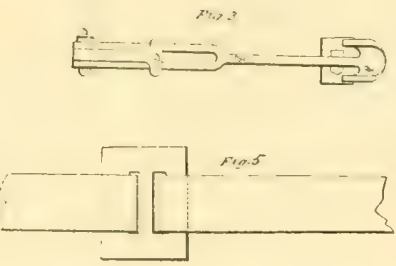

Fis

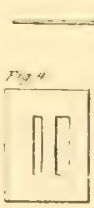

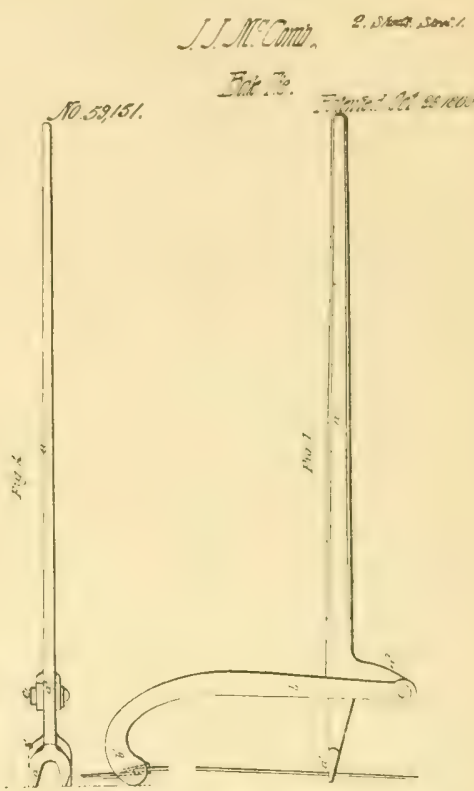

J. Mle Comb.

Cotton Bale Tie.

Tre54,152. Faterited Oct 23,1900

ri.,

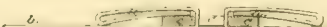

$>r_{y}:$.

mand $\Rightarrow$ 
IF Milligan: vineet's:

Cotton BaleTie.

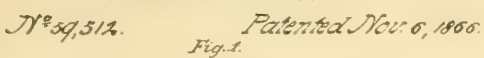
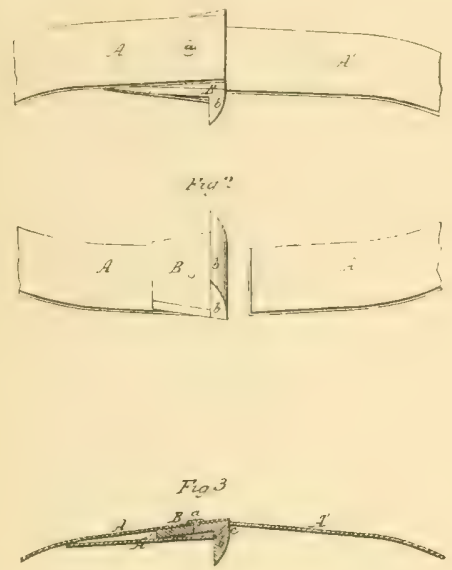

10. 59.293

\section{A. Taridar,}

Ontar Buic Tie.

Poremes Cir soreos.

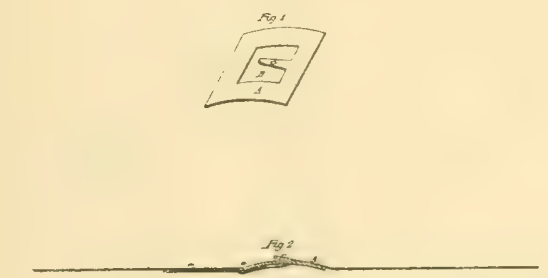

ryg 2
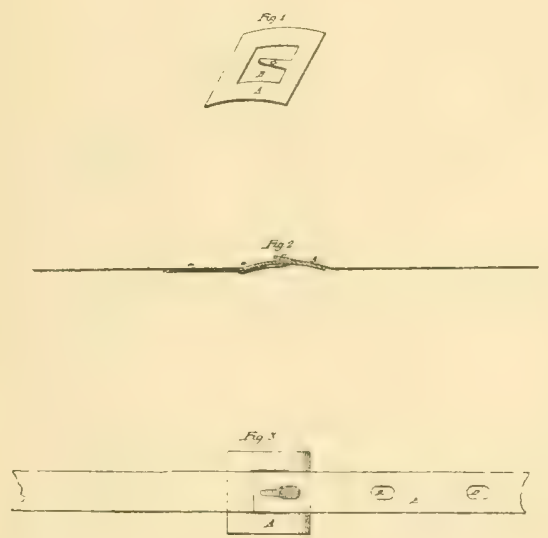

J.P. Mlitligan.

Sheerz,

estevis
गु?59,512.

Paterted Dou 0,1806.

$\mu_{q}$

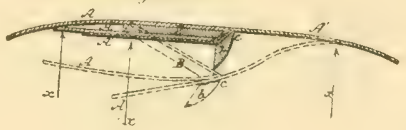

27. Oriors.

Coltan Bate Tie.

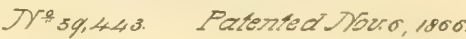

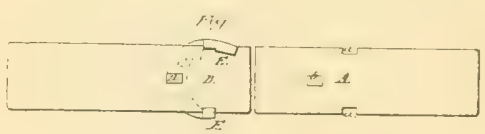

Fis.

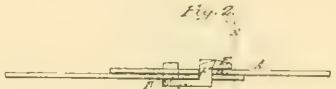

Fig: 
AMEIRICAN COTION BAIA ITIS.

Shifeadiberg

cons. Bus: Tic

r.6015\% ibtertecilie:

4,1800

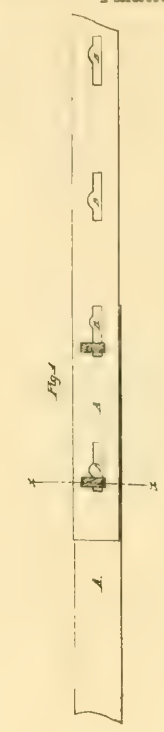

in

\section{R.G.Lalling.}

Collor Baic Tie.

Triopsis Palented Dec is, isso.

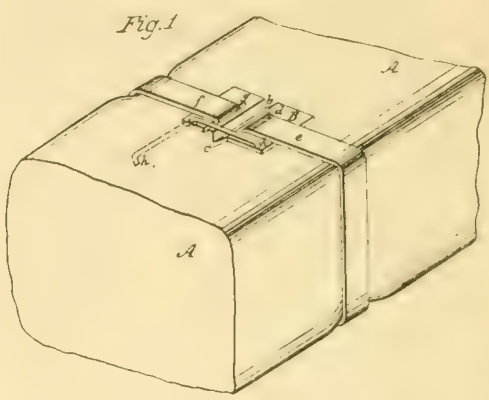

Fig. 2

(1)
R.G.Latiting.

Cotton Bale Tie.

Mroys\% Paterted Jarsis, $180 \%$

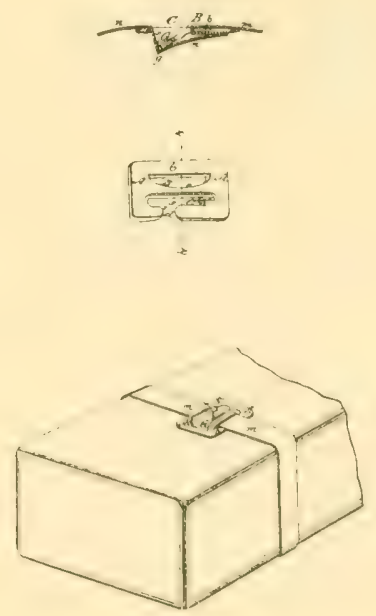

HFassman.

Cotfor Bate Tie.
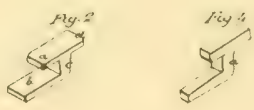


\section{H. Passmas? \\ Collon Bale Tie.

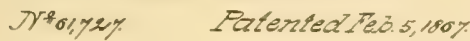

Fig. 1
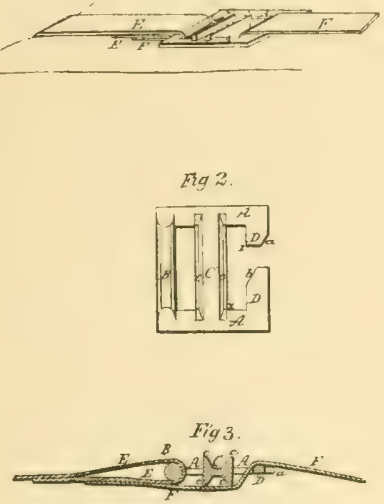

STreqe

Collon Baititie.

10.01808.
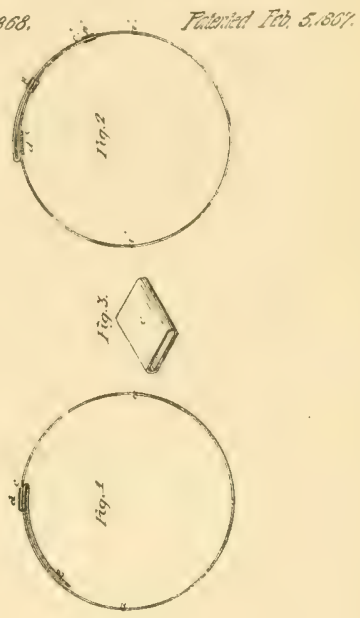

Jinight.

Collon Bale Tie.

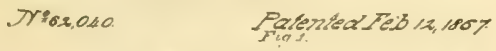

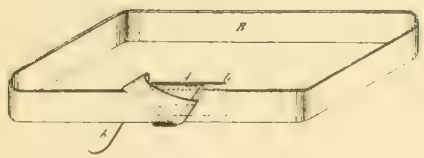

Fin 2

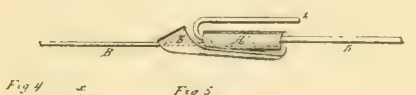

Figy

Eus 3

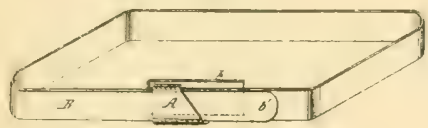

$\checkmark$ Reinecter.

Collon Bale Tie.

10. 69,008.

Fatentad Fe' 12.00\% 


\section{H. Fassmann. \\ Cotton Bate Tie.}

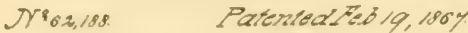
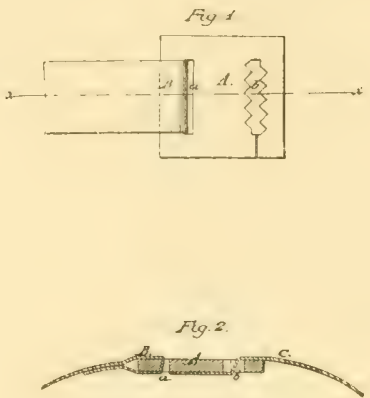

SRerse,

Collon Bate hile.

N10.63955. Faicented FES. S5. 1807

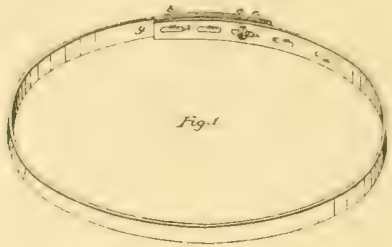

[y

rig 3

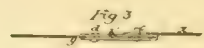

C.M.PE:ty,

Cotbon Bale Tie,

NPe62,560,

Collon Bale Tie.

Tres,400 Paterited Feb.26,180\%
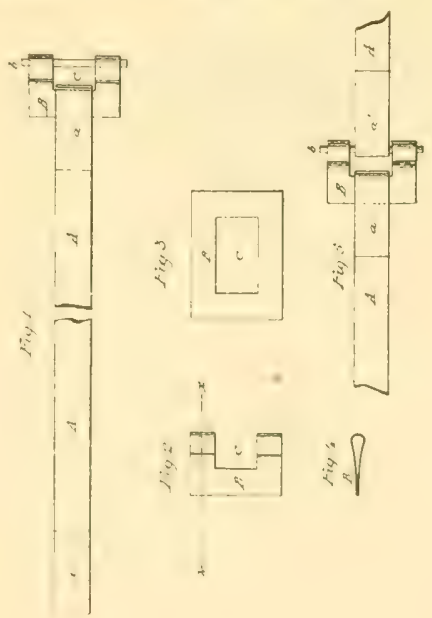

$\therefore \frac{4}{8}$

$\approx 2$
Paterted Mars; 1867

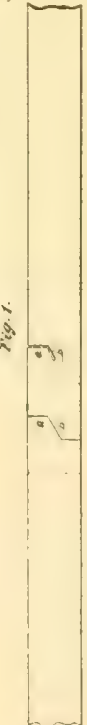

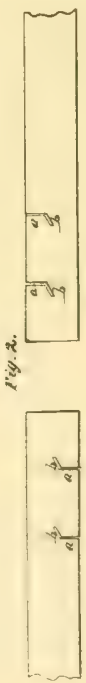




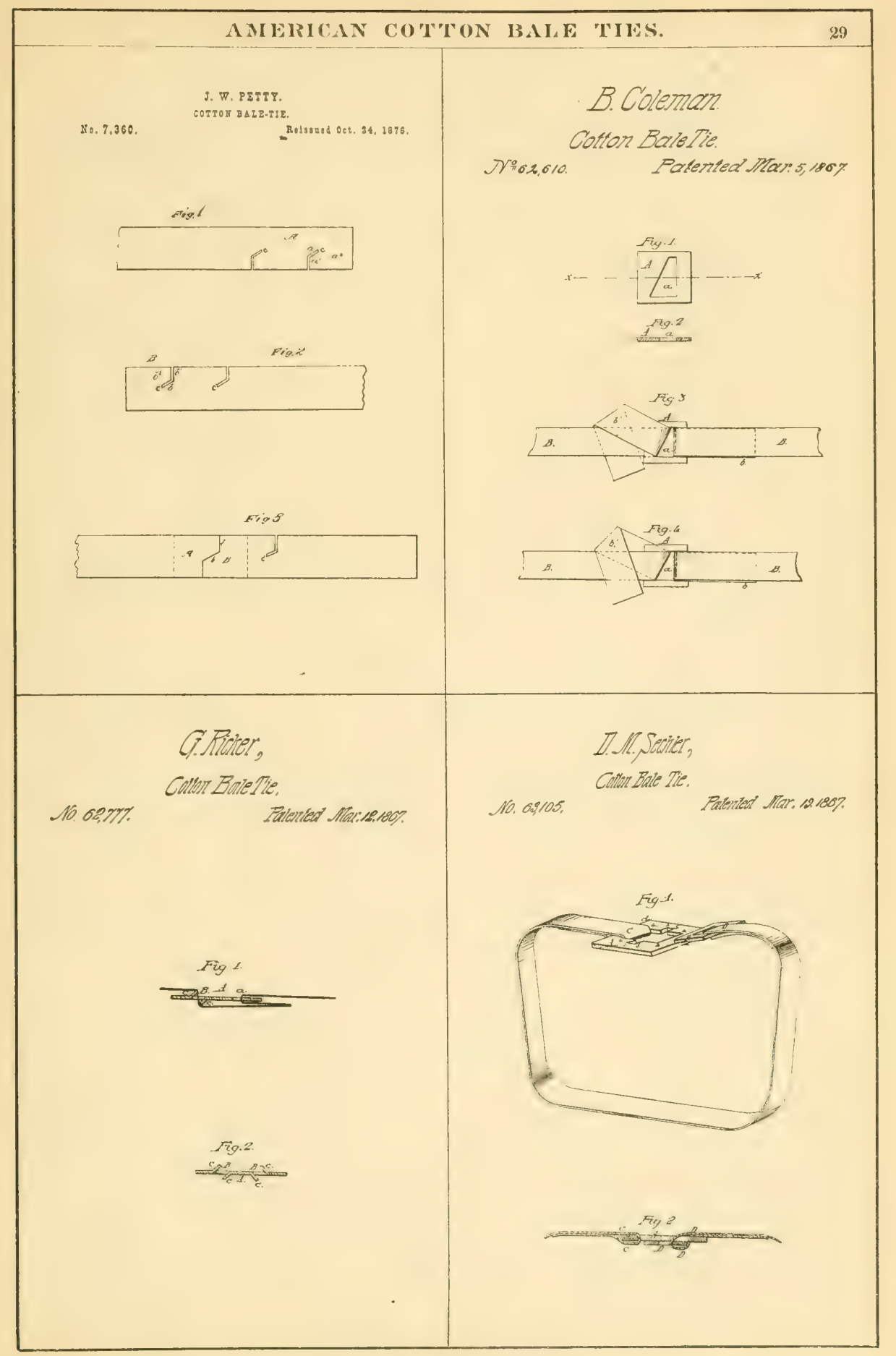

AM. PHOTO-LITHOGFA PHIC CO.N YIOSBOMES SMACESS 
Nó, Cortos Ball Tit.

Ollactariel.

$\therefore-\cdots$

No.03100.
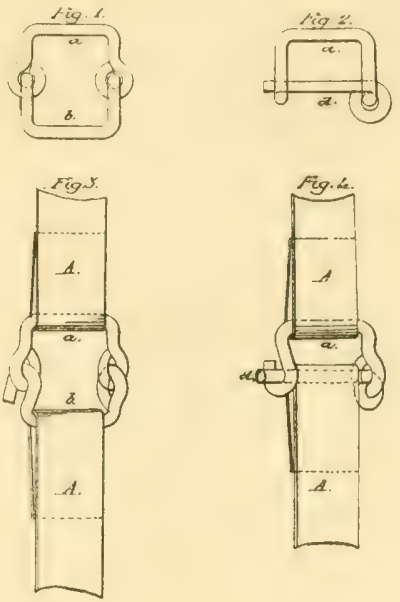

Folented Nar:26:1007

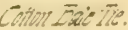

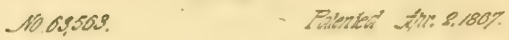
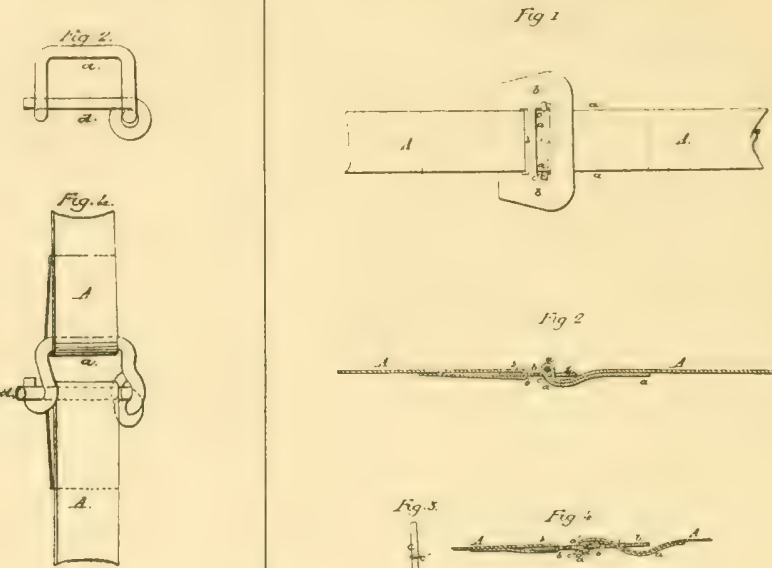

$\sin 2$
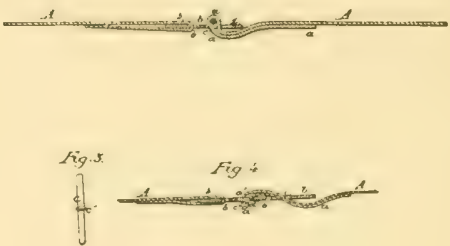

Na $0.38 \%$

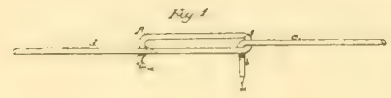

Fig:
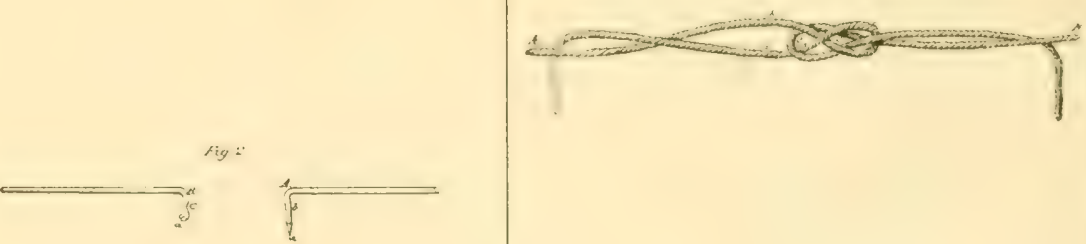


\section{SRogers \\ Cottor TBateTie.}

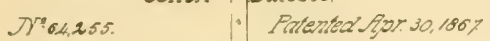

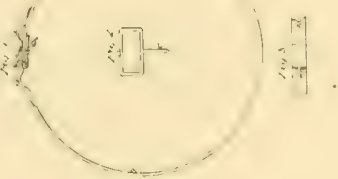

M.P. Manty,

Bale Tie.

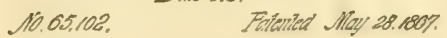
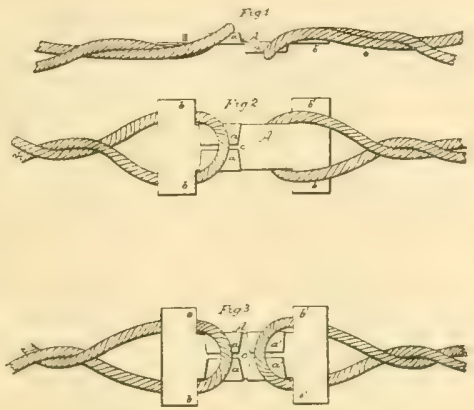

$\operatorname{rg} 4$

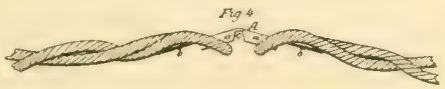

7). Onians.

Cotton Bale Tie.

ro64.096. Paterted Mray 14, $180 \%$
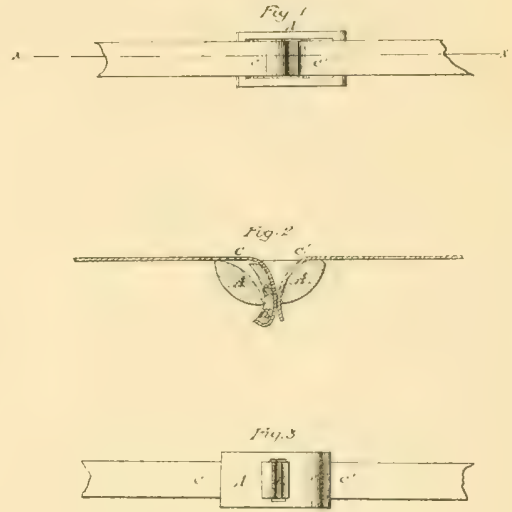

HLampsor

Cottor Bate Tie.

Mriosesq Parented Mray, so, $180 \%$
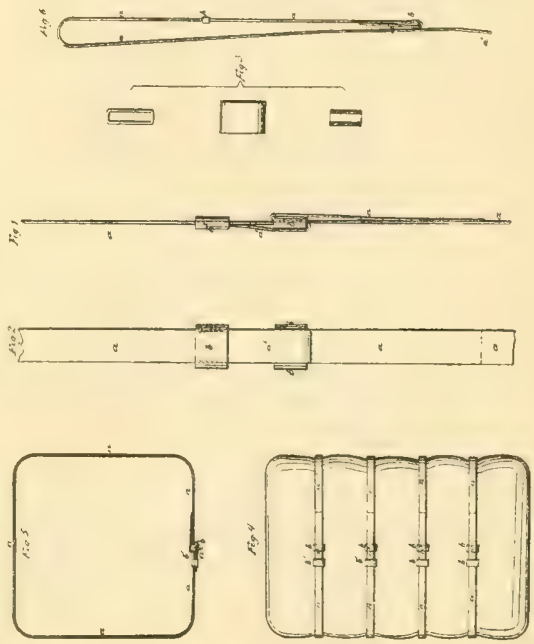


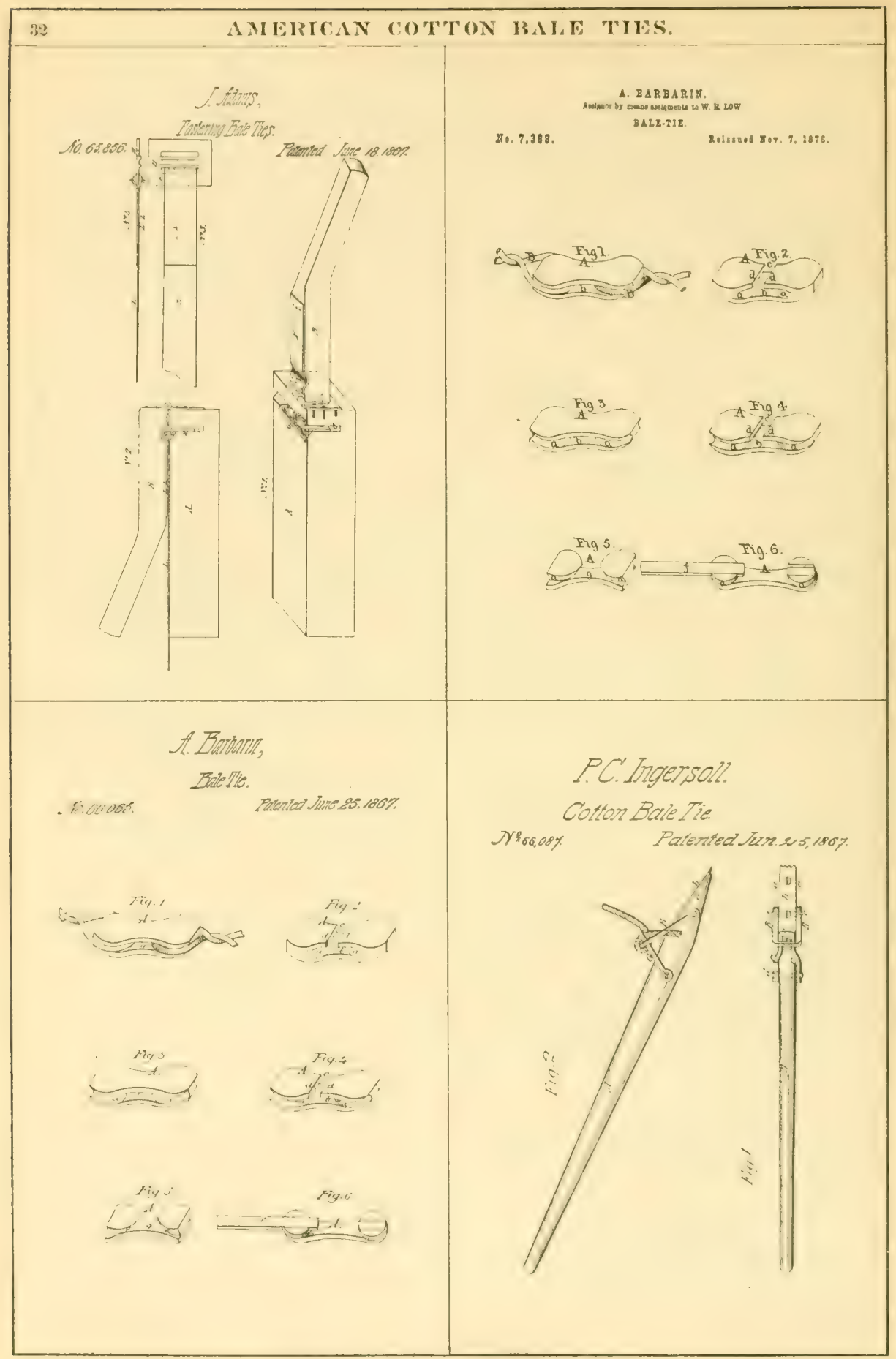

AM. PHOTO LITHOGRA PHIC CO NY Y OSUCONES PACCISS 
\$1 07.098

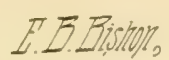

Bale Tie.

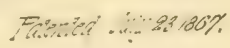

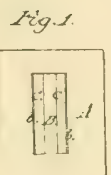

Fin. 2

त्व.
$-.0 .6 \% 23 \%$
Sintiter:

Gatribiefie.

Fientat $30.185 \%$

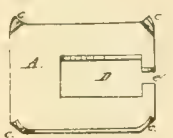

L.F Mitlinal,

Bate Tie.

10. 67.384. Falented July $30.180 \%$

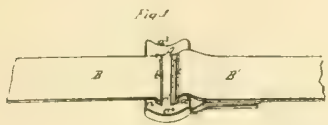

lice $?$

Q.2.

Fing 3

[1]

\section{a. Trente}

Fale The.

10. 6270\% Patentad Stay. 13.180\%
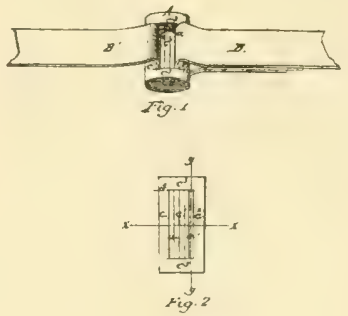

2: 此

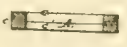




\section{Littleioirs. \\ Cotfon Bale Tie}

Profyyy Patented fing 13,150y
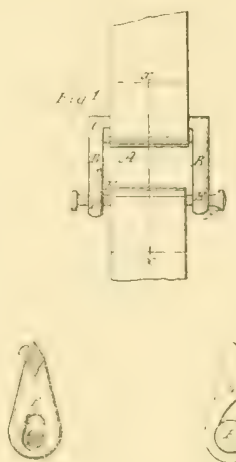

A. Barbalin,

Enle Me.

10.08149

Patented Aig: 27. 185\%

ल)

siv $y$

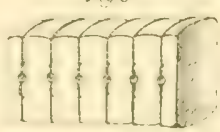

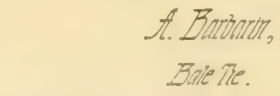

$10.68,140^{\circ}$

Priented Ly.2\%180\%

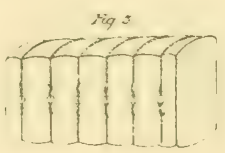

$-1 /-C \ldots 2$.

Linic jic.

10.08107

Paterich tho as 108\%
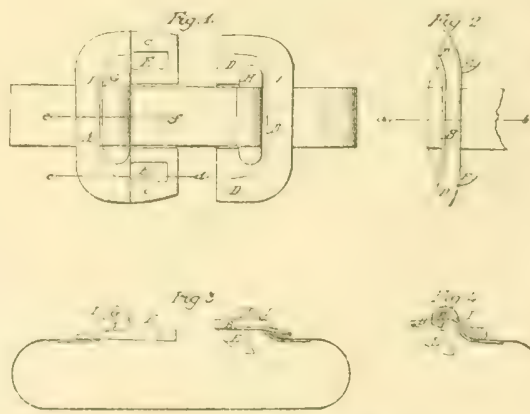

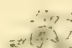

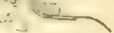

$\therefore$ ix: 20

- 120

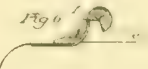




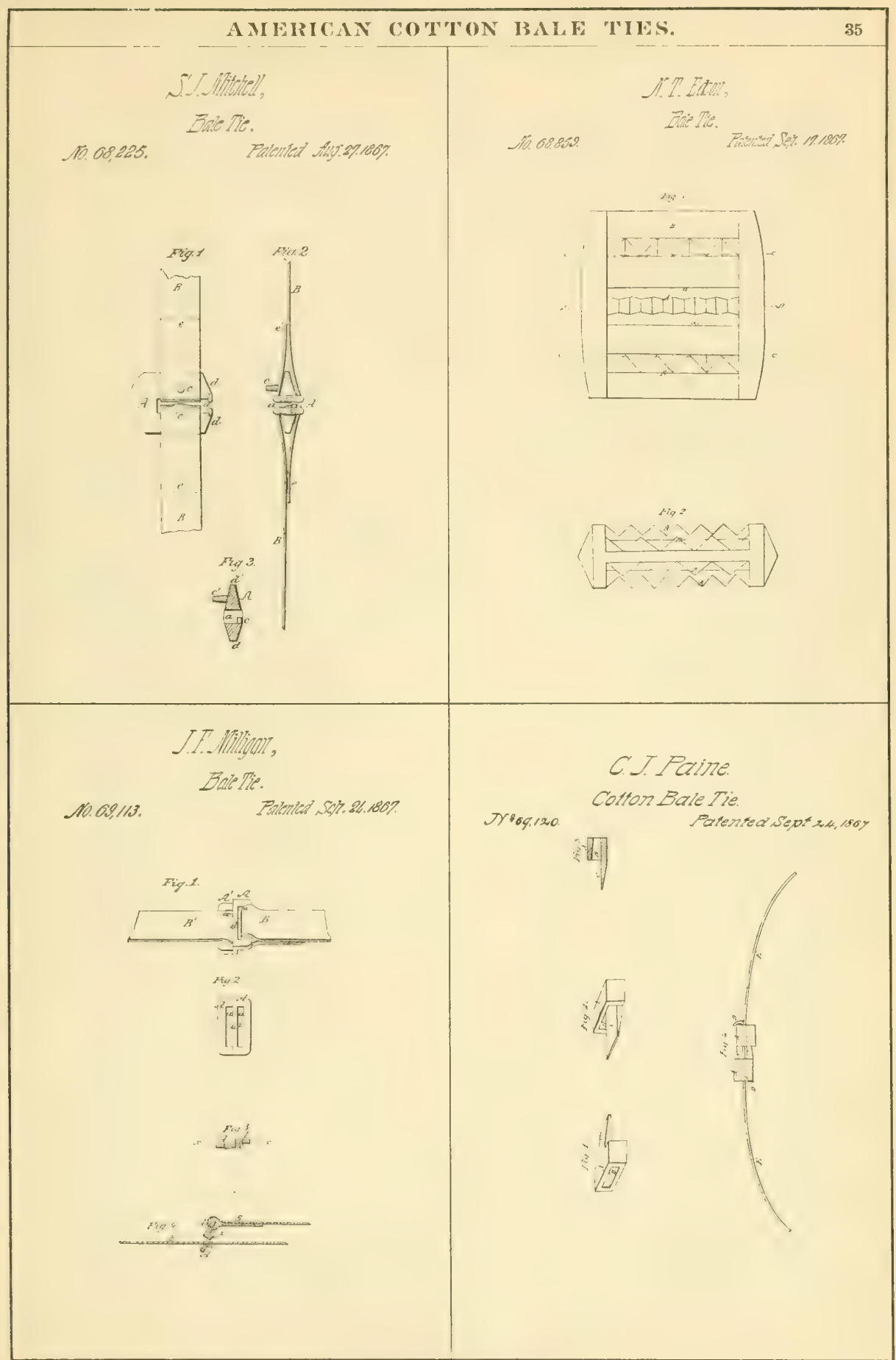




\section{$-1+\cdots+\cdots$}

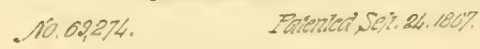
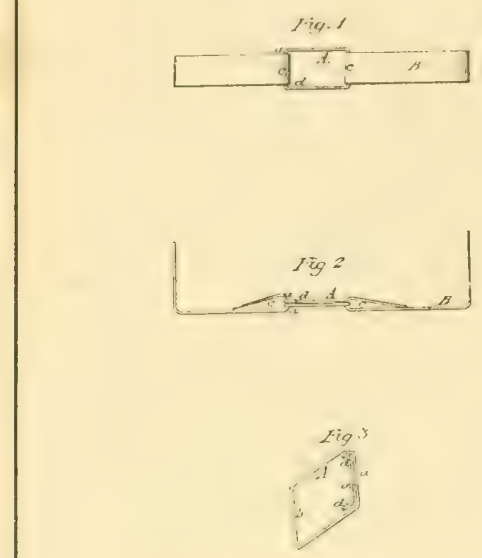

Colno Baterie.

10.09849. Fitenter at 15.1847.
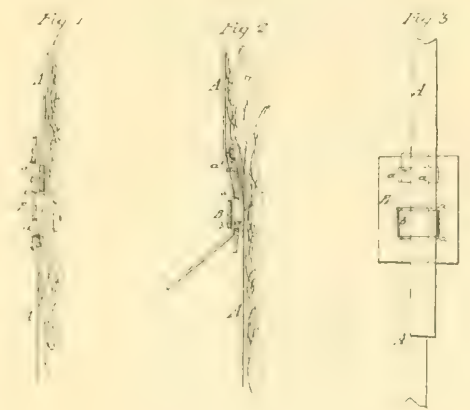

S.L. She ralala, 


\section{R.HLEchy \\ Colton BaleTie.}

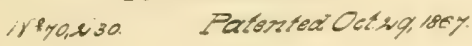
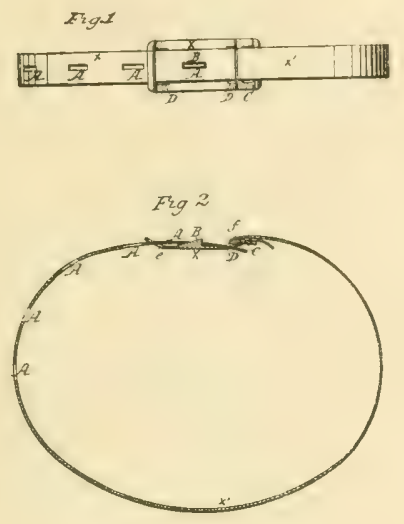

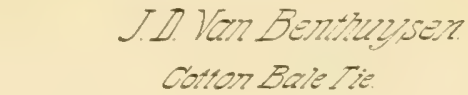

Troyo,ags. Patented Oet 39,1 for
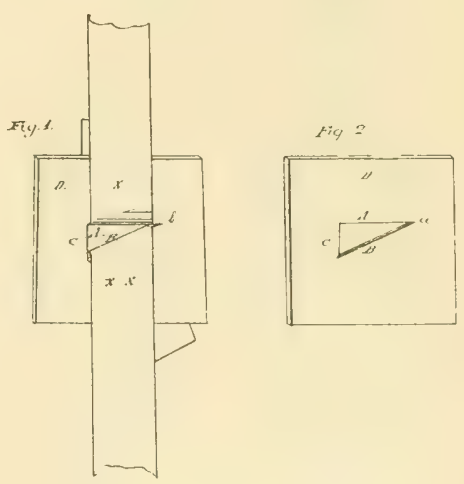

\section{HE. Nerritt, \\ Bule Tie.}

10.70,452. Falented Mar.5.180\%

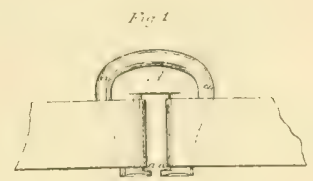

\section{S.T. Bantill,}

Bate Tic.

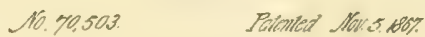

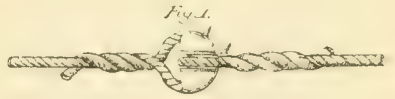




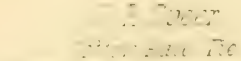

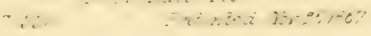

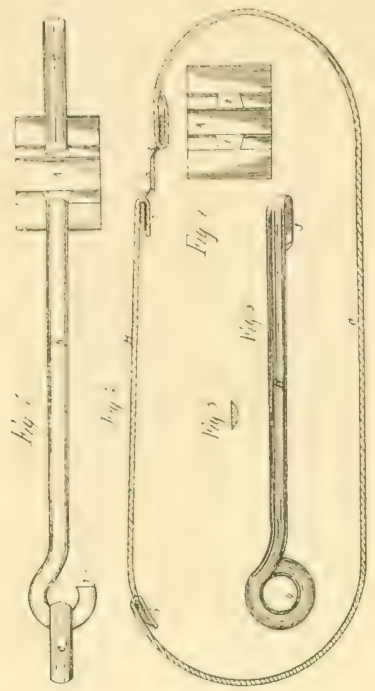

C. IIr doge.

Cozzon:Bale Tie.

Tr:73026. Patented Jan 7,1868
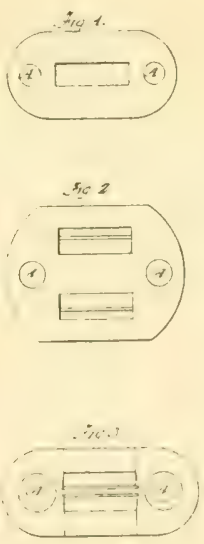

718 B7

JOHN H.FRALEY

IMPROVED COTTON TIE.

PATENTED

DEC 101867

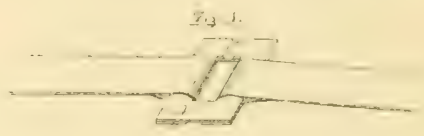

$1,3.2$
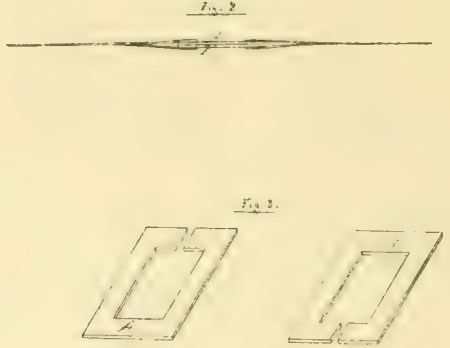

73034

PATENTED

JAN 71868

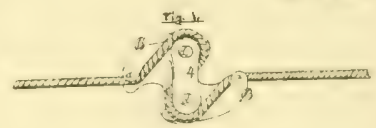




\section{T. Guyol,}

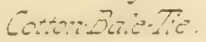

$-7, \%, \%$
A. C. Fletcher.

- $a$ ii ri-iener.

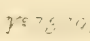

Patenzea Tin :81608.

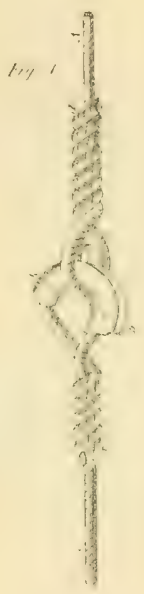

Patented Gorn. 28: sos:

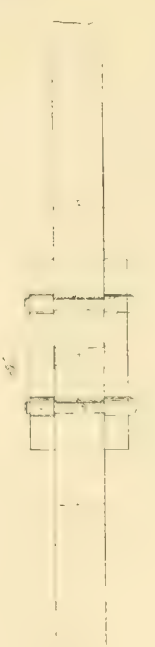

!

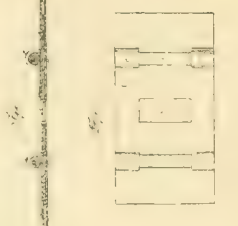

i.

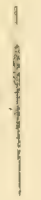

Soseph Bragg Durn's Bale Rio.

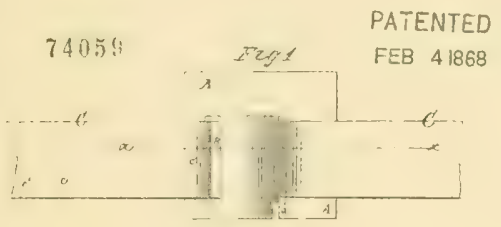

Ir:74070 Patentea Feb. 4.1868

A. C.Fieicher.

Cotzon-Bale Ties. 


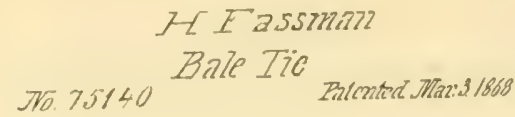
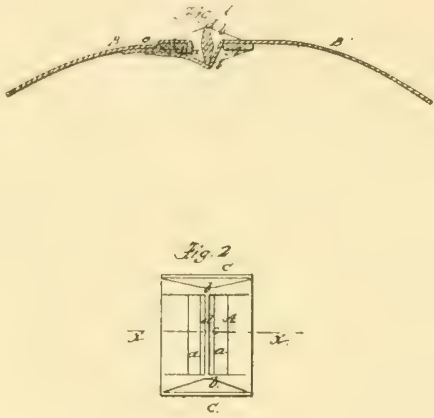

1). Trombriage

Colton Bale Tie.

$\pi x: 75319$ Pazenzeä.Mar:101868

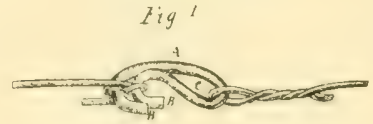

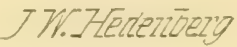 \\ Cotton Bate Tie}

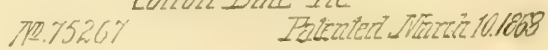

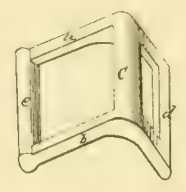

\section{Trowbriatye}

Collon Bale Tie

Trisss\% Reivsued Miar 23, 1809 .
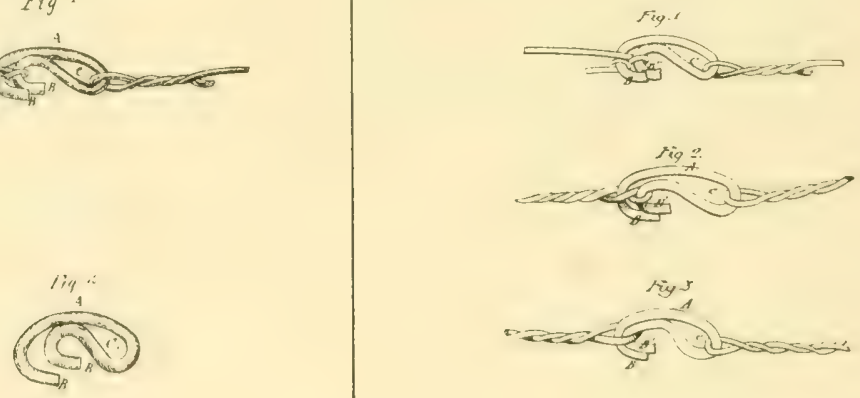

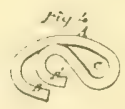




\section{E.S.Roberts Bale Tie.}

$75+61$
PATENTED

MAR 101868
J. I. Sheppard.

Cozzon-Bate Tie.

Mr:75705 Pazented Mar 17,1808
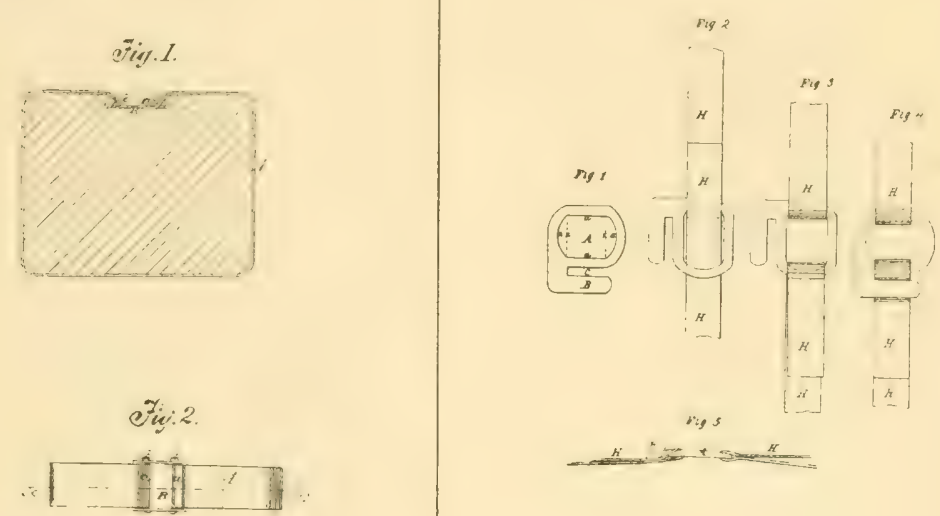

IN Barnum.

Cozzon-Baze Tie.

r.76141 Pazenzeà Mtar 31,1868.

\section{J. Barnurn \\ Cozzon-Baze Tie.}

Tr: 76142 Patentea Mar 31,1868.

然,

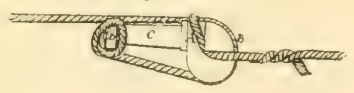

$y^{2}$

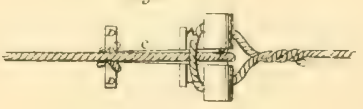




\section{IIT Barnum}

Colion-Bare Tre

Fazente à-Mar. 31,1868.

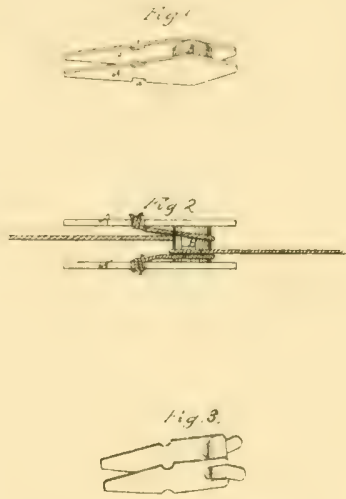

J. W. Barnum. Colzon-Bale Tie.

$x^{8} 76144$ Pazenzea Mar. 31,1868.

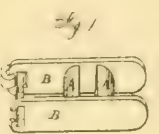

$4:$

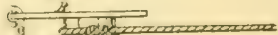
$\frac{1+\operatorname{sen} 4}{B}$

\section{J. Barnum.}

Cozzon-Baze Tie. Mrs76145 Patented Mar. 31,1868
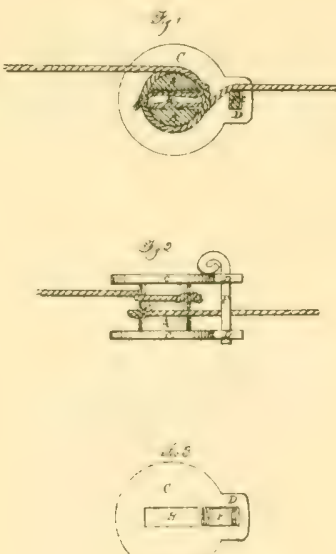

\section{J. M Barnum} Cozzon-Bale Tie.

MY $76146 \quad$ Patented Mar.31,1868.
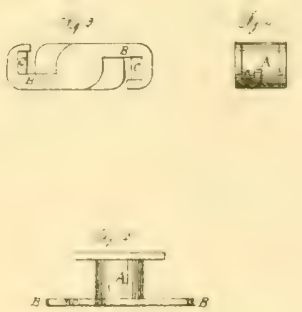
I. Mitrer ü

Band for Baling Cozzon

Yr:762.38 Patenzed Mrar 31/868
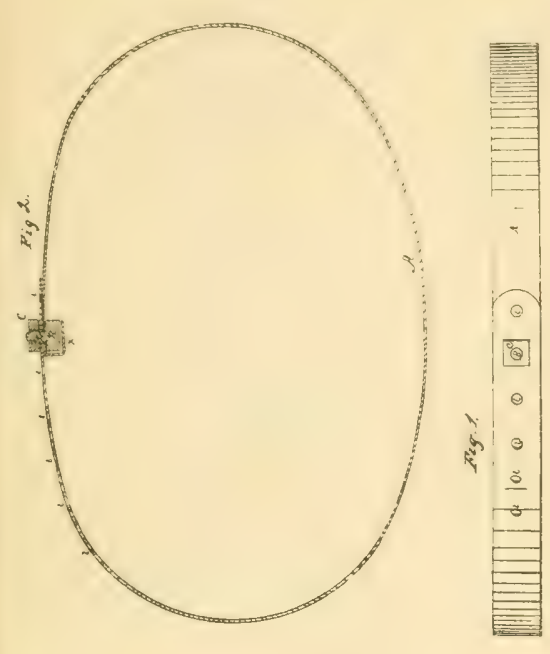

G. F. Sever,

Collon Dhe The.

10. $97.7 \% 5$,

Patented Nayive rese
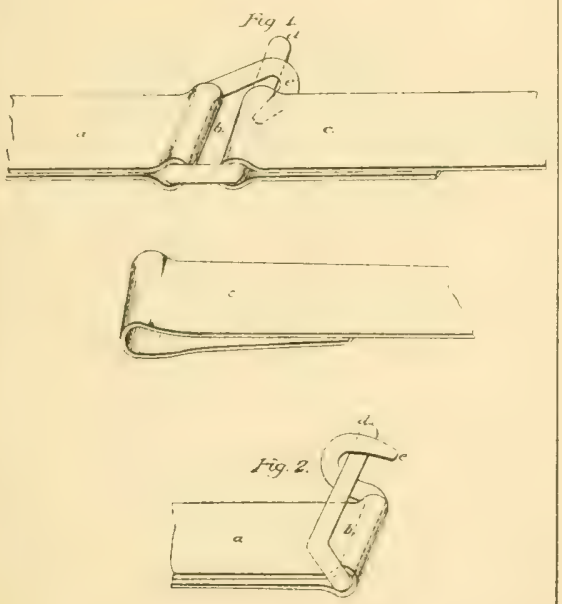

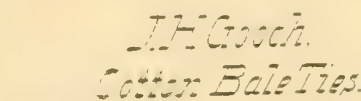

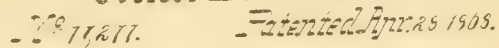

Fig.1

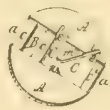

Fal) :

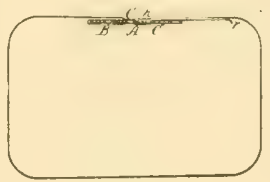

S. STrone

Gollor Balieflie.

10.81018. Fateried Aly \%1865.
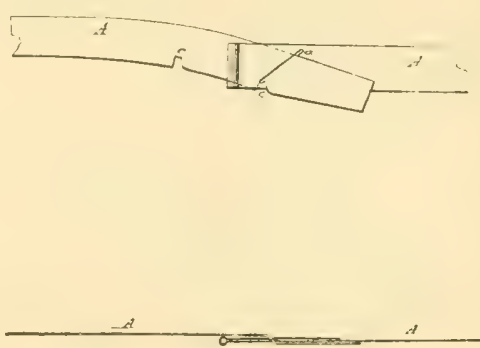
Joing S. Wozziz.

Cozzor-Baze Tie.

$27 \div 89,612$

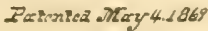
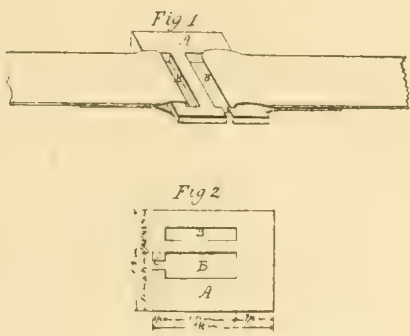

Fiy 3

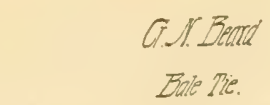

10.82844 .

Palented Mall 11.1809.
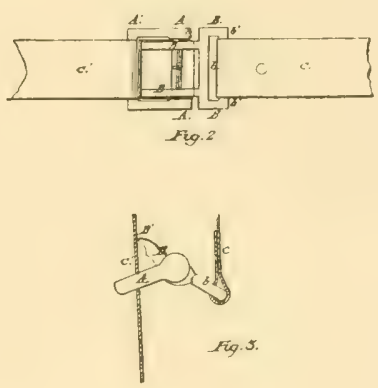

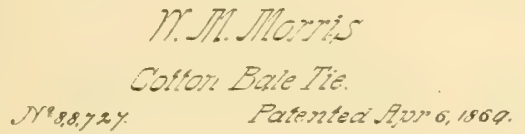

B. Pr. Field

Colton Bate Tie

rosq.136. Paterted qurzo,1009.
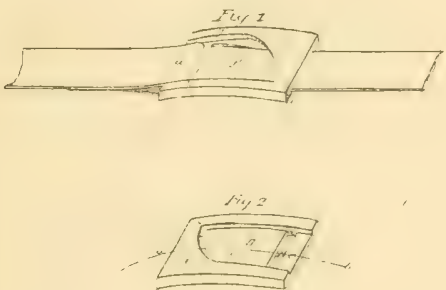

rigs $F$ 


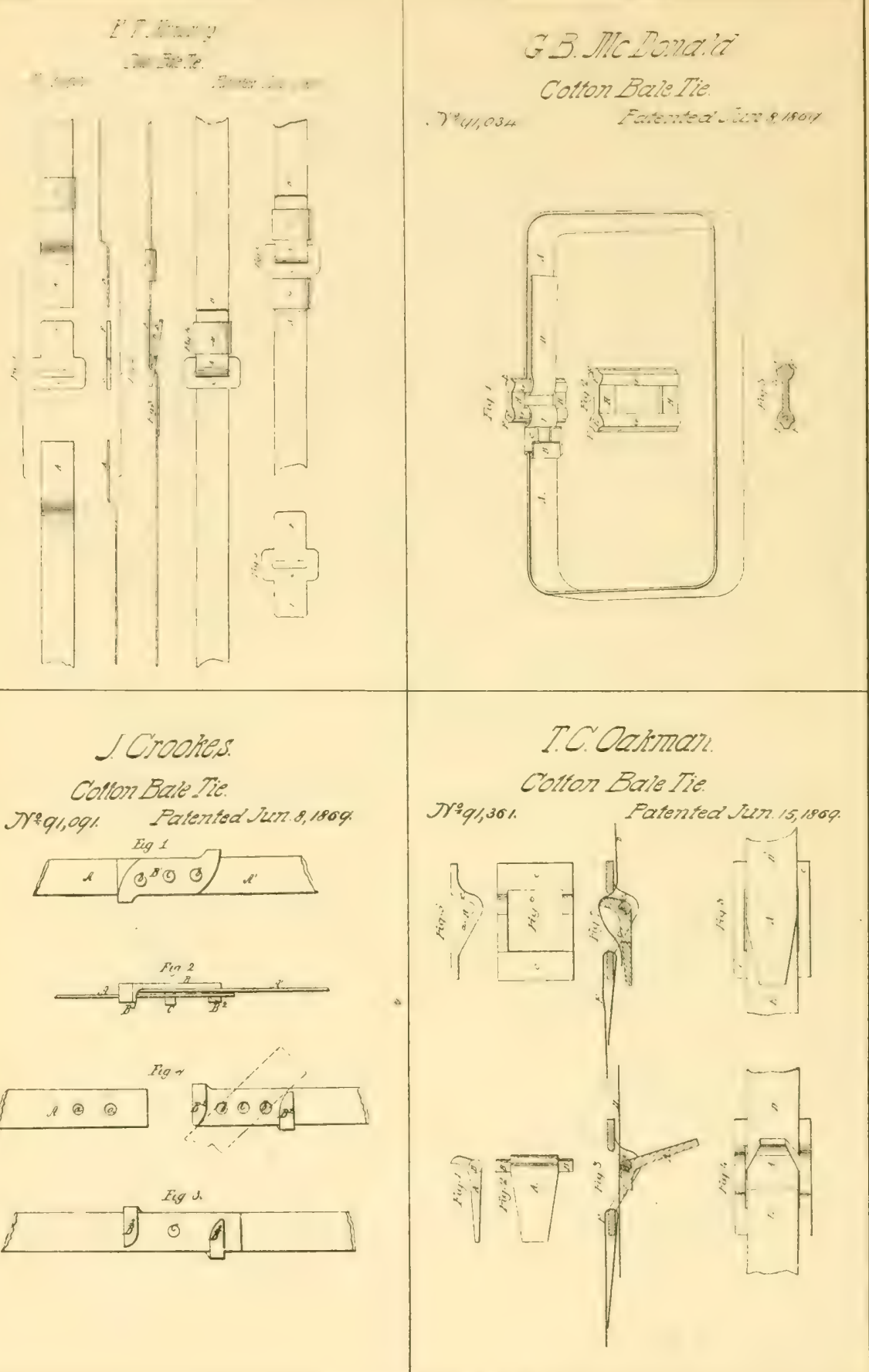




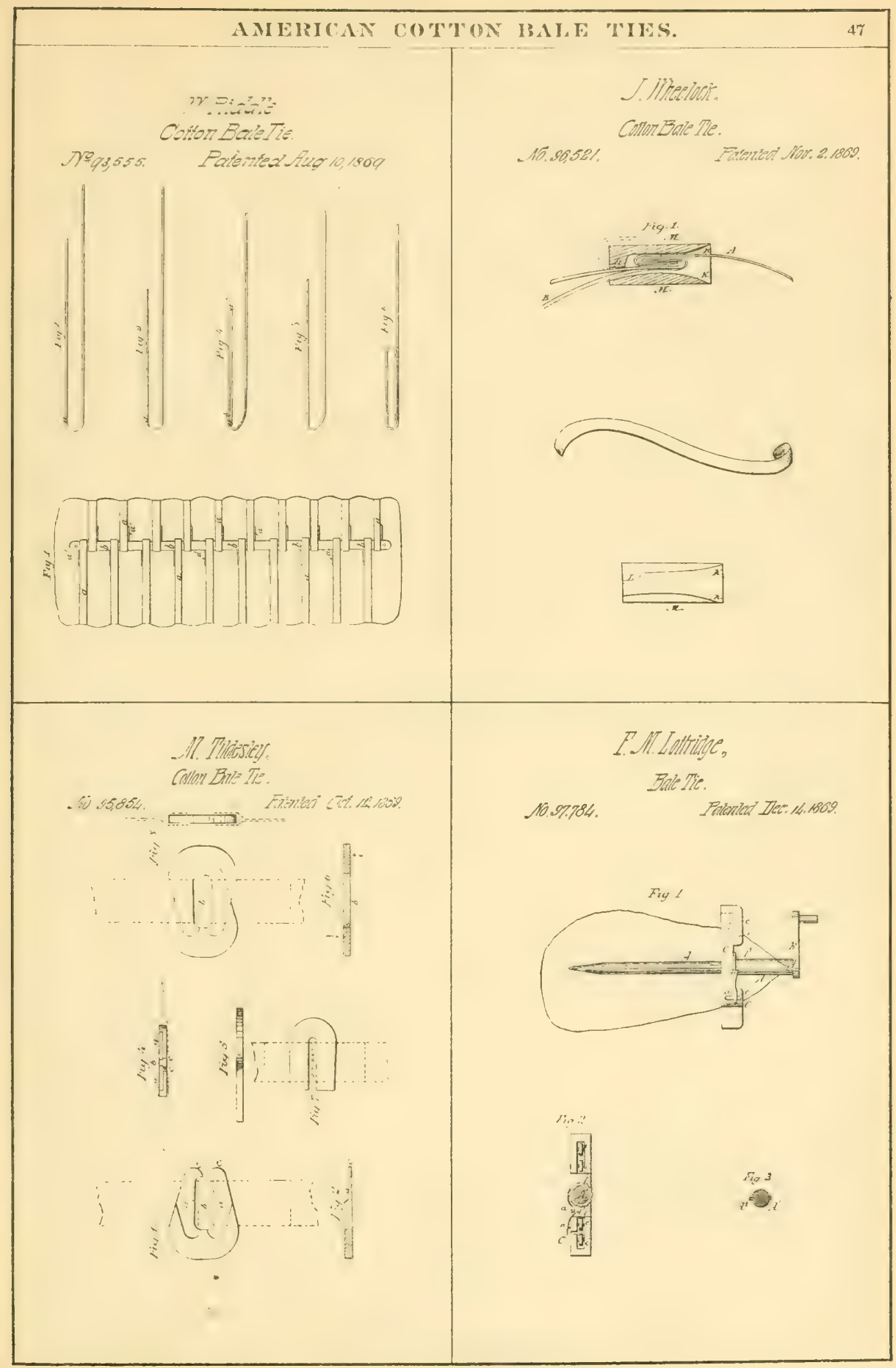


MMEICAN COTTON BAI.E TIES.

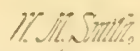

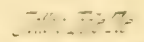

$\therefore \because \cdots \quad=\because 1809$
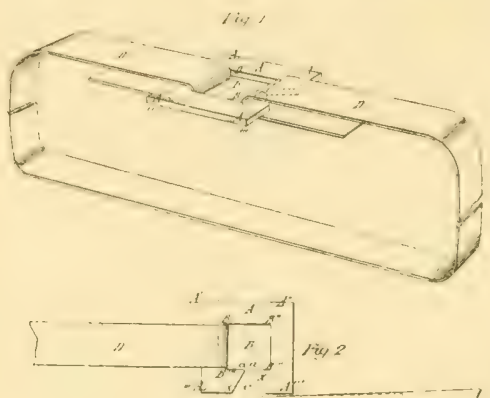

, th

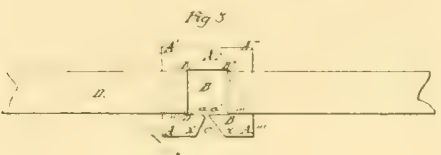

E. $5.25 N 08$.

WIAE BALE FASTIMIYO.

\$. 7,026 .

B日isgnt6 $\triangle 8+12$ 4. 1876.

Fiy 1

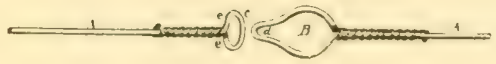

Fis. 2

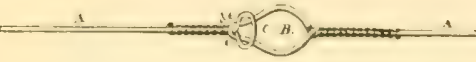

ESEME,

Enichio.

$10.98,109$

Palenter Per: 211000,

Fig 1

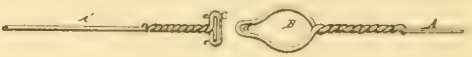

Aig. 2

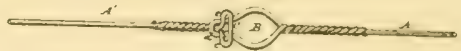

Fig.s

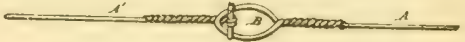

E. S. LENOX.

WIRE BLLE YASTEXIYG

80. 7,027.

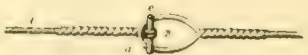




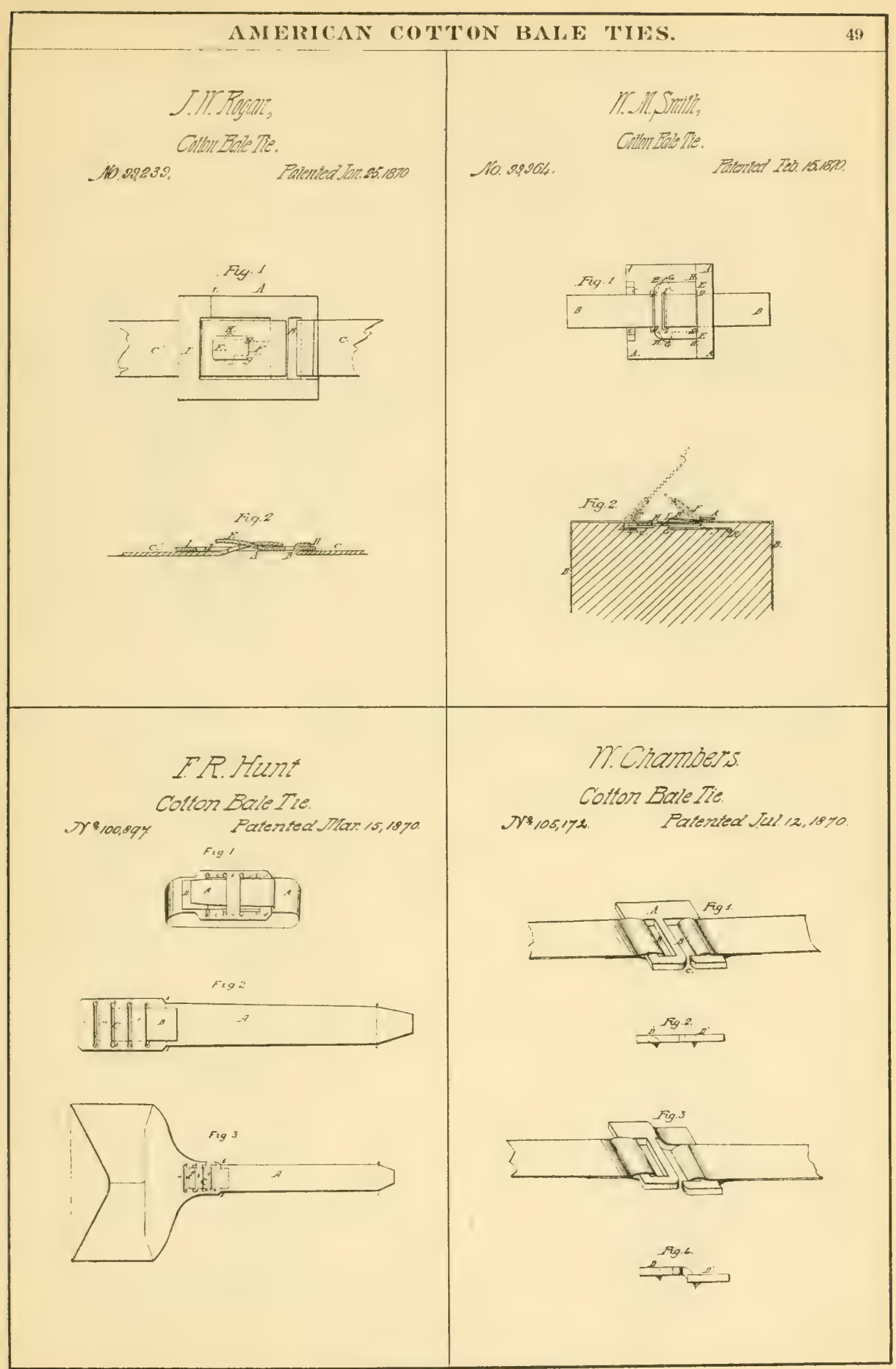




\section{S. Soritall,}

Bale Jie

10. 106038. Falented Hils:28989.

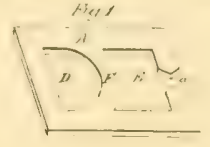

Fig?

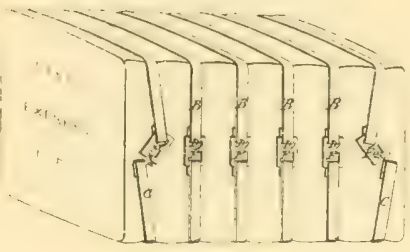

M.P. Clant,

File Tis.

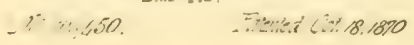

$\therefore$

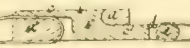

Ap 2 .

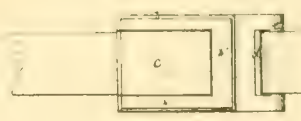

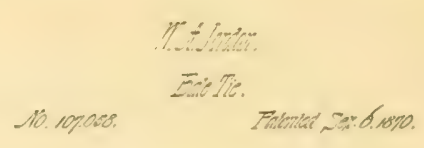
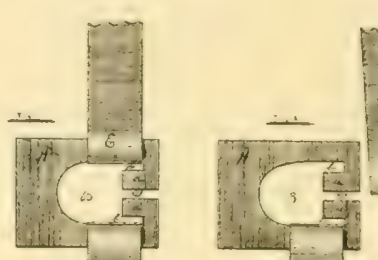

(2)
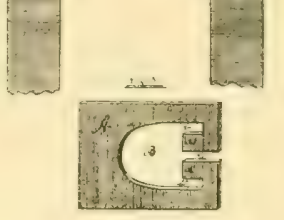

E.P Tones.

Guten Eale Tie.

Tr\%109,000. Patentea Oet 25, $18 \%$.
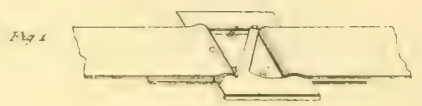

$\lim :$
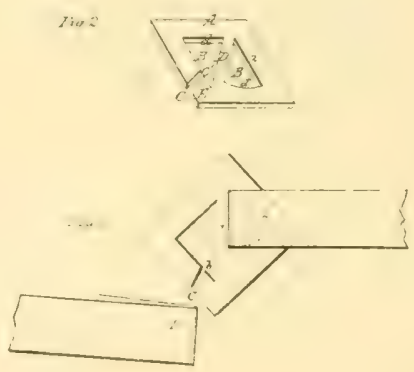


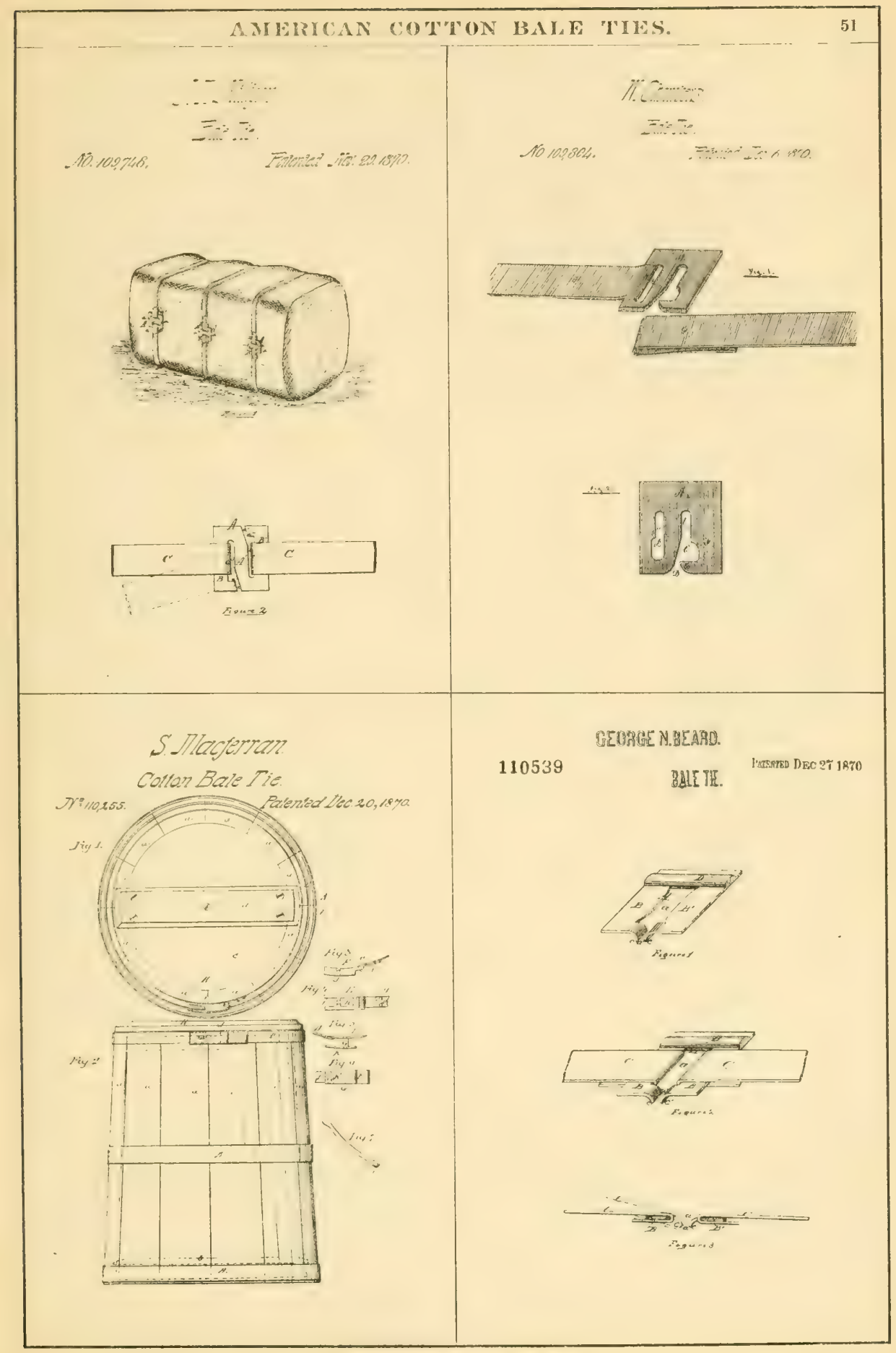




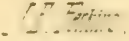 \\ $=\pi x^{\circ}$.}

MO. 114.375. Filerted Mar. \%. 1897.

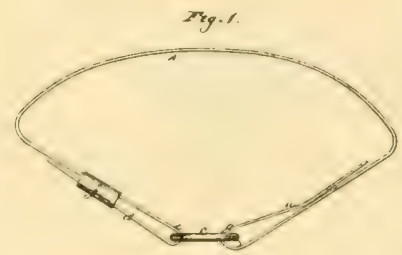

$3 y 2$

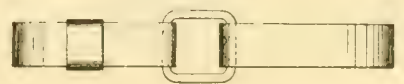

Limese jants.

Bat Jie.

15. 119518

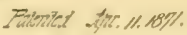

Fk. 1

$01= \pm$

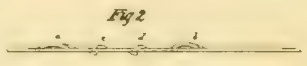

Fing

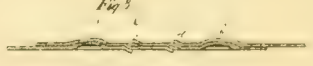

s

$n_{n=0}^{4}$
M. MARTIN.

Improvement in Machines for Adjusting Cotton-Bale Ties. No, 114,581 . palentod May 9, 1871.

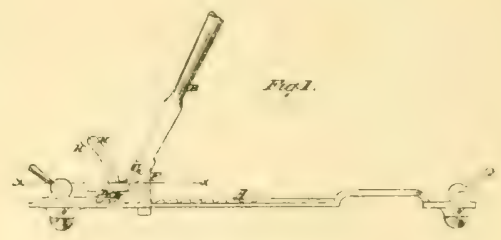

sey is.

$2 \% 2$

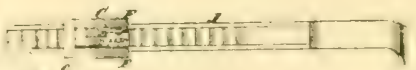
ता 


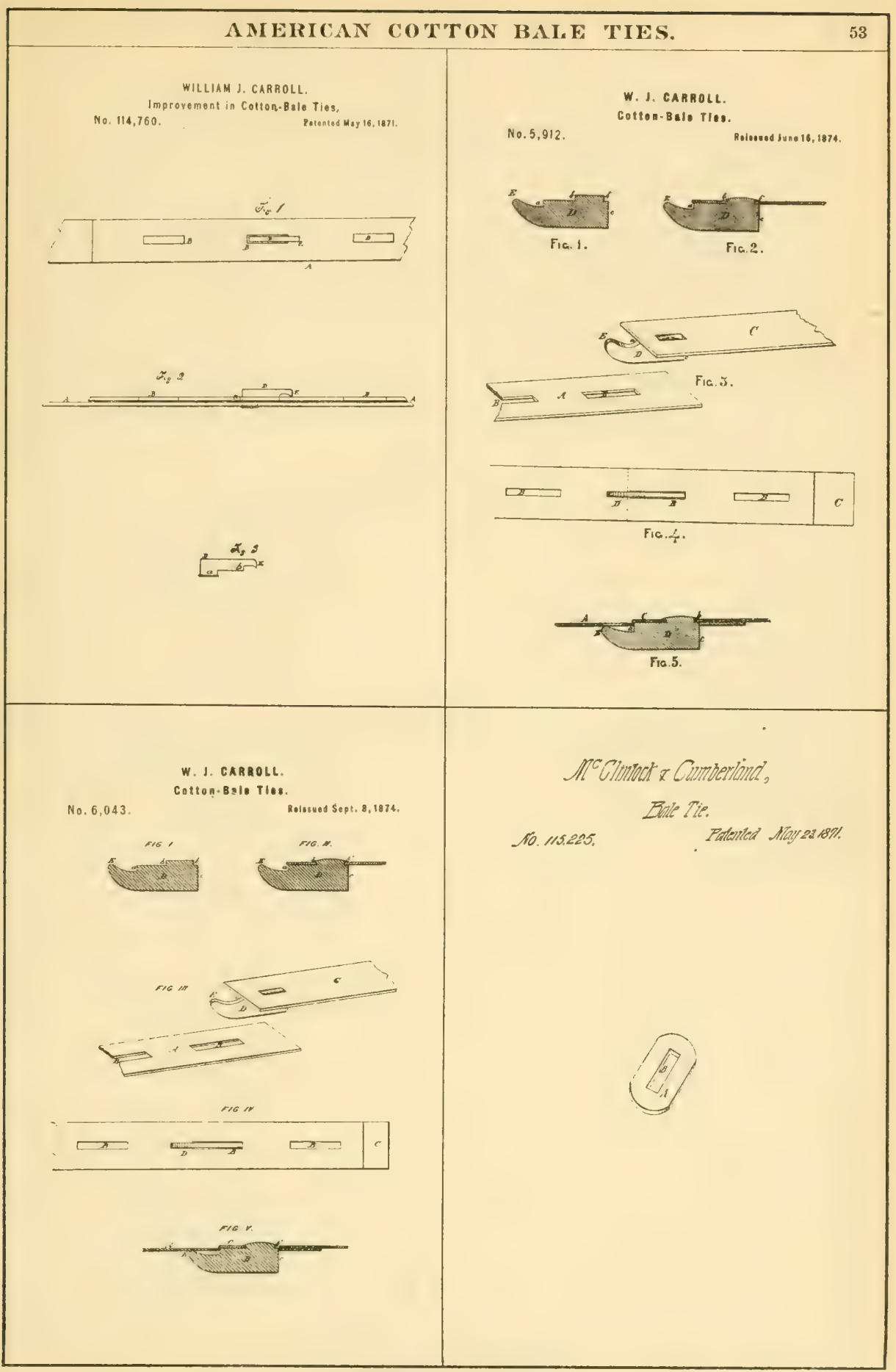


1.R. MCCLINTOCK.

$\mathrm{N} n 54^{\prime} 4$ Cotton. Bale Ties.
S. BRETT

Improvement in Bale-Ties.
Palented lune 6,1871.

No. 115,692
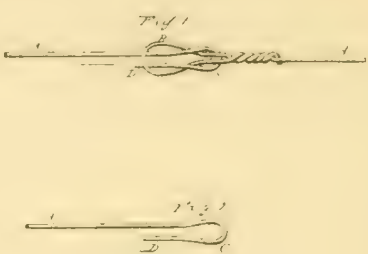

$-\pi g:$

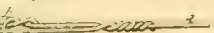

1. R. MECLINTOOK

Cotton-Bale Ties.

No. 5,910

Roisued June 16, 1874

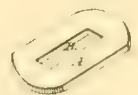

Gernge Pandie' Cottonibale Rie

116825

Figh A Aakra JuL 11 187!

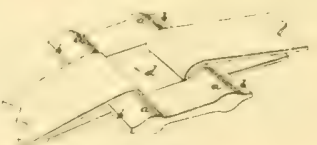

Fing

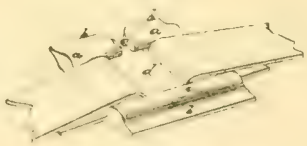

Fin. 2

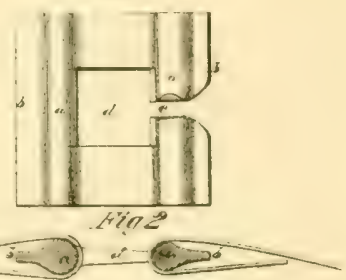


Charles (: Jolinsen

Open slot Tie

116964

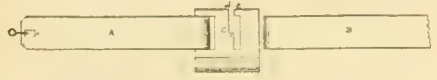

$\therefore$ :

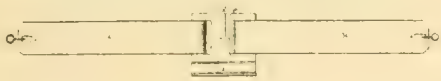

3

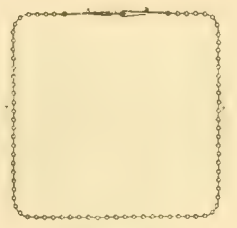

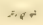

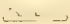

BNEMRD IUL 111871

117202

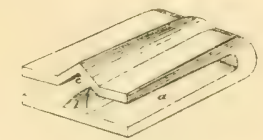

$F_{111} \div$

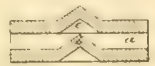

$x \geqslant 7$.

$-]^{2}-\cdots+\cdots$

SAMUEL. MATHER.
Improvement in Cotton Tie Stratcher.

Sylvester aleurs. Meinal Hoopl.

Pसा
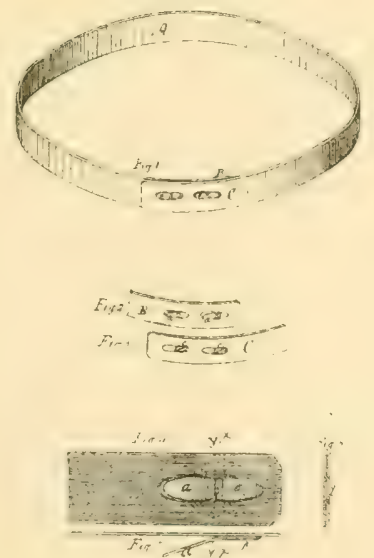

No. 118,254 .

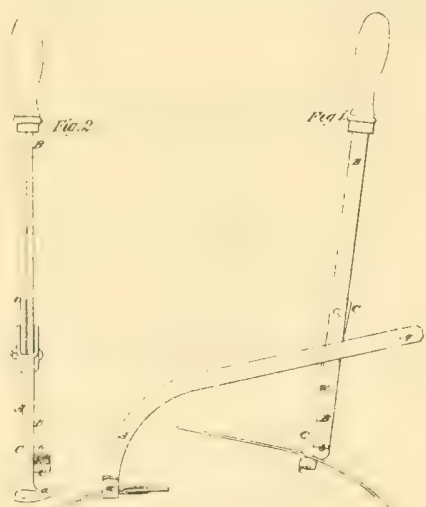

Fig. 3 .

Seng 2 IN to IT

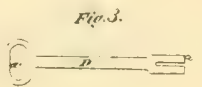


JOHN L, SHEPPARD.

Improvement in Bale Ties.

No. 118,286 .

Patented Aug. 22, 1871,

Iig. 1 .

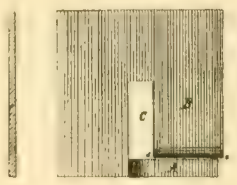

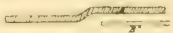

fig. 2 .

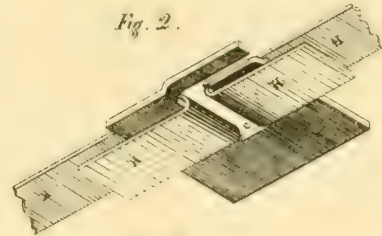

Fig. 3.

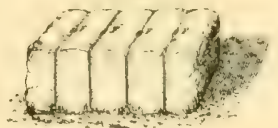

RICHARO T. YAADLEY.

Improvemont in Balo Hooks.

No. 119,213 .

Patentod Sop. 19, $187 \mathrm{~L}$
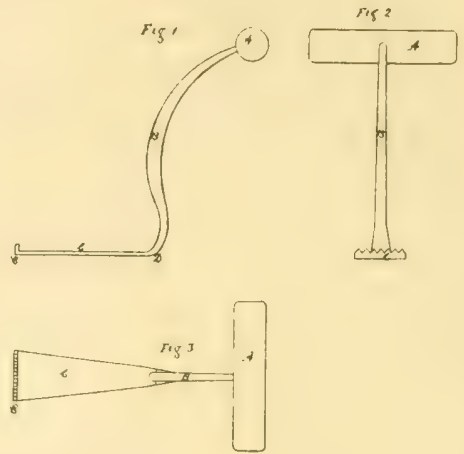

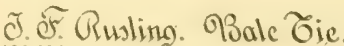

Sole T'ée.
No. 120,045.
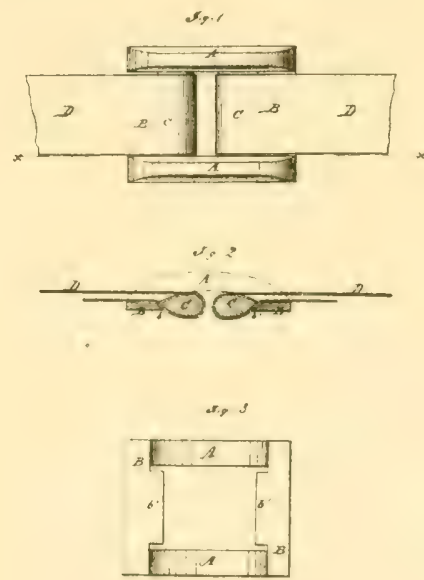

Patsited Oct. 17, 1871.

\section{No. 120,104 .}

$r \%$
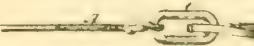
JOHN DOWNES.

Improvemert in Metallic Bands for Baling Cotton, \&C.

No. 120,727 .

Paterited Nov. 7,1871.

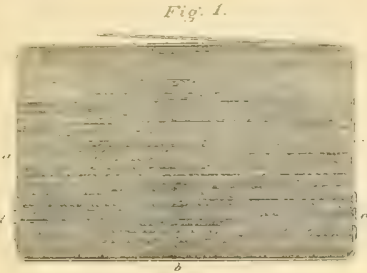

Fer: :

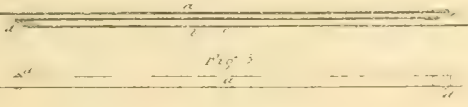

Fig 4

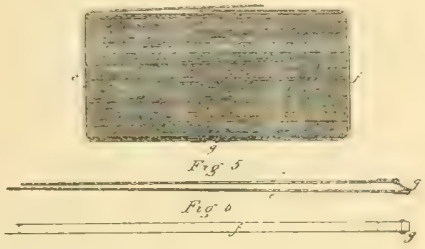

MARTON T. COE'S XMTROVTX

COTTON BALE TI在 XCA

No. 121,756

Patented Dec. 12, 1871 .
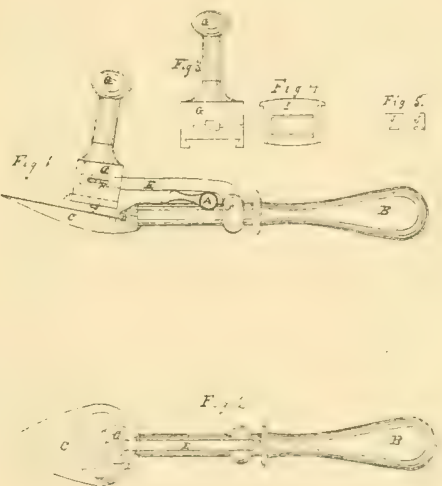

No, 121,988

F. G. BROWN

Improvement in Bale Ties.

Palented Dec, 19.1871

Improvement in Metallic Bands for Baling Cotton, \&c.

No. 120,727 .

Patented Nor, 7, 1871.

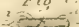

Tio: 9 .
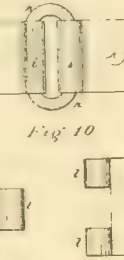

$F_{i g} 11$

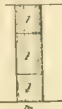

Fis 12

(in),

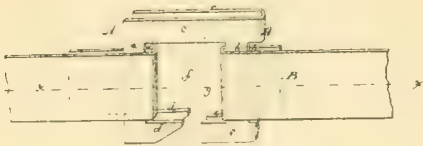

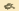

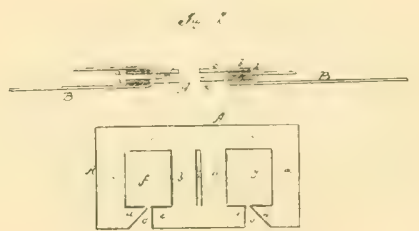


JOHN T. BUTLER.

Improvement in Bale Ties.

No, 122,563 .

Patented Jon, 9, 1872.

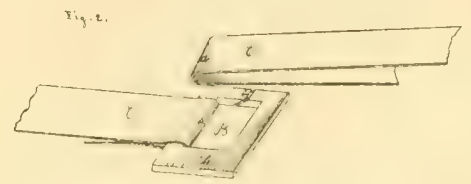

WILLIAM PARSONS.

Improvement in Bale Ties.

No. 122,907

Palonted Jan. 23, 1872.

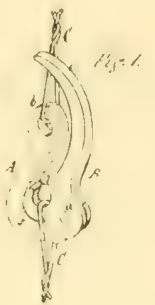

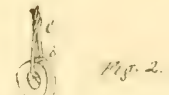

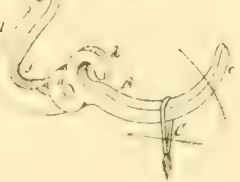

JAMES C. COIT.

Improvement in Bale Tie and Straining Lover.

No. 122,813

Patentod lan. 16, 1872.
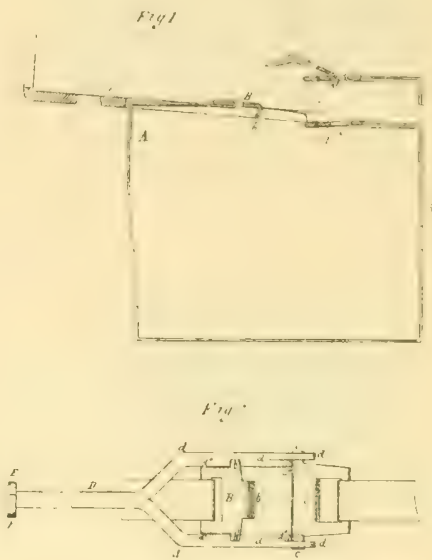

GEORGE BRODIE.

Improvement in Band Tighteners.

No. 123,228 .

Patented Jan. 30, 1872.

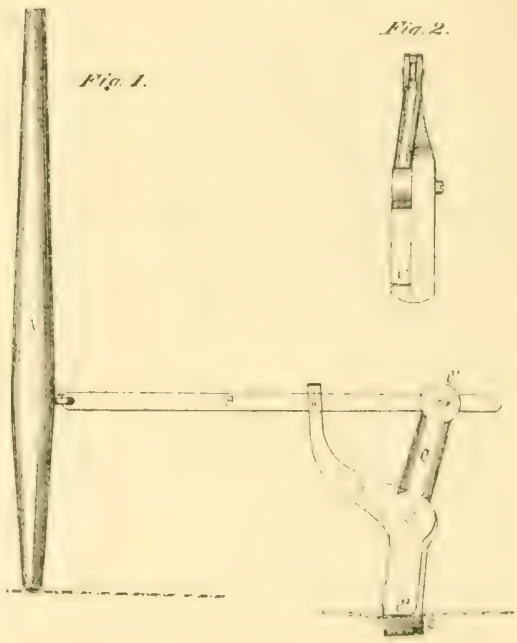




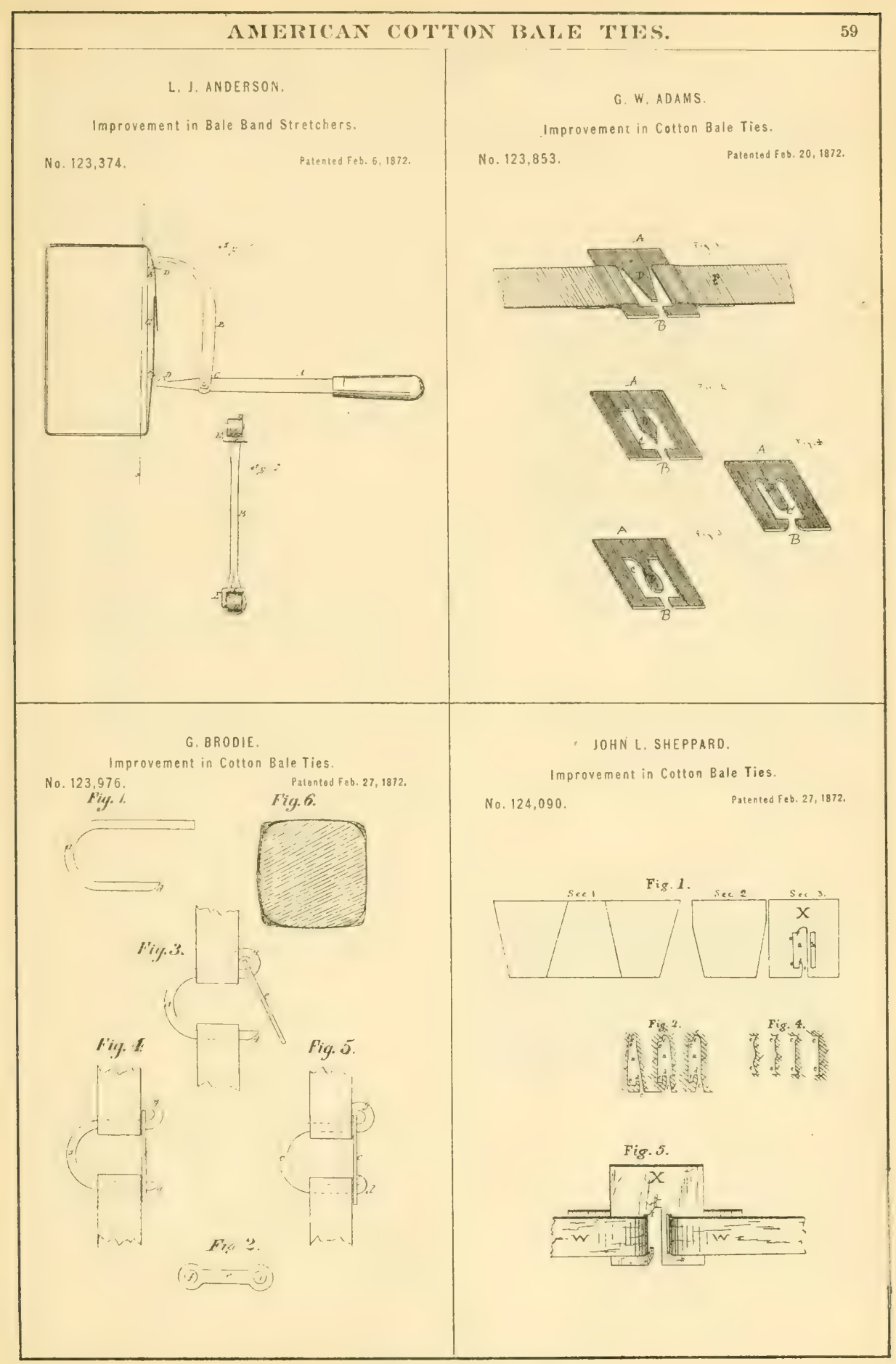




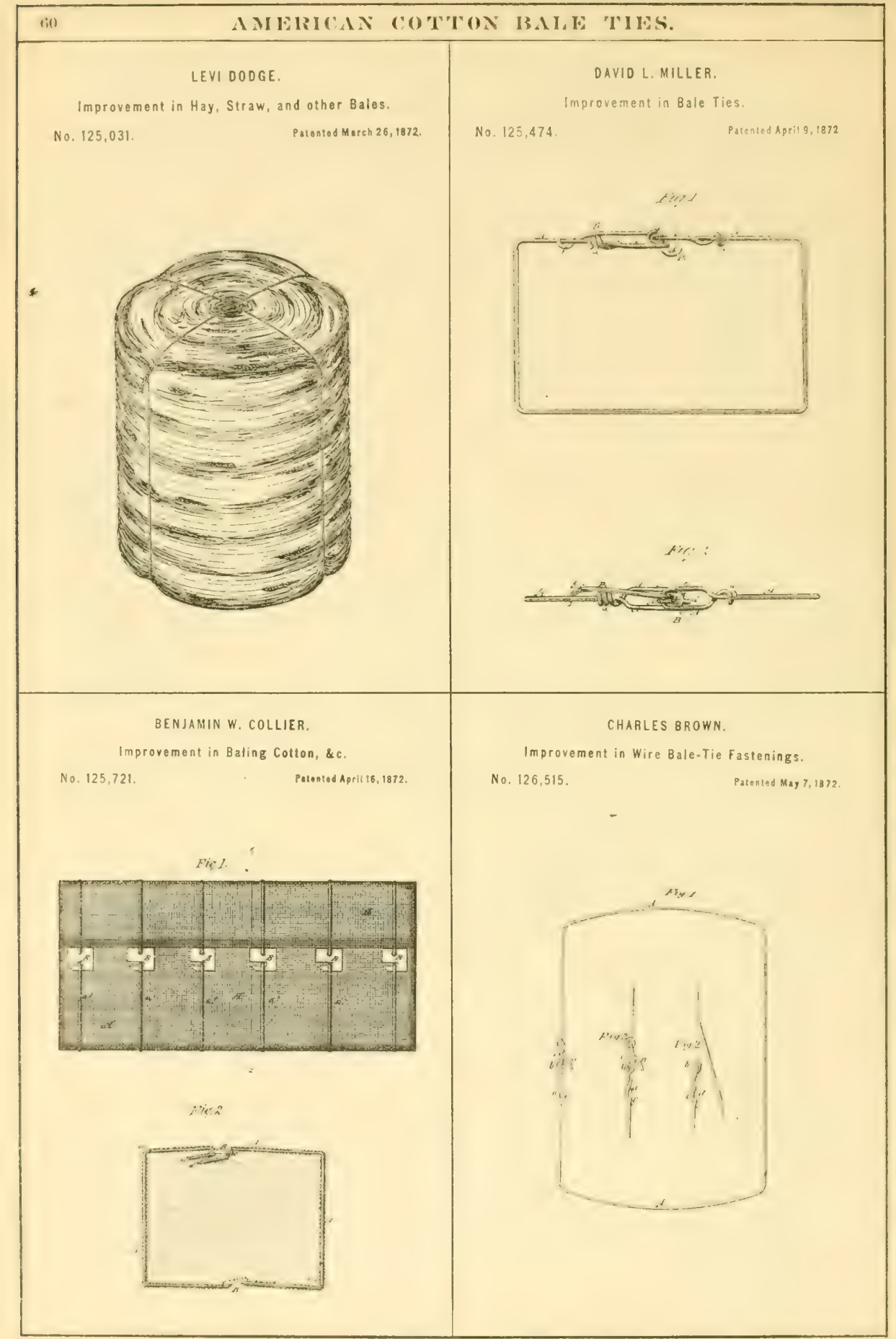


WILLIAM MCNABB

Improvement in Cotton. Bale Ties.

No. $\{26,645$

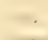
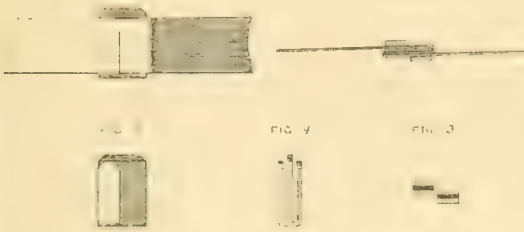

$\begin{array}{r}84 \\ 7+4 \\ 4 \\ \hline\end{array}$
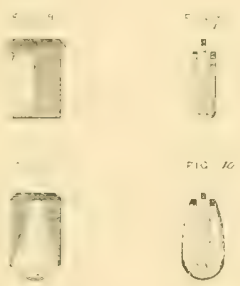

-1., $1 t$

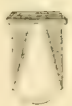

H. C. $B A B C O C K$

Improvement in Baling Manure.

No. 128,454 .

Patented fuly 2, 1872
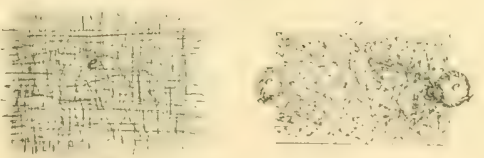

EDWARO A. FRANKLIN.

Improvement in Cotton-Bale Ties.

No. 126,687

Patonted May 14,1872 .
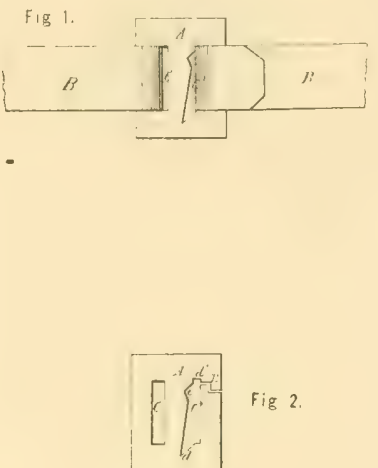

Improvement in Wire Bale-Ties.

No. 128,803 .

Patented Juiy 9,1872

$$
\text { (E) }
$$

Fis:

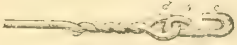

Evecisand
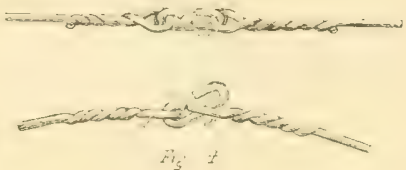


\section{H. T. MINOR, JP.}

Improvement in Cotton-Bate Ties.

No. 129,157 .

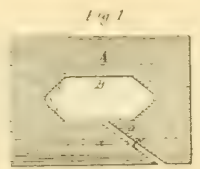

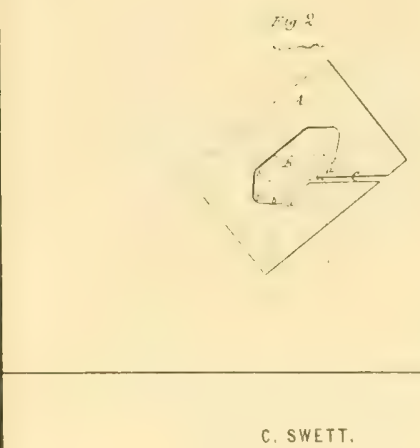

Improvement in Cotton-Bale Ties.

No. 129,187 .

Patented fuly 16,1872
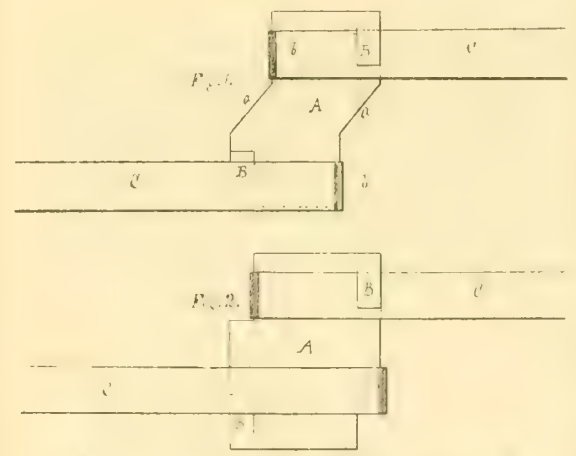

$\ldots+\ldots+\cdots+2$

F.8. 3.

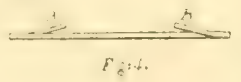

C. SWETT.

Improvement in Bale-Ties

No. 129,186

Patented July 15, 1872.
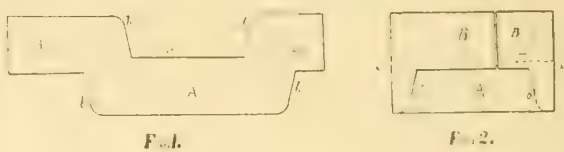

$f: 2$.

F. 5 .

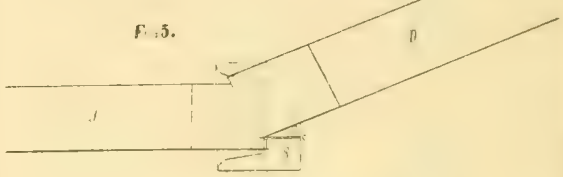

li: I.
C. SWETT.

Improvement in Colton-Bale Ties.

No. 129,188 . Patented fuly 16, 1892 .
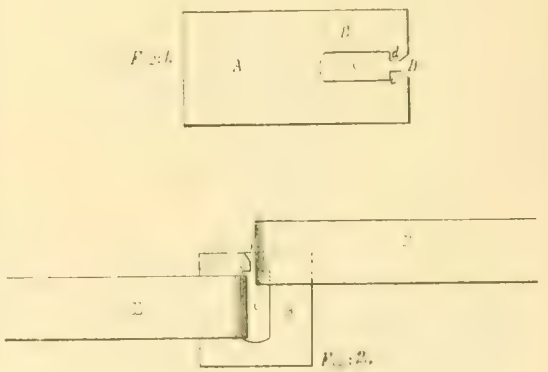


\section{SWETT.}

Improvement in Colton-Bale Ties.

No. 129,189 .

Patented july 16, 1872.
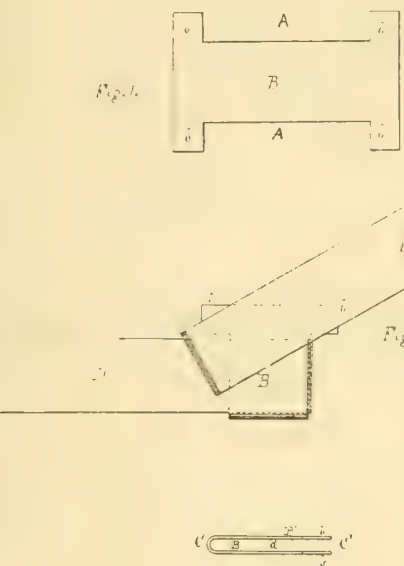

$\Gamma_{\mathfrak{n}}: 3$.
Improvement in Cotton-Bale Ties.

No. 129,191

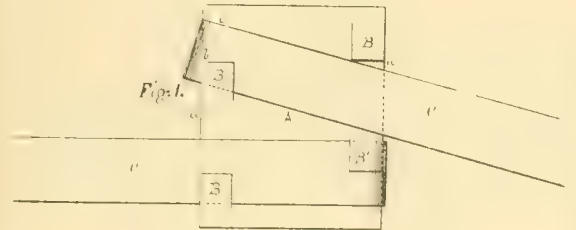

Patented July 16, 1872

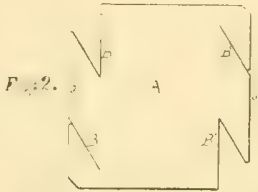

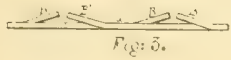

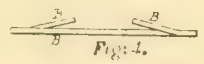

C. SWETT.

Improvement in Cotton-Bale Ties.

No. 129,190 .

Patenied July 16, 1972
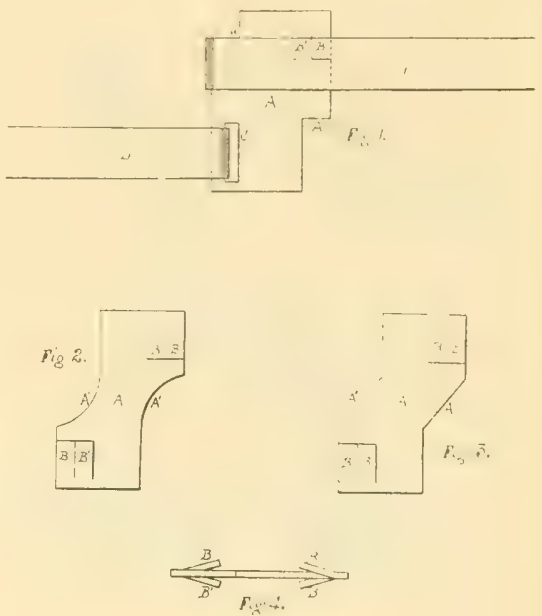

J. C. COIT.

Improvement in Bale-Ties and Straining-Levers.

No. 129,715 .

Palented July 23, 1872.
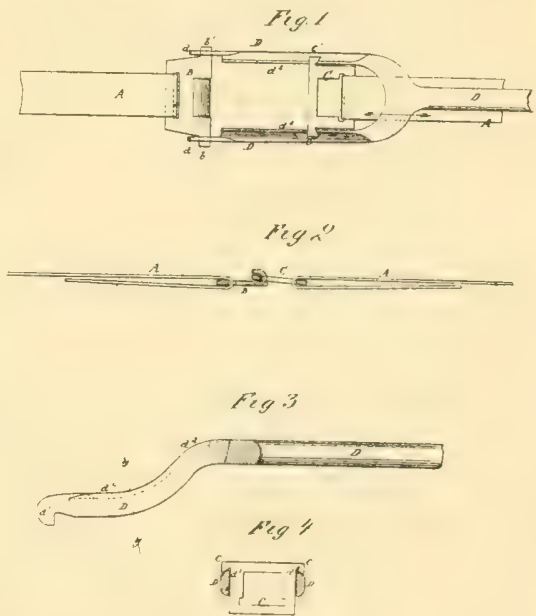


\section{j. F. MILLIGAN.}

Improvement in Hoop-Tie for 8 ales.

No, 129,851 .

Patented July 23, 1872.

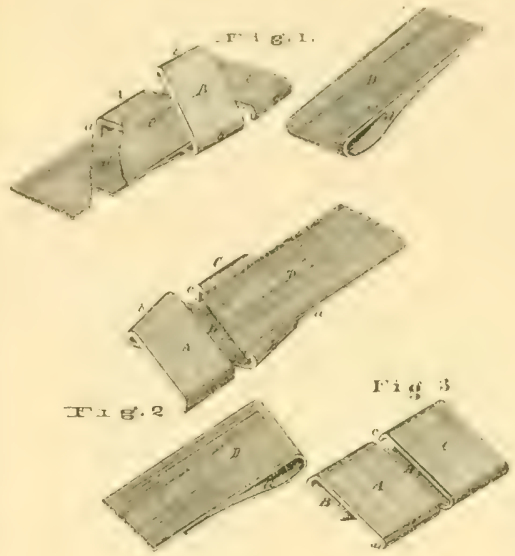

G. BRODIE.

Improvement in Cotton-Bale Ties.

No. 129,925 .

Patortod July 30, 1872. Fie 1
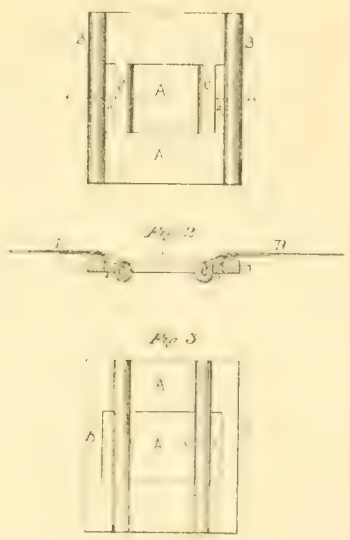

E. J. BEARO.

Improvement in Cotton-8ale Ties.

No. 129,917 .

Patented Juiy 30, 1872.

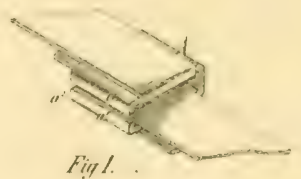

$$
\frac{a+t=?}{\text { Fiy ? ? }}
$$

J. L. HAIGH.

Improvement in Bale-Ties.

No. 130,218 .

Patented Aug. 6, 1872.

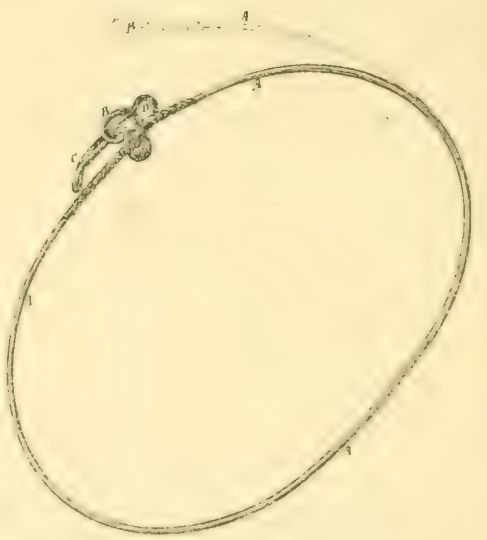


R. S. GOODGION.

improvement in Cotton-Bale Ties.

No. 130,293

Patented.Aug. 6, 1872

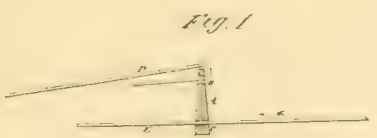

igis

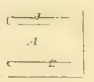

D. S. SKINNER.

Improvement in Cotton-Bale Ties.

No. 131,573 .

Patented Sep, 24, 1872
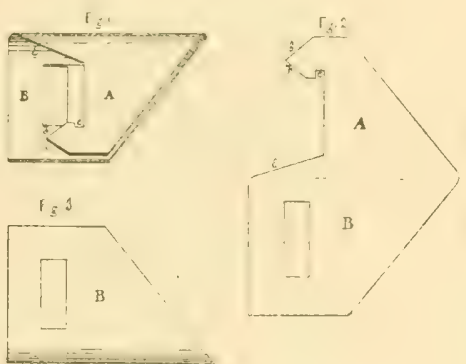

$\mathrm{F}_{2}{ }^{4}$

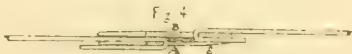

D. MCCOMB.

Improvement in Wire-Ties for Bales of Cotion and Like Material.

No. 130,519 .

Patented Aug. 13, 1872.
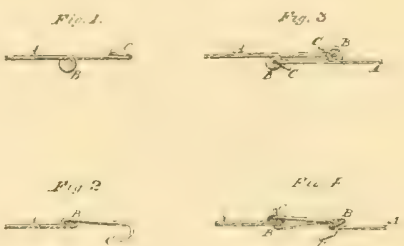

N.S. WALKER.

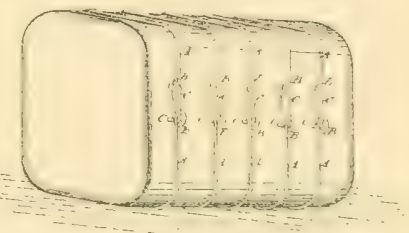

improvement in Bale-Ties.

No. 132.223. Patentod OCt, 15, 1872.
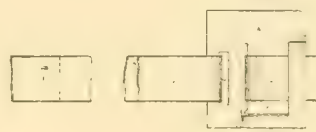

4
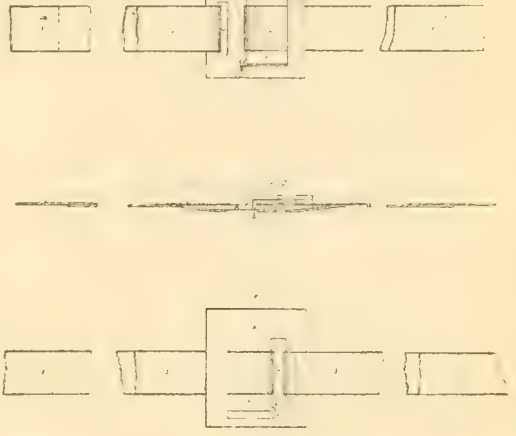
L. ARNOLO.

Bale-Ties.

No. 133,349 .

Patenlod No4, 26, 9872 ,

Fie. $l$.
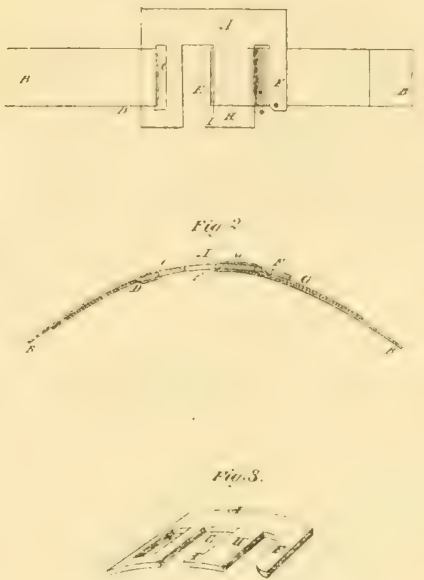

R. S, SAYRE.

Balo-Tio fastener.

N. 133:41: $\therefore$,

Palented Dec. 10, 1872.
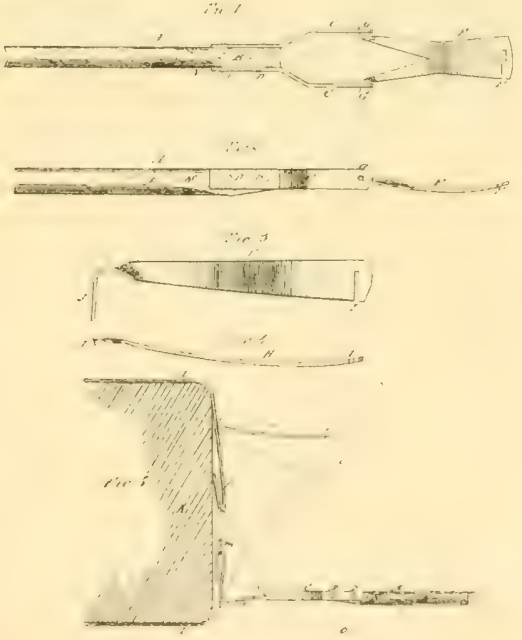

F. $\cos \%$.

Bale-Ties.

No, 133,412 .

Palenied Nov, 26, 1872.
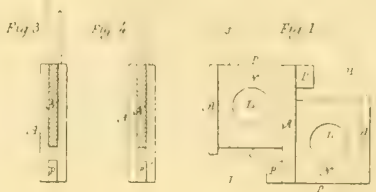

Sif is

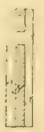

$$
\text { 군. }
$$

H. A. HOUSE.

Bale Ties.

No. 133,858. Patented Dec. 10, 1872.
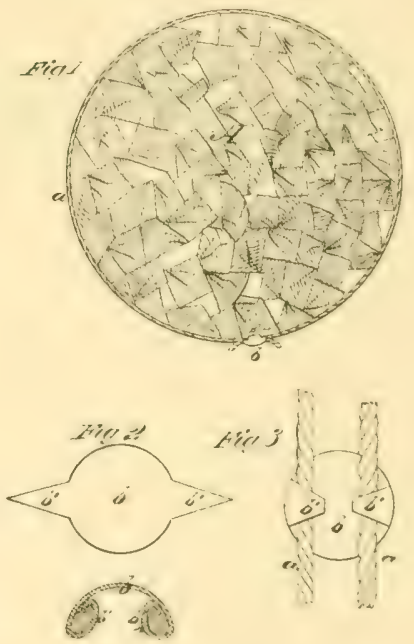


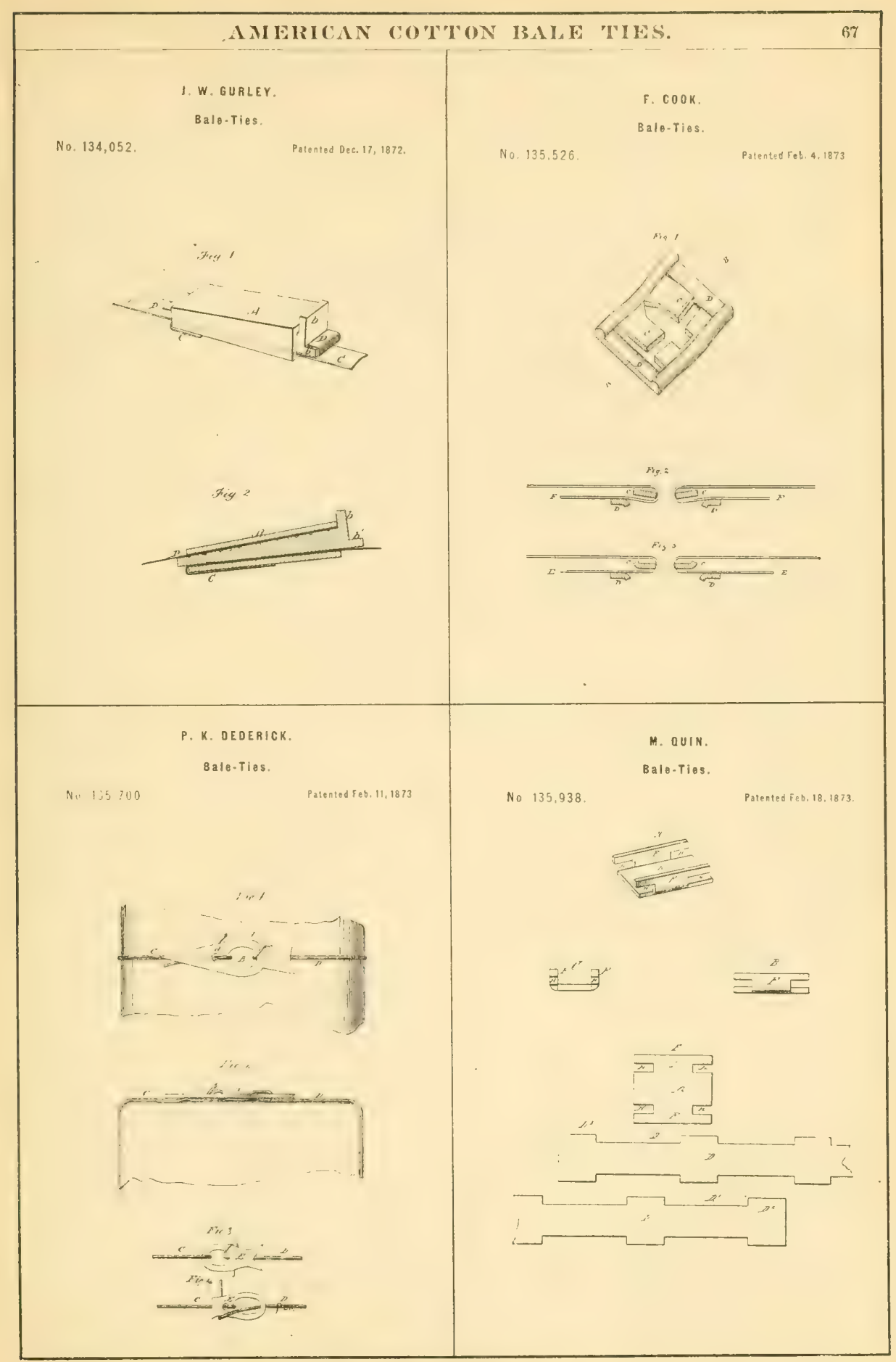


A. 1. GOING.

Cotton Bato Tios.

No. 137.30

Patented April 1, 1873.

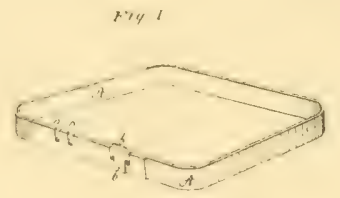

ig. 2

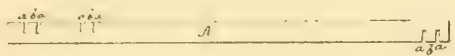

J. W. HEDENBERG.

Bale-Ties.

No. 137,549

Patenied April 8, 1873.

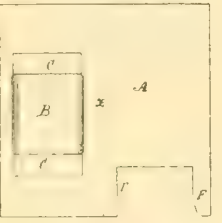

Fiy 2
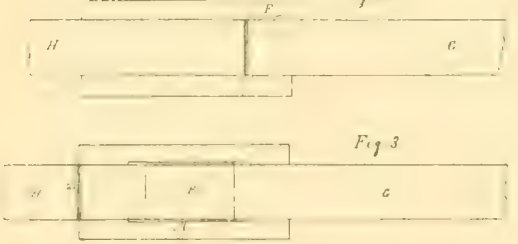

Fig
A. J, GOING.

Copton-Bale Tías.

Nin 5,553

Roissued AgRust $26,:-73$.

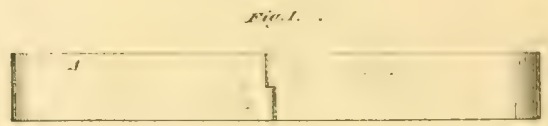

Fier $\ddot{n}$

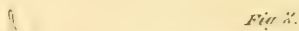

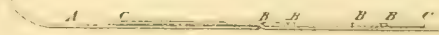

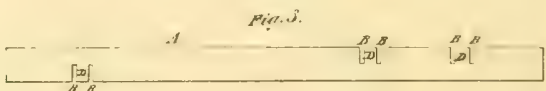

W. C. RAMSAY,

Cotton Bale Ties.

No. 137,570

Patented April 8, 1873 .

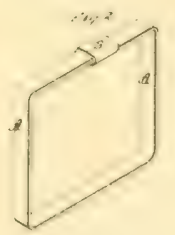


F. COOK.

Bala-ties.

Ni. 138,479
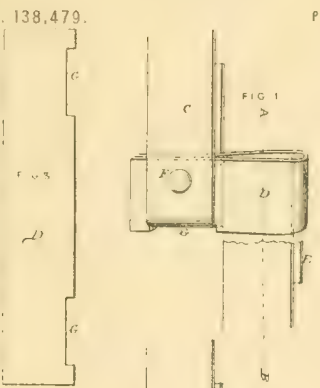

Patented May 6.1873.

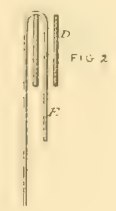

F. $\operatorname{coOK}$.

Cotton-Bale ties.

No. 138.481

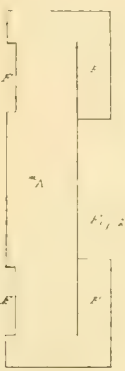

Polented May 6,1873 .

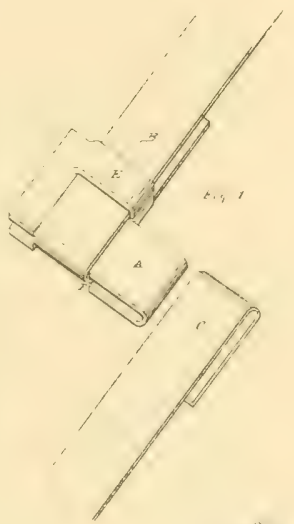

$x, 4$
F. COOK.

Bale-Ties.

No. 138,480 .

Patented May 6,1873.
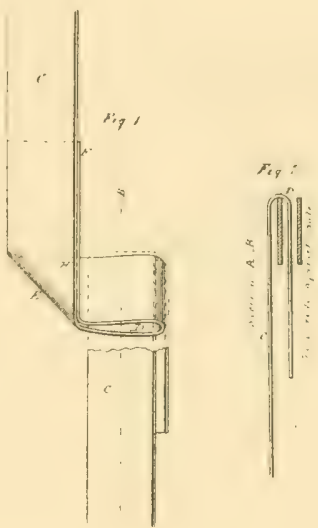

Fig.

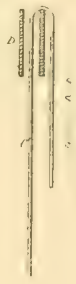

F. $\mathrm{COOK}$

Cotton.Bala Ties.

No. 138,482

Palented May 6, 1973.

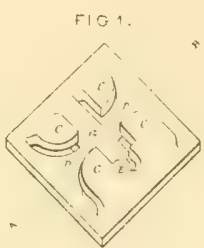

F.G 2

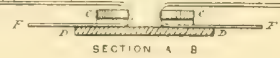

F. G 3

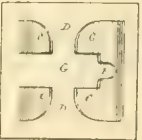

DOTTOM VIEW 
F. COOK.

Corton-Bale Ties.

No. 138.483 .

$\begin{aligned} & f i, i L_{i}^{\prime} \\ & L^{*}\end{aligned}$

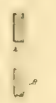

W. D. FIELD.

Cotton-Bale Ties.

No. 138,492 .

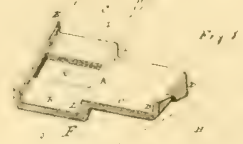

Patented May 6, 1873.
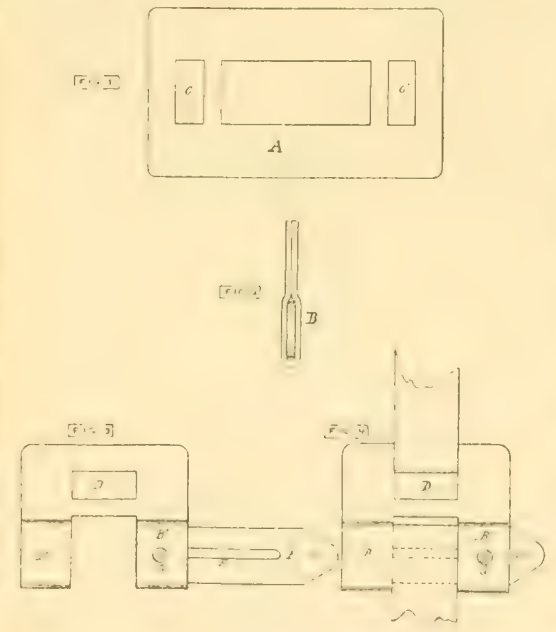

F. $C 0 O K$.

Cotton-Bale Tís.

No. 138,484

Patented May 6, 1873
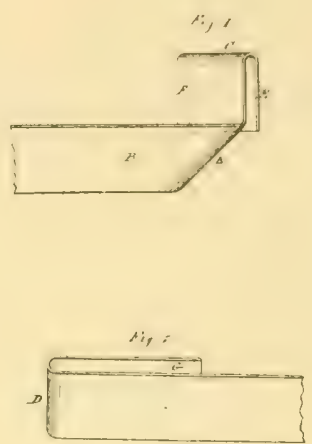

E. P. $10 N E S$

Bale-Tios.

No. 139,675

Patented June 10 ,
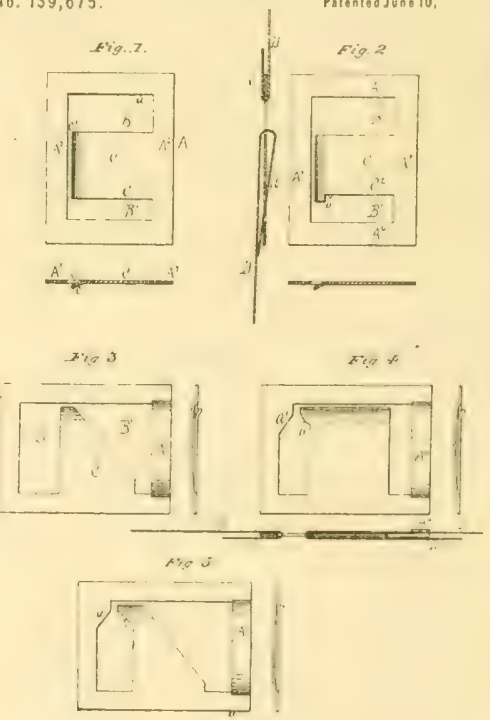
A. S. ARMSTRONG.

Coteon-8ala Ties.

No. 139,754
F. COOK.

Cotton-Bale Ties.

No 139.777 Patented June 10.1873
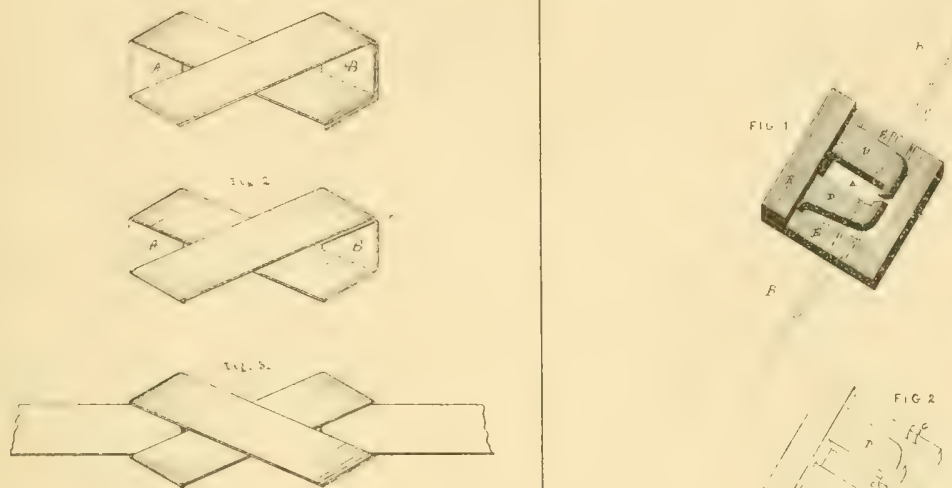

W. D. FIELD.

Cotton-8ale TiBs.

No. 140.024
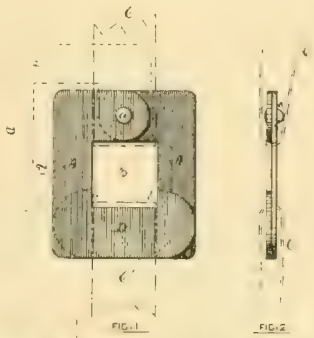

Fic. 2

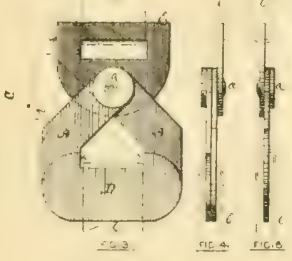

F. COOK

Cotton-Bate Ties.

Patented June 24, $\$ 973$.

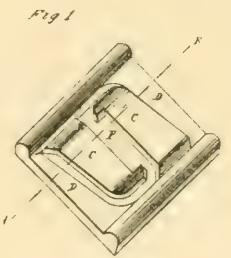

5,2

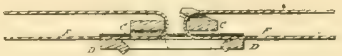



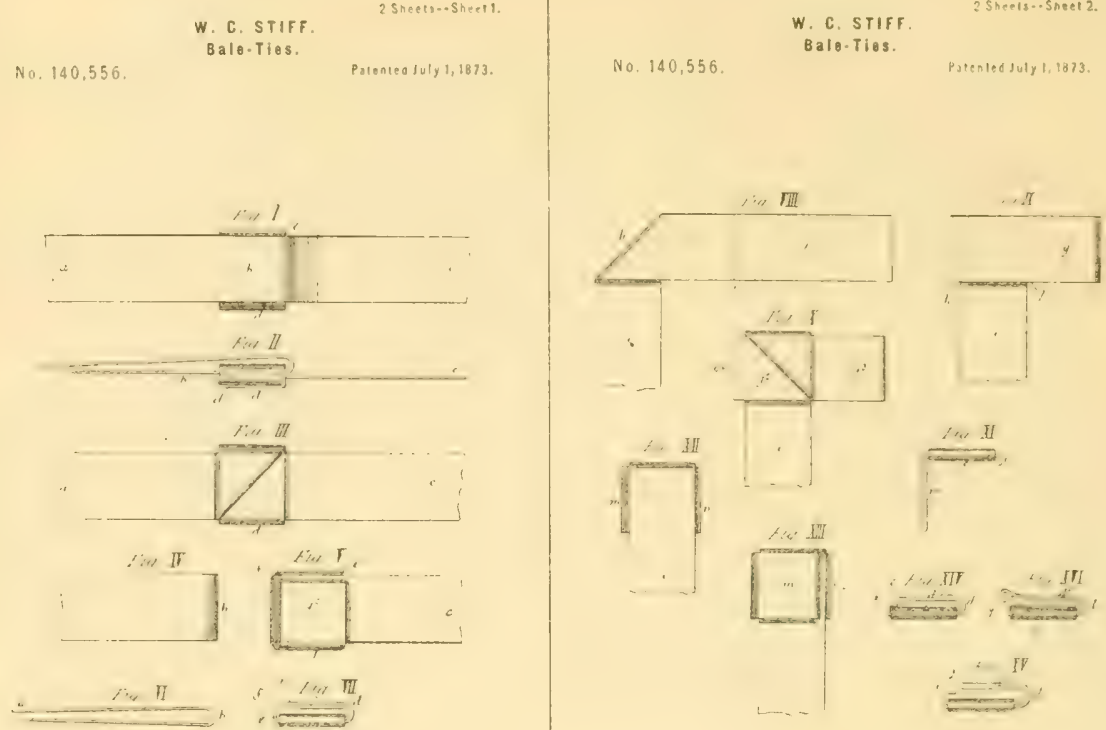

R. W, $C O B B$.

Cotton-Bale Tias.

No. 140,575

Patented July 8,1873
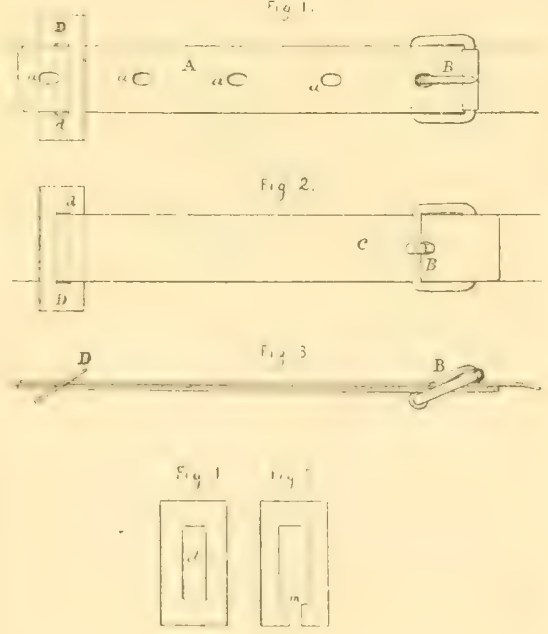

No. 140,556 .

F. $\operatorname{coOK}$.

Cotton-Bate tís.

$140,766$.

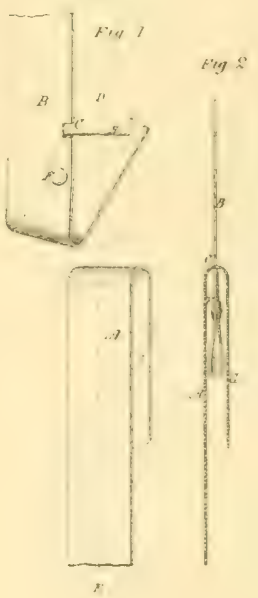

Patented July 15, 1873.
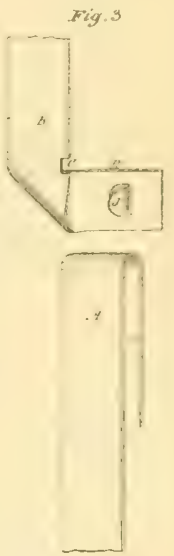
E. I. BEARD.

Band or Hoop-Tios for Cotton-Bales.

No. 140,873

Patented July 15, 1873

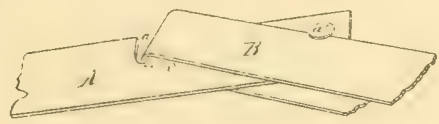

FIG.I.

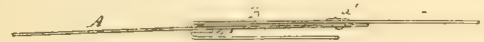

FIG. 2 .

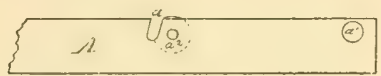

FIG. 3.
F. M. LOGUE.

Balo-Band Stretehors.

No, 141,447

Parented August 5, 1873
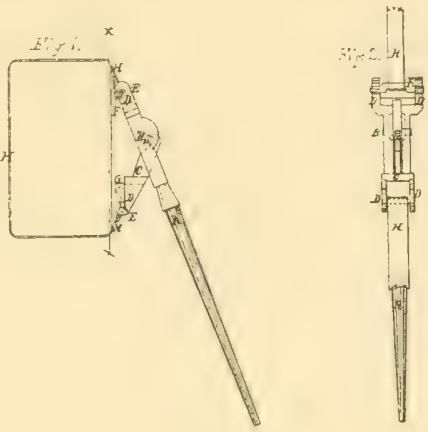

L. DOTY.

Cotton-8ale Ties.

No. 141,494 .

Patented August 5, 1873 .

Fig. $l$.

No. 141,636 .
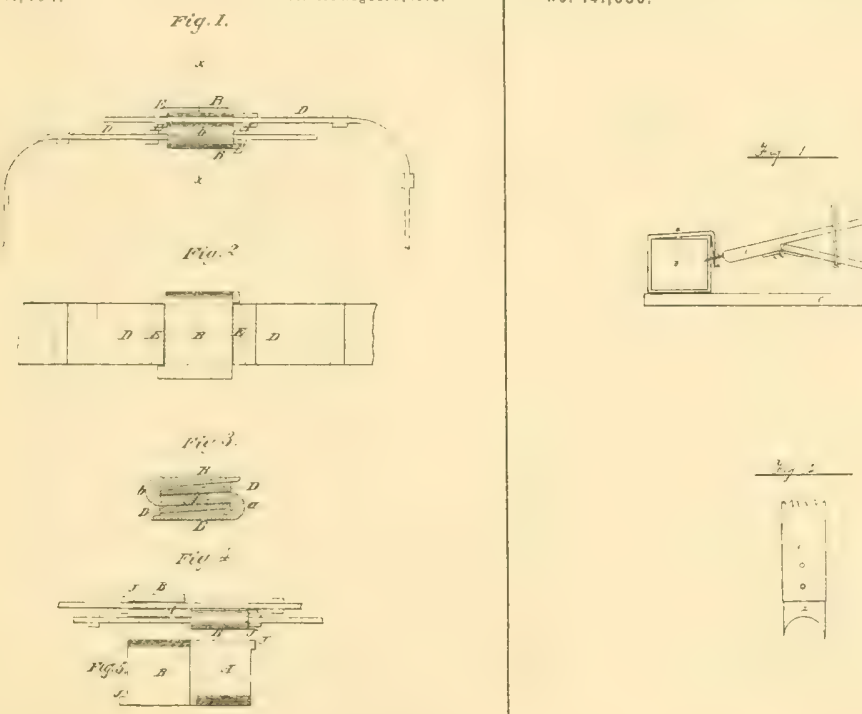
G. L, LAUGHLAND.

Wire-Ties for Ballng $\mathrm{H} \& \mathrm{Y}, \mathrm{\&} C$.

No. 141,879 .

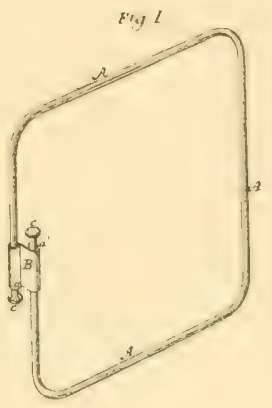

Patentod Aurust 19, 1873 .

W. J, ORR.

Cotton-Bale Tles.

No. 142,505 . Patentod Seplember 2,1873
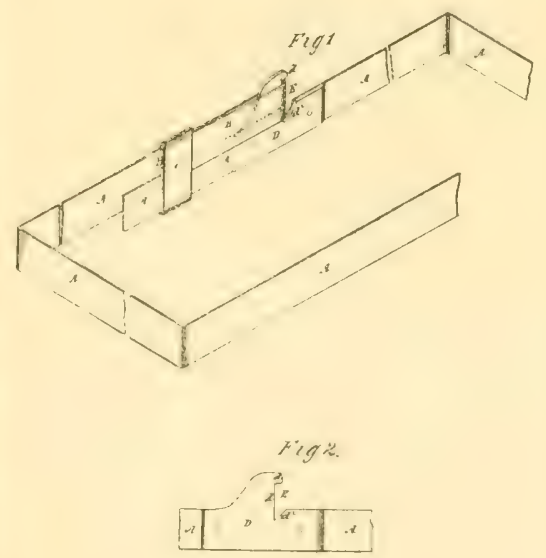

F. $\operatorname{COOK}$

Cotton-8ale Tís.

No, 142,001

Patented August 19, 1873.

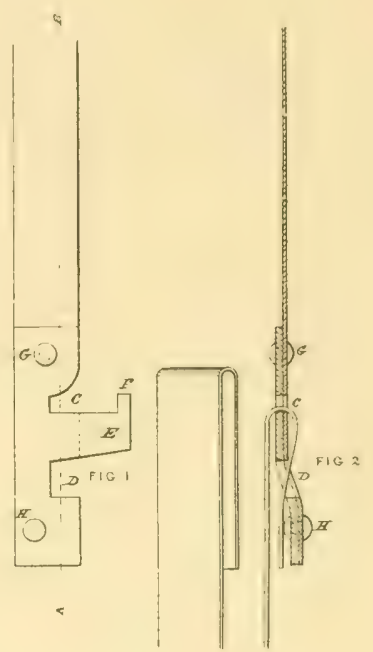

H. D. STARR.

Cotton-Bale TIos.

No. 142,527 .

Palentod Septomber 2, 1873.

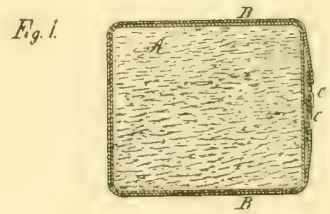

$$
\text { Fig' }
$$

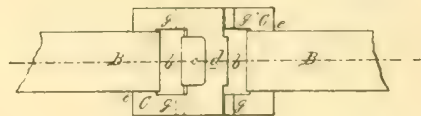

Fig. 3.

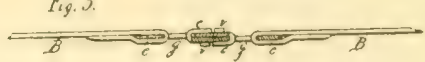

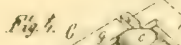




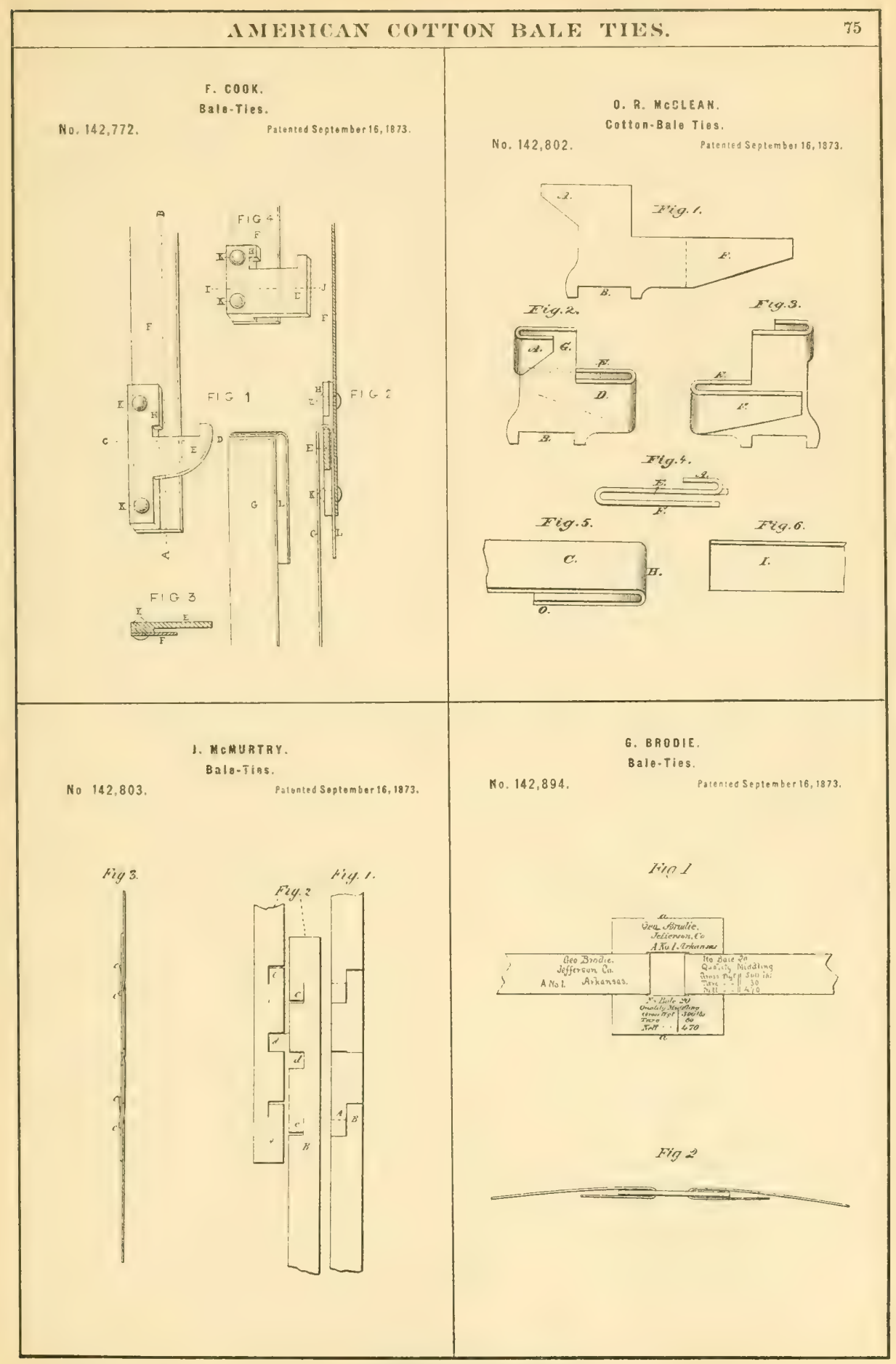


T. CROMER.

Cotton-Bale Ties.

No. 143,124

Patontod September23,1973

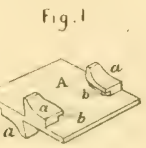

Fig. 3.

D A. $\frac{a}{a} \quad d \quad e^{2}$

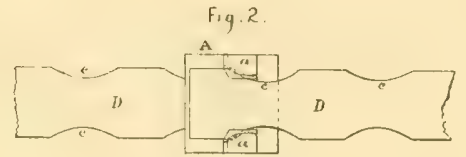

G. N. BEARD.

Cotton-Bale Tlos.

No, 143,319.
F. $C 00 \mathrm{~K}$.

Bato-Tios.

No. 143,223

Patentod September $30,1873$.

Patented Soptomber 30,1823.
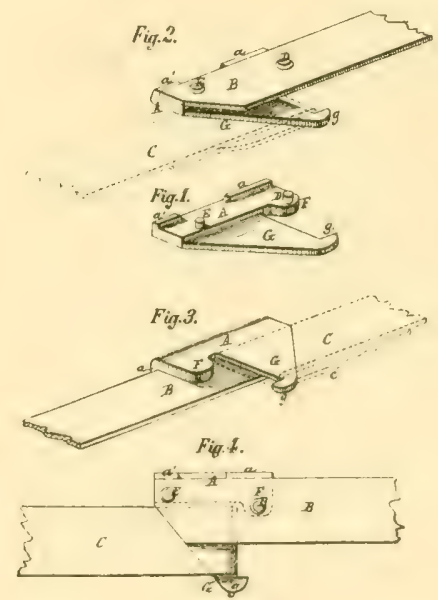

J. M. GOLDSMITH.

Cotton.Bale Ties.

Patented Septembor $30,1873$.
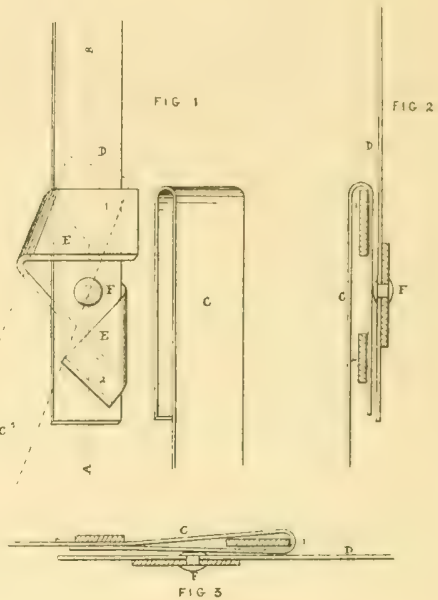

No, 143,343

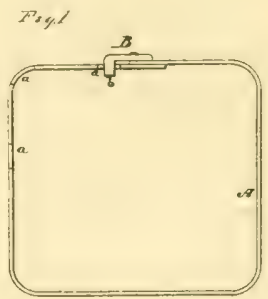

$$
A_{3} 2
$$

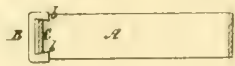

Heg 3

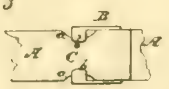


B. KIMBALL.

Cotion-Balo Ties.

No. 143,911

Palented Oct. 21, 1873.

$z_{8}, j$

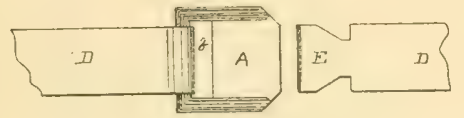

7., 2

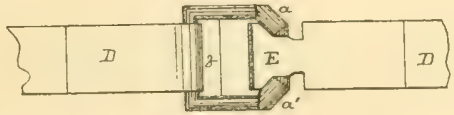

7q. 3

$D \ldots \theta^{\alpha}$

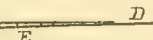

T. D. LEONEARO.

Bela-rio Clamps.

No, 144,776.

Patonted Nov, 18, 1873 .

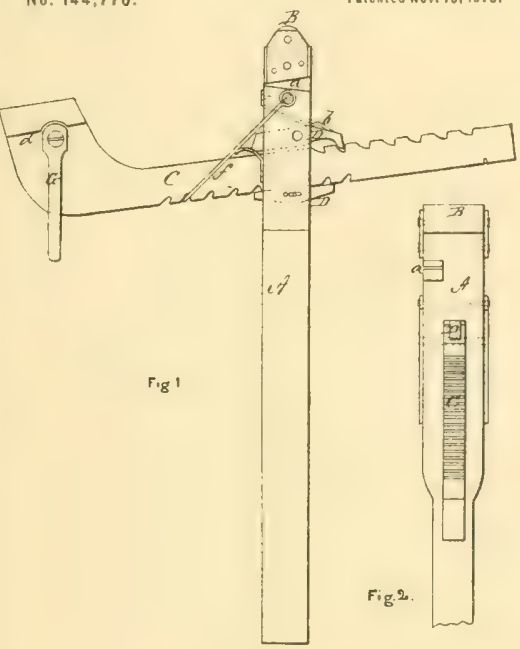

A. 6. BUFORD. Cotton-Balo Tios.

No. 144,502 .

Patonted Nov, 11, 1873.
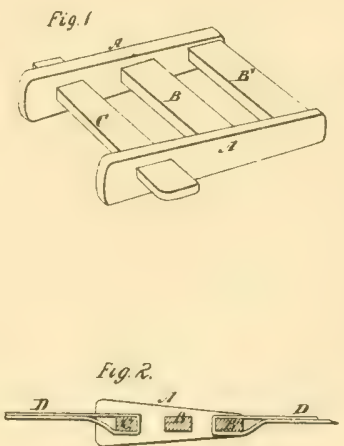

F. QUARLES.

Cotton Balo-Tios.

No. 144,793 .

Patented Nov, $18,1873$.

$$
\text { FIC } 2
$$

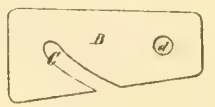


L. GARTER.

8ele-Tías.

No. 145,091

Patentod Doc. 2,1873.

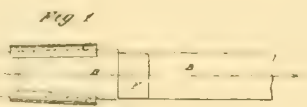

*

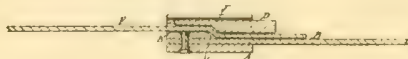

I

1. HECLEAK.

Dovices for Forming Bale-Tlos.
No. 145;357. Patonted Dece 9, 1873.

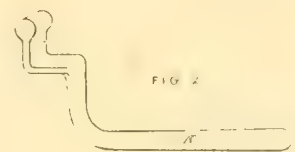

fifs

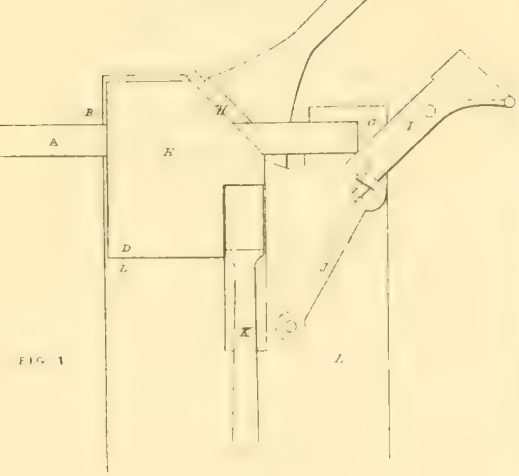

6. N. BEARO.

Cotten-Bale Ties.

No. 145,273

Patenled Dec, 9, 1873.
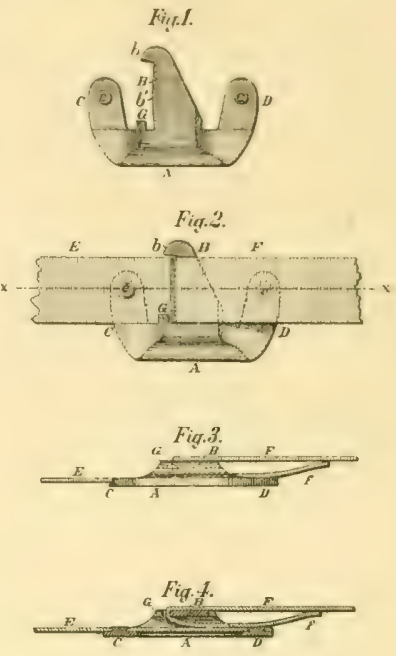

J. MGCLEAN

3 Sheels.. Shed 2.

Bovicos for Forming Bale.Tles.

No. 145,357 .

Palented Dec, 9, 1873
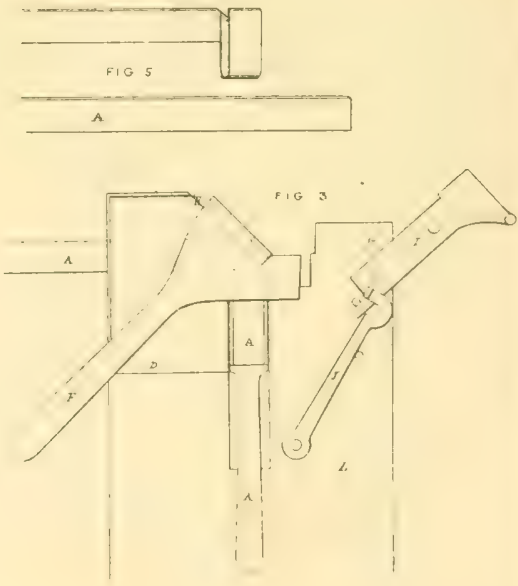
J. MCCLEAN

Dovices for Forming Bale-Ties.

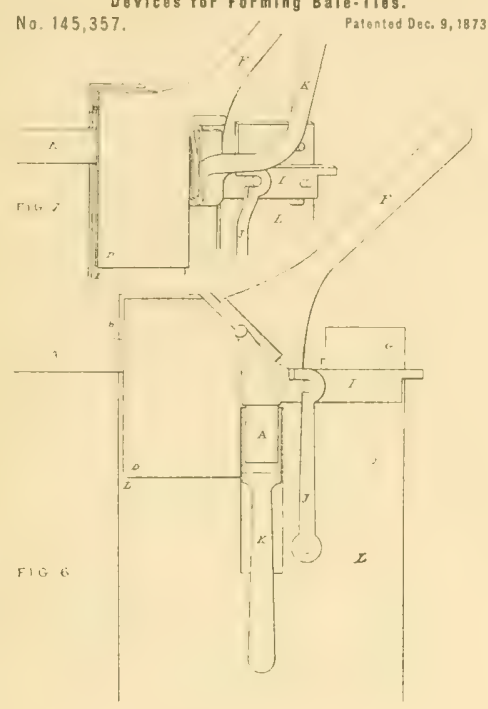

D. S. SKINNER

Cotton-Bale Ties.

No. $115 \$ 30$

Palented Dec. 16,1873
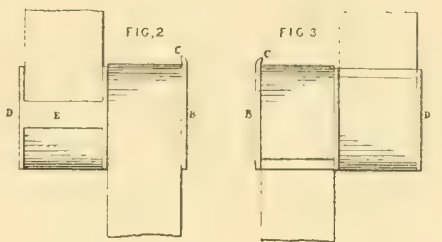

FIG. 1

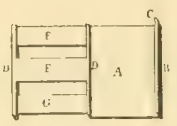

F. $\cos x$.

Balo-Ties.

No. 145,847 .

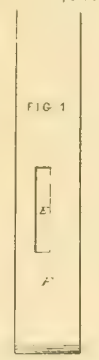

Patented Dac. 23,18i3.

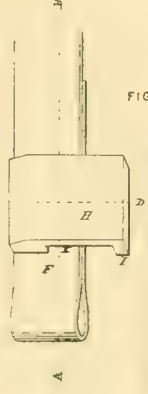

FIG 9

FIG $10, \quad$ G $P$ FIG
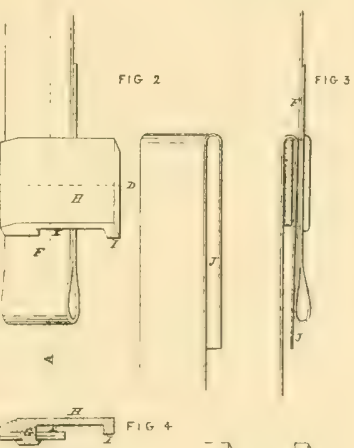

$\overbrace{0}$ FIG 5
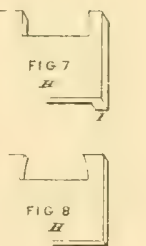

l. WEIL.

Cotton Balo-Tios.

No, 146,037 .

dig. 2.

$\stackrel{0}{i}$

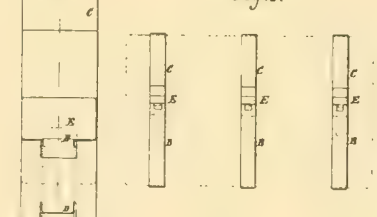

th

tris

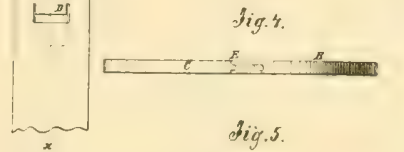

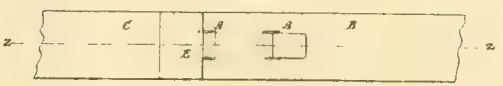

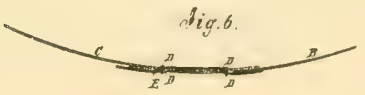


1. W. HEOENBERG. Balo-TIBS.

$N_{0}, 146,529$

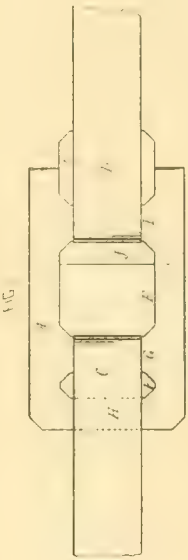

Palented 12n, 20,1874
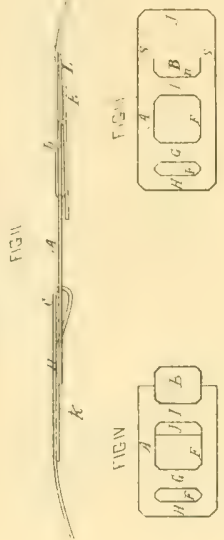

W. A. JORDAN.

Cotton-Balo Tiss.

No. 146,911 .

Patentod Jac, 27, 1874

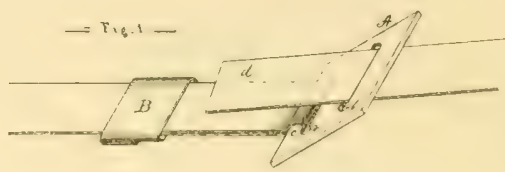

$=r \cdot q 2=$

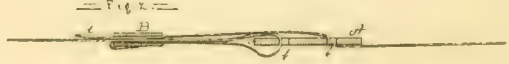

C. DRISCOLL.

Bala-ries.
No, 147,015 Balo-TIgs.

Patented Feb, 3, 1874.

Fig?

Fig 3

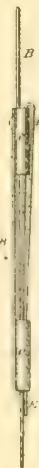

Patented $5 e b, 3,1874$

No.147.049
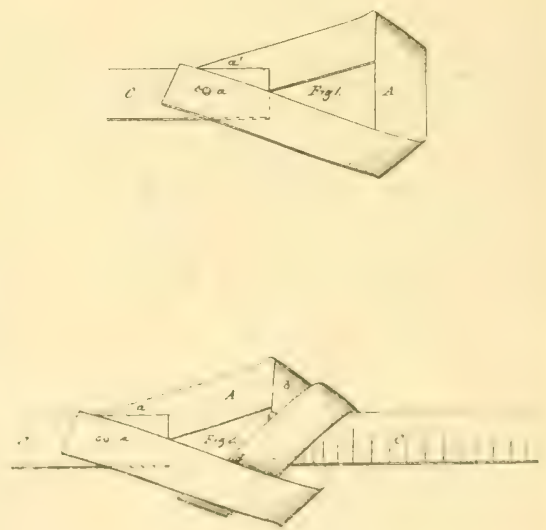


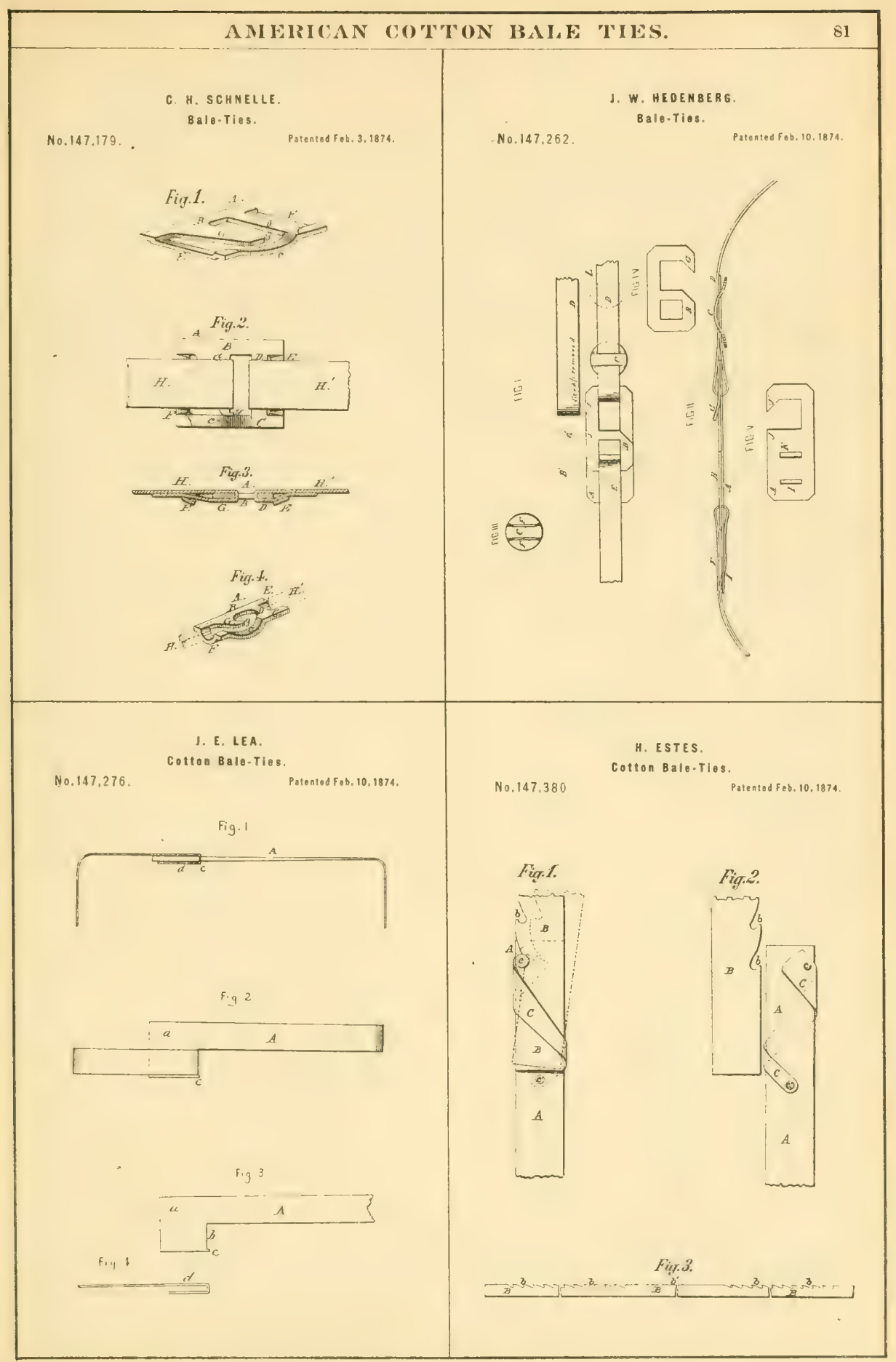


H. ESTES,

Cotton Balo-Ties.

No. 147.381.

Patentod feb, 10, 1874.
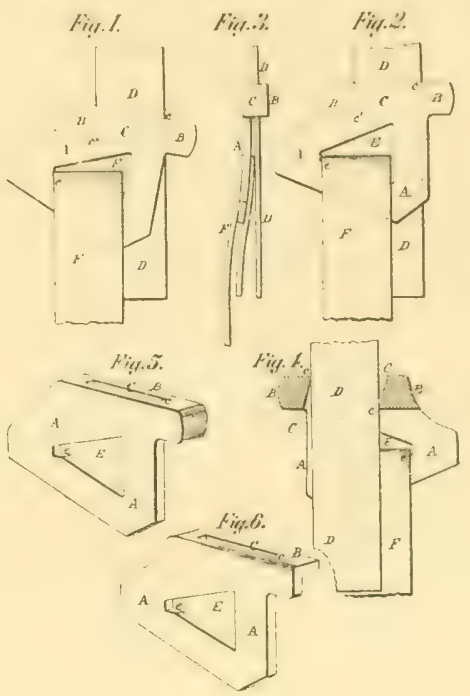

E. J. BEARD

Cotton Bale-Ties

No 147,811

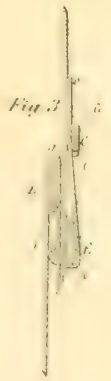

R. FELL, Jr.

Cotton Balo-Tios.

$N_{0}, 147,757$
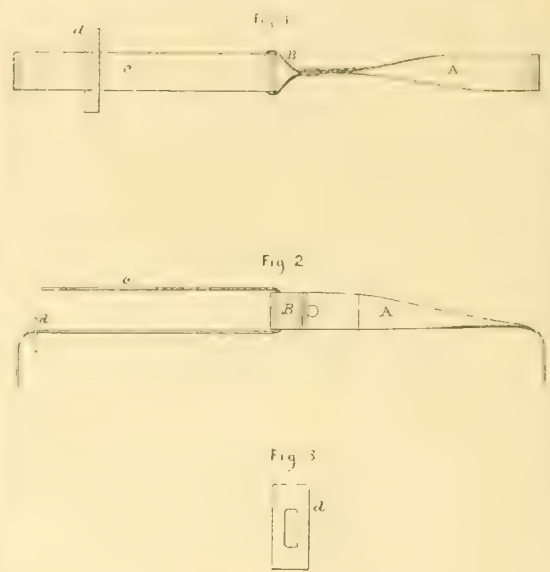

E. W. WHITEMAM.

Cotton-Bale Ties

No. 147,883

Fi:4:

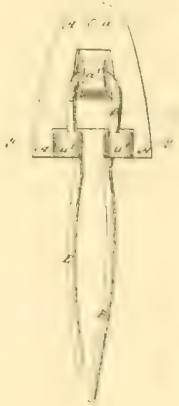

Patented Feb, 24, 1874.

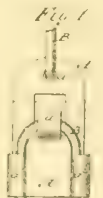

$60:$ 


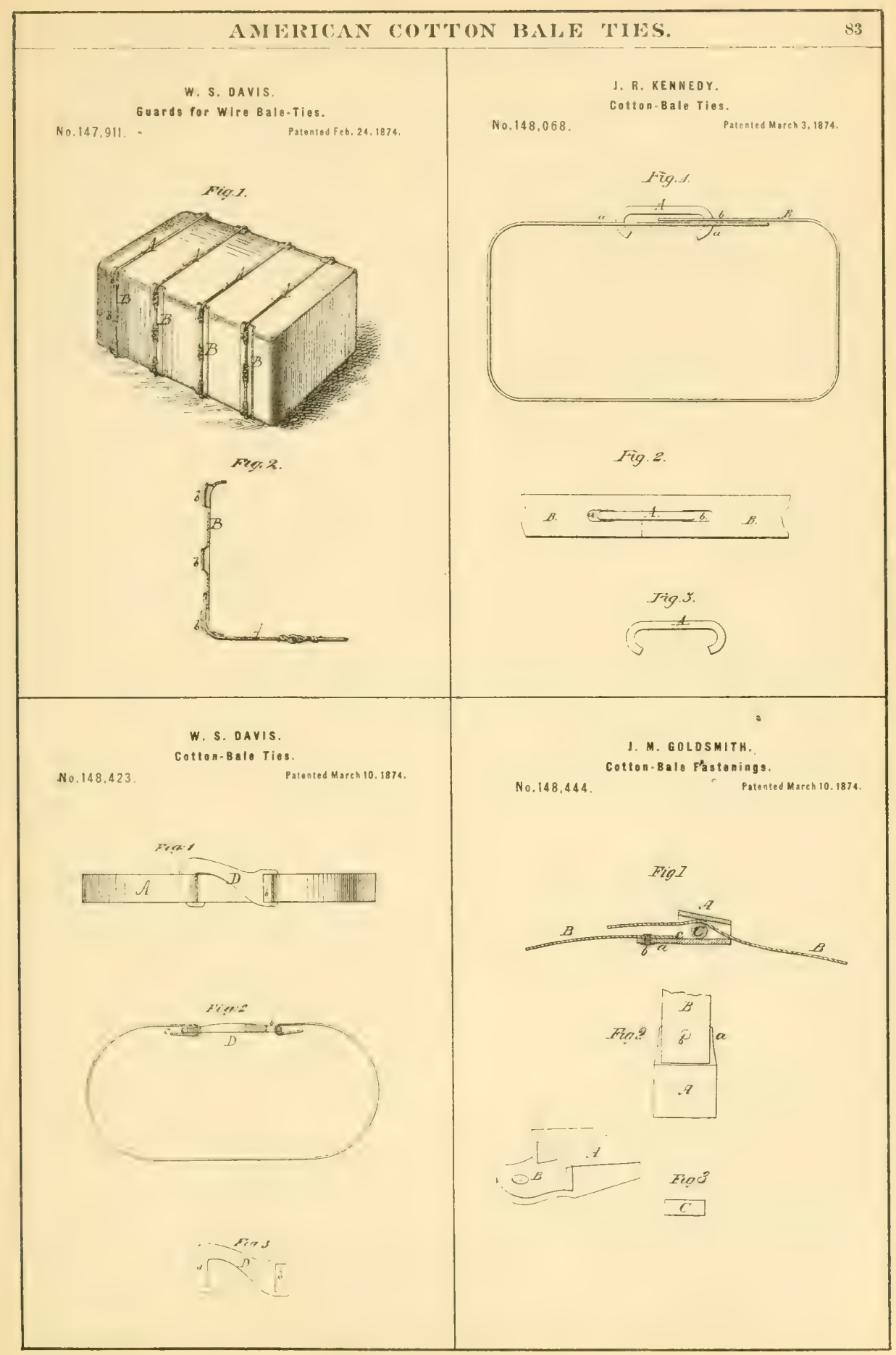


F. LOGUE.

Bale-Bands and Buckles.

No.148.890.

Patentod Maren 24, 1874.

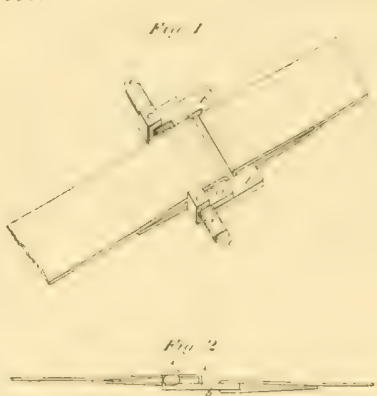

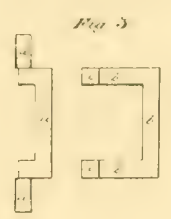

A. J. NELLIS.

Cotton-Balo Ties.

No.149,144.

Patentod March 31, 1874.

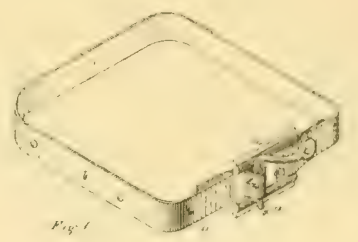

J. G. ANGELL.

Cotton-Bale rias.

No.149.424

Patented Aprll 7, 1874
A. A, GOLDSMITH.

Cotton-8ale Tís.

No.149.468.

Patented April 7, 1874.

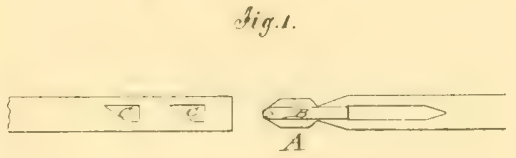

ig. 2.

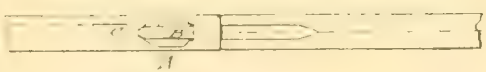

fig. 3 
T. F. SHERRILL.

Cotion-Bzlo ties.

No.149,531.

Fatented Aprll 7, 1874.

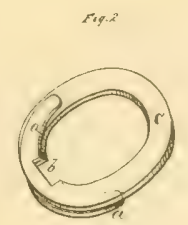

A. 1. NELLIS

Cotton-Bale Ties.

No. 149,949 .

Patented Aprll 21, 1874
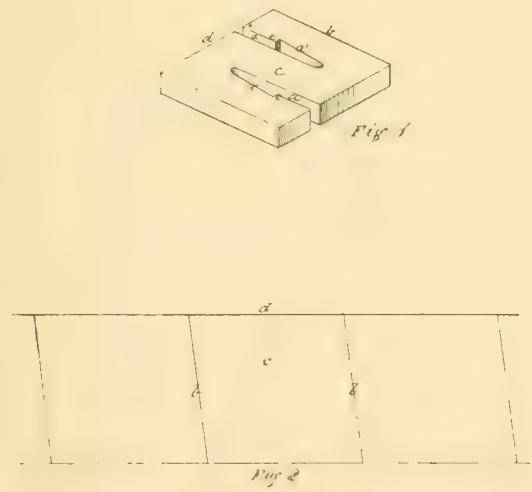

1. L. RANDOLPH.

Cotton-Babe Tles.

N?.149,605.

Patented April 14, 1874.
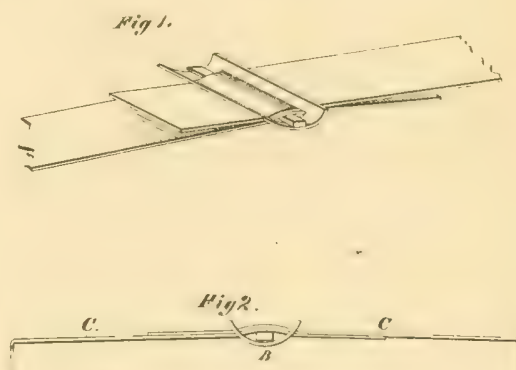

Fig 3.

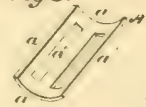

순 4

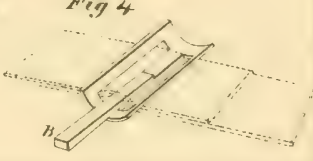

E. H. STAEFORD.

Cotton-Bala ties.

No. $150,096$.

Patented April $21,1874$.

incel.
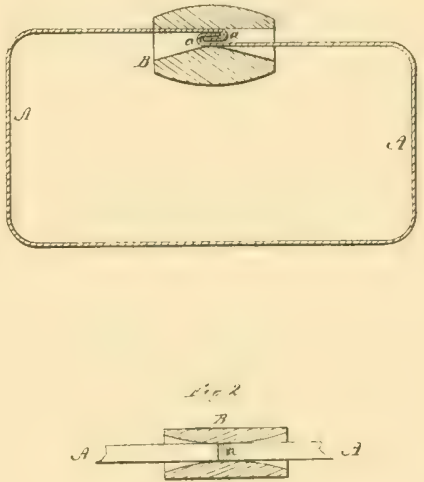
A. B. HAGAMAN. Balo-TIBS.

No. 150,238
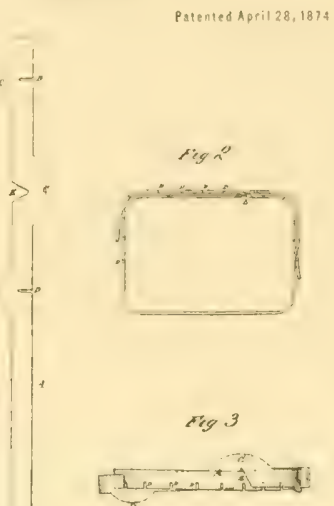

1.W. PARISH.

Balo-TIBS

$N_{0}, 150,885$

Patented May 12,1874.

Fig. 7
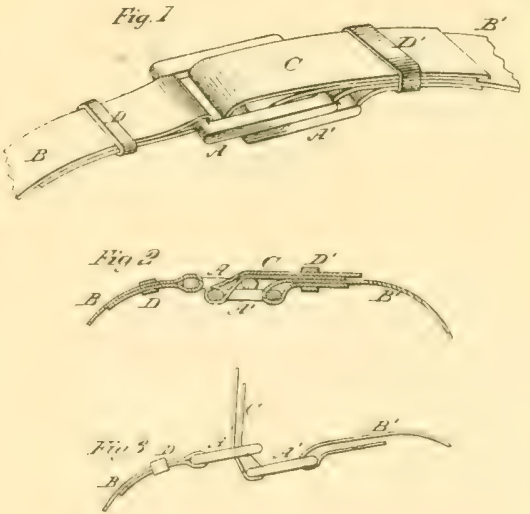

iin
J. H LANE.

Cotton-8alo Tios.

No. 150,246

Patented April 28, 1874
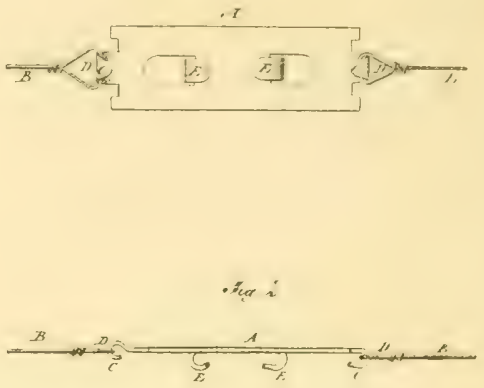

F. L. BATES.

Balo-Ties.

Patenled May 19, 1874.

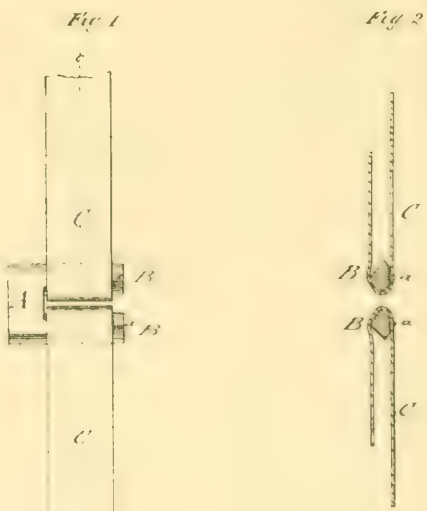




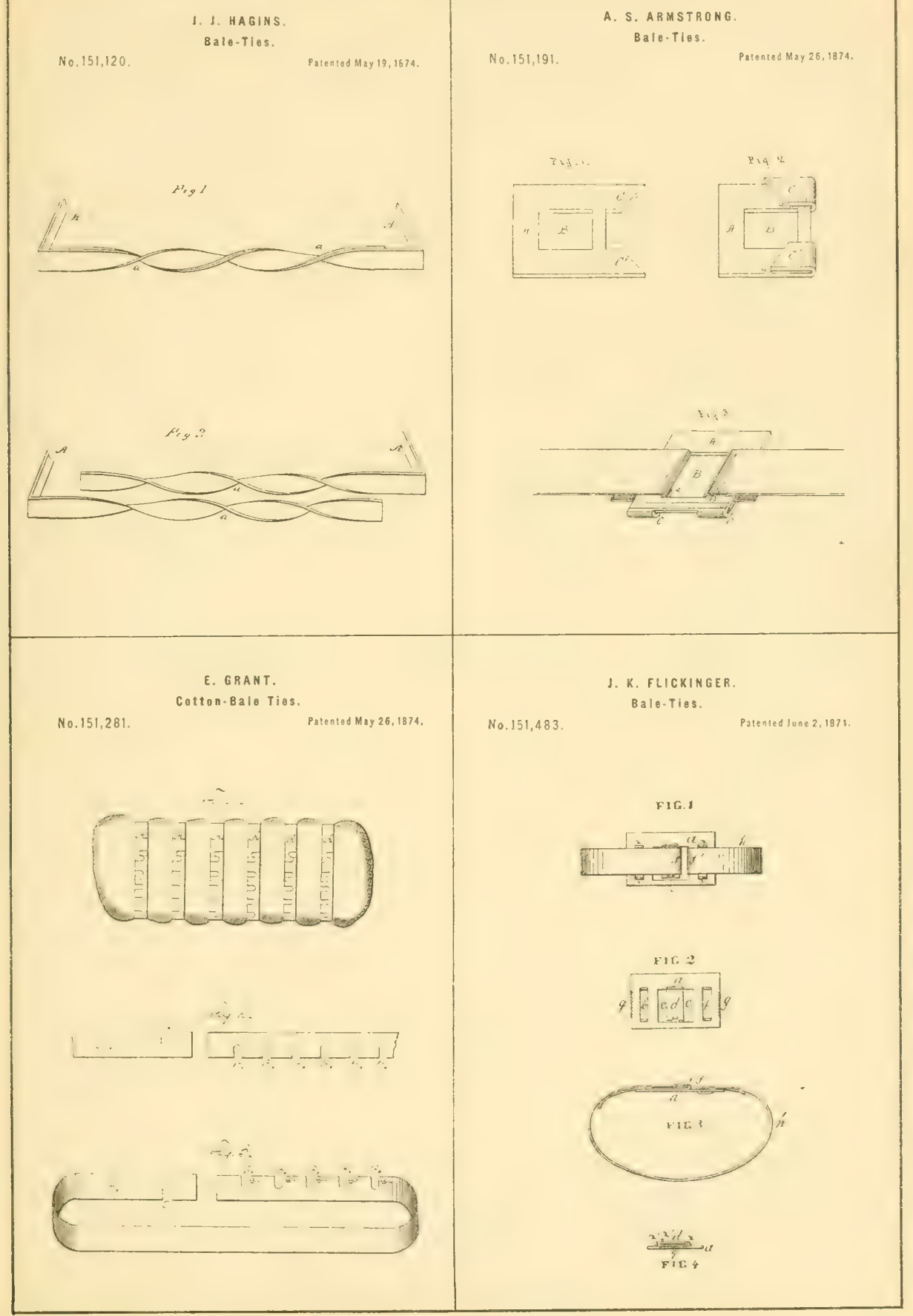


W. S, DAVIS.

Bale.Tlo fastenlnge.

No.151.572

Patented June 2, TB74.

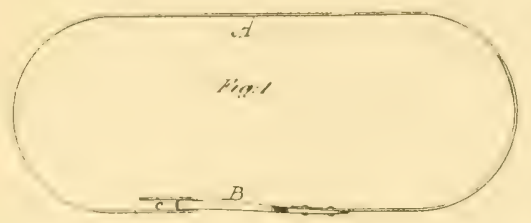

G. BRODIE.

Cotton.Bato TiBs.

No. 151,831 .

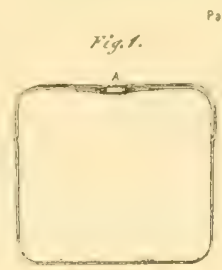

$\therefore$ is 2

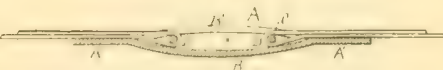

$\therefore$ J

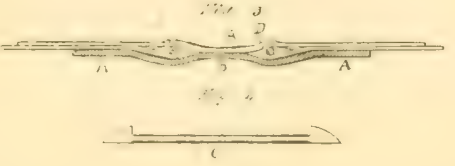

G. B. FORO

Bala-Tles.

No. 151,770

Palonted June 9, 1874.

Fie

$\left|\begin{array}{c}4 \\ 8\end{array}\right|$

Nio 2
man.
and

Tios

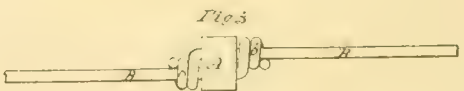

Bale.Ties.

Patented June 18, 1874.

No.152,138
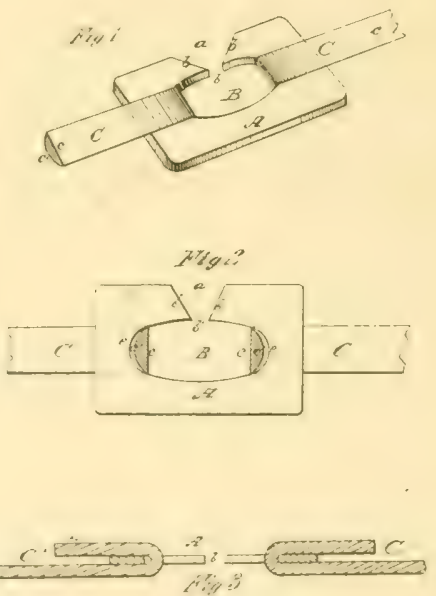
A. A. GOLOSMITH.

Cotton-8ale Ties.

No. 152,362

Patented dune 23,1874 .
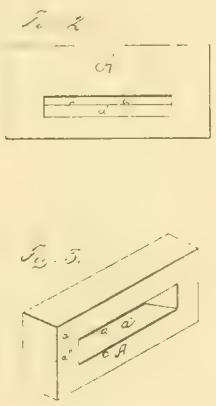

J. M. GOLDSMITH.

Cotton-Balo TIos.

$N_{0}, 152,480$

Patented June 30,1874 .
G. W. SCOTT.

Cotton-Bale Ties.
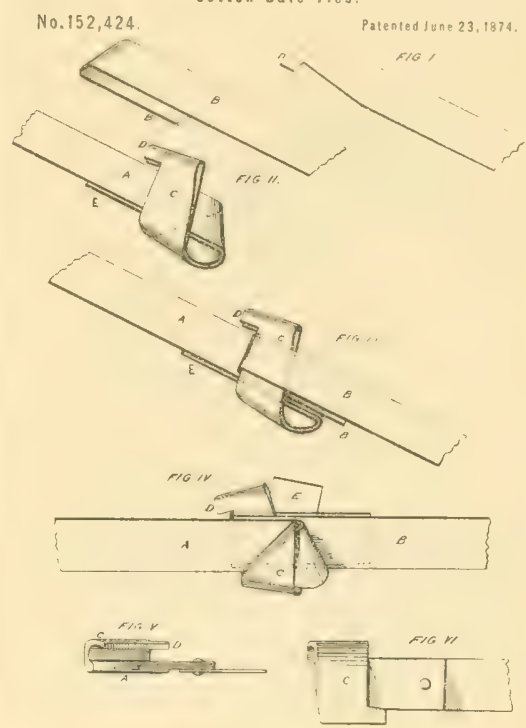

W. C. BANKS.

Cotton Bale. Ties

No.152,823
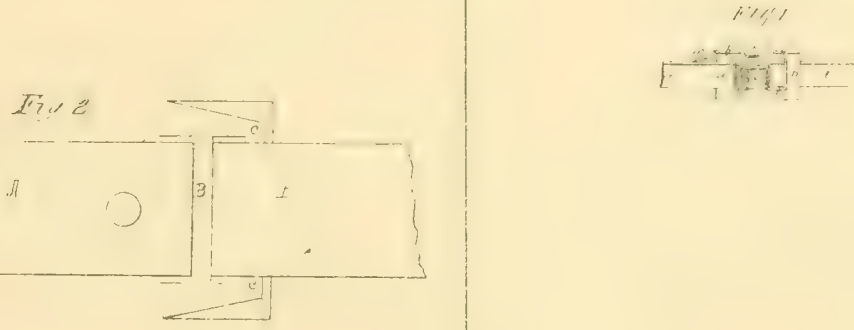


\section{AMIRICAN COTION IBAIE TIES.}

A. BALOWIN.

Cotton-Bale Tís.

No.153,035

Patented Iuly 14, 1874.
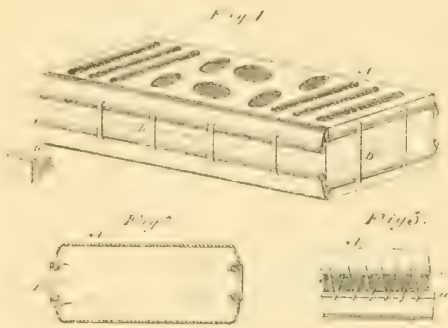

firei.

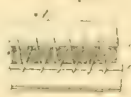

F."." "

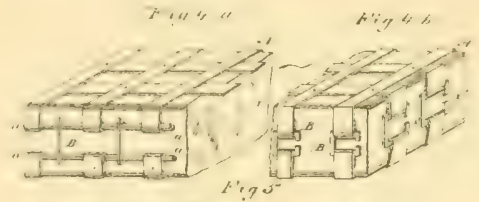

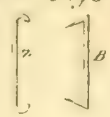

Y. F. WRIGHT.

Cotton-Bale Ties.

No. 153,469

Pstentod July 28, 1878 .
W. COOPER.

Cotton.Bala Tís.

No. 153,317

Patented July $21,1874$.

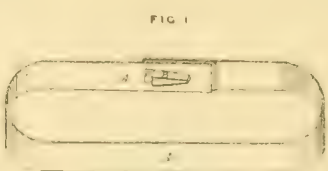

rie: is

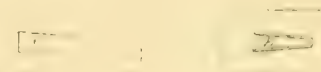

Fic 1:
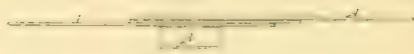

Fic III

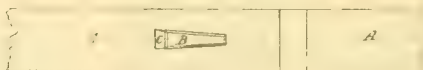

J. G. BATTELLE.

Cotton-Balo Tlos.

$N_{0}, 153,656$

Patented Aug. 4, 1874.

Wis,

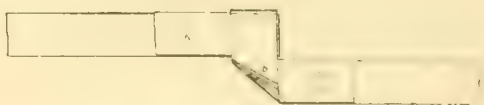

Tiv.

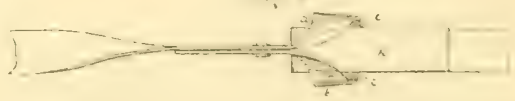


W. CRONE \& T CROMER. Cottor-Bale TIOS.

No. 153,669 Patented Aug. 4, 1874 .

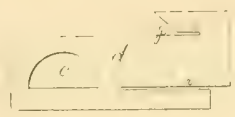

$\therefore 2 \%$

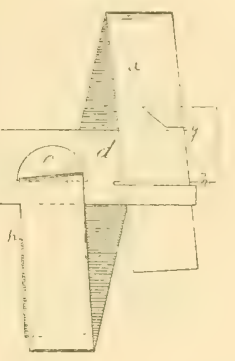

W. S. DAVIS.

Cotton-Bale Ties.

No. 154,229

Patented Aug, 18, 1874.

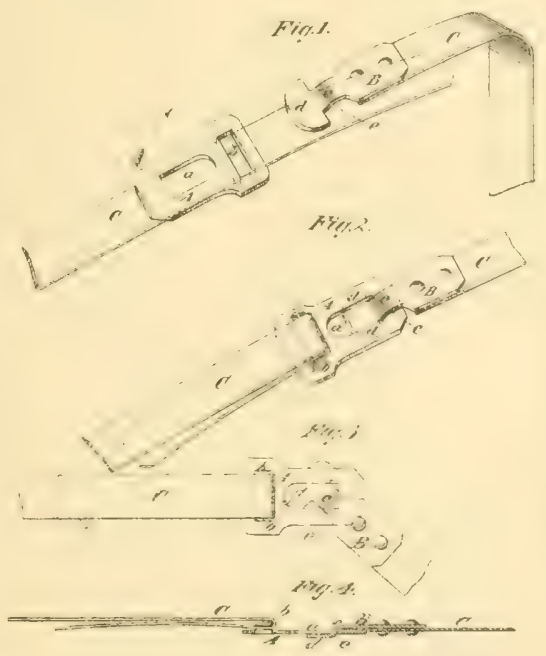

A. A. GOLDSMITH.

Cotton-Bale TIEs.

$N_{0} .153,820$

Patontes Aug. 4.1874.
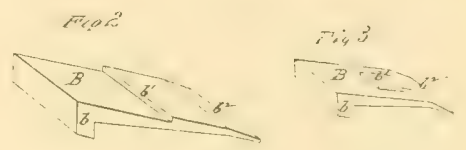

सहक :
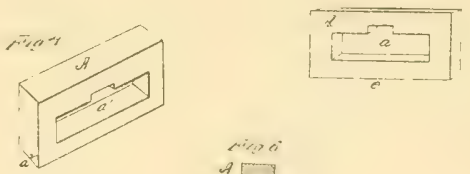

R. D. MCILWAINE.

Cotton-Bato Tios.

Patented Aug. 18, 1874,

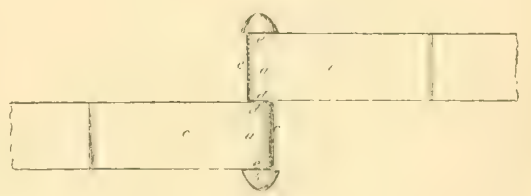


1. D. HUSBANOS, Ir Bate-Ties.

No.154,797

Patented Sept, 8, 1874
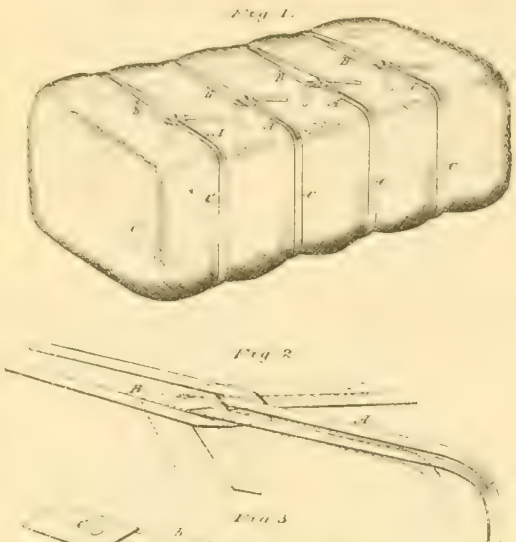

W. M. SMITH

Cotton-Bale Ties.

No. 154,920 .

Patented Sept. 8, 1874.
W. R. LENAPO

Cotton-8ale Ties.

No.154,799.

Palentod Sept. 8,1874.

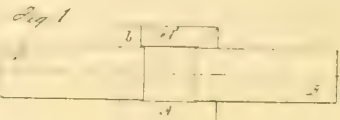

is is
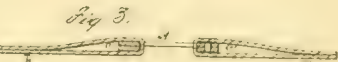

O. D. \& E. C. WOOBBURY.

Cotton Bate-Ties.

No, 154,998 .
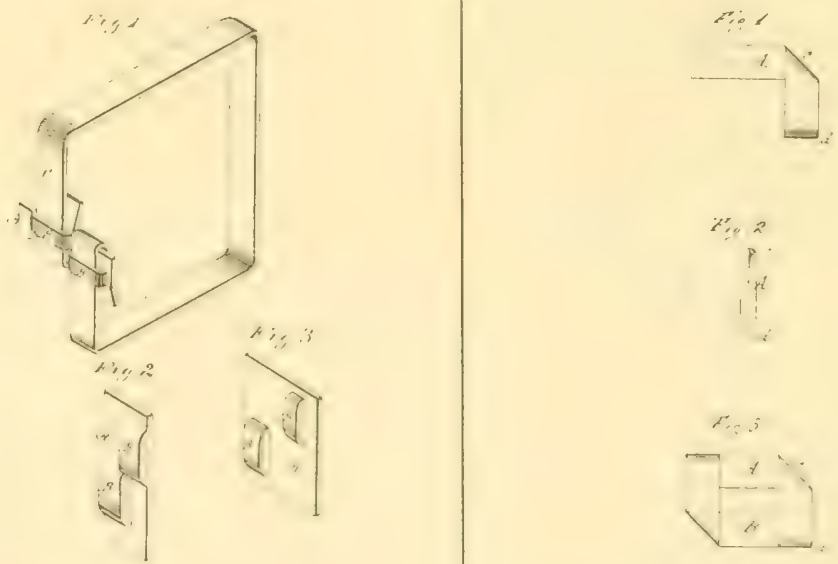

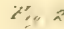

$p$

$\cdot y^{\prime}$
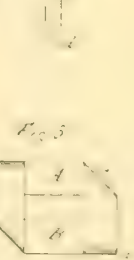
A. A. GOLOSMITH.

Bale-Ties.

No. 155, 234 .

Patentod Sept. 22, 1874
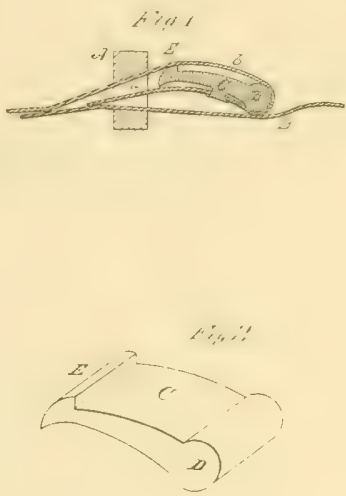

A. A. $\$ Z A B O$

Cotton-Bale Ties.

No, 155,344
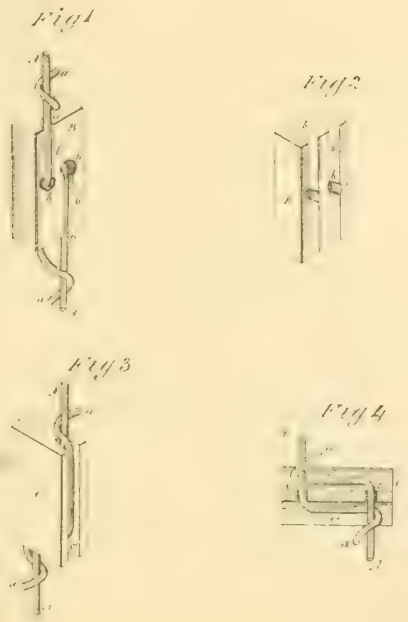

W. H. TILLERY.

Cotton-Baie Ties.

No. 155,271.

Patented Sept. 22,1874.

$$
\text { Fi: } 1
$$
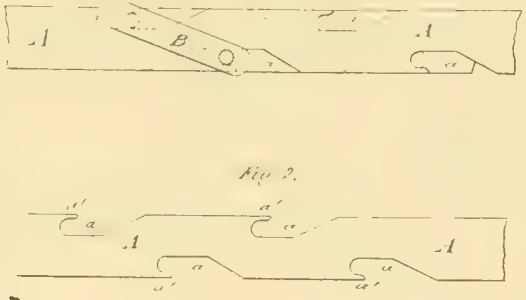

Fig 3.

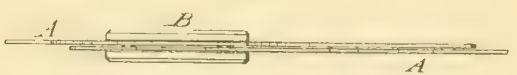

J. BOISSEAU,

Bala-Tías.

No. 155,413

Patonted Sopt. 29,1874.
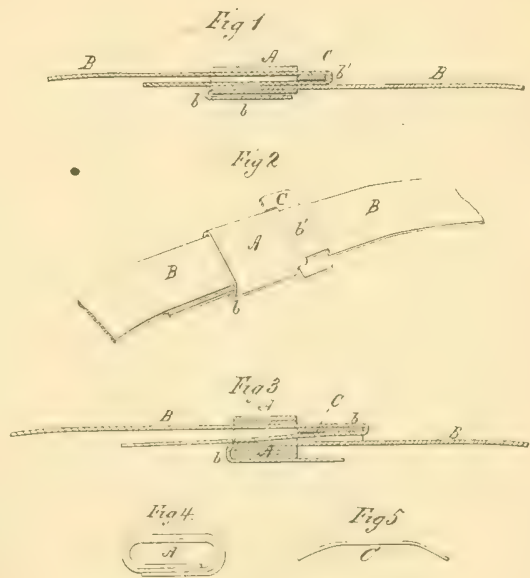
No. 155,981 .

Eale-Ties.

Patentod Oct. 13,1874

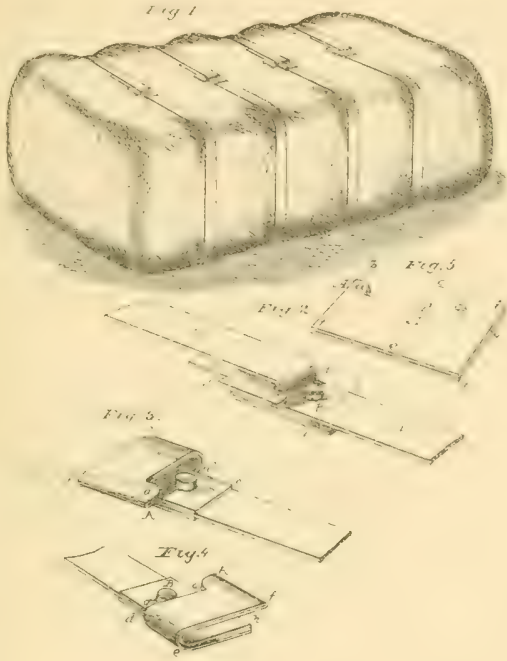

B. T. BROWN. Bale-ties.

No, 156,013 .

Patented Oct. 20,1874
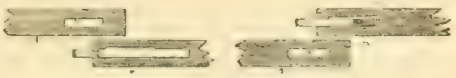

G. W. SCOTT.

Balo-Ties.

No. 155,982.

Patented 0cl, 13,1874

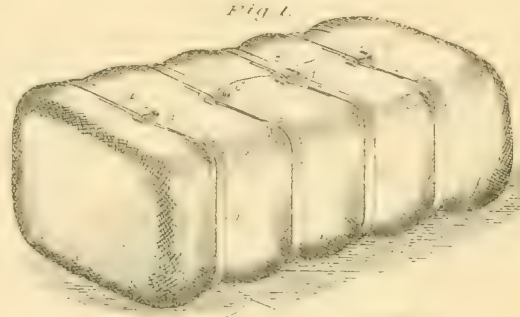

$x+2.2$
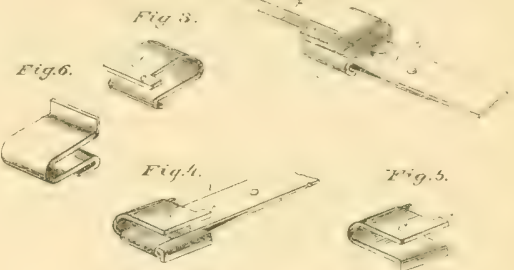

Fig.s.

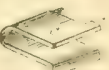

R. TERRELL.

Bale-Tiss.

Patented 0c1. 27, 1874.

No.156,262.

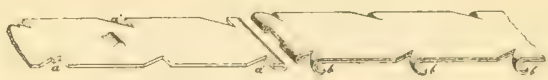

Fic: 1 .

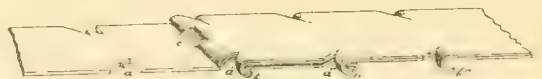

$F_{1 G} \geq$.

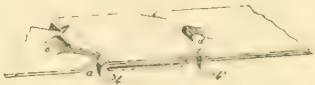

Fia.5. 
B. TERRELL.

Bale-TIOS.

No. 156,263 .
H. 8. JONES.

Balo-Tios.

No. 156,292 .
Patentod 0et, 27, 1874.
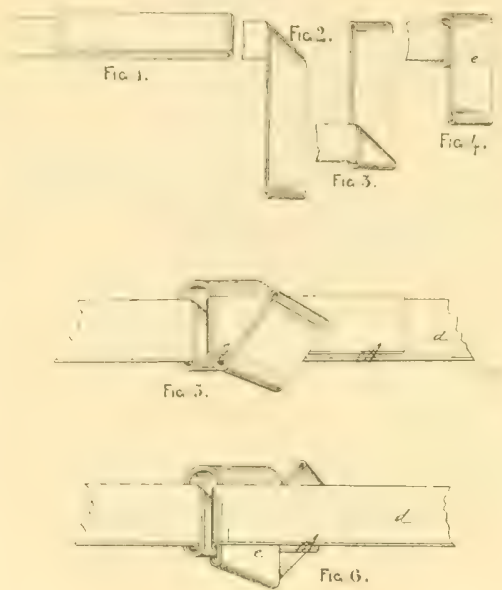

B. MONTFORT.

8alonties.

No. 156,490

Patented Nov, 3,1874.

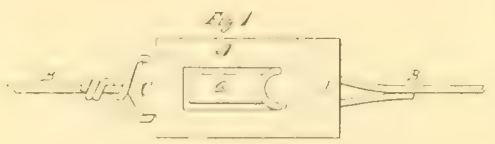

$\therefore ?$

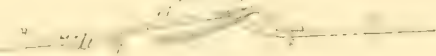

- $\because$
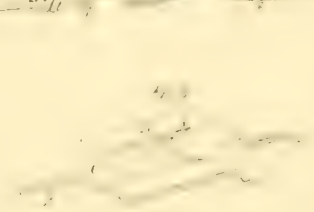

W. S. DAVIS.

$8 \mathrm{alB}$-Tiss.

No. 156,546 .

Patented Nov, 3, 1874.
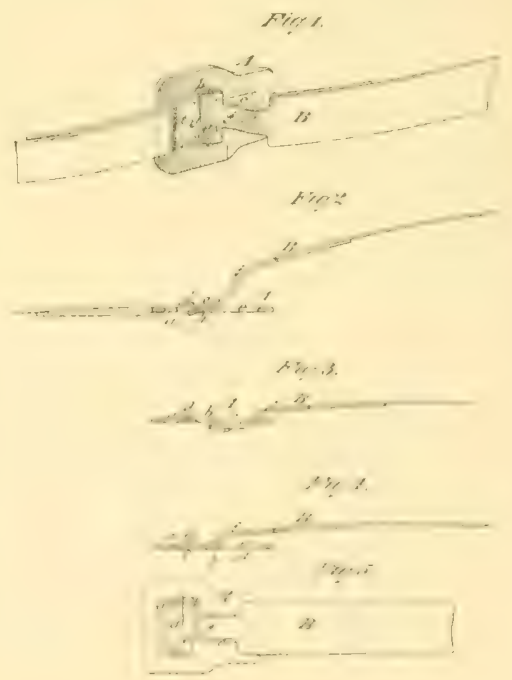
W. S. DAYIS.

Ba!a-TiQs.

\$0, 156,547.

Patonted Nov, 3, 1874.

15y. 2

$.1+i, \ldots$

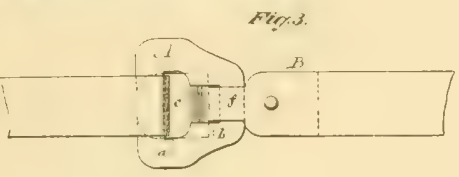

6. N. BEARD.

BalB-TIES.

No. $156 ; 752$.

Patented Nov, 10, 187h

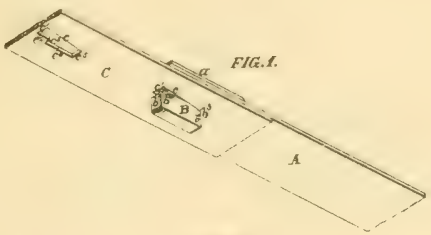

FIE. 2.

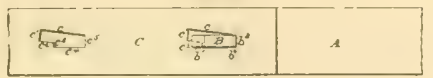

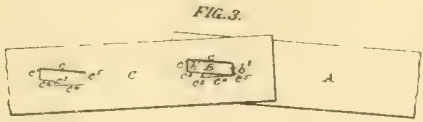

A. A. $52 A 80$

Bale-Ties.

No. 156,827 .

Pelented Nov. 10, 1874.

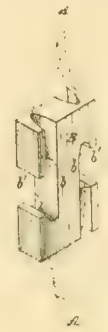

6. N. BEARD.

Bale-TIEs.

Patented Nov, 10, 1874
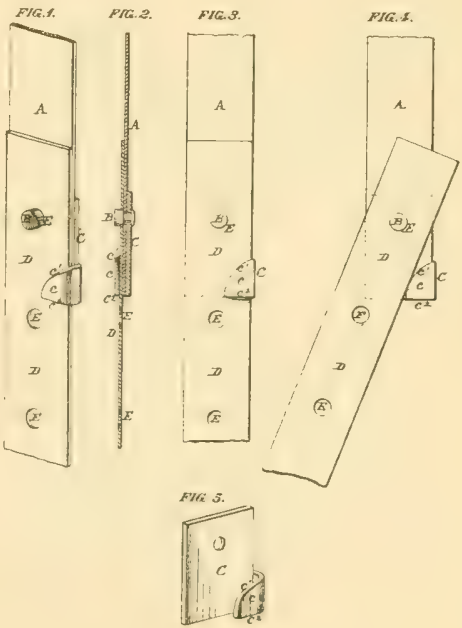
6. M, BEARD.

Palonted Mor, 10, 1874.
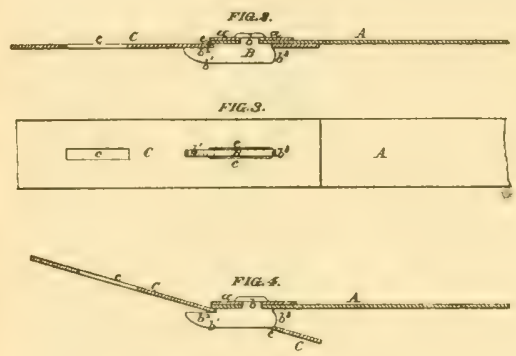

H. 8. HUTCHISON.

Bato-Ties.

No 157,005 .

Patentod Nov. 17, 1874.

Tia.

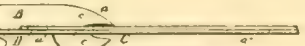

A. ALLAN I BURNS

BaIB.T/O8.

No. 156,965

Patenlad Nor. 17, 1874.

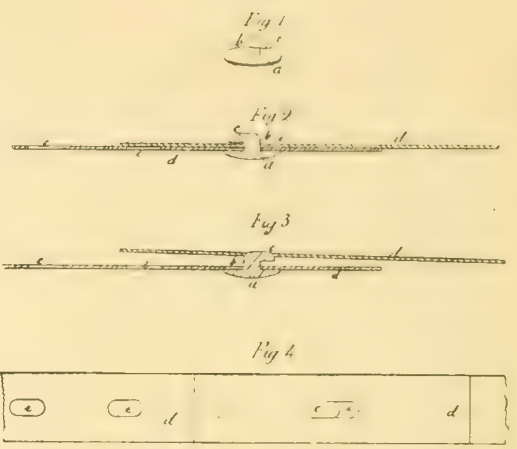

Figs

c

1. H. SMITH

Balenties.

No. 157,032

Patented Kov, 17, 1874

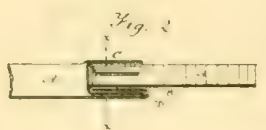

Irq 2 -

ज्ञ 
S. I. LEACH.

3alo-TIEs.

No.157, 206 .

Patented Nov, 24, 1874.

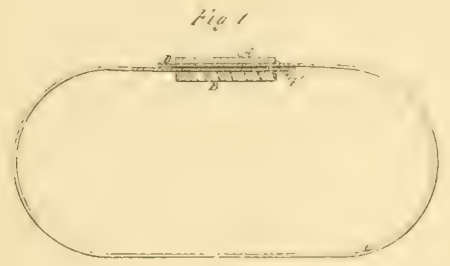

Tia.

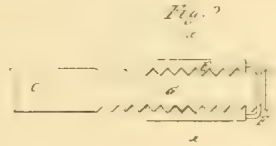

Fit. 3.

$\sigma{ }^{D}$

J. L. REESE.

Balo-Tios.

No. 157.223 .

Paloncod 1ov. 24, 1874 .
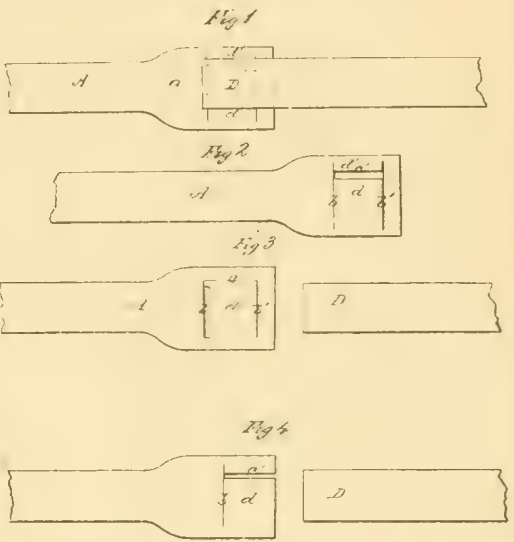

1. N. SMITH

C. A. WARD.

Cotton-Bale Ties.

No. 157,303 .

Patented Dec. 1, 1874.

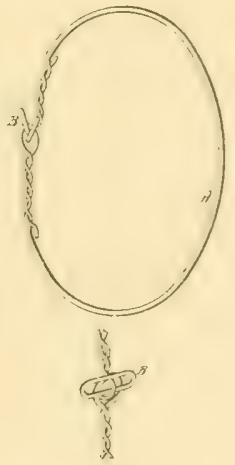

Devices for Forming and Fastoning Bale-tios.
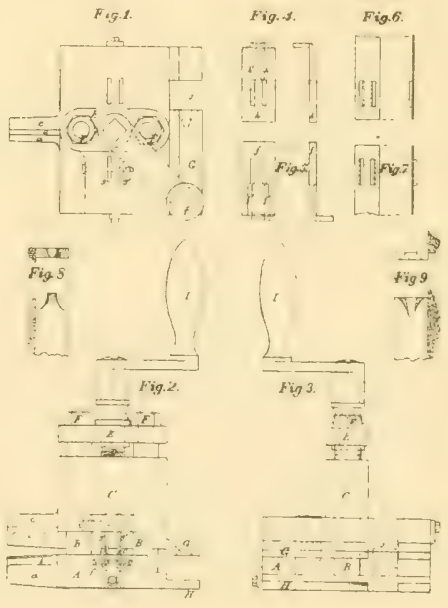


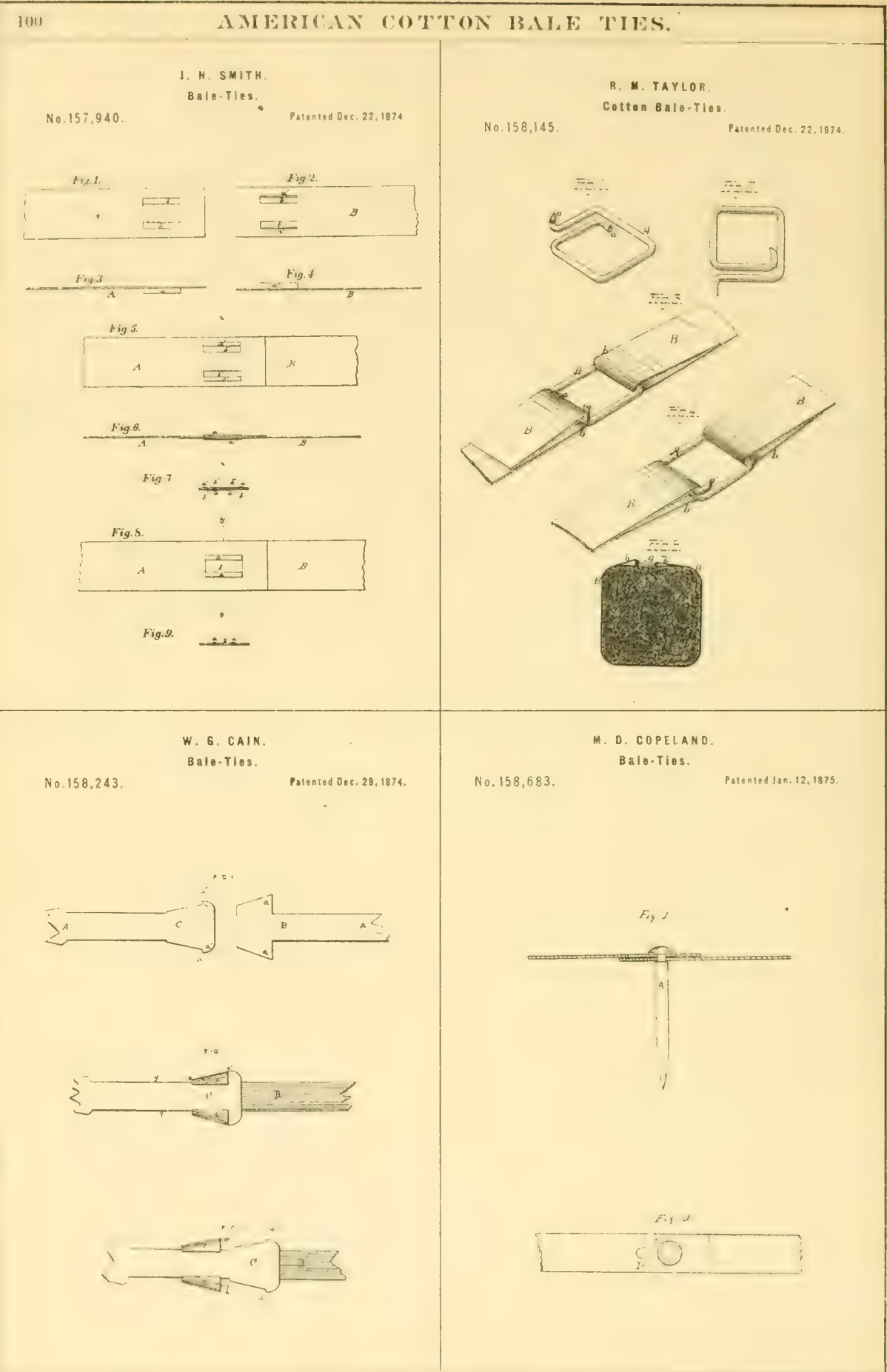


No, 158,733

$$
\text { J. W. PHILP }
$$$$
\text { 8ate-Tias. }
$$

Palented Jan, 12,1975.

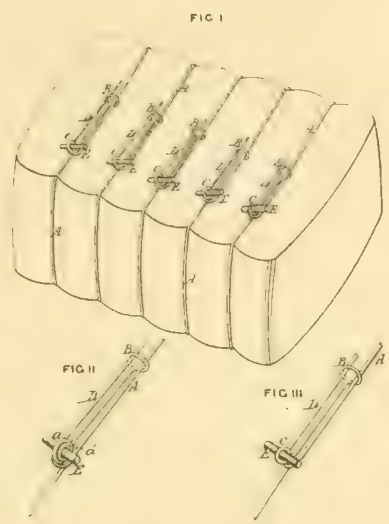

F'2gl.

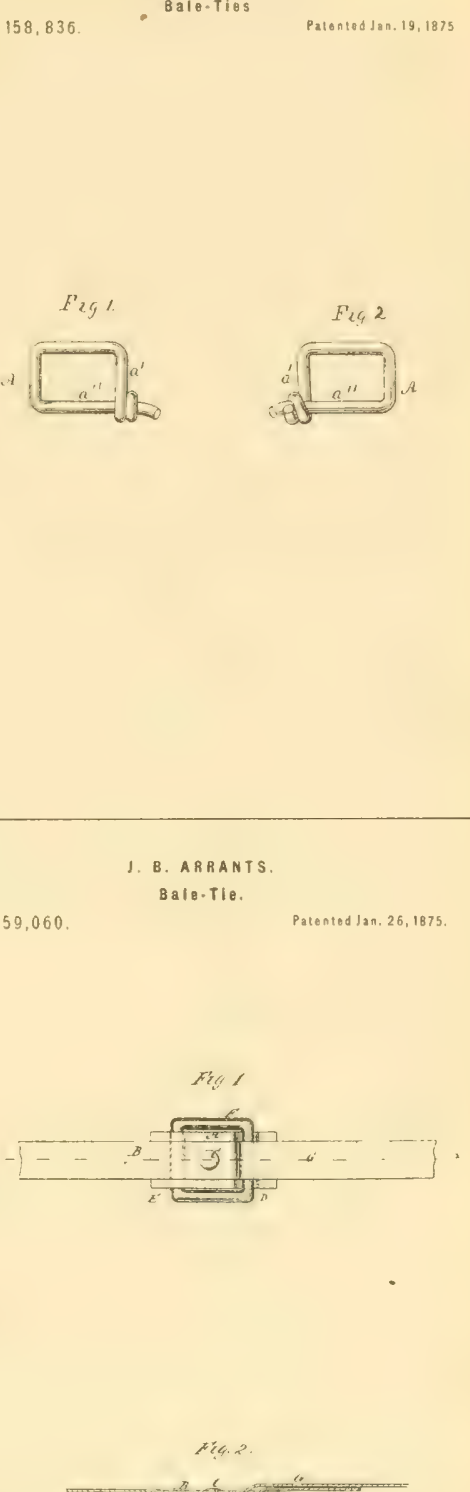

$F_{14} 2$

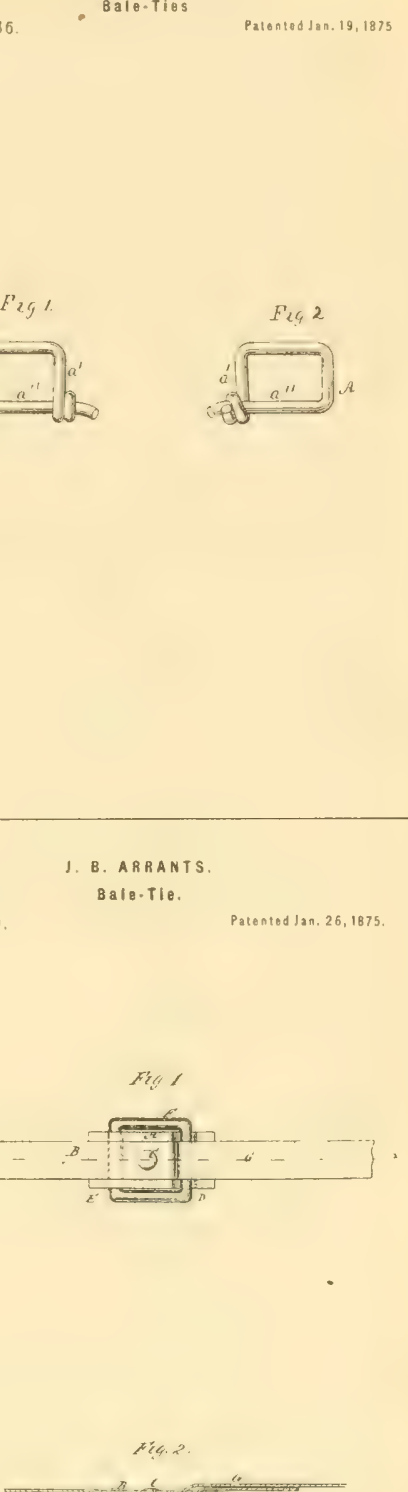

1. B. ARRANTS Bair.tie.

No. 159,060

Patented Jan. 26, 1875.
No. 158,985 .

A. O. SCHULTZ,

Palented lan, 19, 1875

Fis. 1

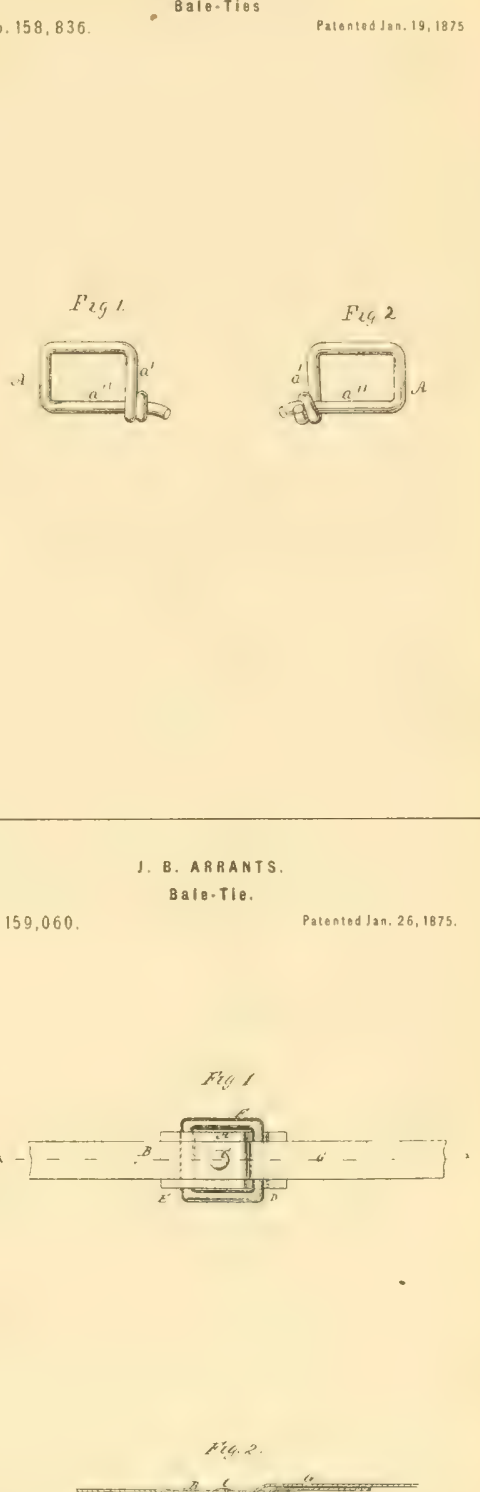

txice $x^{2}$

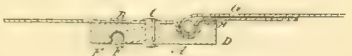


A. A. GOLDSMITH. BaIe-TIOE.

No. 159,089,

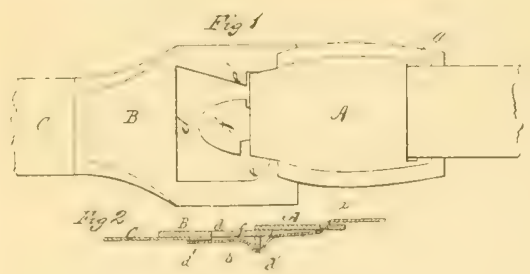

Figs
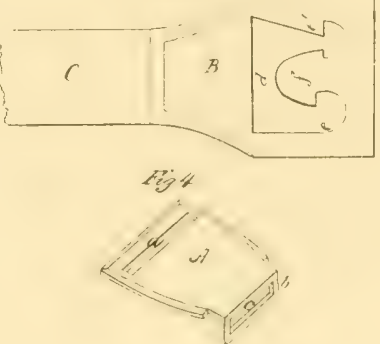

S. H. GILMAN,

8 ale.TIO.

No, 159,258

Polenied fot, 2,1875

$F_{2 y}$,

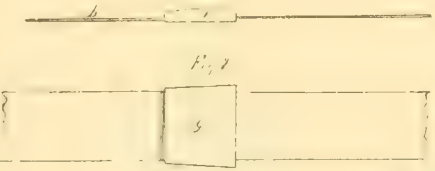

Lis ?

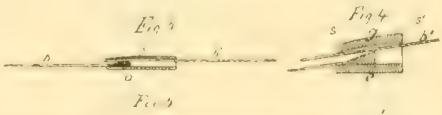

I., $y^{\prime}$

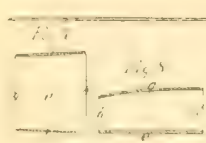

..

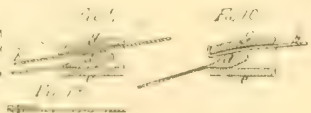

W. ILER.

Devico for Balling Cotton.

No. 159,098

Patentod Jan. 26,1875
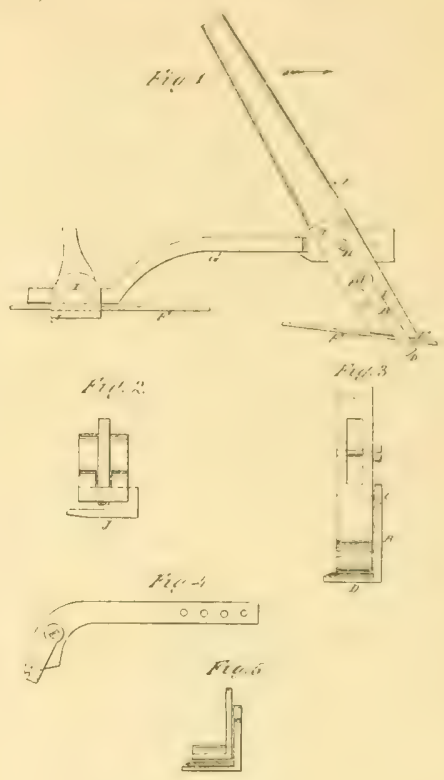

H. B. JONES.

Cotion Balo.Tte.

No. 159,268.

Patontodfeb. 2,1873
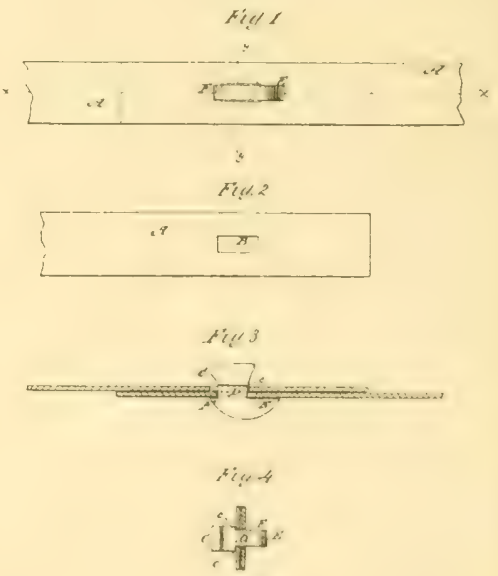
AUGUSTINE BALDWIN.

Method of Fastoning Cotton-Bales. No. 159.378 Patented Fob. 2, 1873
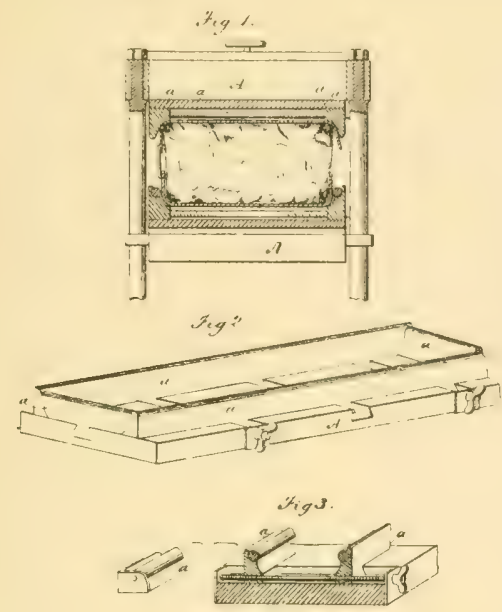

1. L. REESE.

Bale-TIE.
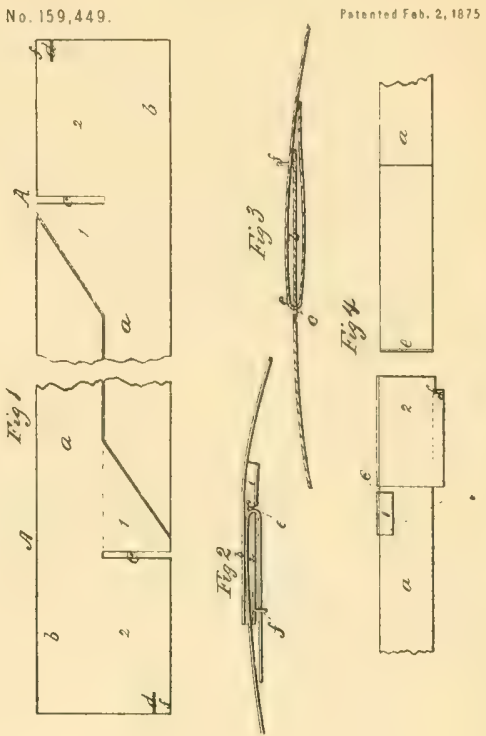

J. THAYER,

Cotton-Balo Tio

No. 159,531 .
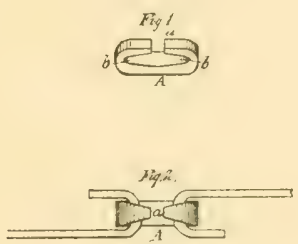

$\frac{\operatorname{lig}^{4}{ }^{4}{ }^{-4}}{b}$
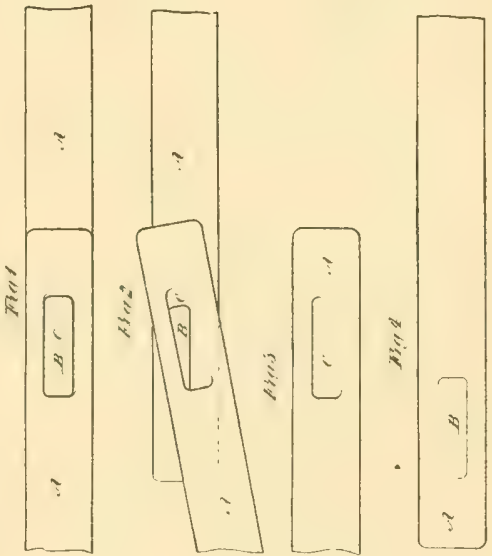
A. 1. NELLIS.

Machine for PalntIng Balo-Tles.

No. 159,703

Palonted Fod. 9, 1875

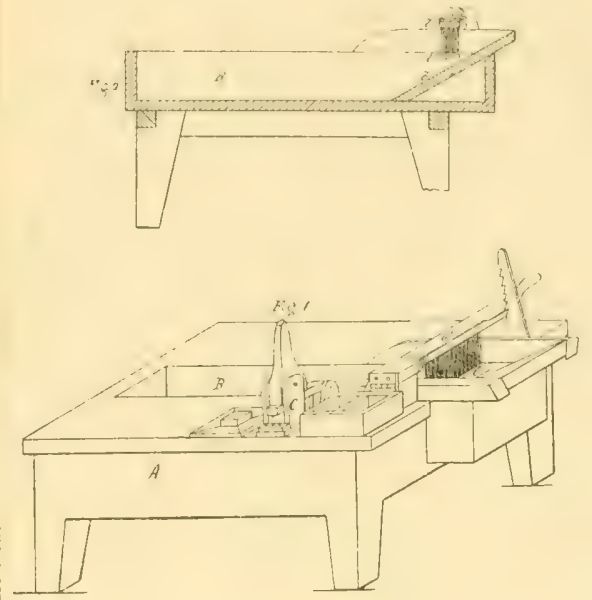

A. A. NELLIS.

BaIB-T/8.

No. 159,704

Patented feb. 9, 1873 .
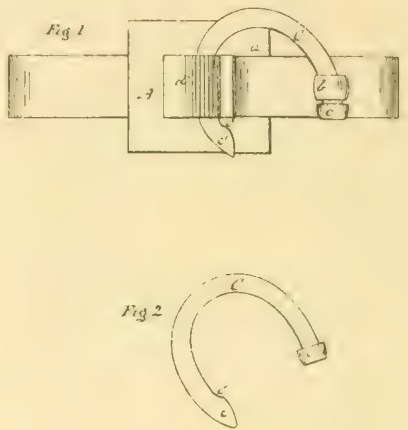

$\operatorname{mg}_{3}(6)$

A. A. GOLDSMITH.

Bale-Tie.

159,815

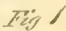

Patented Fob. 16,1875

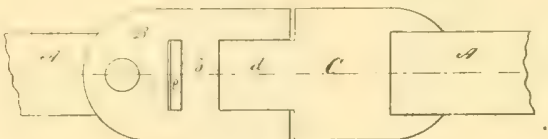
ABंin in

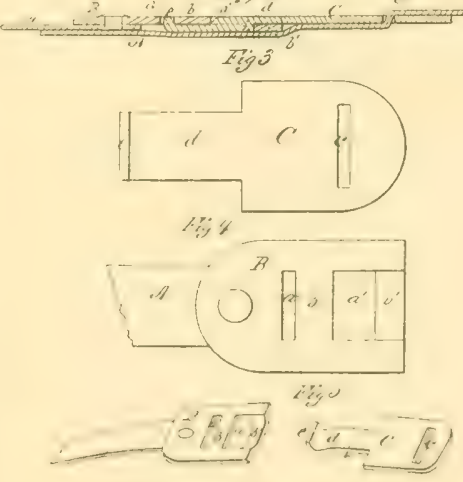

W. A. JORDAN

Bala.ties.

No. 160.331

Palented Mareh 2.1875
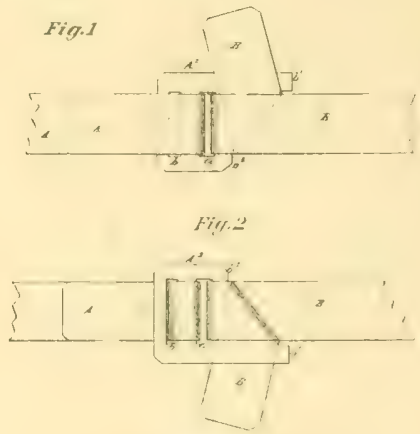

Firl. 3
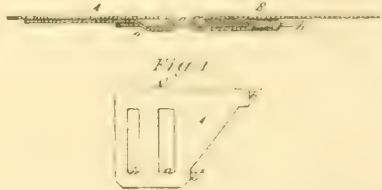


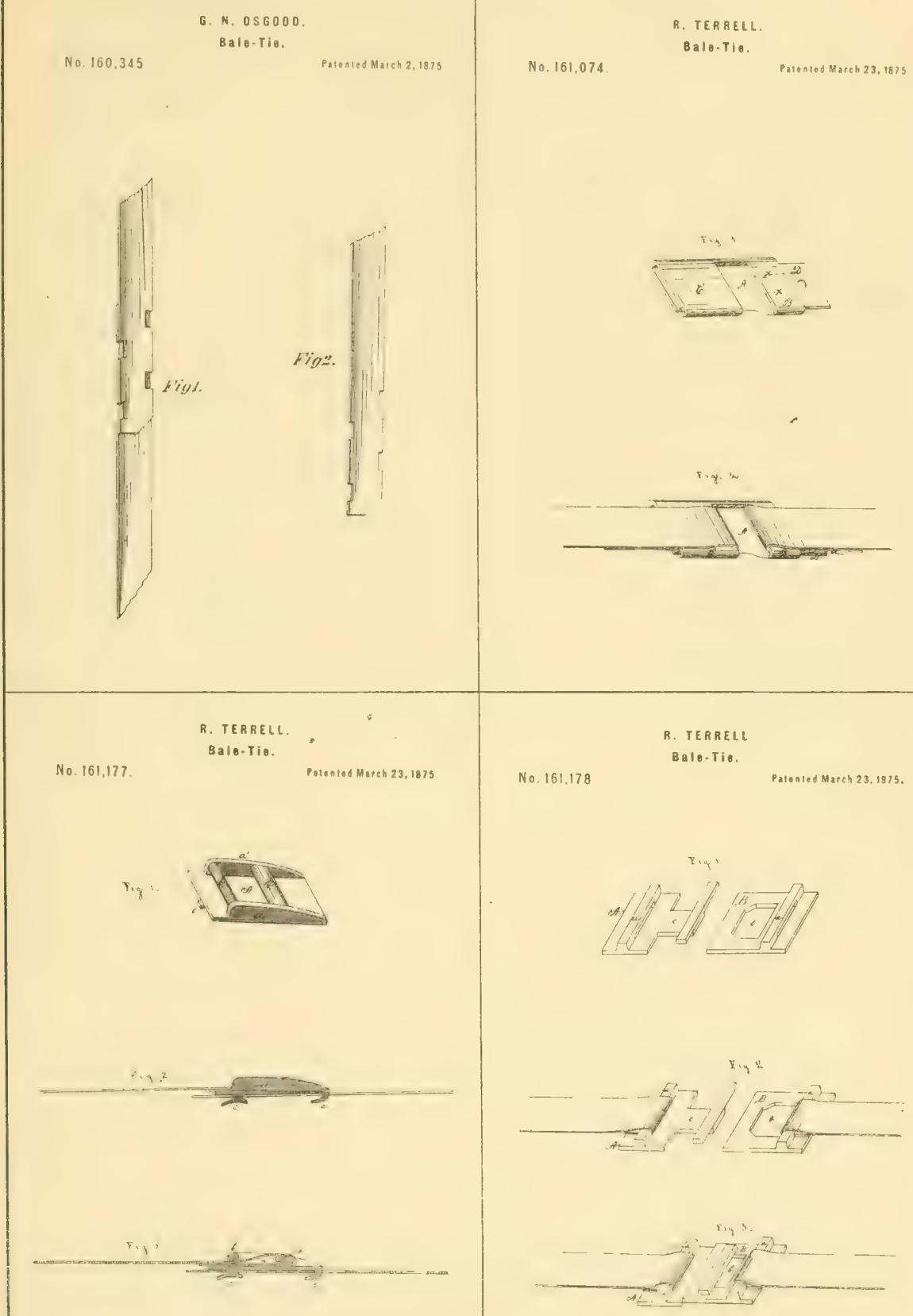


J. H. HAROMAN.

Bale-TIO.

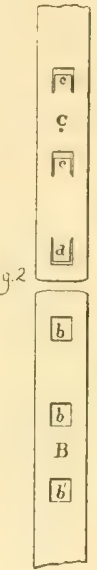

H. B. IONES.

Bale-TIo.

No. 161.416

Patented March $30,1875$.

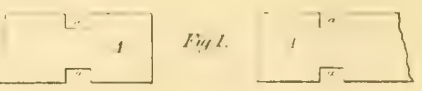

Fin: :

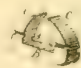

Siaf 3

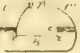

F'y

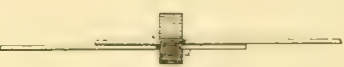

Fis ;

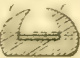

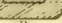

$A$

f. W. PHILP

Balo-TIo.

No. 161,819
= T. T. BROWN

Balo-TiE

No. 162.023

Patented Apsil13,1875.
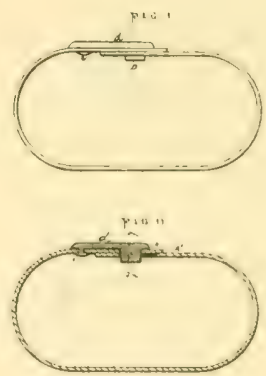

pin ...

ru.

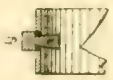


J. M. GOLOSMITH Bate-Tie.

No. 162.054

Patented Aprill13.1875

Fig

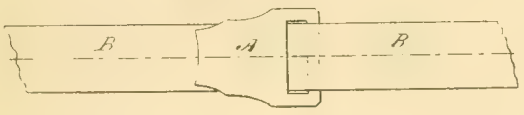

IX;

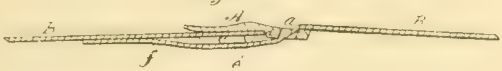

1. J. HOLLOMAN.

Balo-Tie.

No 162,654

Palented Aprll 27, 1975
1. W. DEYO

Bale-tis.

Palentod April 20, 1675.

No. 162,354
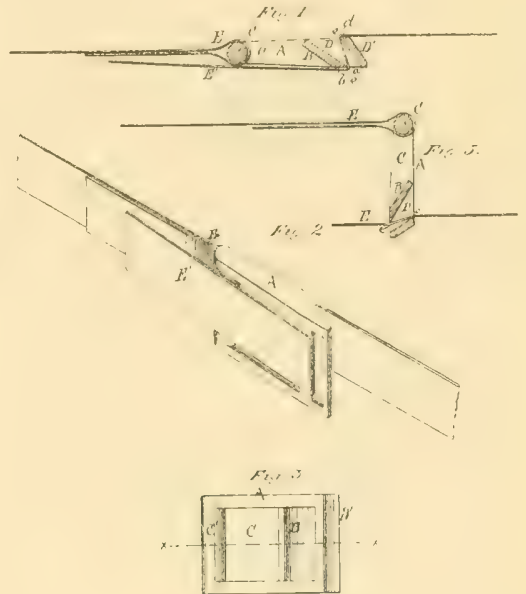

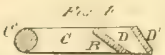

D. E, MCGARRAH

Bale-8and Tightener

No. 162.672
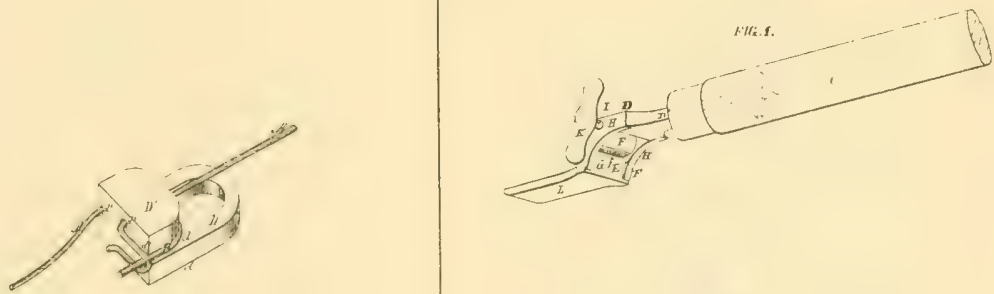

FIG

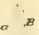

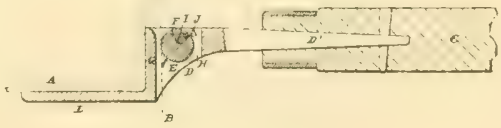


6. W. SCOTT

Bale.TIO.

No. 162,699 .

Patonted April 27, 1875.
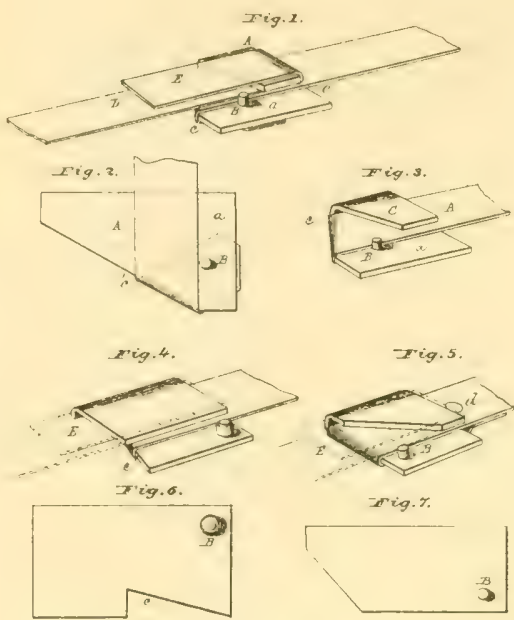

जing.

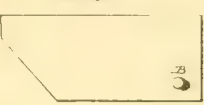

8. ARRANTS

Balo-Tí.

No. 163,133

Patented May 11, 1875.
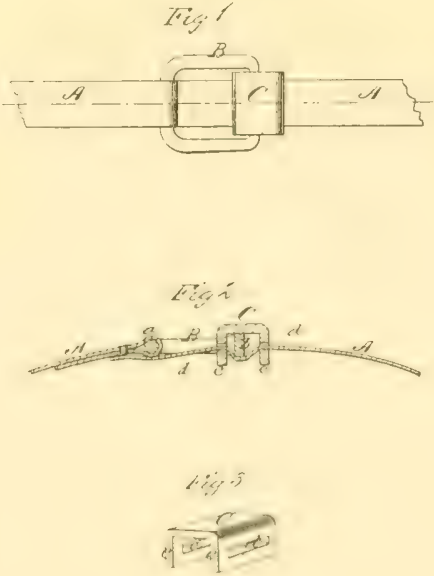

D. R. MCCLEAN.

BalO-TIO

No. 152.844

Patented May 4, 1875
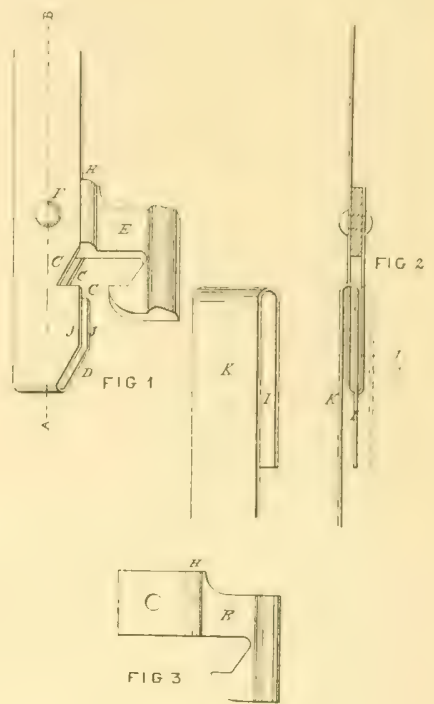

C. J. BEASLEY.

Bate-Tie.

No. 163,138

Patented May 11, 1875.

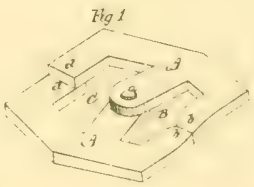

Fy? 2

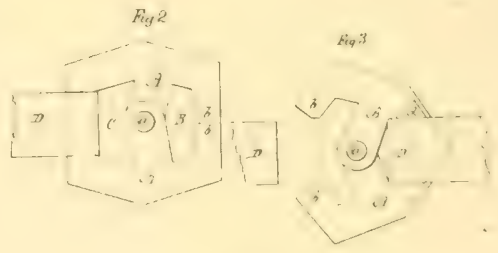

Fig 4

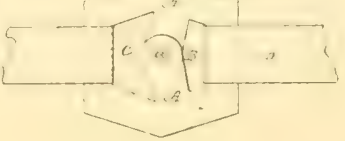


W. L. ROSE.

Bale-TIE.

No. 163,331

Patented May 18, 1875.

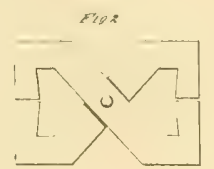

W. A. $10 R D A N$.

Bale-TIO.

No. 163.380

Patented May 18, 1875
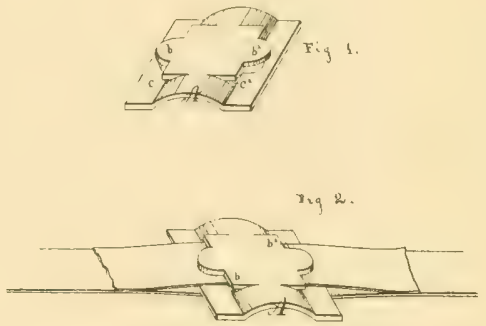

I.g. 9.

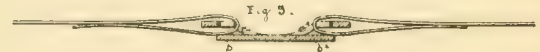

1. H. GOLDSNITH. Bal6-Ties.

No, 163,649 .
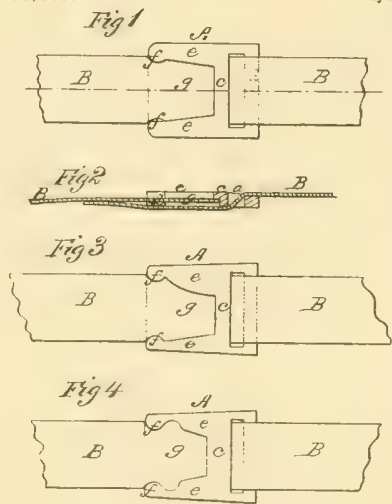

Figes

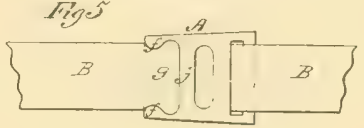


B. GOLDSMITH

2 Shoots... Sheot 2

No. 163,649
1. W. PHILP.

Cotton-Bale TIE.

No 163.803

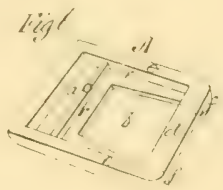

Figy

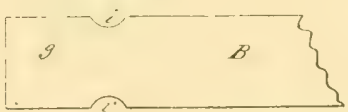

iigs

$\therefore$

I. N. SMITH

Bale-Tí.

No, 163,815 .

Patonted May 25, 1875
E. D. CHADICK.

Bale-TIE.

Patented Jugo 8, 1875

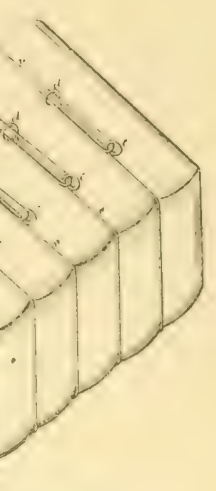

Fig.2. Fig.3. Aig. ${ }_{B}$ Fig.5.

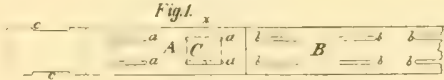

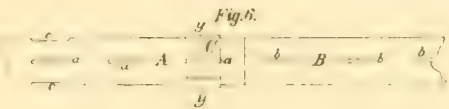

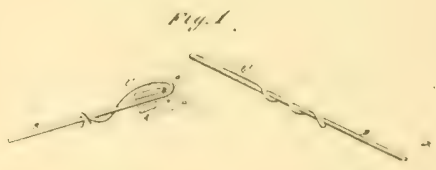

${ }_{B}$ Fig. $7 . \quad$ Figf.

Fign: 
J. M. GOLOSMITH.

Bala.Tie.

No. 164,164 .

Patonted June 8, 1875 .
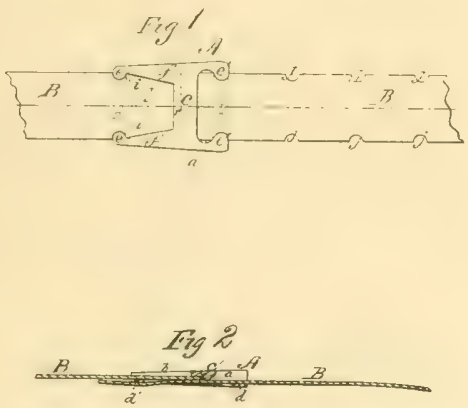

1. 60 LOSMITH.

8 alo- Tag.

No. 164,165

Patentad fune 8, 1875

$$
F_{2}^{2}
$$

A $A$ i2

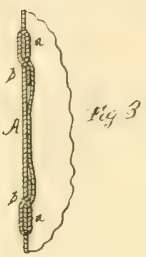

A. EICHHOLZ.

Bale-Tí.

No. 164,821

Patentod fune 22, 187
No. 164.817 . Balo.TIO.

Patented June 22, 1875

fich.

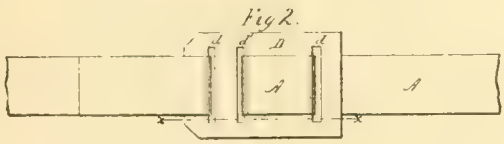

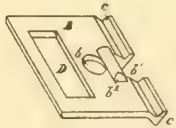

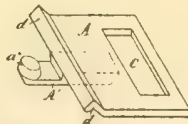
figf
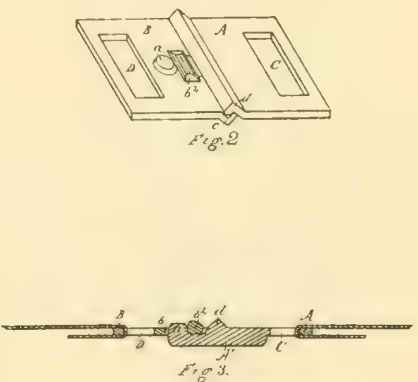
1. H, HARDMAN. Ba/8-T108.

No. 164,835

Patoniud June 22, 1875 .

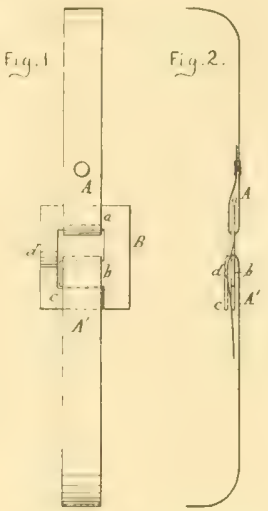

b. L. SHEPPARD.

Bals-8and Tightoner.

No. 165.374

Paiented July 6,1875
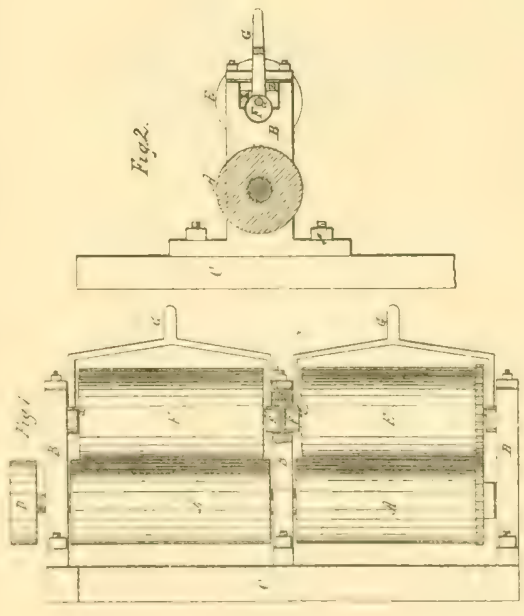

W. P. ELLIOTT Bale-tho.

No. 165,081 .

Palented Jone 28, 1875.
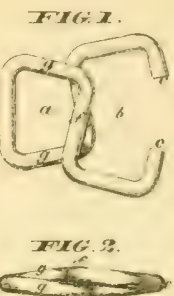

स्था

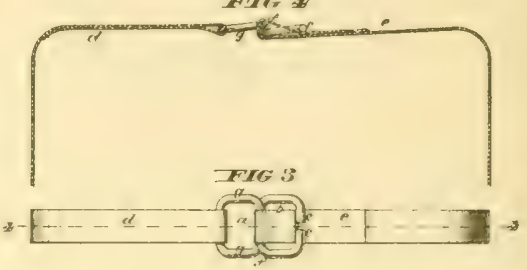

P. B, DAWSON

Bale-Tie.

No. 165,407.

-Patented fuly 13,1875.

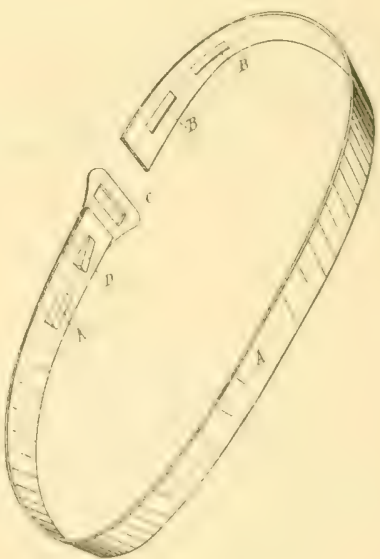


W. GREET.

Hook Bale Tie.

No 165,996 .

Patented July 27, 1275.

$\operatorname{Pag} 2^{2}$

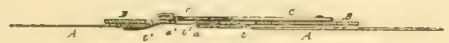

S. SULLIVAN.

Modo of Applying Sample-Patch to Cotton Balos.

fio. 166,158 ,

Patented Jaly 27, 1875.

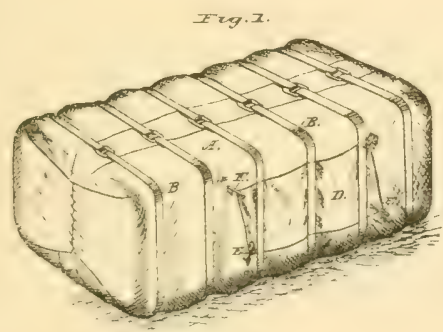

$(\underbrace{-\infty E}_{4}$ Fig. 2

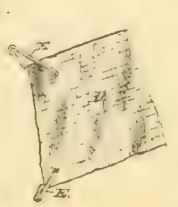

H. ESTES.

Balo-Ties.

No. 166,085 .

Patented fuly $27,1875$.
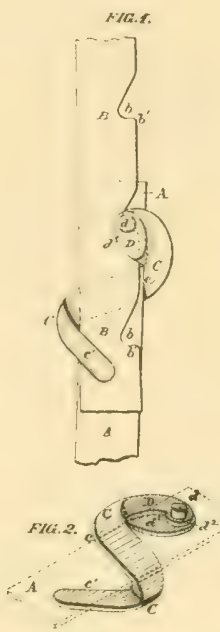

H. J. WRIGHT.

Bale-Tie.

No. 166.326 .

Patentod Aug, 3, 1875
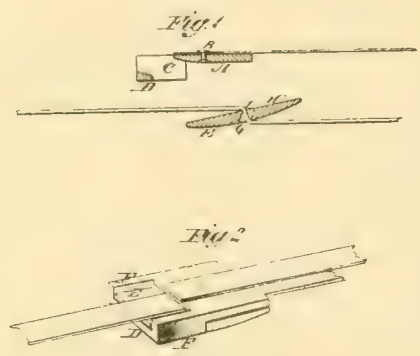

Fier 3

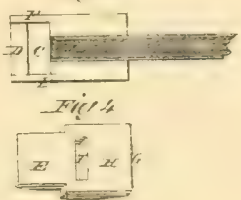


H. Z, YOUNG.

Bale-Tí Clamps.

No. 166,491

Palentud Aug. 10, 1875.

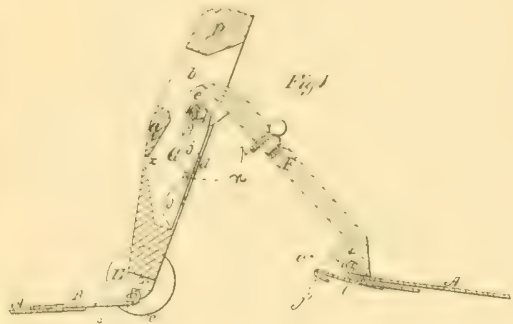

$$
\text { Fig. }
$$

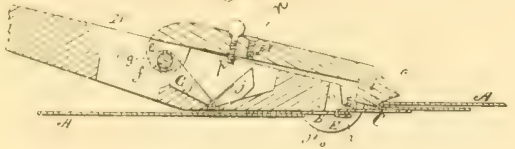

J. M. SEYMOUR.

Process of Bating Hay. Cotton, \& $c$.

No. 1006,640 .

Patontad Aug. 10, 1875.

Tiy:1.
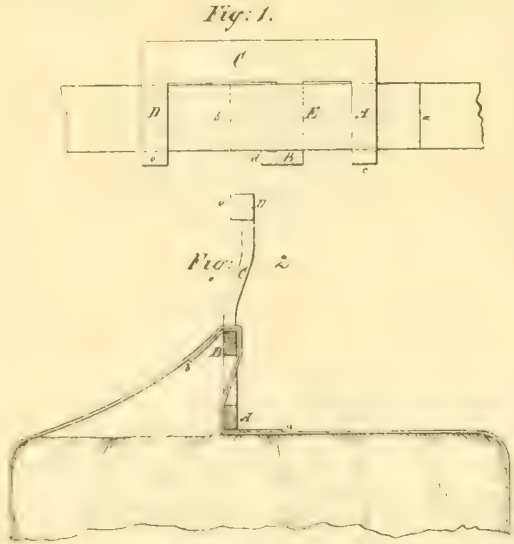

Fin: 3.
H. B, JONES.

Balo-Tio.

No. 166,614

Patentud Aug. 10, 1875.
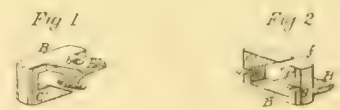

Fic , 3
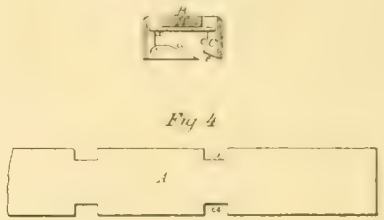

Fig 5.

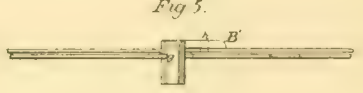

A. A. $\$ 2 A B O$

BaIE-TIE.

No. 166,652

Palonted Aug. 10, 1875.

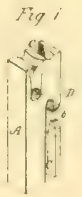




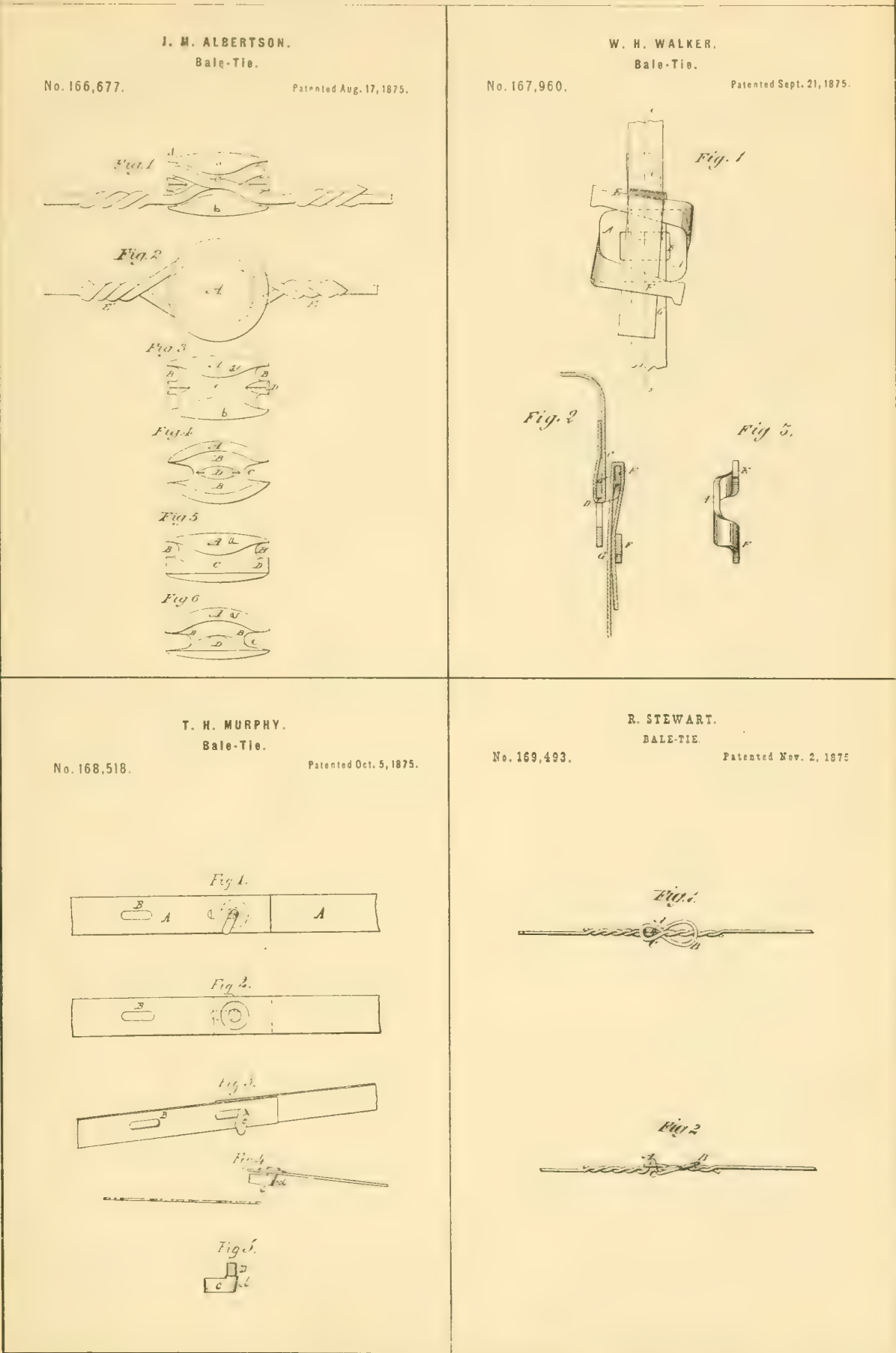




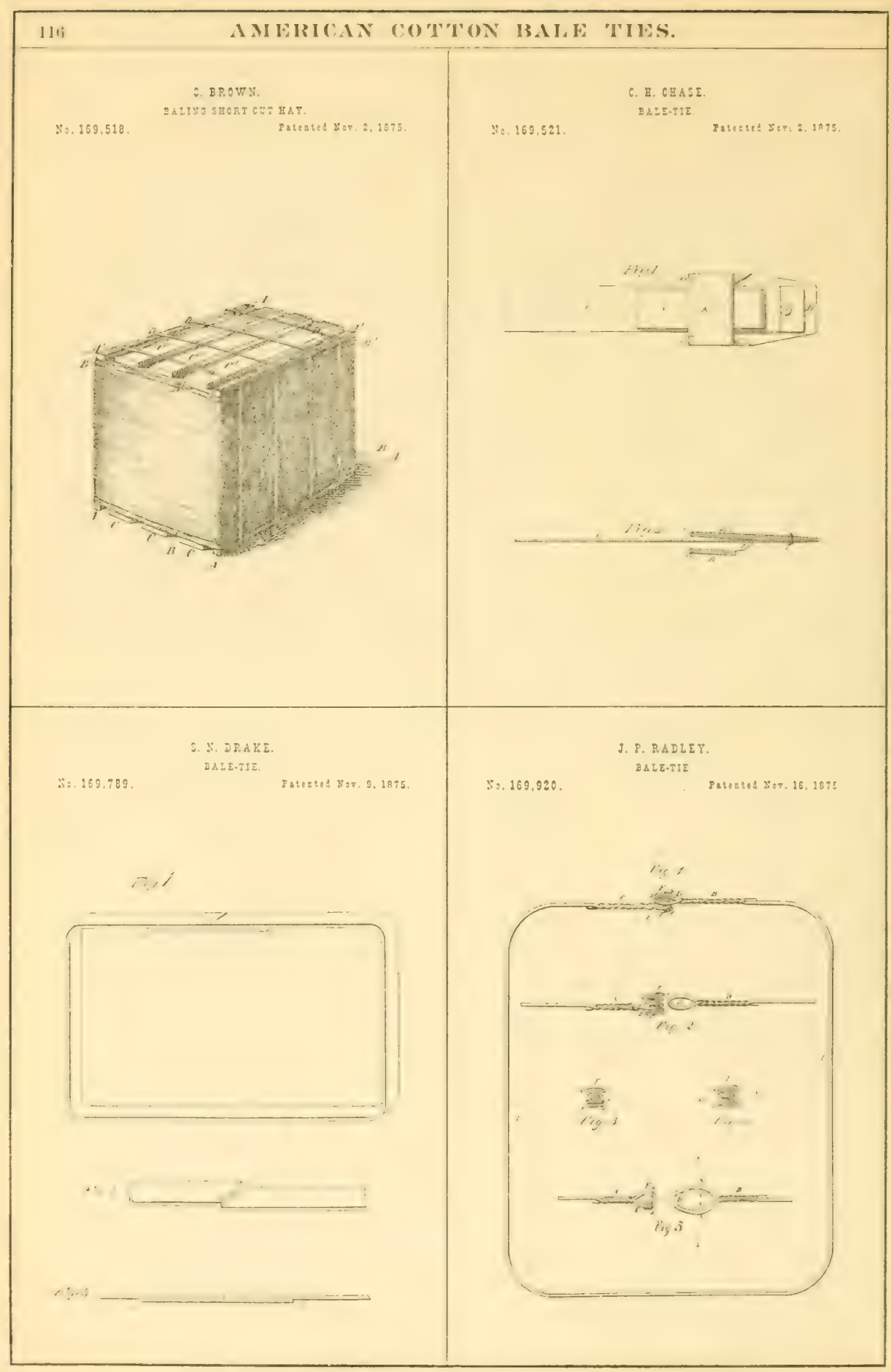




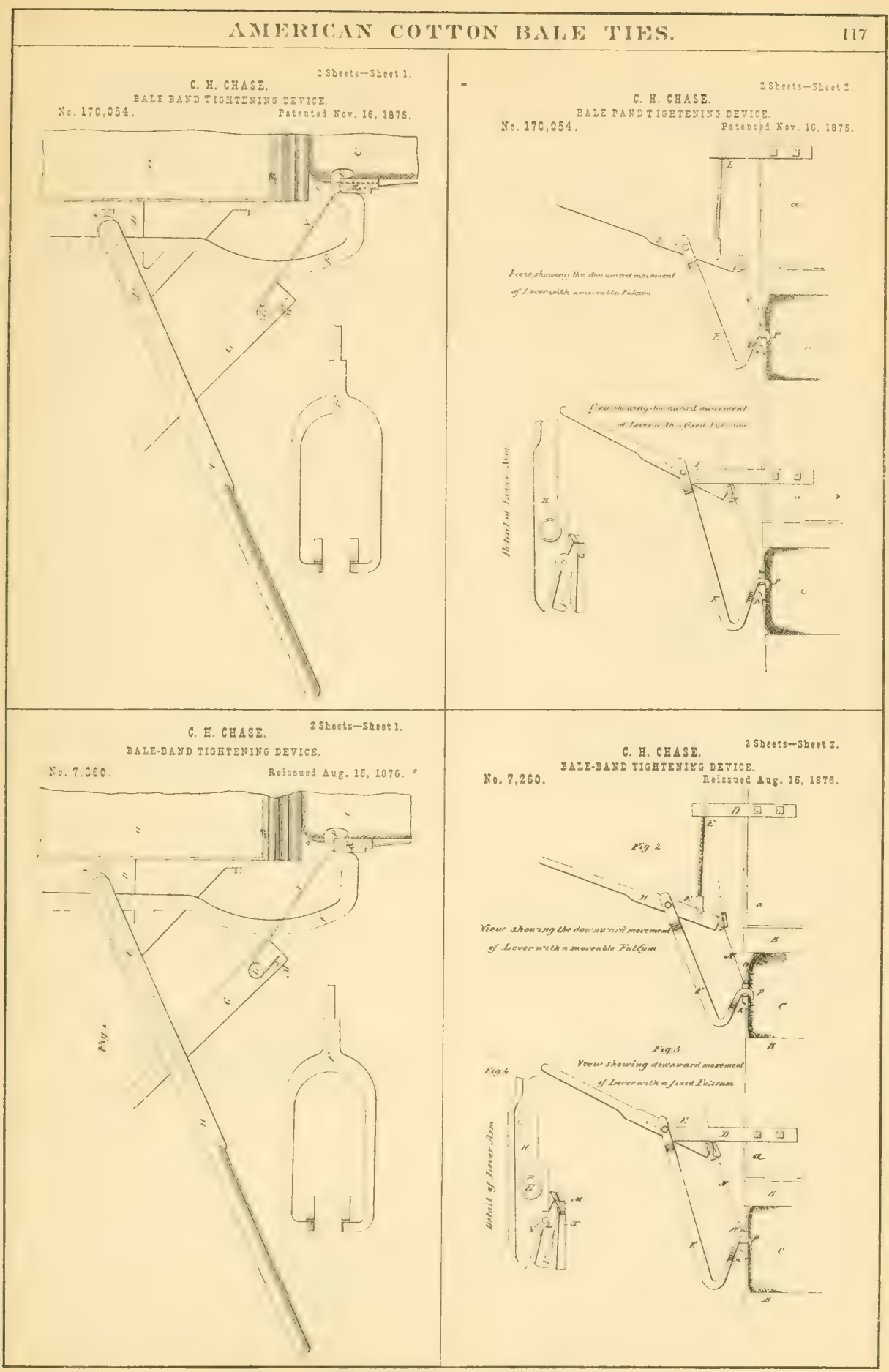


2. 2. STOCEER.

BALE-BAUD STRETCHER.

Nio. $170,411$.

Patentod Xov. 23, 2875

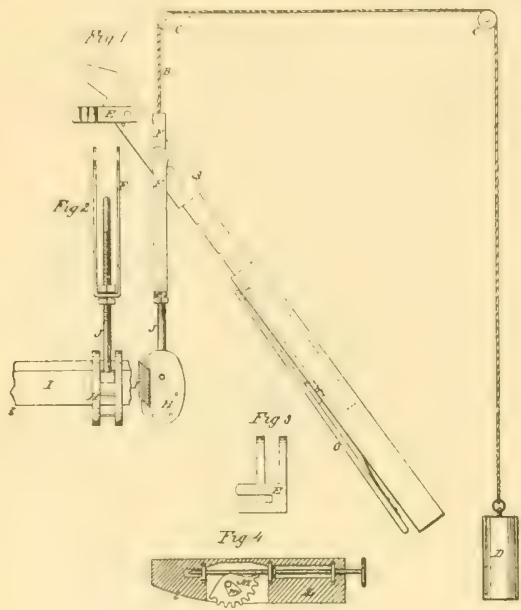

A. N. POWELL.

BAIE-TIZ.

No. 170,589

Patentod 807. 30, 1875 .
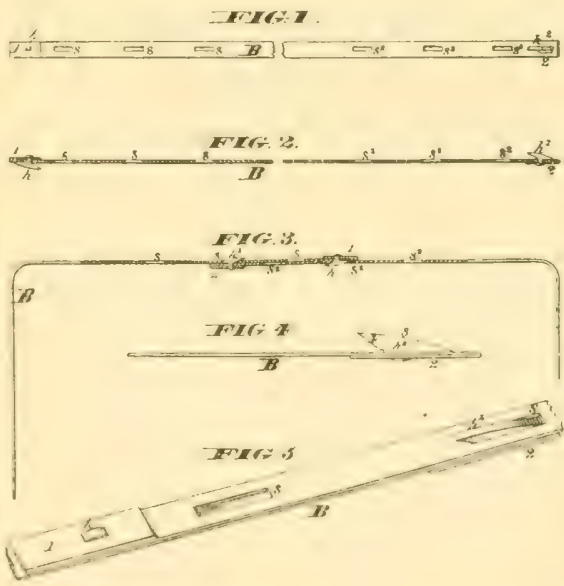

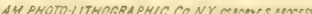

T. H. $M$ TRPEY.

DETICZ POB BALY COTTOS.

Ptinted Sor, 30,1875 .

No, 170,446 .

tis 1 .

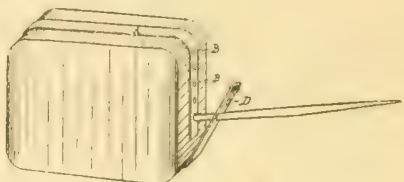

Fig 2.

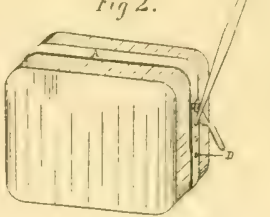

Fig 3.

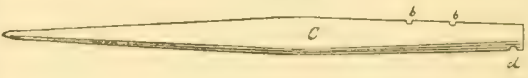

E. O. SCBARTAN \& 3. B. GARDN $28 R$

No.170,597. BALZ-TIE. PLEtod BOT. 30, 1875.

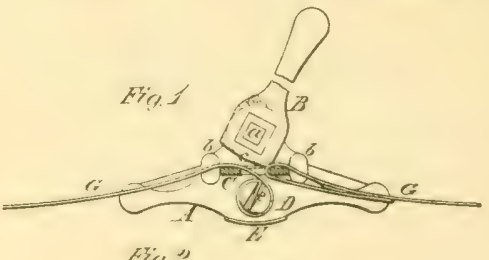

Fi:1
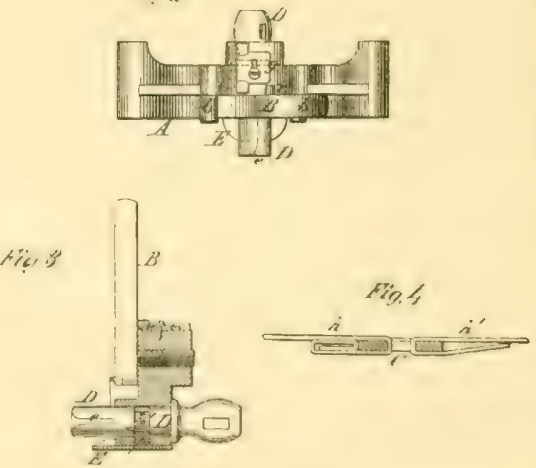
E. 0. SCBARJAN \& 3. H. GARDN ERRets-5teet 2 BALE-TIE.

No. 170,597 .

Fatented Btor. 30, 1875.

Fiy,

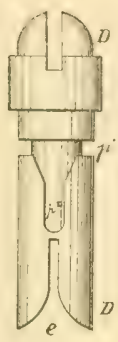

P. B. DEDERICZ.

BALE-TIE.

Pateated Dot. 23, 1875

8.. 271,215.

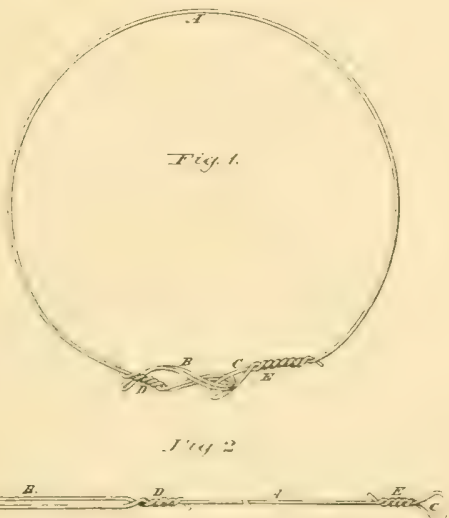

L. i. $B O D E N D A X E R$.

BALE-TIE AYD EOOF+LACER.

Ne. 170,932 .

Patentod Dec, 24, 1895
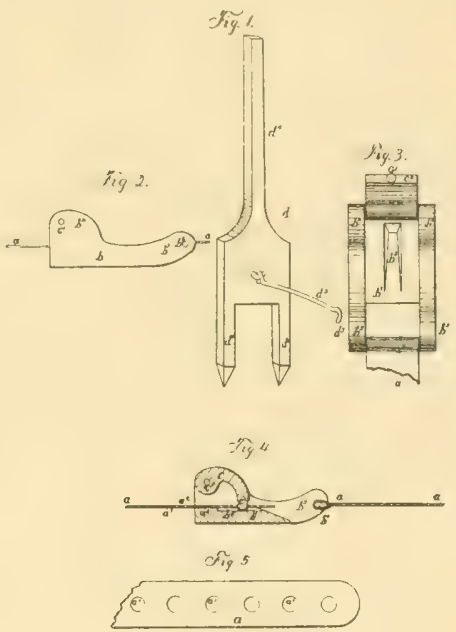

R. LONTFORT.

BA:E-TIE.

Fatented Dec, 22, 1975.
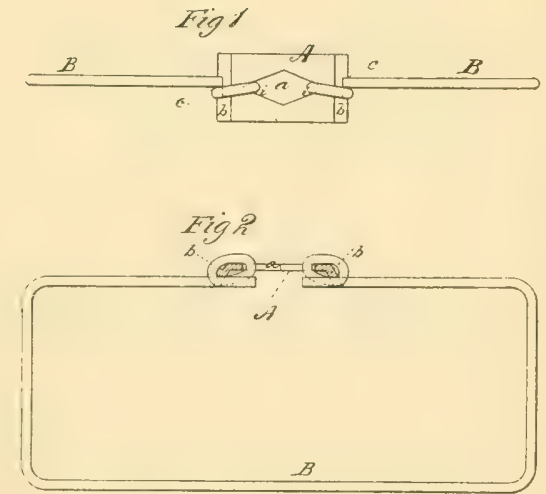
S. B. QIL $84 \mathrm{AN}$

2 Sbotts-stout?.

COTIOZ BALE-BASO IISBTEXI.

ic. 271,560. Patuetod Doe. $28,1875$.

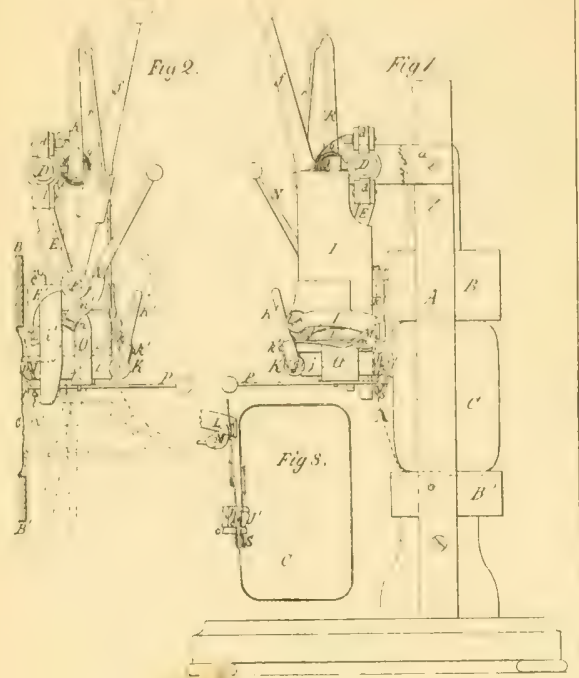

S. B. GILMAN.

MACHIRE FOR EXTYIRO BAYDS OX COTTOR+BALES.

No. 171,659 .

Paterted Jaz. 4.1876 .
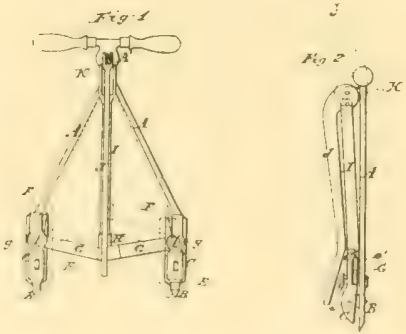

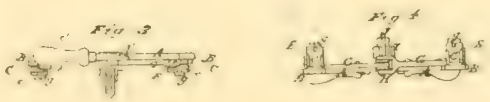

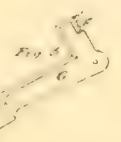

S. E. GILNAN.

CETTCX BALE.3ASD TIOITEYER

80. 171,560. Faterted Dec. 26.1875.
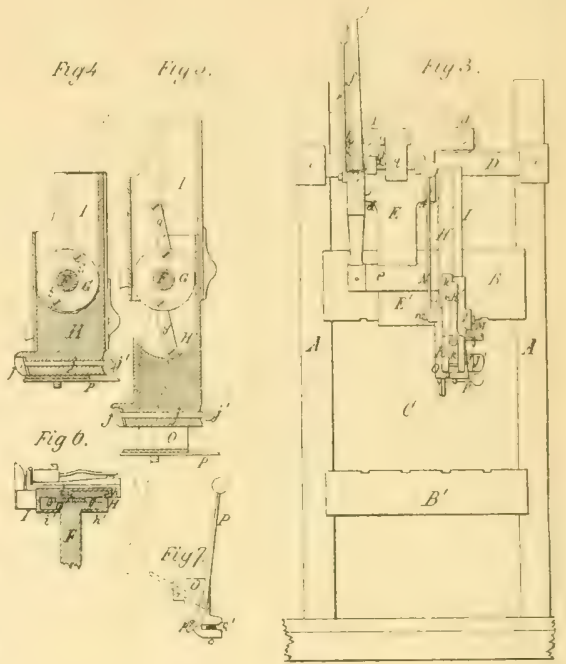

S. B. GILKAK.

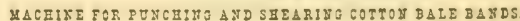

Xo. 171,660 .

Pstontod J23. $4,1876$.

Fig. 8

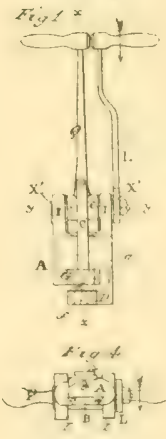


D. ฉ. HATHIAS. BAZE-TIE.

No, 172,330

Faterted Jan, 19. 1970.
Q. GALE.

BALE-TIS.

No. 272,417 .

Patented Ian. 18,1376
A $\quad n$ (2) Fig.1.

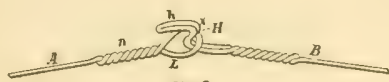
Fig. 2

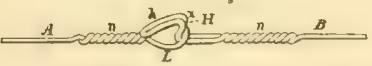

Fig. 3 .

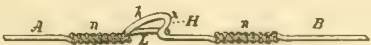

Rig.4.
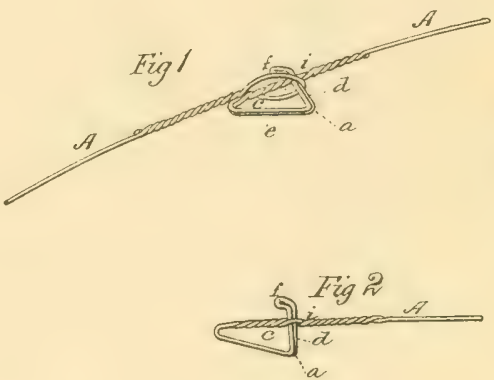

Fig 3

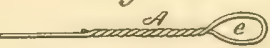

C. R. ВERRON.

BOCELES FOR COISOR-BALIXC.

No, 172,434 .
$F 21$.

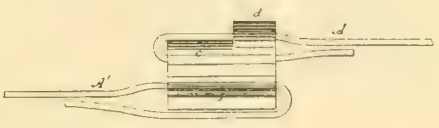

Fig 2
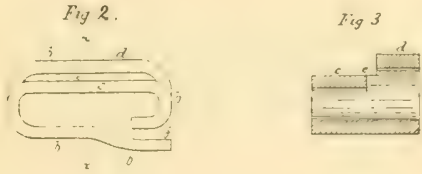

จ. F. P. $\triangle L E X A N D E R$.

BALE-TIR.

X. 172,683

Sig: 1.
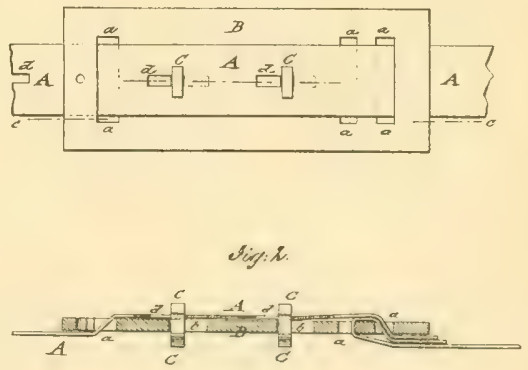

$F i y 4$

Sigy:3.

$\square$ 
W. P. BDRROW \& H. B. NICHOLS.

Vo. 172.845

BALE-TIE.

Fetonest Fot. 2. 1976.

Fig. 2.

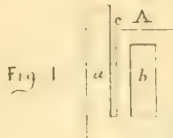
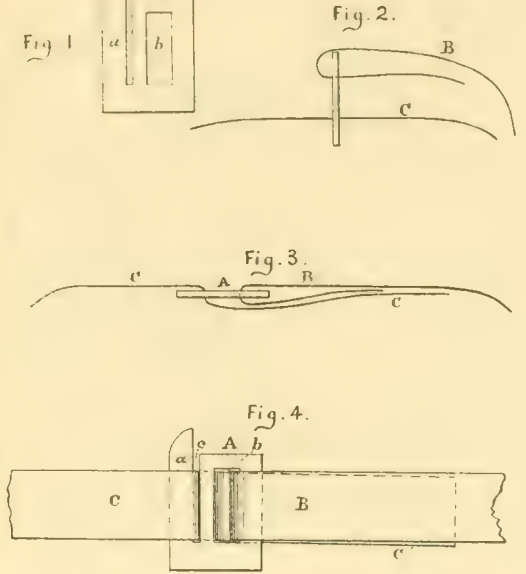

ง. C. RIETHบช̈LปะR. B. $\triangle 2-3 \pm E$

Patontod Fo8, 1, 1876.
ล. \$. \$TE: T0:.

$B \triangle Z \bar{E}-\overline{I E .}$.

No. 172,897

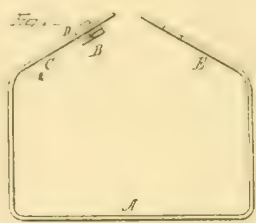

$52-$

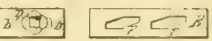

$\therefore=3$.

$=4$

$\frac{\sqrt{3}}{\sqrt{3}}$

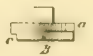

zing

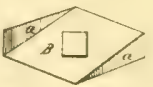

T. BAILE

BA2ะ-วนะ.

No. 172,947 .

Palestod Fib, 1, 1876 .
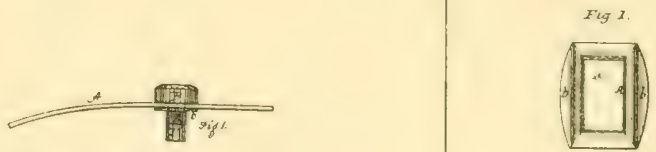

Fig. 2 .
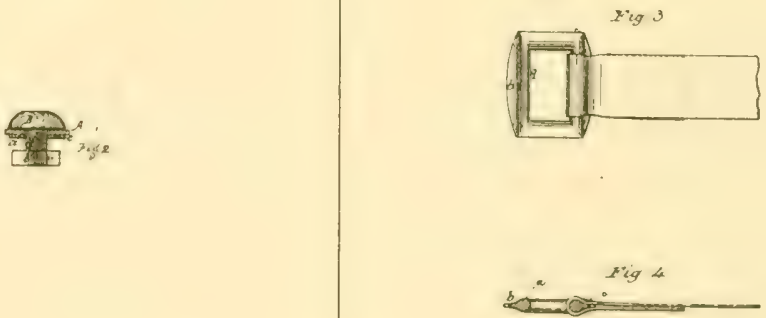
ง. C. RIETHМت̈LLER.

CHECE FOR CORTOX-BALES.

Xo, 272,937 .

Fatoniod Fob, 1, 1876.
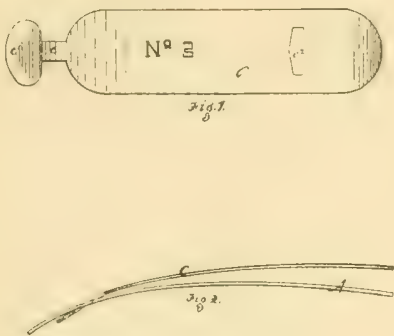

S. H. GILRAX.

उALE-TIE.

$80.173,119$

Eatentod E०b. 8, 1876.
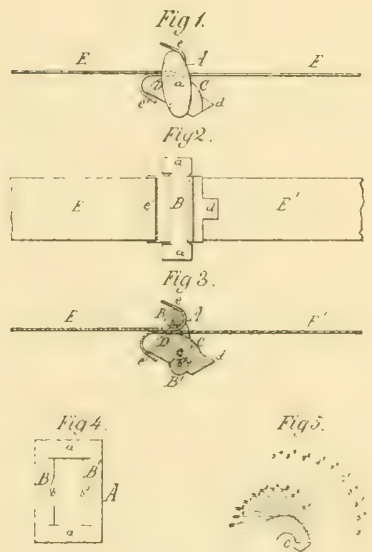

S. B. GILMAN.

No. 173,118.

PLtersed Fob. 8, 1876
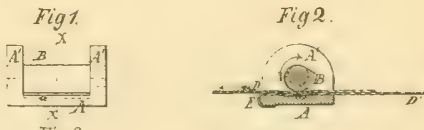

Fig4.

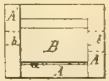

Fig 5.
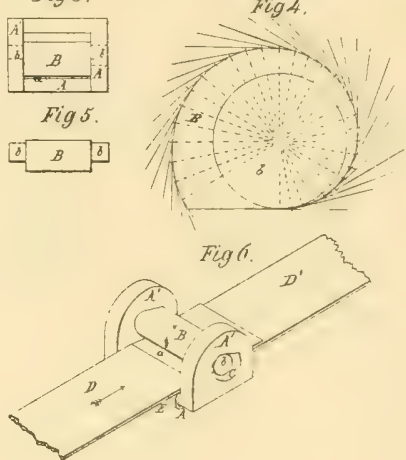

Patonted Fob. 8, 1876.

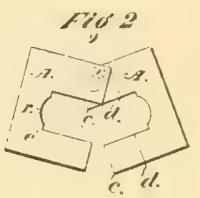

Fig:3 का: का

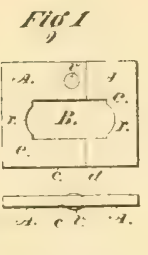

$F \% 1$

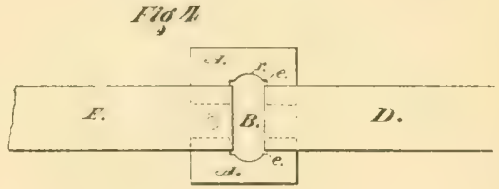


J. 24. ERANDENBUEO BALE-TI:

$\because: \because: \because: ?$ Faterted Feb. 1E, 1875.
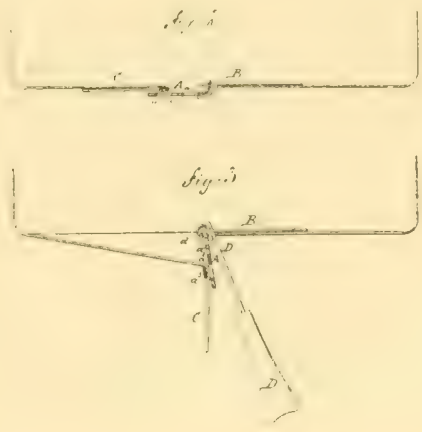

3. W. KOULION उALE-TIE

Patented Fo: 22, 1876 .
$N 0.273,597$ W. S. DAVIS BALE+TIE. Patooled Pot. 15, 1876.
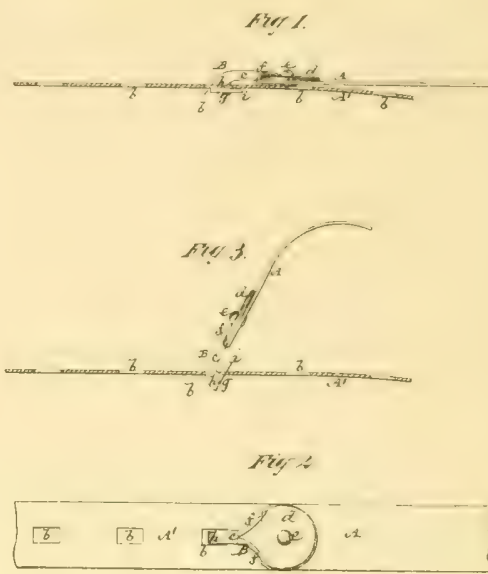

S. CALLANAN

BALE-TIE.

Patustod Fob. 22. 1876
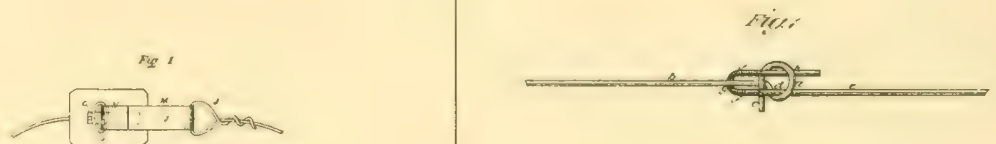

Fin $x$
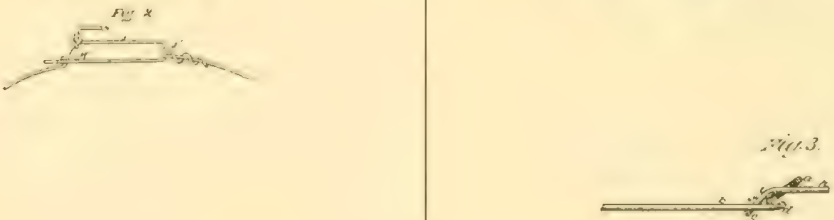
D. Z. UATIIAS.

उALE-TIE.

$x+1 ; 4,082$

Pateatod Fob. 29, 1876.
3. A. BOSTWICR.

BALE-TIZ.

No. 174,109 .

Patested Fob, 29, 1896.
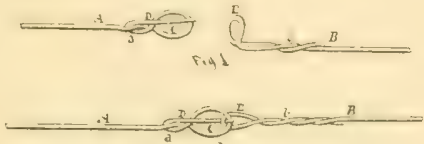

rit?

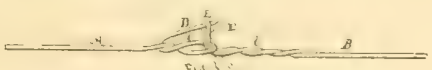

fis.:
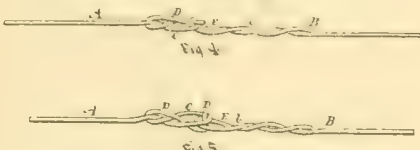

Fit 5 .

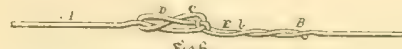

ring.

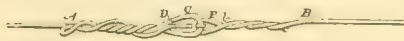

Fig. $\bar{i}$.
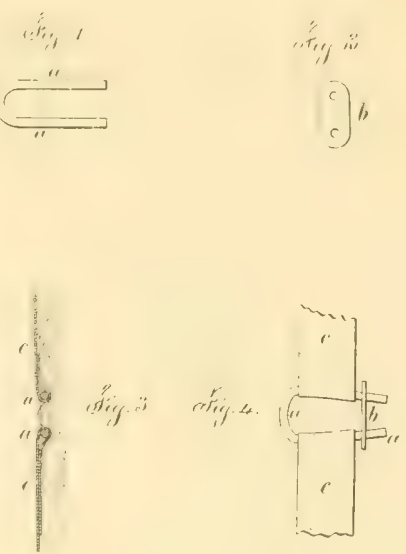

J. L. SHEPPARD.

BALE-BARD TIGHTERER

No. 274,580. Fatented Larch 7, 1876.

Eatented Fob, 29, 1976

Fig. 7 .

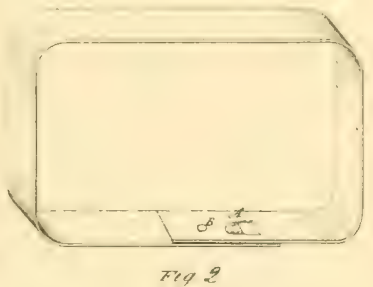

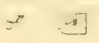

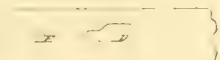

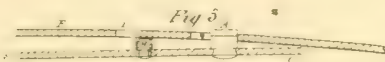

Aig 4

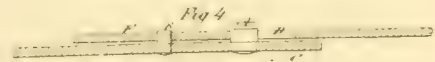

Fis is

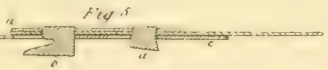

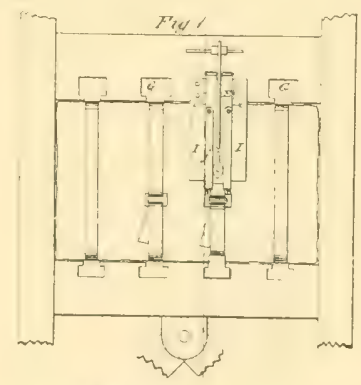

I3y 2

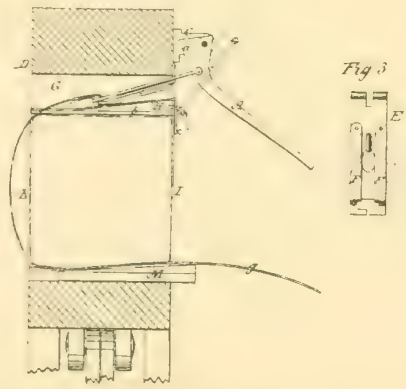


P. SLATTERY.

COTTON BALETIE.

No. $274,707$.
J. S. \& C. R. BERROX.

BALE-TIE.

30.174 .730

Satorted Katch 14, 1876 .

Sir.

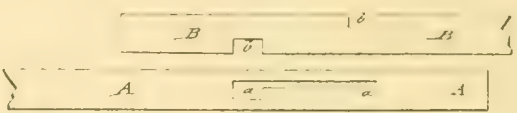

in: $i$.

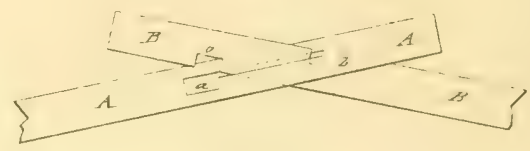

ig:s.

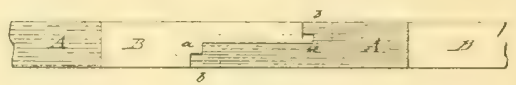

3. TRATER.

BALE-TIE.

Fatexted Xarch 28, 1976 .

Fig.1.

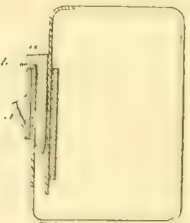

Ii, $=$

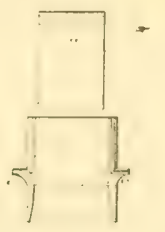

Fin:

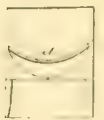


A. KILXER. BALE-TIE.

No. 175,711.

Patented April 4, 1876 .
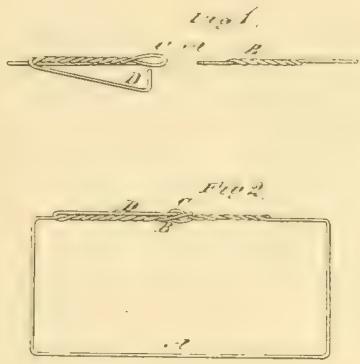

E. A. RAXSEY.

BALE-TIE.

$\$ 0.175 .752$

Batentad Apri1 4, 1876 .
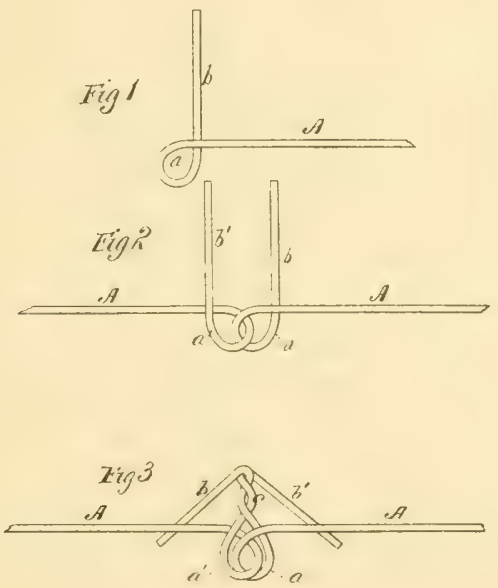

R. C. LUDLOW. BALE.TIE.

$N .175,720$

Fatuated April 4, 1876
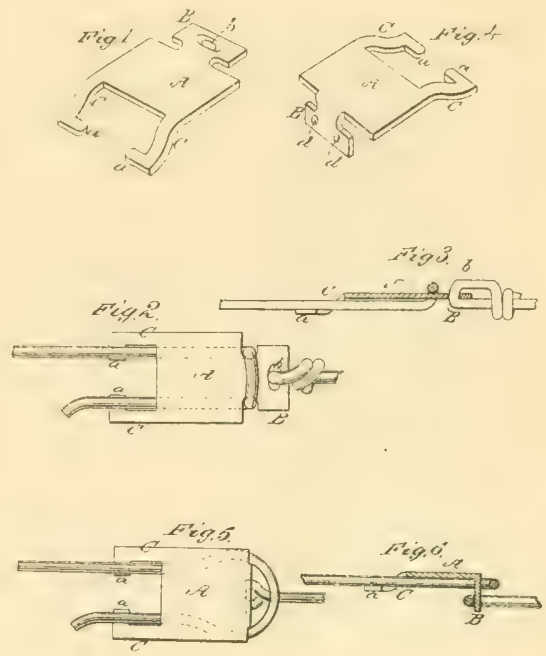

S. D. P DRDY.

BALE-TIS.

No. 176,049

Patorted Apris 21, 1676. 
W, ROGERS.

3 Sheots-Shoot2. ATTOKATIC BALE-TYIXO YTCFAXISX. Xo. 176,355 PLic:101 Apt16 28, 1876

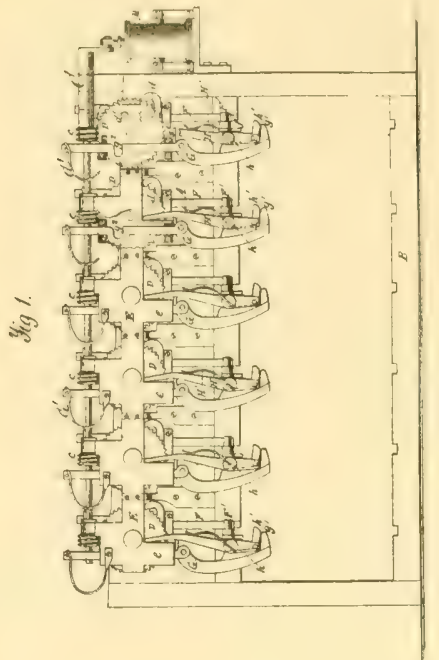

W. ROOERS

3 sheots-shet: 2 No. 176,355 Patented Afril 18. :a76.

Hey 2.

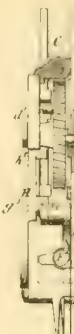
$\triangle T$ TOX $\triangle T$ TI BLZ-TTIYO XECZAZISX
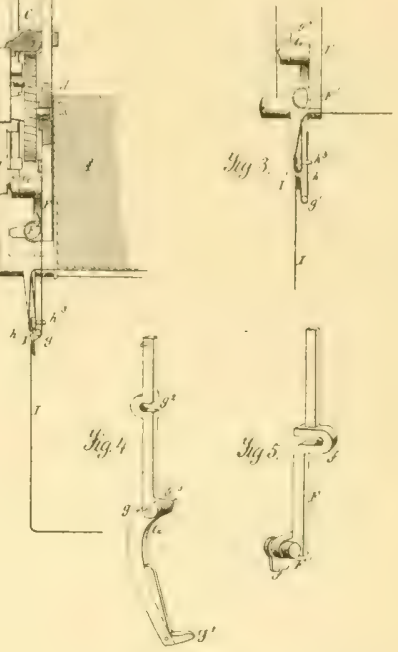

o. S. TRANCE. BALE.TIE.

Fatogted Ap:it 26. 1876 .
No. 176,623 . x. $276,355^{4}$

W. ROQERS

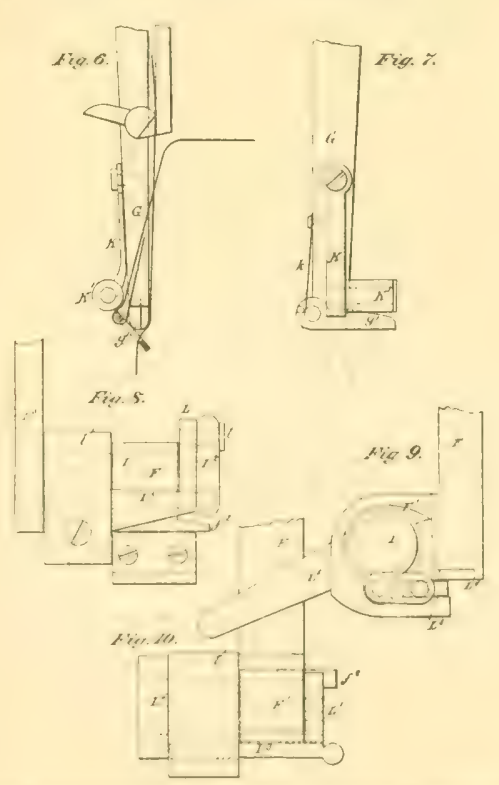


ล. S. IRANCI

BALETLE.

Vo. 176,614
B. K. DEDERICK.

BAZE-TIE UACHINE.

80.177 .221

Pa:cutad 3a\% 9. 1876
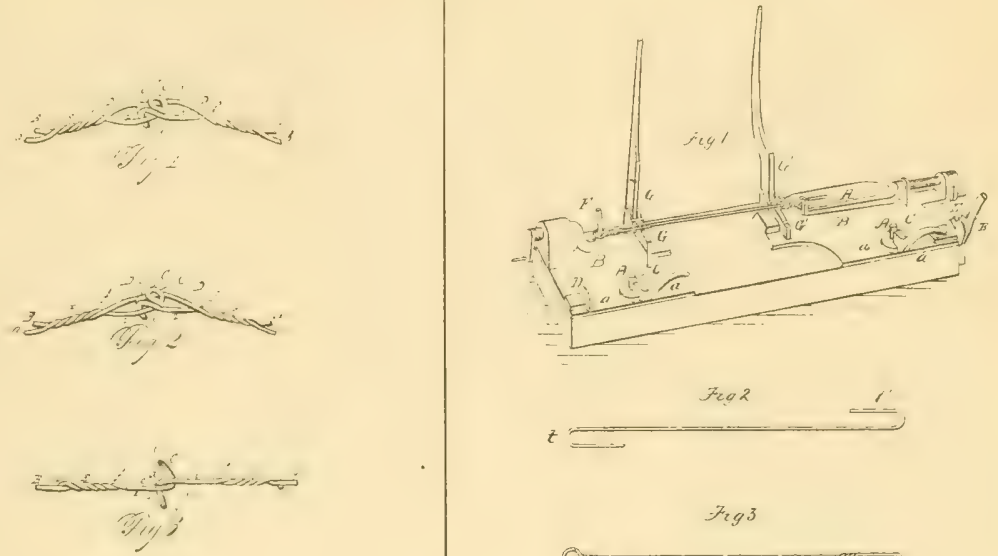

Fro 2

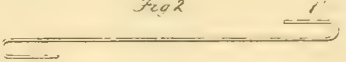

$t$

fig 3

Com

J. X. OOLDSLITH.

BALE-TIE

Patezled Kay 26, 1876 .
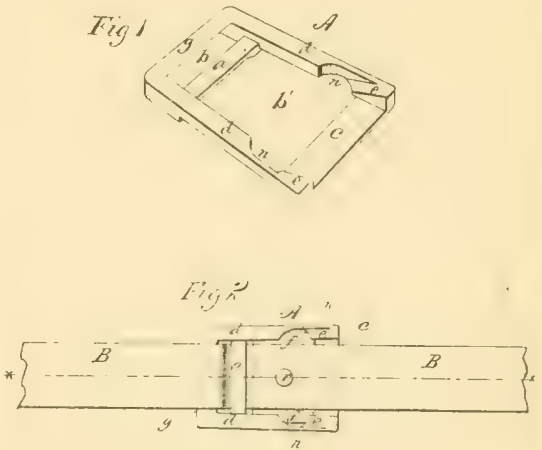

Figio

No. 177.330

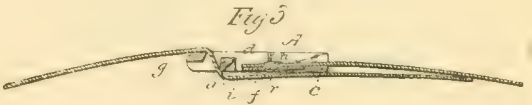

Patented X1y 9, 1876

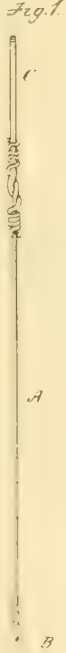

3. B. DEDERICZ.

iึ. 177.222

WIRE BALETIES.

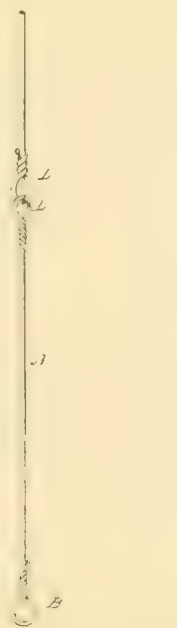


S. MEMURTRY.

СOTTON-BALE TIE.

vi. 177,659 .
3. บeชนRTRY.

GOTTO: $2 \dot{B}=-715$

มีค. 277.651
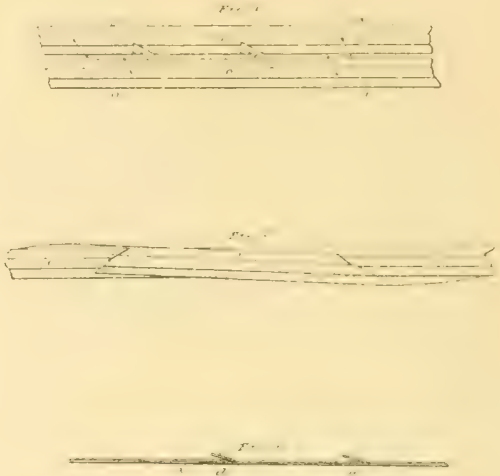

2. S. BRIOOS.

BALETIE.

Patuated Yay 23,1675.

No.177,683.
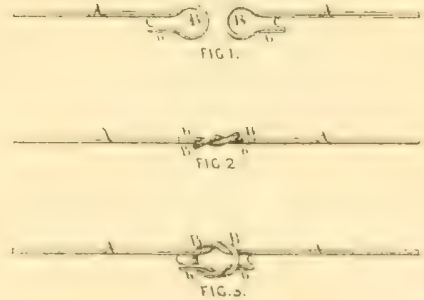

1i. 16

${ }_{516} 4$

J. 2. RANE LLFH

No. 177,957

Patertet K28 30.1976

Frid :
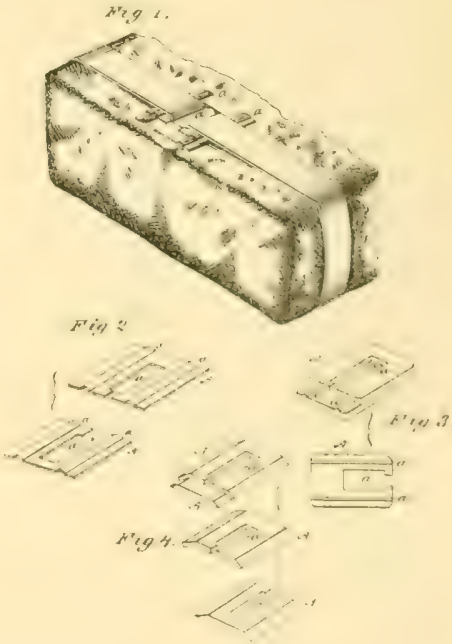
vi. 278.027

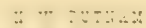

$\therefore \quad:-2: 1:$

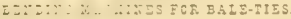
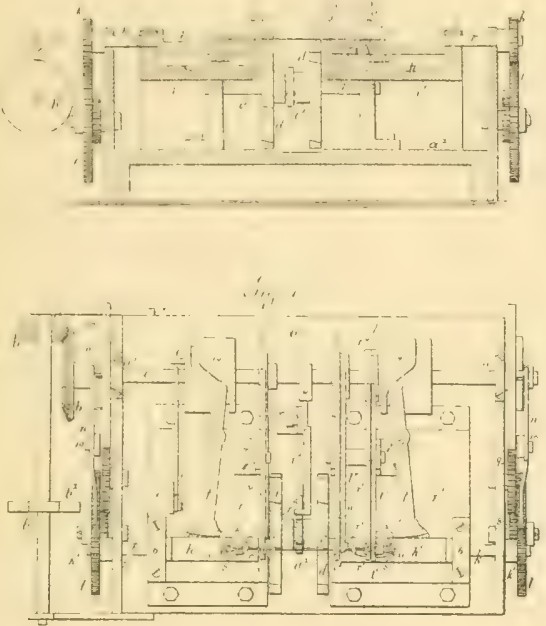

*. W. PบรYAK

3 Sheats-Shec: 3.

WIRE BENDIM J HACYINES YOR BALE-TIES

Xi. 178.027
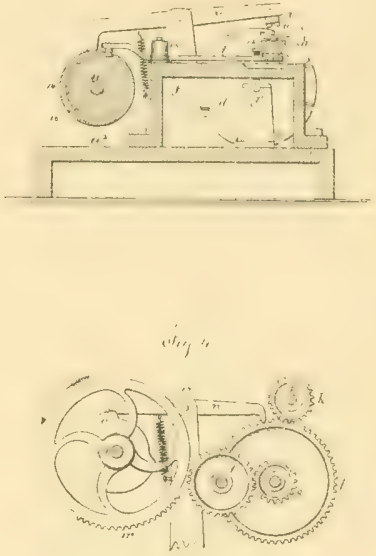

G. D. JEWEIT.

BAIING-ROPE. *

No. 178.156
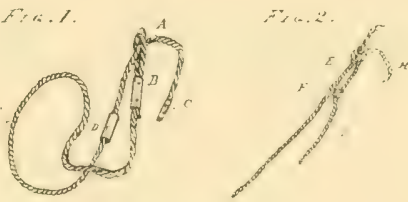

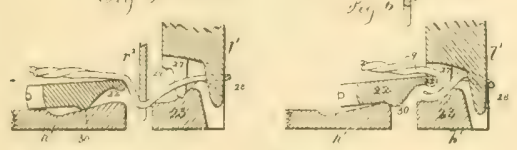
igg $; r^{2}$
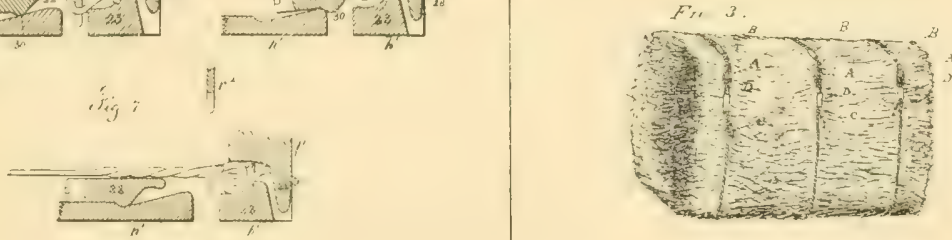
ร. H. SNYDER.

BALE-TIE.

No. 178,196.

$P a t 0=t e a$ Say $30,1 E: 0$

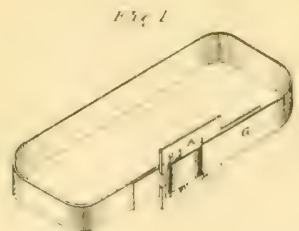

A : : :

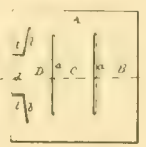

W. S. DAVIS.

BALE-TIE.

No. 7,252

Foissued $\Delta$ gg. 8, 1876 .
No. 178,418 .

S. DATIS

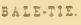

PLtนR:1 JuE0 6, 1876 .

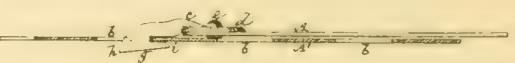

Fier: 2

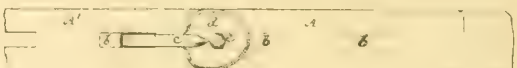

Mig.s

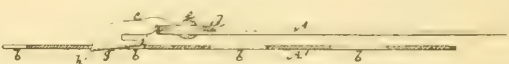

. PALUATIER

BAIE-TIE.

Puteriod 5net 13. 2876

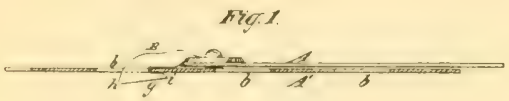

No. 178.665 .

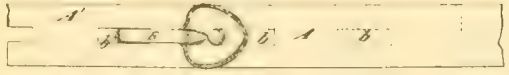

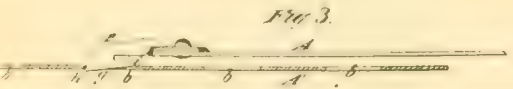


B. R. FOWLER. BALE-TIE.

No. 178,754 .

Poteated Juge 13, 1876 ,

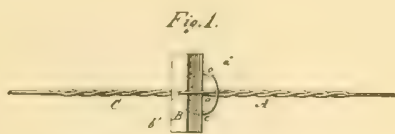

Fi: 2

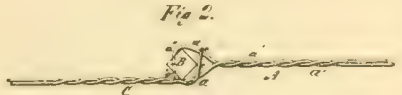

Fig.s.

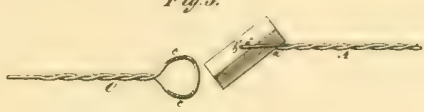

No. 179,762

\section{A. A. OOLDSMITH}

3ALE.TIE.

Eatented Ju20 13. 1576
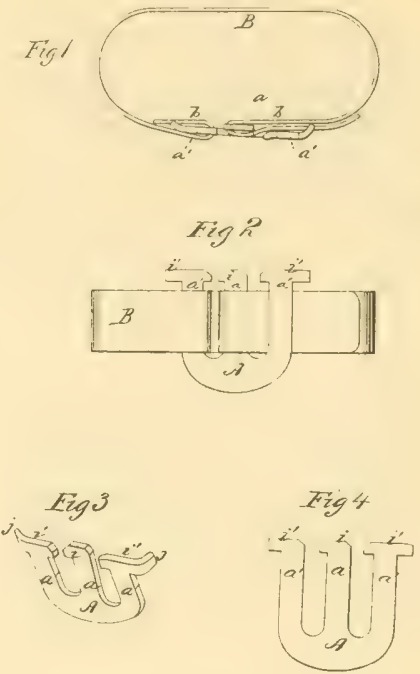

B. HEMPSTEAD BALE-T1E.

Painates June 13, 1875 .

50.178 .771$.

Y. 179,578 .

B. C. $C T 020 \mathrm{~W}$

BA2E รIJ.

Pacosed Jalg 4, 1896 .
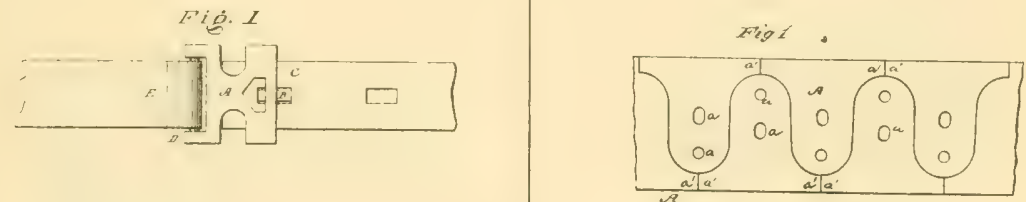

Fig. ?
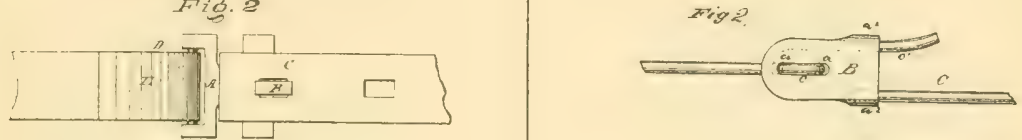

$F^{2} i=.5$
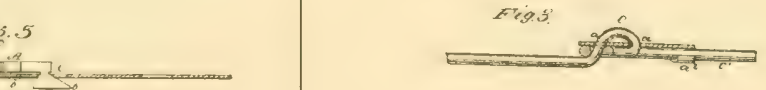
B. A. RA $25 \Sigma$ Y.

Xo. 179.604 .

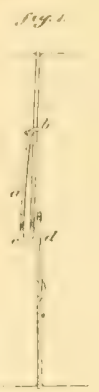

\section{R. Do QR $A$.}

BALE-TIES.

S. $179,841$.

Patontod 5uty 19,1076 .
Paseout suly 4.1876 .

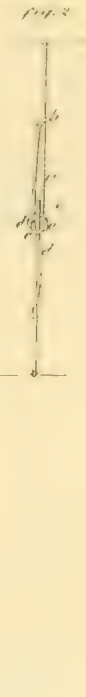

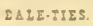

W. B. HAYEEN.

B. $\{5-712$.

No. 179,654 .

P1:00:0 Jo15 11, 1896

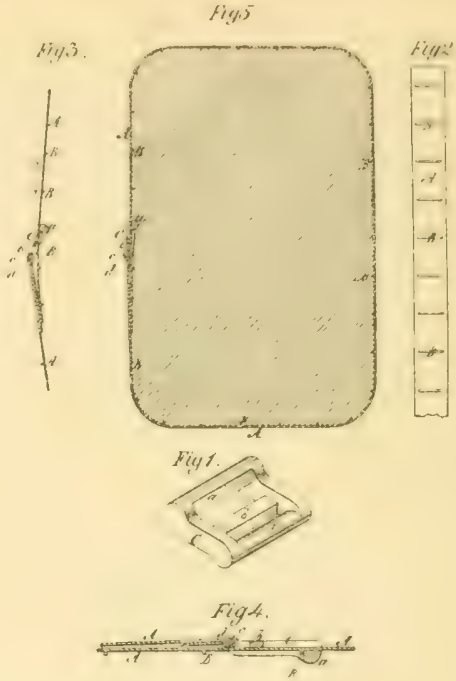

I. A, DRARE

2 sreats -5 set 1

APPARATUS FOR PACEIVO AXD BATINO COTTCX.

No. 279,848 .

Fatealod Int5 28, 1875.

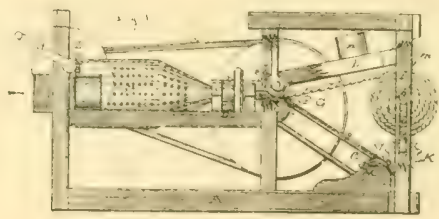

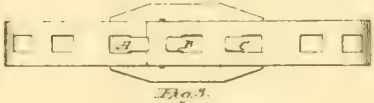

A. $\left[\begin{array}{ll}D & 0\end{array}\right]$

$x^{2} x^{2} 9 x \leq$

zla.s
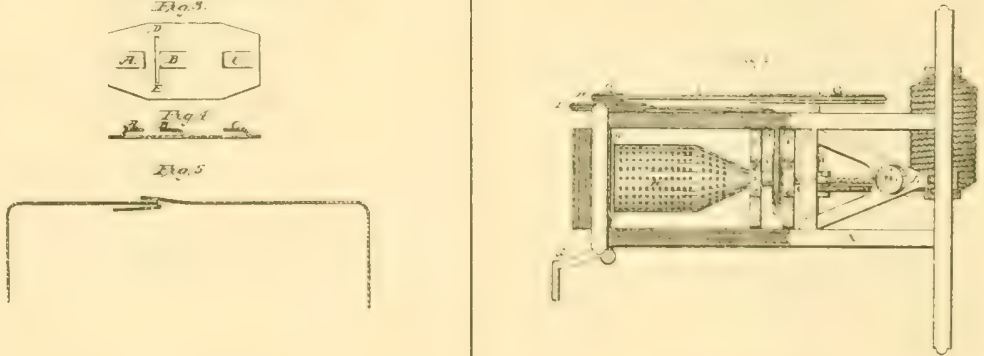
J. A. $D R A K E$.

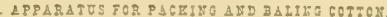
Ne. 179,848 .

Fatentad $502728,1326$.

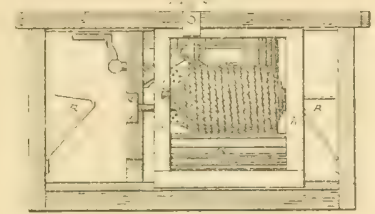

3. $\triangle . D R A K E$.

METHOD OF BALING AXD PACZIHG COTTON.

No. 179,849

P2tented J315 88. 1875

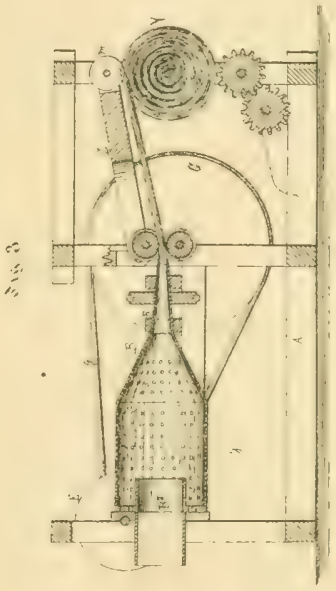

3. A. DRARE.

3ETTED OF SALISG AND BACEINO COTTOX.

Si2. 179,819 .
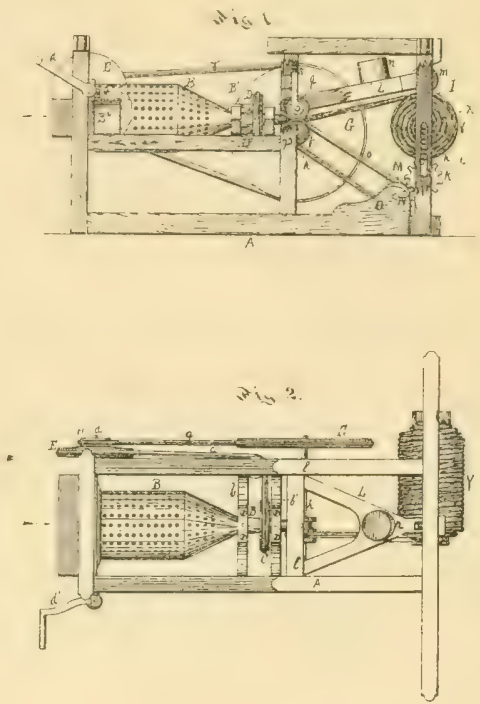

2. A. $D R A B E$.

METHOD CE BALING AND BACEING COTTOH.

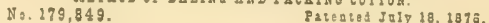

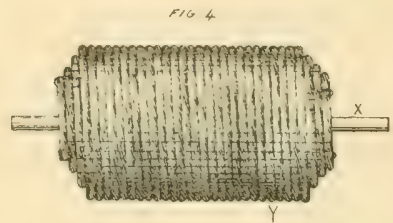

FIG

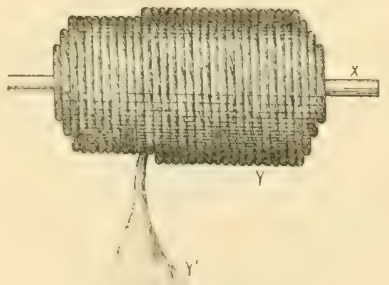




\section{IS. SEYMOTR.}

No. 179,872 . BUCZLES POR COTTOYHAALE IIES. Fio:\%

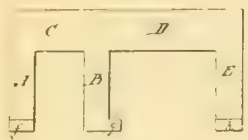

$\frac{4}{4} \operatorname{cic} \pi-\pi \frac{\pi}{\pi}$
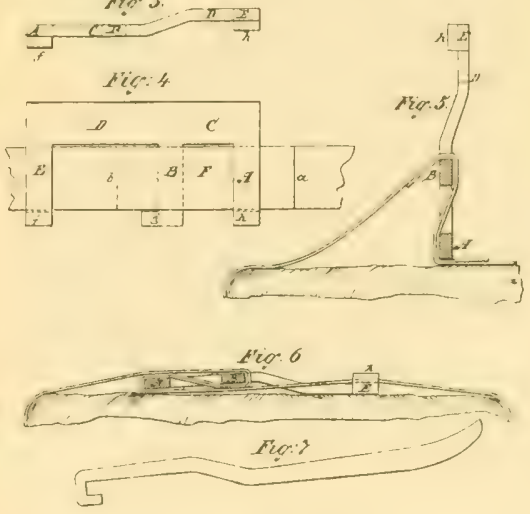

\section{D. PDRDY.}

BALE TTIMG ATTACEUENT TOR BALIVE PRESSES. No. 180,788 . Aig: 2

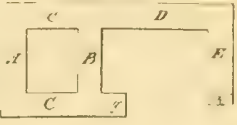

צ. 180,388 .

3. ห. STYDER. BALE-TIE

Pateates Jut5 25,9878 .
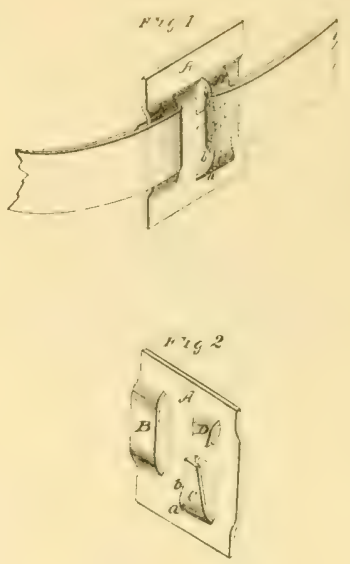

No. 180,897

¿. C. $Z \cap W E E R$.

EALE-TIES.

Patented Ang. 8, 1876
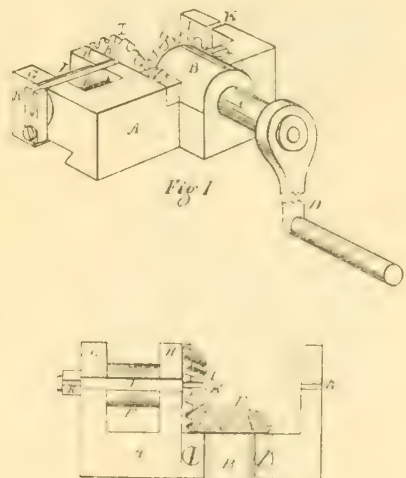

ri, $:[;]$
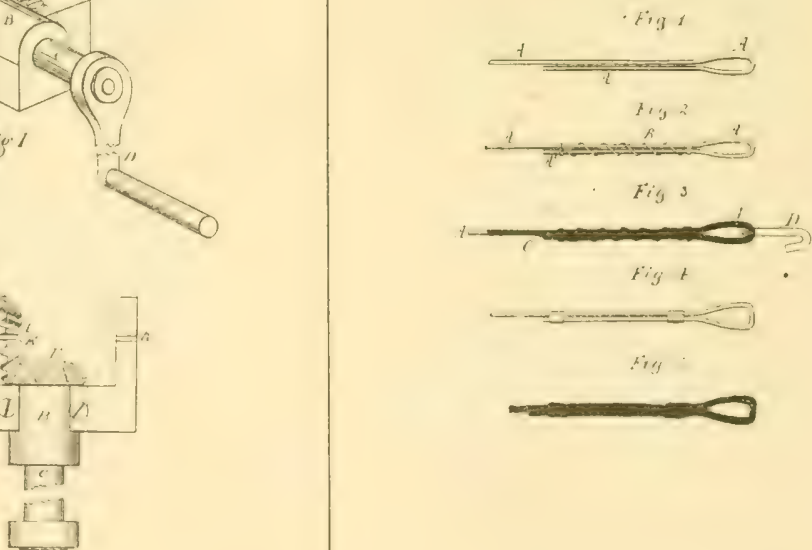

fig $t$

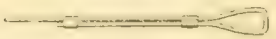

Aif 
D. OLUSTED

ZOCES FOR BALE-TIES.

No. 180,910 .

Pateated Aug, 8, 1876 .
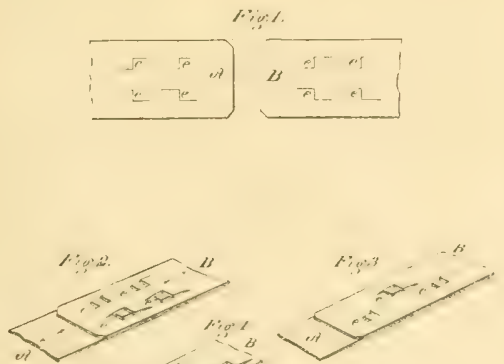

$-\infty$
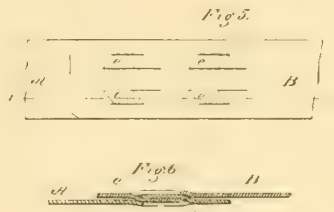

R. DE GRAY

2 Sheats-5koet 1 .

BAND PULLIXG ARD LOCBING XACRIXES FOR BATIYG COTTOU.

No. 181,052.

Patenced Ar8, 15,1875 .
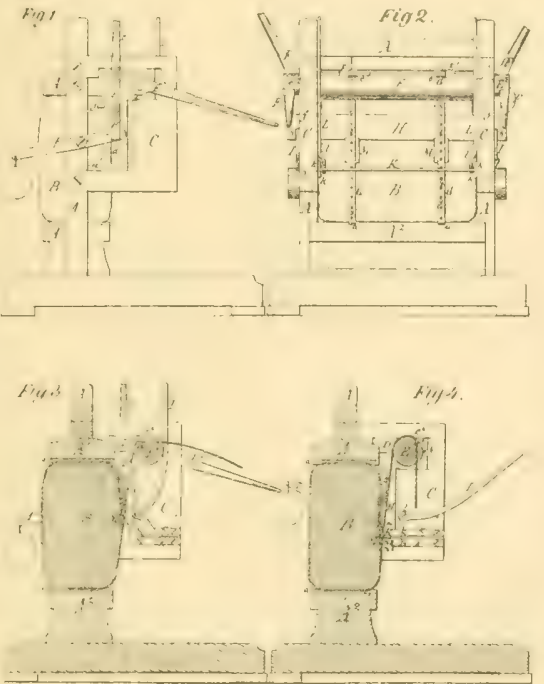

ग. THA

BALE-TIE TIAHTEXER.

No. 181,020 .

Patertet A $13,15,1626$
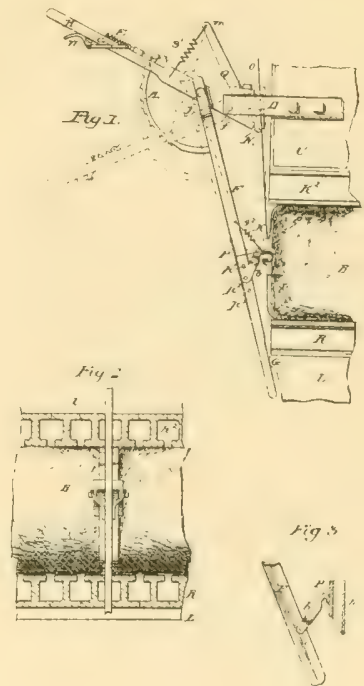

R. De GRAY.

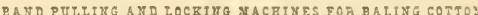
No. 181.052

Eateater

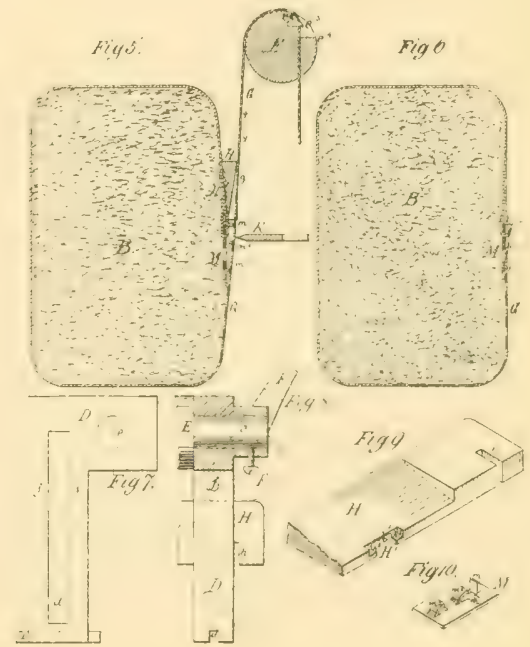




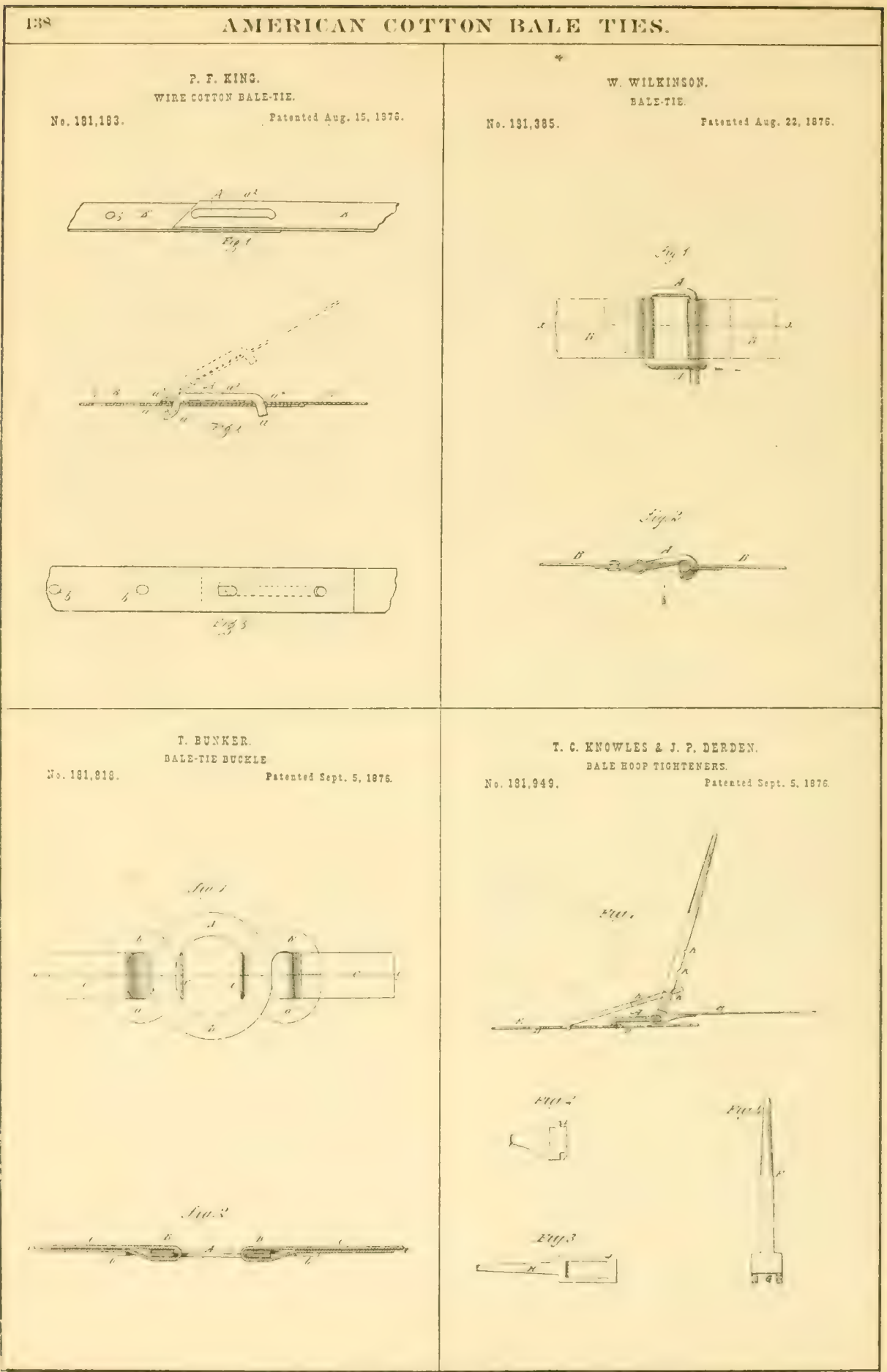




\section{H. LILLINOAR.}

EALE-TIES.

No. 182,031

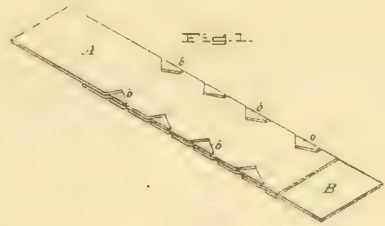

폴.․․․

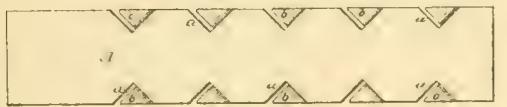

포코.

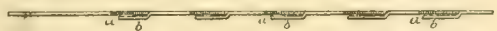

W. B. HALELTINE.

BALE-TIE.

S. 182,757

Patsated oct. 3, 187 t.
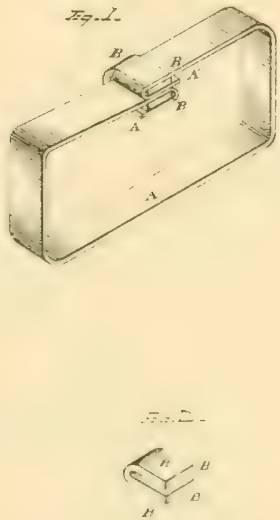

ร. G. WHEELER.

KETHOD AND MEAUS OF TREATIXG COTIOH-3ALES FOR AMD DURIYE COXPRESSTOY.

No, 182,339 .

Patested sept. 19, 1876.

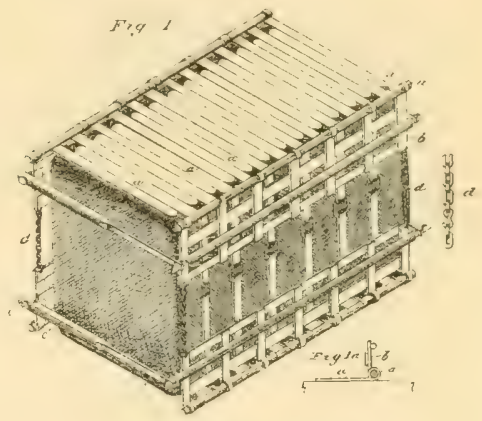

1"⿻ 2

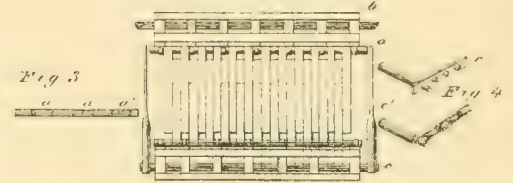

2. E. $\Sigma$ VANS.

BALE-TIES.

ร.. 182,810 .

Pateated Oet. 3, $\$ 876$.

Fig. 5 .

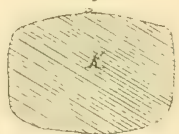

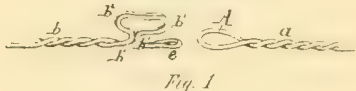

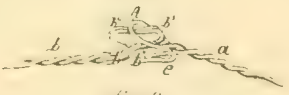

(iis: :

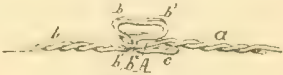

Hig.

b

Fis 7 . 


\section{1. *7. 또s}

GALETIES.

No. 183,053

Futerted Oet. 10, 1876.

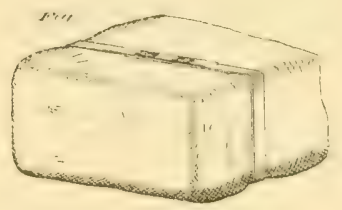

L.en.t,

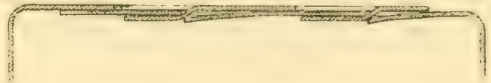

3. TWEEDDALE.

BAIE-TIE.

No. $183,234$.

Fateded Oct. 10, 1876.
C. ZRIEQ.

BALE-IIES.

No. 183.058

Eatertud Oet, 10, 2876.
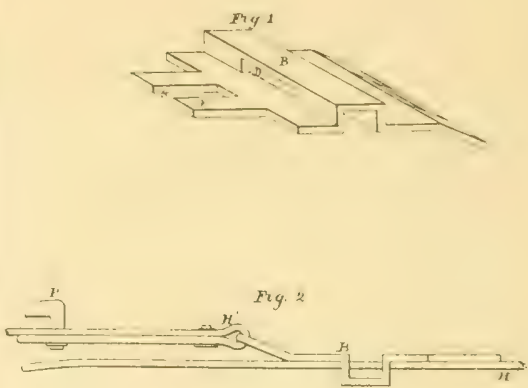

S. \. $D R \triangle E E$

YARTFACTURE OF BALE-TIES.

No. 283,382 .

Patealti oet. 17. 1876 .

Fig.3.
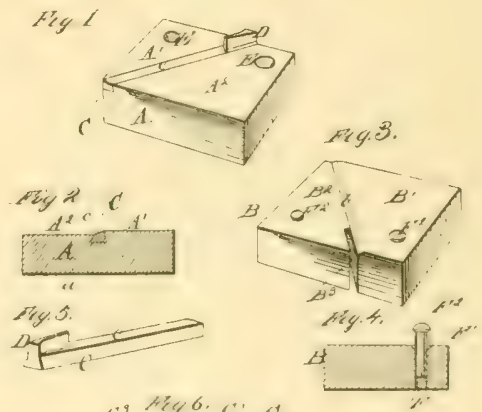

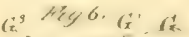

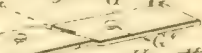
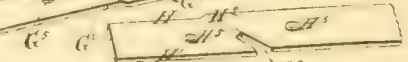

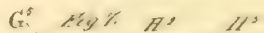

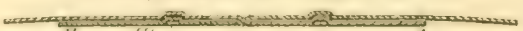

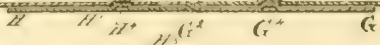


A. A. OOLDS $17 \mathrm{~K}$. BALE-TIES.

No. 183,390

Patented Oct, 17, 1876 .
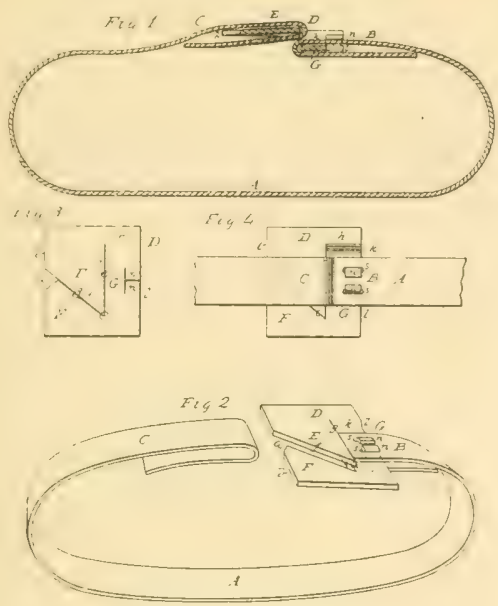

2. ว. IEWIS.

EิALE-TIE.

Patented Oet. 31. 1876

Ne. 183,943

le, d
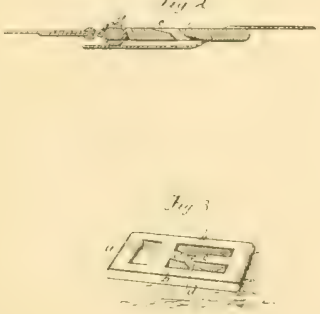

E. E. PIERCE.

BALE-TIE.

Xo. $183,702$.
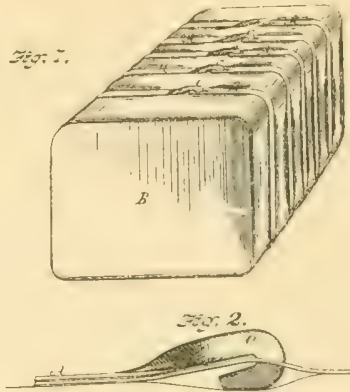

$\approx=3$

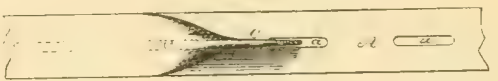

Fin: 4

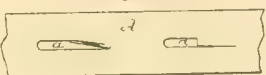

C. $\triangle \triangle N, D E R 2 E Z$.

BALE-TLES

No. 184,272.

Dacented yor. 14, 2976
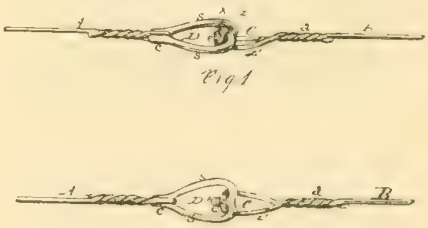

in:

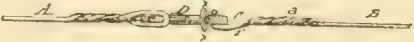
in 3

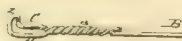
Fig. = 
xง. $834,397$.

3. W. $\triangle \triangle C U H B E R$. BALE.TIES.

Pasoged 807. 24, 1896.

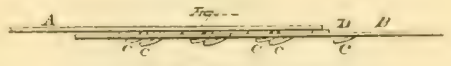

Fra.2-

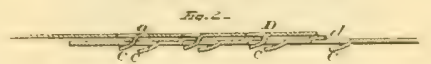

F̄a.:

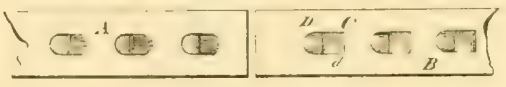

$5=$

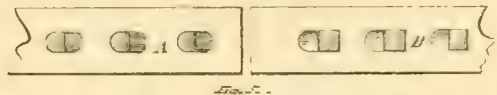

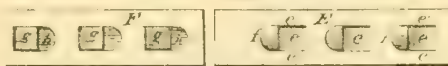

$x \rightarrow \ldots$

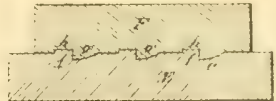

2. W. $2 A C E X 8 E R$.

จ. 184,397.

2 Ssouts-shopt 2.

Patusted gor. 24, 1876.

F⿻,

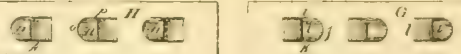

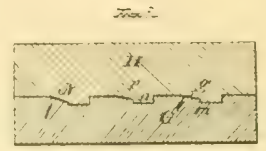

G. S. ERANCE.

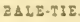

No. $184,607$.

Patentod $797,21,1976$.
No. 184,448 .

YACEIYE ECR YARIYG BALE-TIES

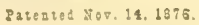
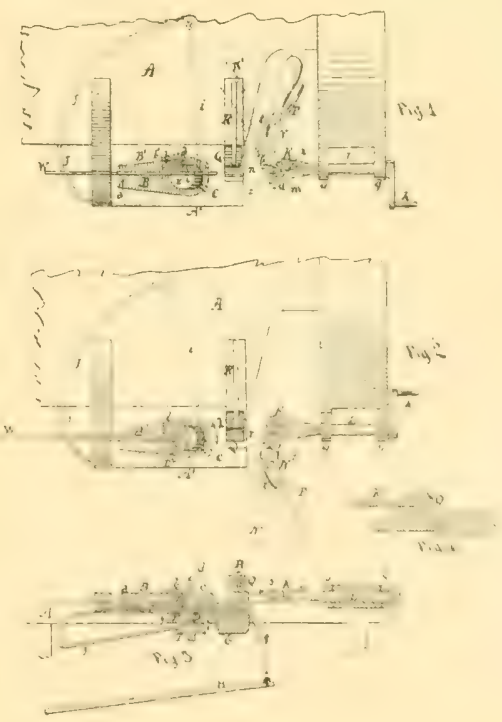

\section{$\because \because \cdots 1$}

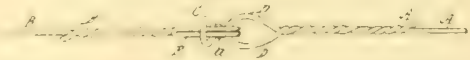




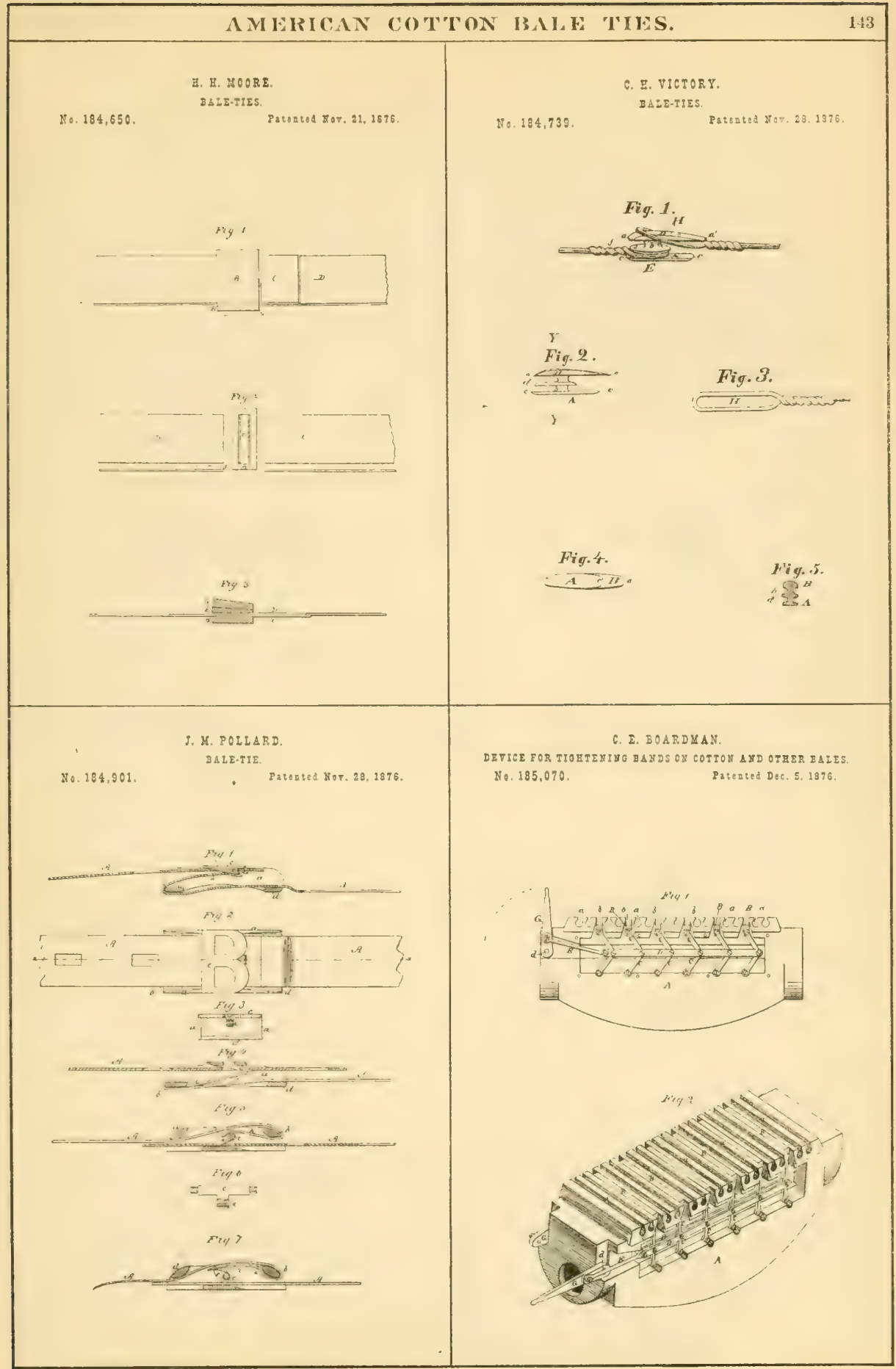


P. C. INGERSOLL.

MEAXS FEE BLING UAYTRE.

So. 185,106 .

Patezed DeC. 5, 1076

Sitg 1
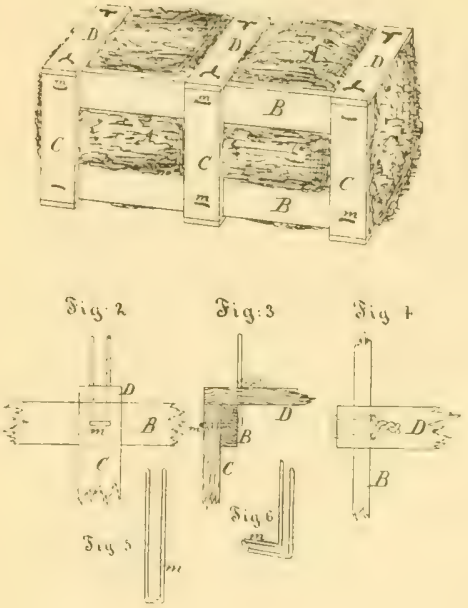

ง. S. FRANCE.

IALE-TIE.

No. 185,310

PatonLA Det. 12, 1875
3. C. DJ BOIS.

X.. $185,304$.

BALE.TIE

Patude1 Dec. 12, 1398.

Iii)

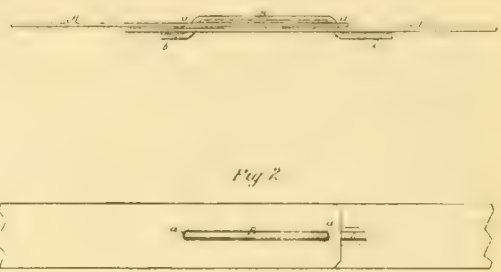

Fig 3

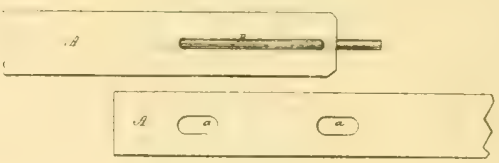

C. Y. PEARRE.

BALE BAID.STRETCHEIS.

No. 185,347. Pateated Det, $12,1876$. $\therefore i^{2} \lim _{i=6}^{2} 1$

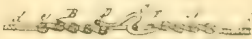

xie 2

$-x^{2}+x^{2}=2 x^{2}-2$ ind 
W. P. GERLAC\&.

BALE-TIE.

No. 285,519 .

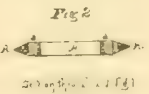

S. R. KENNEDY. BALE-TLE.

xio. 185.544.

Patented Dac. 19, 1996.

Fig 1
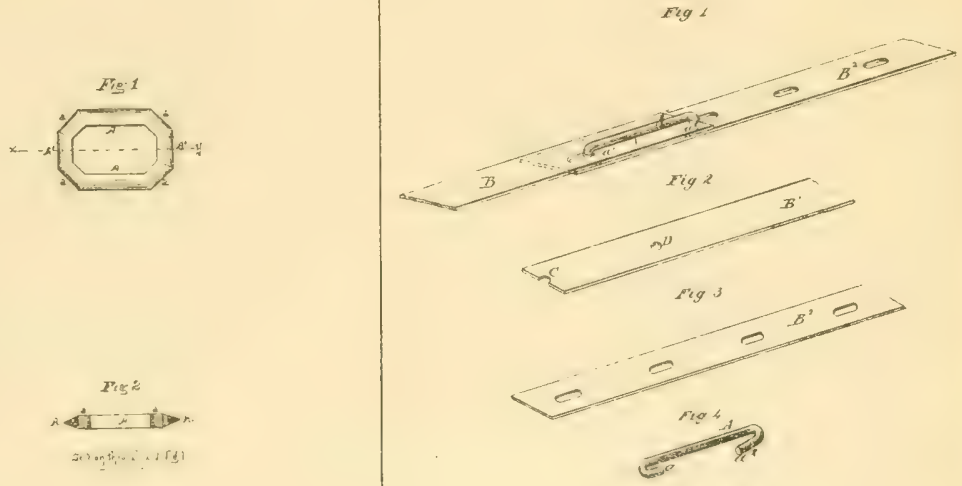
No. 2125sipen
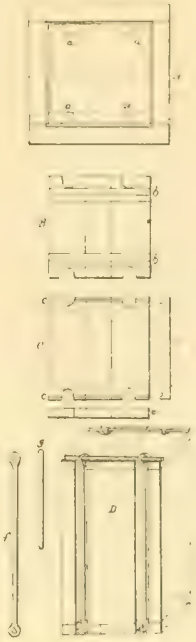

Fus,

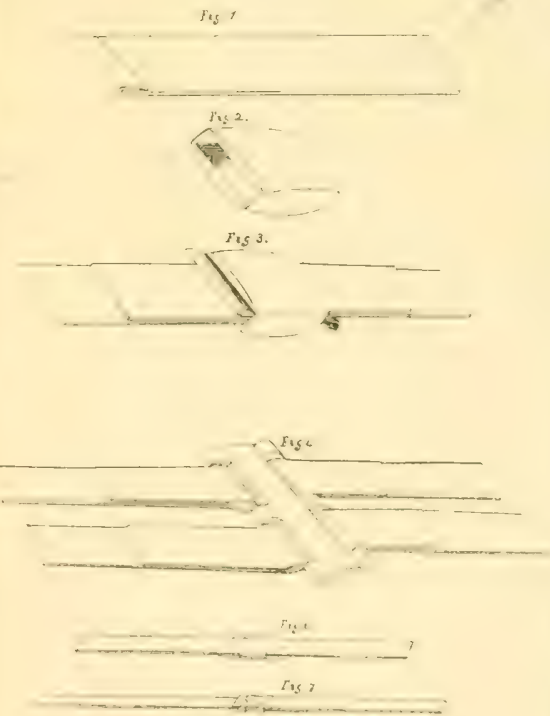

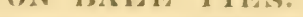

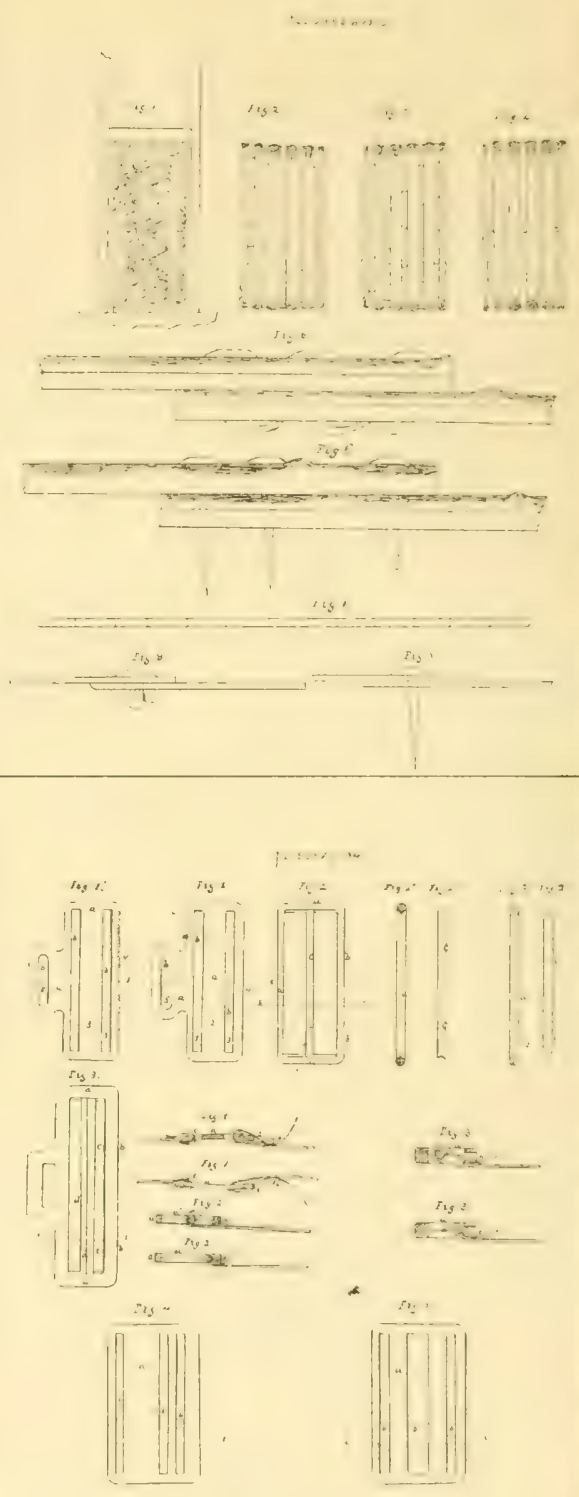

b.

if. .

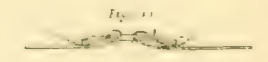




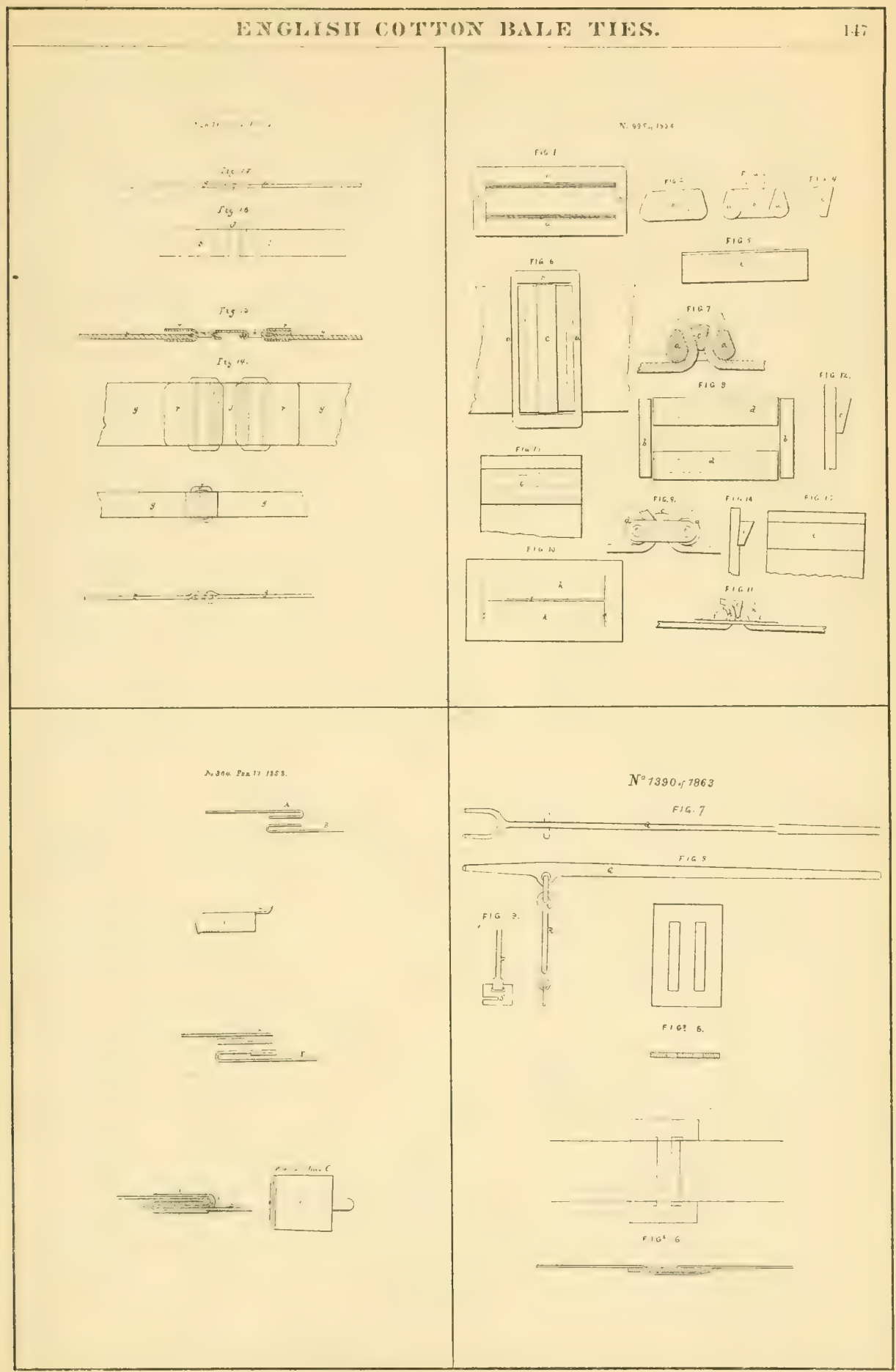


$N^{\circ}$ s96\% \% 1863.
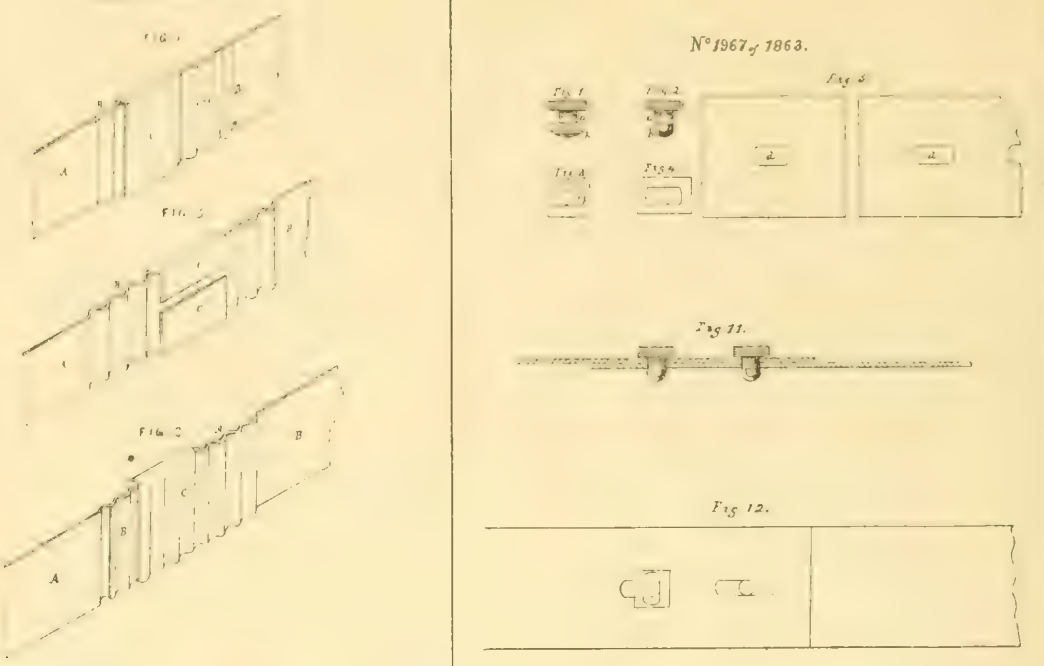

Tis 12.
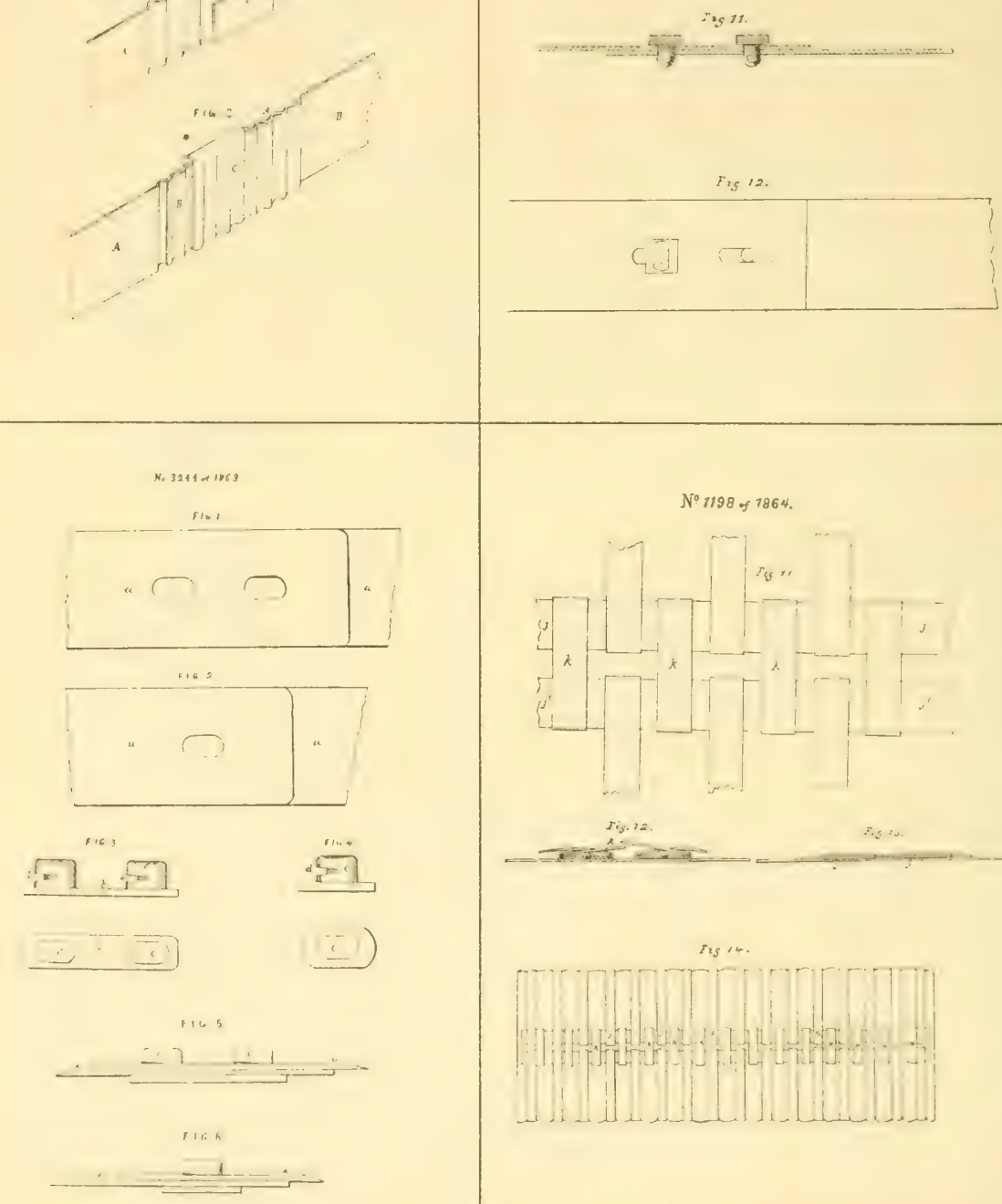

$N^{0} 1198$ of 1864.
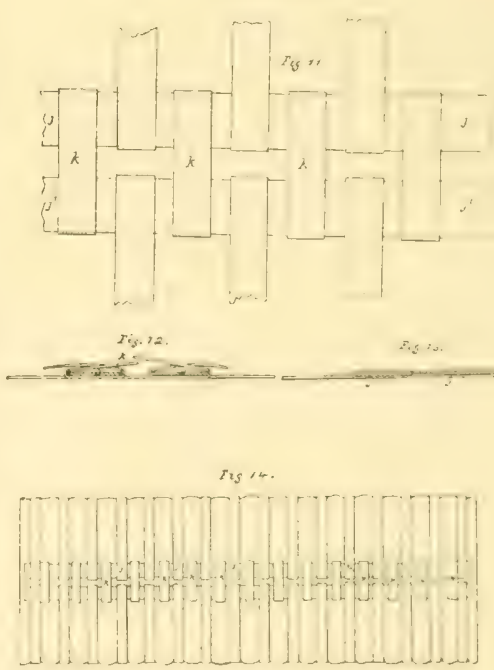


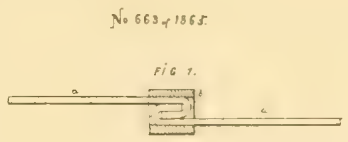

$N^{\circ} 2837$ of 1865
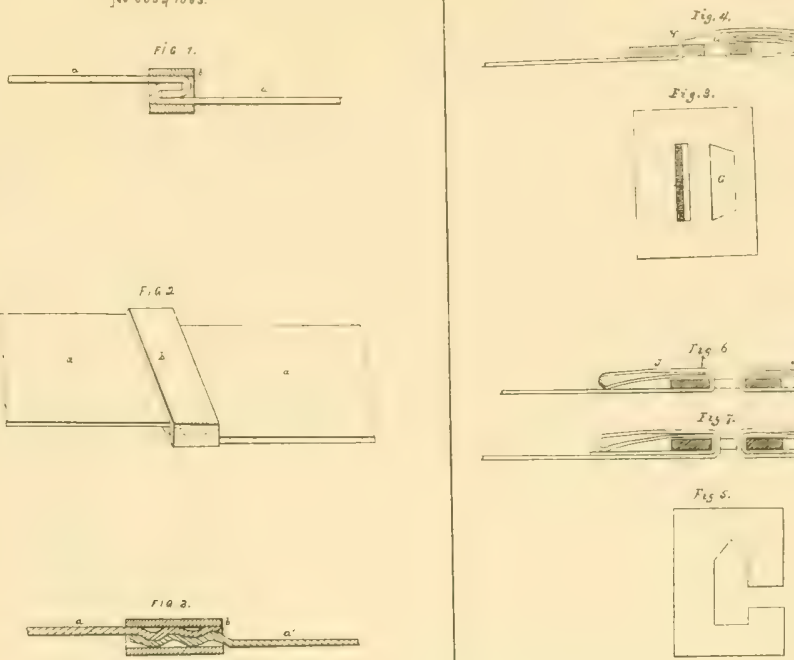

N: 2991. Nov. 151866.
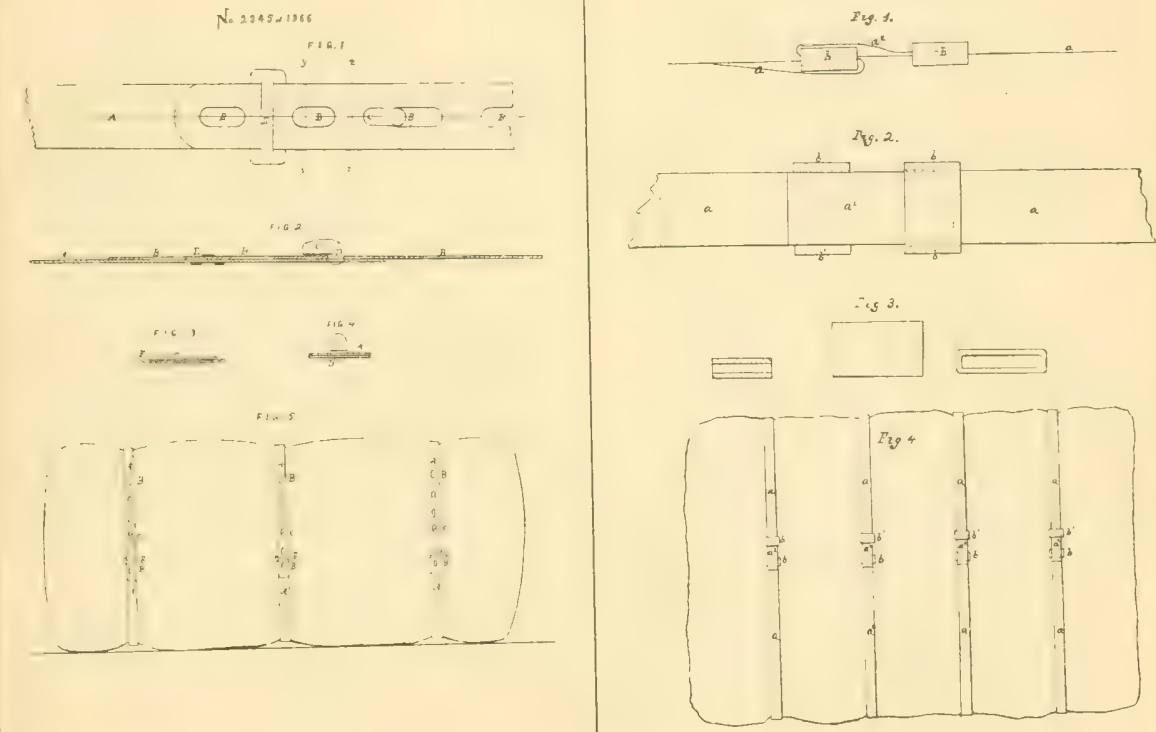
, $1, \ldots \ldots$

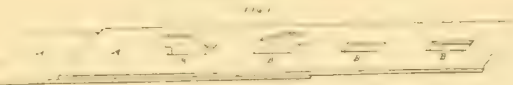

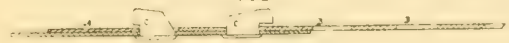

fit 3.

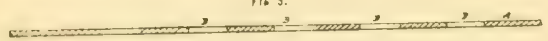

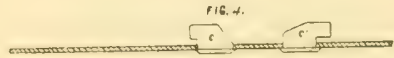

atis

$\square$ ए

A D. T862. Nar. 6 N:630

KEWTON'S Specireator.
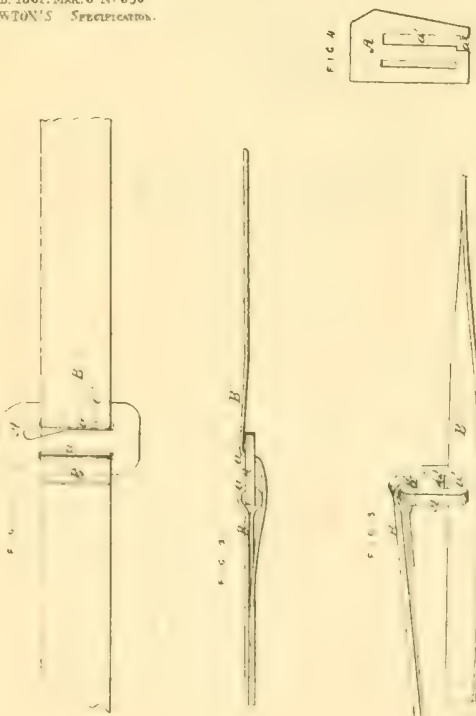

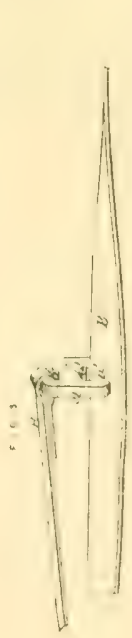

A.D. 1867. Apm, 6. X: 1096

IUCAS' SERTIRLariox.

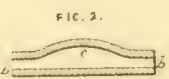

16.3

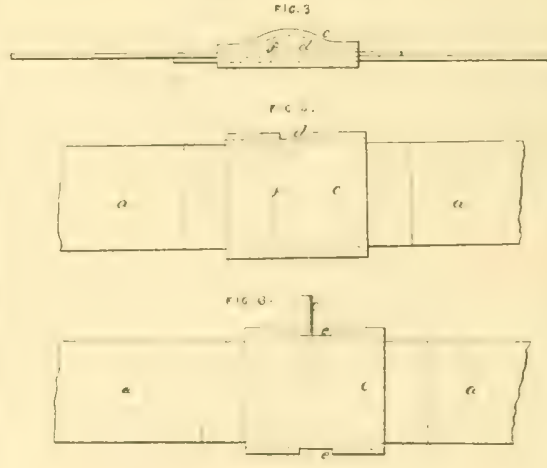



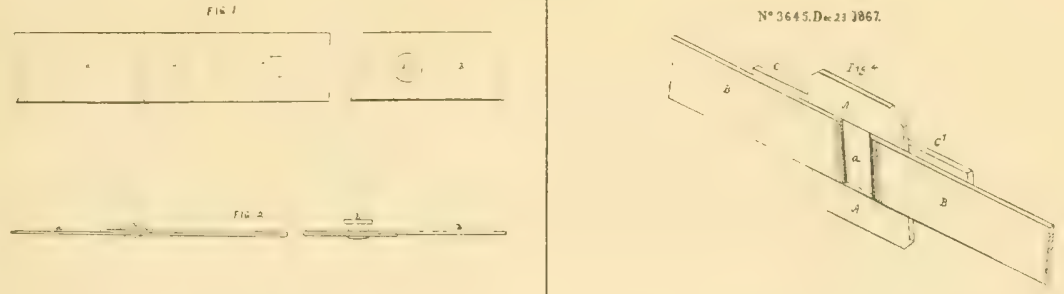

Ne. 1972,180

fi:

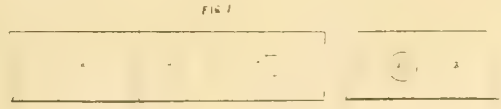

Iis 3.

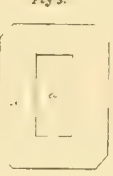

fics

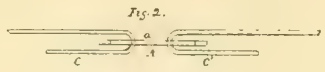

2. 2

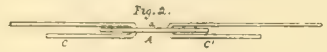

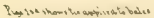

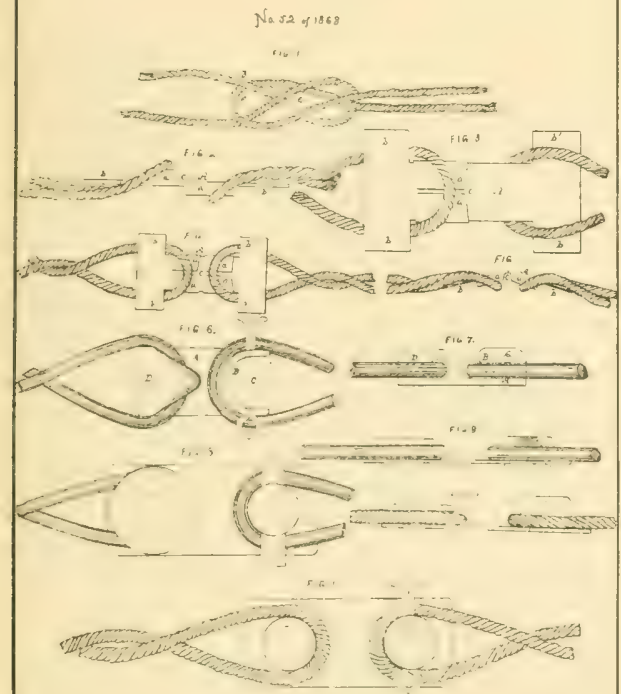

$\sqrt{6} 1996+1968$

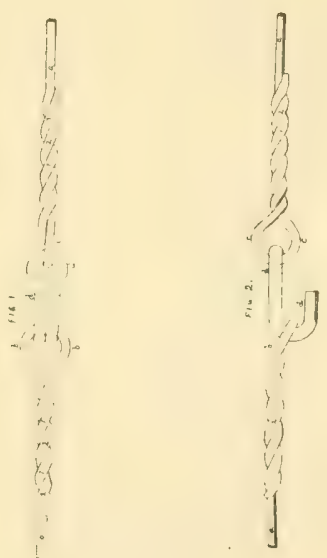




\section{G $1 \mathrm{I}$}

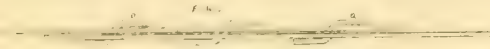

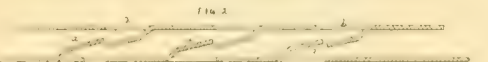

fig 4
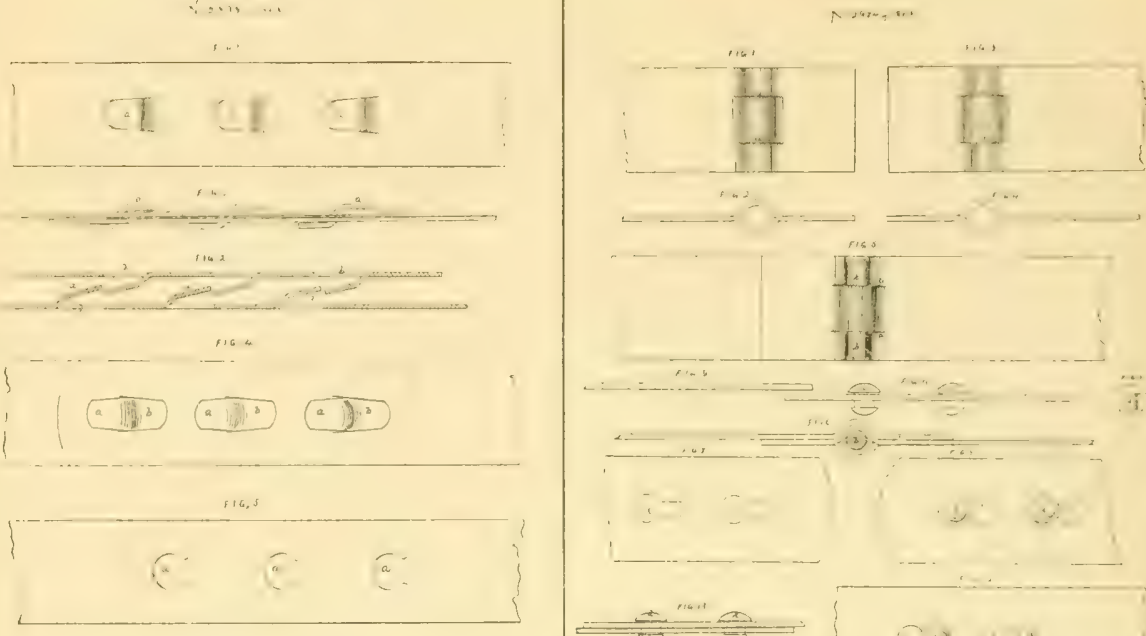

$+\frac{2+1}{2} \stackrel{x}{=}$

$=4$ os $\Rightarrow$
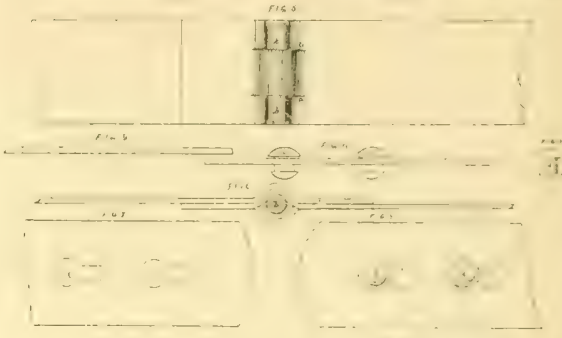

$2 x+1,1$

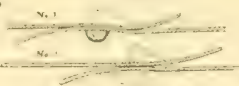

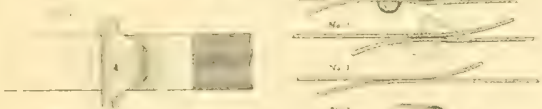

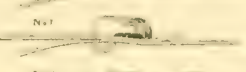

$\lim _{1}, \ldots$

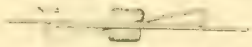

$1\left[\begin{array}{l}1 \\ 1\end{array}\right.$

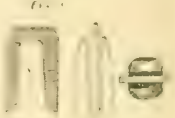

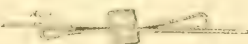
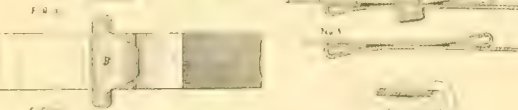

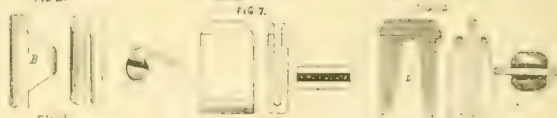
$\int_{016.4}^{216}$
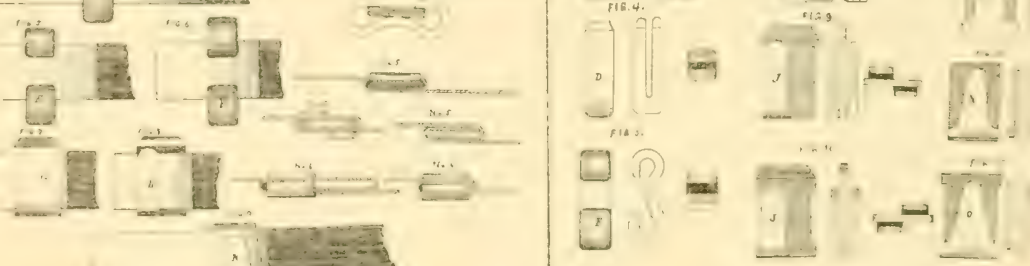


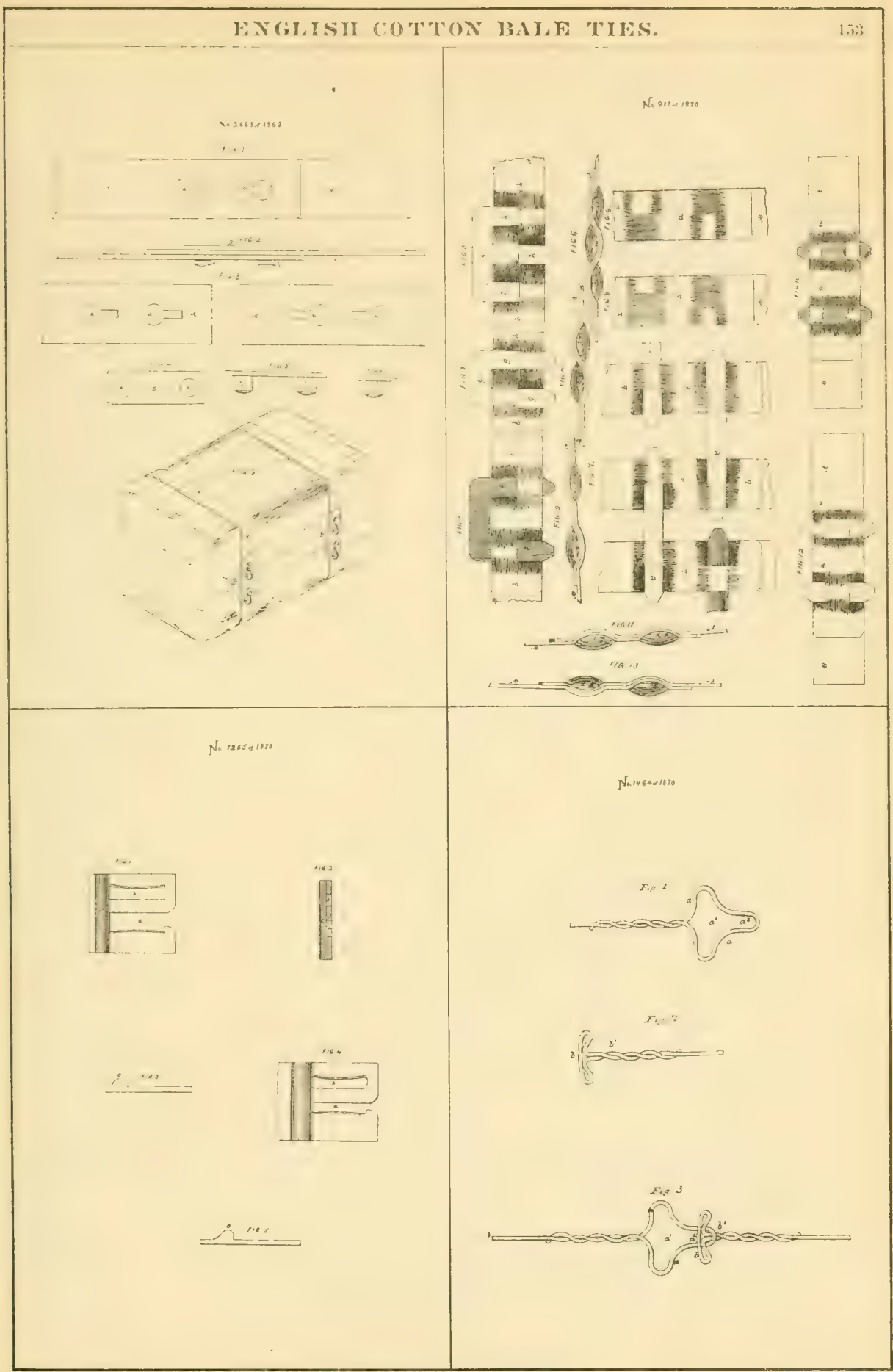




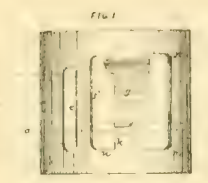

Fig 2

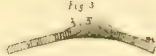

N. Tanes;11,
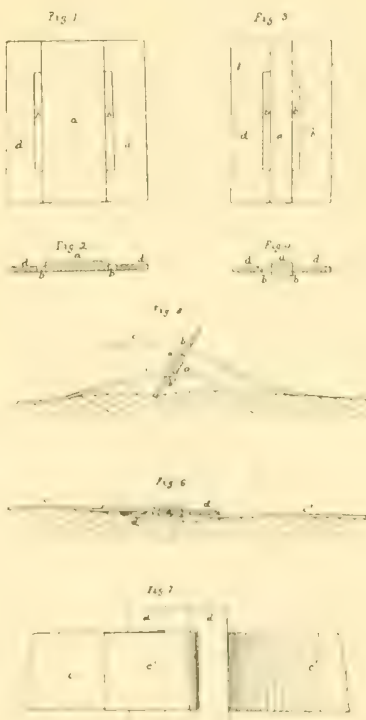

Na. $87+213 n$

4.

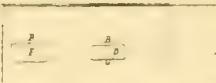

]$^{n, 2}$

[., 3

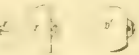

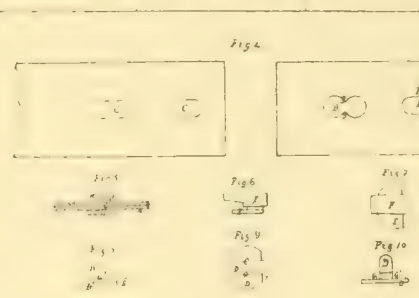




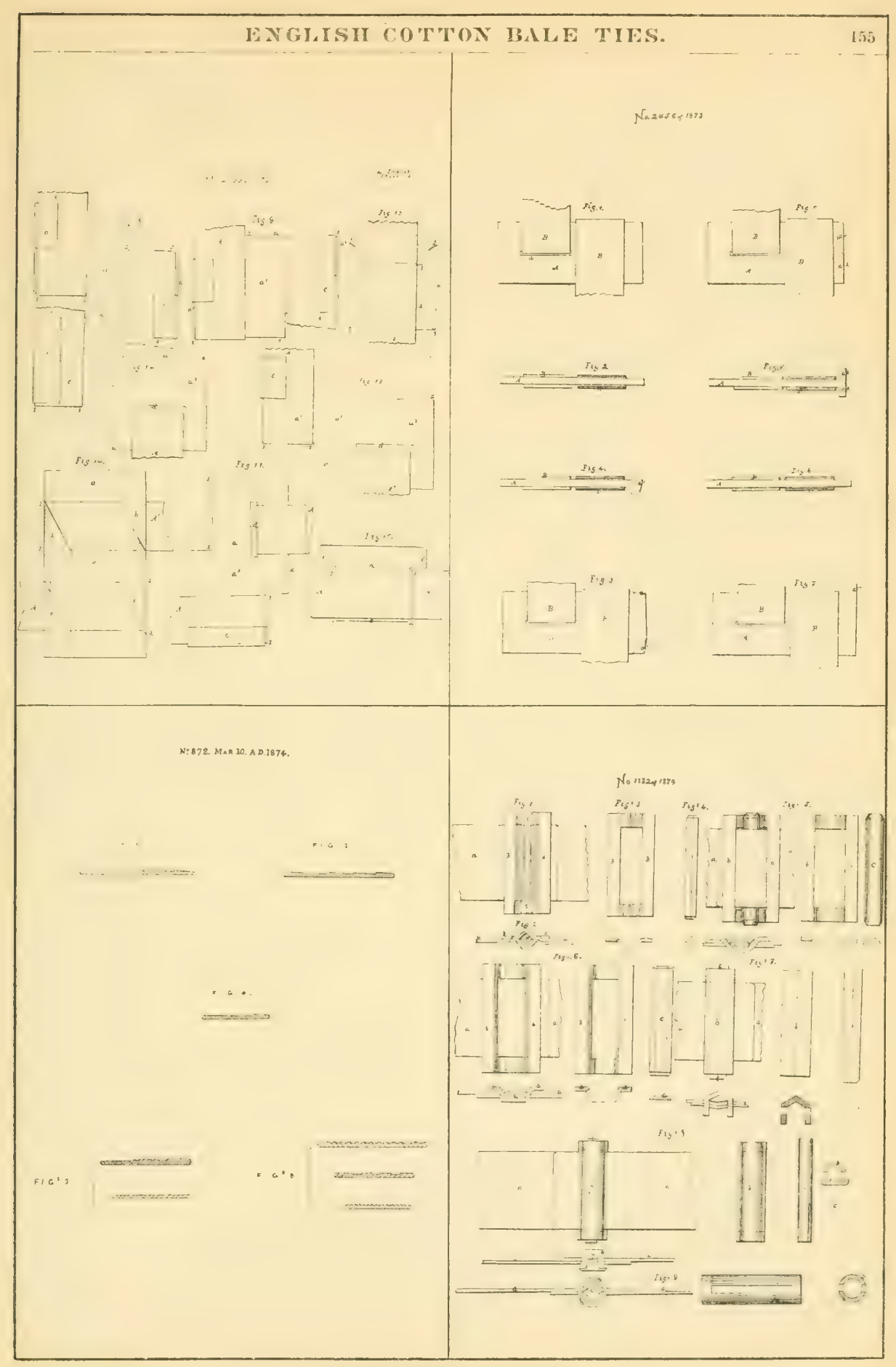


Swo $196,+\infty, 5$

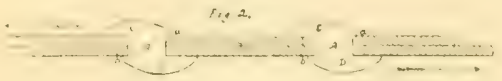

$\therefore$. 3.

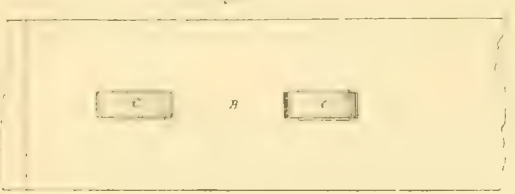

I.s....

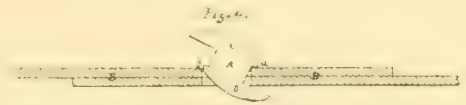

A.D. $1075,0 \mathrm{cr}, 16$ 자 3536
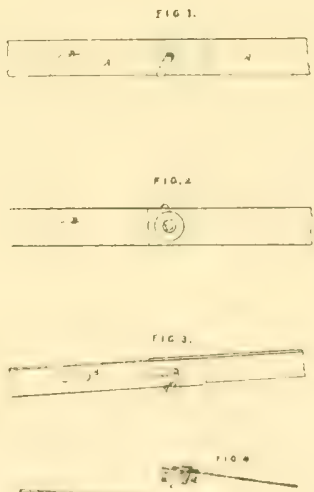

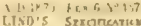

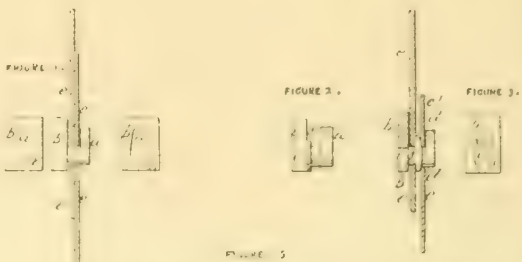

Le $\quad \cdots \quad \cdots+\cdots+\cdots$

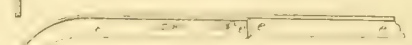

recura.t

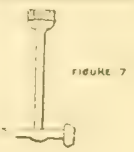




\section{NDEX.}

A.

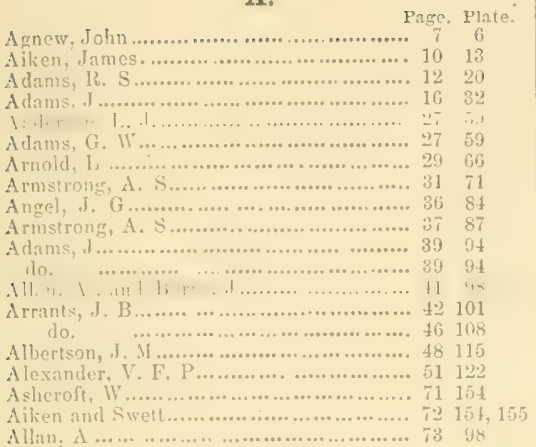

\section{B.}

Brond, $0 . \wedge$

Brodie, Geo

$$
\text { do. }
$$

Buyd, is in

Butler, J. T.

Bier, C. C

Beard, $G, N$

$$
\text { do. }
$$

Booth, James a

Buntiug, '1. B. ............................... 12, 21

Barharig, A n................................ $13 \quad 21$

Beard, G. N.................................... 132 2.2

Buckelew, W. F................................ 19 30

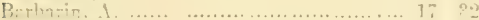

$$
\text { do. }
$$

Bislion, E. It ...

Beart, (i. N ....

Barbarin, A

Barumin, J. II

$$
\begin{aligned}
& \text { do. } \\
& \vdots \\
& \text { in. } \\
& \text { in. } \\
& \text { in. }
\end{aligned}
$$

Beard, (3. N

$$
\text { to. }
$$

Brott, s' $\mathrm{B}$....

Brown, F (B.....

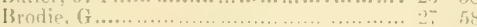

$$
\text { do. }
$$

Brown, C ............................................27

Brlscock. H. C ................................... 28 (j1

Beard, E. I .........................................29 69 64

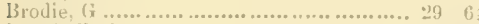

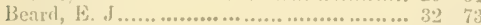

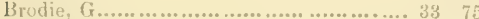

Beard, G. N.................................... $33 \quad 76$

Buford, A. G.................................. 31 it

Beard, G. N................................. 34

Beard, E. J................................. $35 \quad 82$
B.

Page: Plate

Bates, F. L L............................... $37 \quad 86$

Brodie, G................................... $37 \quad 88$

Banks, W. C...................................... $88 \quad 89$

Baldwin, A ....................................... 3890

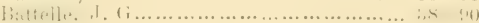

Boisseau, J....................................... $89 \quad 93$

Brown, I. T................................... to 95

Beard, G. N.................................. 4197

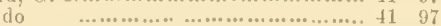

do

Baldwin, A................................... 43103

Brown. A. T...................................... 45106

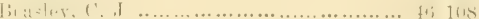

Brown, C..................................... 48116

Bodenhamer, L. I................................. 50119

Bailey, T................................ 51122

Burrow \& Nichols........................... 51122

Brandenburg, J. N............................ 52124

Bostwick, d. A.............................. 52 125

Briggs, J. N ................................. 54 1330

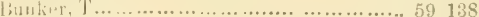

Boardman, C. E.............................. bi 143

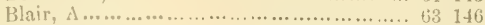

Breck, J......................................... fi3 116

Bull, J ....................................... 64

Buddington \& Hampton........................... 61 - -

Beard, G. N ............................... 65 . 17

bethlivuse, E. T................................. (is $1+9$

Barbarin, A .................................. $66 \quad 21$

Boyd, S ..................................... $66 \quad 150$

Beard, G. N.................................... 67150

Butler, J. T...................................... 68 151

Branch \& Crooks................................... 68 88

do. $\quad$ B................................... 6819

Briggs, T..................................... 68 -

do. ............................................ 6998 152

Brard. F. . T..................................... 70158

Brodie, G ..................................... it 55

Erett, S............................................ 7151

Butler, J. T'.................................... 7158

Beard, E. J ...................................... $72 \quad 64$

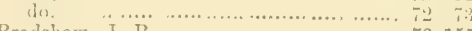

Bradshaw, J. B............................... T3 155 do. $\quad$.................................... 73 155

Buthili If Ifumphrey.......................... it it 156

c.

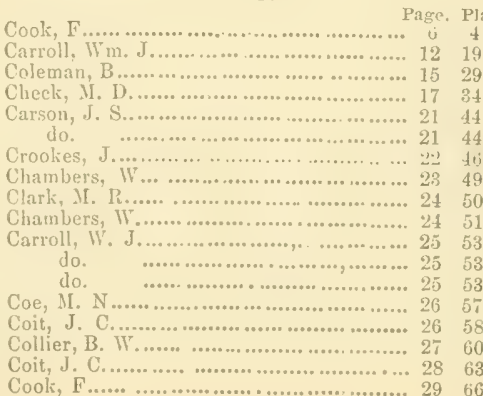

Page. Plate. 19 29 34 44

Cook, F...................................... 2969 
C.

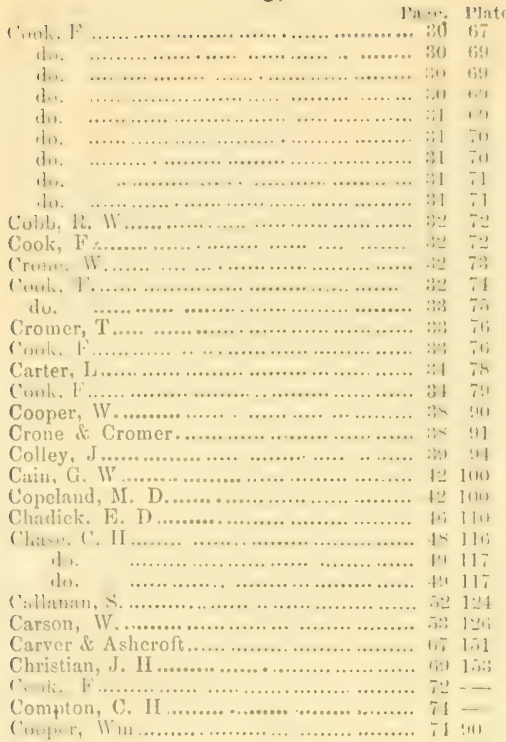

D.

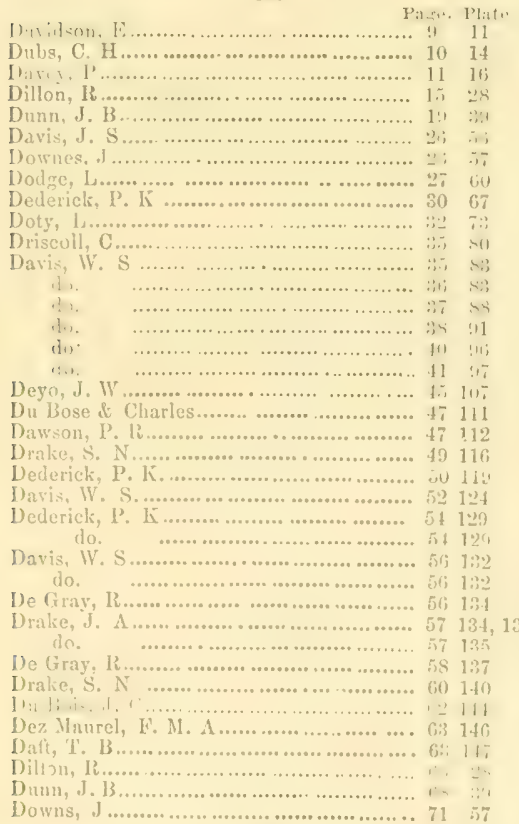

E.

I.,. I. . I, W

Ei: 111, , (). (

E. is 14

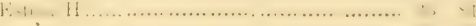
do.

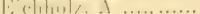
Elliott, II. 1'................................. lit1 H.................................... Wvans, L. E..................................... . . . Edmonson, J............................... \& 1 !

F.

r... $11,+$

Eenwick, 1\}. W.

lassman, F. V..................................... 11 18

Field, E. A n..................................... 12 18

Fassma11, H.................................... $1.1 \quad 20$ do.

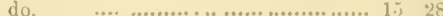

Fraley, J. H....................................... 19 98

Fletcher, A. C.................................. 19) 39 do, A. C................................... 1, 1,

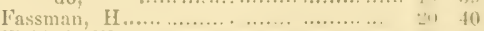

Fieli, B, II,

Franklin, K. A............................

Field, W. D............................... , I 70

ricle

F.1l li...................................,

lilickinger, J.K.............................. $: 37 \quad 87$

Ford, G. B.................................... हो si

Flinn \& Wier....................................... 4 10 ? 10 ?

France, G. S................................... of 12:S do,

Fowler, B. K................................. 56193

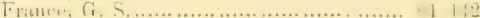
do,

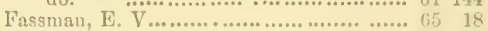

Fassman, H................................ $65 \quad 26$

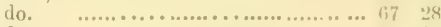
do. ................................. 6ii 27

G.

Page, Plate.

Gridley, J. II ....................................... 13

Guyol, T......................................... 19 19:

(ionch, s. H................................. $21{ }^{\circ} 48$

Goodgion, Ii. S ................................. 2! (5)

Gurley, J. IV .................................. 30 (i)

Going, A. J................................... 80 80 68 do. .................................... 30 68

Goldsmith, J. I........................... i3 76

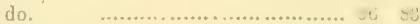

Goldsmith, A. A.............................. ङ зे 84

lir:ut, li...................................

Goldsmith, A. A............................ ii 89

Goldsmith, I. M................................ 87 87 89

Goldsmith, A A do. $\quad$...................................... do. $\quad$...................................... 39 39 94 4 the 1042

(jilman, s. H........................... is 102

(inldsmith, A. A....................... 4t 104

Goldsmith, J. YI......................... fis 107 do. $\quad$............................... 1ij 110 
H.

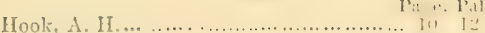

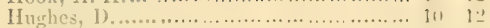

Hughes, Chas, .............................. 11 17

Hedenberg, J. W........................ I1 do

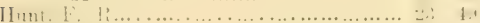

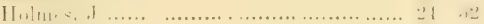

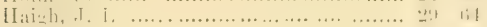

Loust, 11. A.......................................

Hedenberg, J. W................................. $30 \quad 68$ do $\quad$............................... $34 \quad 80$ do.

Hagaman, A. B................................ $36 \quad 86$

Higins, J, J ................................... $37 \quad 87$

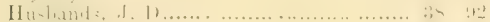

Hutchison, H. G............................. \$1 98

Hardman, J. H................................ 44106

Holloman, J. J................................ $45 \quad 108$

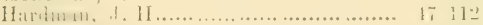

Herroll, C. IR.................................... 51 1:1

Horton, J. li................................. 52125

Herron, J. S. \& C. R.......................... 53126

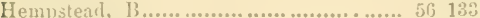

Hayden, W'. B............................... 56134

Hazeltine, IV, B................................. 59139

Hess, A. IV.................................. 59140

Hughes, $C$, .....

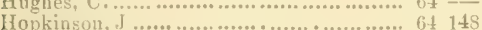

Holmes \& slack................................ 655

IInte. 11 . . L. II

I.

Page. Plate.

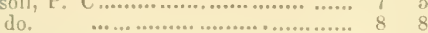
do.

Irvine. W. X[................................ 21 44

Iler, IV ........................................... 43102

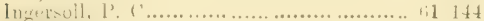

J.

Jeffery, E. A............................... Pnge. Plat Jordan, WV. A ........................................... 2t 50 do.

Jones, E. P........................................... $24 \quad 50$

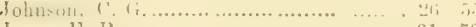

Jones, E. P.................................. $31 \quad 70$

Jordan, W. A .......................................... $34 \quad 80$

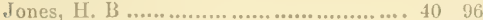
do. $\quad$..................................... 43102

Jordan, W. A....................................... 41101

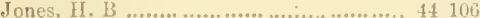

$$
\text { do. }
$$

18114

Jewett, (1. D ....................................... 5.5131

Jones, L. ['

Johnson, C. G.................................. 72

Jones, E. IR ............................................ is 50

Jordan, IV. A.................................. $73 \quad 80$

K.

Page. Plate

Knomles, II

(9) 11

Ku $\begin{aligned} & 1 \\ & n\end{aligned}$

Kimball, B .............................................. 38 is

Kennedy, J. R............................... $35 \quad 83$

Kimler,

King, P. F....................................... ss 13.

Knorles, 'T. C., and Derden, J. P.......... 59 13.

Krieg, C........................................ 59140

Kennedy, I. R ................................... (6) 145

Knowles, II ...................................... 65 . 11

L.

Page, Plate.

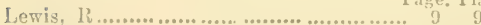

do.

Inanghborough, W. S................................. 10 14

Lee, Z. W., and E. D ......................... $10 \quad 15$

Lee, Z. IV .......................................... 13 22
I.

Pagc. Plate

Lee, J. C.................................... 1328

Latting, R. G............................... $14 \quad 26$

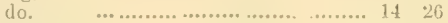

Lampson, H ................................... $16 \quad 31$

Littejohn, L...................................... 17 34

Lecky, li. H .............................. 18 3i

Lottridge, F. AI.................................. 22 47

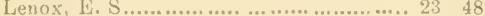

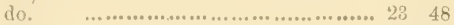

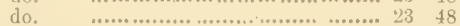

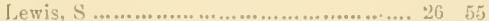

Lenox, E. S................................... $28 \quad 61$

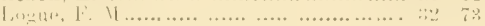

Laughland, G. L............................ 3ㄴ 74

Leonard, I', D................................... $31 \quad 77$

Len, J. E........................................... $85 \quad 81$

Logne, F. II ..................................... $36 \quad 84$

Lane, J. H........................................ $36 \quad 86$

Lenard, W. R................................ $39 \quad 92$

l.

Ludlow, R. C ..................................... $53 \quad 127$

do

Lowber, D. C .................................. 57136

Lewis, D. T...................................... 60141

Lampson, H................................. G0 149

Lee, J. C....................................... 66 6 22

Luens, T. H......................................... G7 150

Latting, R. G............................... $67 \quad 26$

Lowber, D. C.............................. $68 \quad 151$

Larmuth, iv ..................................... 695 -

Lenox, E. S.................................... 70 .

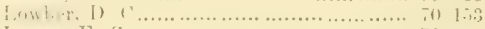

Lenox, E. S .................................. t to -

Leng, J. S..................................... 70 154

Lindon, H....................................... 71154

Laughland, Geo. L.............................. T* it

Lind, I ........................................ 74 15,

III.

P:i:an. Plate

: 2

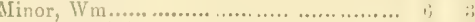

McILrtry, John ............................. . ; i

Manny, John P.............................. i

MeNurtry; J................................ In $]$

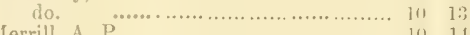

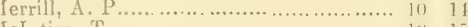

IcIntire, T............................... 10 10

MeComb, J. J ................................ 11 is

Milligan, J. F........................... 1: $1: 4$

Merritt, I. H.............................. 1: 19

McIntire, 'T'................................. 1:

Io Ilurtry, $J \ldots \ldots \ldots \ldots \ldots \ldots \ldots \ldots \ldots \ldots \ldots, \quad 12,21$

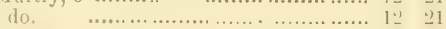

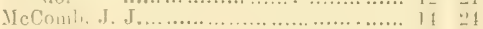

Milligan, John E................................ 1! 14

Macilaniel, 0 ................................... $16 \quad 30$

Maury, M. F................................. $16 \quad 30$

Maurry, IV. 1...................................... $16 \quad 31$

Milligan, J. F............................... $17 \quad 83$

Mitchell, S. J..................................... 18 is 35

Milligan, J. F ...................................... 18 35

Vorden, S nu...................................... $18 \quad 36$

Merritt, H. B .................................. 1939

Mudge, C............................................. 19

Norris, V. H................................... 21 45

Mainwaring, E. 'T ............................. 2.24

II cl)onald, J. B............................... $22 \quad 46$

Millioan, J. F................................. $21 \quad 51$

McFerran, S..................................... 2151

Martin, N ..................................... $25 \quad 52$

MeClintock, J. M ............................... $25 \quad 58$ dn. $\quad$................................ 25,54 do.

Mathers, S.................................. 26 55

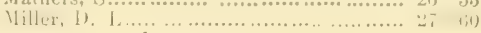


IH.

U. \, I : Y

Minor, H. 'I'

Milligan, I. H....

Mecomsts, 1)

Mcelsim, 0.12

If IInrtiy, d

McClean, .

NeCloan, ( ) B

Mangh:m, J. J ...

Alellwain, li. 1).

Montfort, li ...

Mecleath, 0 , B.....

Inphy, 'l'. J ...$$
\text { do. }
$$

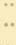

Montford, IR .........

Mnnlton, G............................. $1: 1$

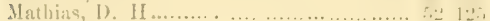

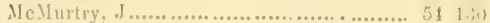

$$
\text { do. }
$$

$5+1,11$

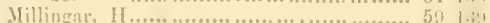

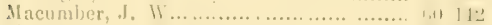

Moore, II. II............................. niा $11: 2$

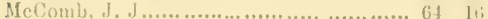

MleComb, 1) ..................................... of 11 ;

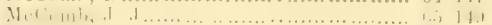

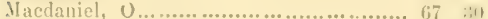

Maury, J.................................. 68 1 1 .

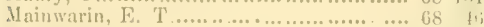

MeNahb, W............................... 699 1:2

$\$$ cl)ougall, A................................ 69 .

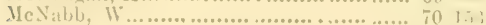

Marsden, $\$$.................................. 78 .

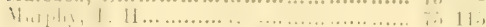

1V.

Neames, Charles............. I'ane.

Nuttall, I.................................... 9 111

Nellis, A. J................................ 36, !

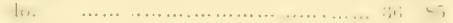

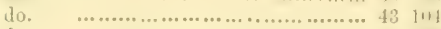

do.

Noblit, J ................................... 52 1 12.

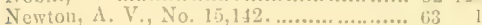

0 .

Olmsteal, 1). G...............

Onions, 11 .......................................... in

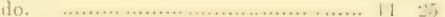

130. …............................ 11

Oliver, H. W. Jr............................. 21

Oakman, T'. C.................................

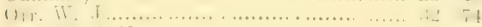

Osgood, G. N .................................. if 11.

111.. 1 . 1. 1) ...

P.

Provost, Chas. J

Flant, I. C..................

Penniston

I') I I , it

P'etty, ol, IV

Paine. $\mathrm{C}$.

I'i i i I I I I

Perkins, J. IH...

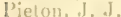

Pin in

I.

$$
\text { ilo. }
$$

do.

Powell, A. N....

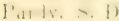

P.

l'age, Ilate

Putnnm, II. W................................ 65 13I

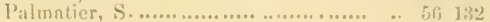

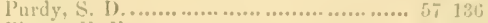

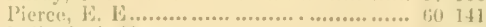

Pollard, J. II n.................................. (i) 14:

Pearre, C. M............................

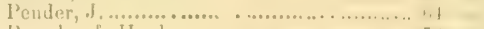

l'nrmley of Hughes .........................

Q.

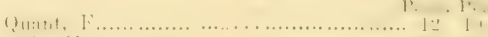

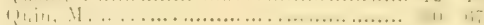

Quarles, $\mathrm{F}$

R.

Richard, A. C

do.

I. . $-1, \ldots$

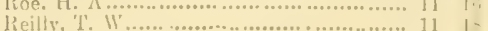

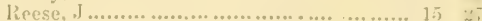

Reinecker, J........................................... 15 15 :

Reеse, J ....................................... 15 15

licker, Gico ................................... 16

Risler, S. 0 ................................... 1t 14

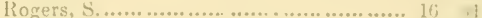

lioberts, I. S................................. 2 24)

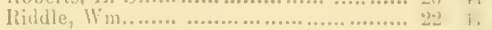

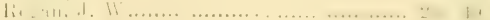

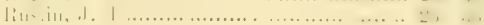

Ramsay, W. C

liandulph, J.

lin $\ldots, 1.1$.$$
\text { in. }
$$

Livas, II: 1 .

liadley, J. I’

liethmuller, J. C.

liamsey, B. $A$

Rogers, IV ....

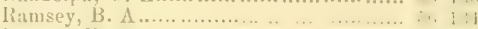

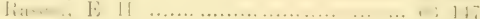

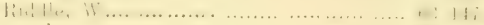

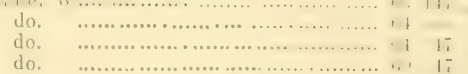

S.

P'age. 1 . 1.

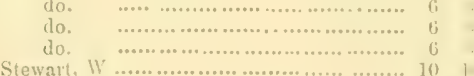

Senver, 6. A .............................. 18 :

Swelt, C....................................... 1:

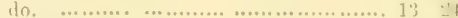

Seckler. 1). M.................................... if :

Shepprard, .. L................................... is .

Snear, I. K ................................... $1 !$

sheppard, d. L L...............................

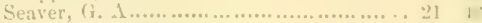

Shone, 1. $A$.................................. 21 1,

smilk, If. II ................................... 23$\}$ in

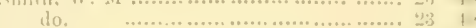

Sheppard, J. L..................................

well,
dis.

do.

do.

do.

skinner, [). S .

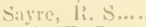

sliff, wr. C.

Starr, II. I)

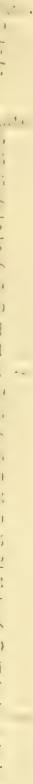

\section{.}


S.

Skinner, D. S.

Schnelle, C. II

Sherrill, I'. F.

Stafford, E H

Scott, G. IV

Smith, IV. II ....

Szabo, A. A ...

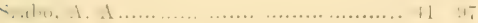

Smith, J. N................................. 11 98

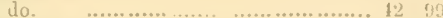

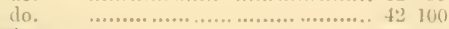

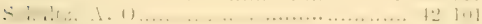

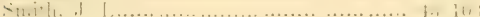

scott, G. W .................................... 45108

Smith, J. N ...................................... 1ti 110

Sheppard, J. L............................... 17 17 112

Sullivan, S................................... 47113

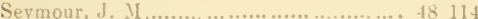

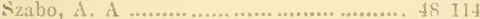

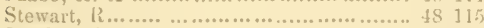

Stoeker, J. Z .................................... 49 118

Schartnu, E. O., and Gardner, J. H....... 49 118, 119

Stenton, IR. S.................................. ; il 12.2

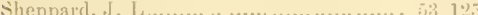

Slattery, 1 ..................................... 53120

Snyder, J. H ..................................... 55 132

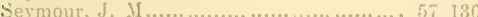

Snyder, J. H.................................... 57186

Sawatier, IV .......................................... 6939

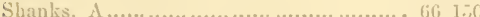

Sweet, J. E....................................... 68 -

Sparrow, . 1............................... 71 -

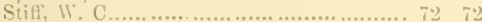

Stiff and Sheldon................................ it it

Seymour, J. II .................................. it is 114

T.

Talhot Jameg M Page. Plate.

Tarleton, .11. A ......................................... 14 2.

Truman, J. TV .................................................... 18

Trombridge, 11 .................................. 20 40

$$
\text { do. }
$$

Tingley, t . . . .

Tildesley, II ........................................ 2.2 47

Tillery, W. H................................... 39 99

'I'errell, R...n..................................... $40 \quad 95$

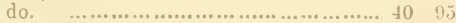

Taylor, R. if .................................. 42100

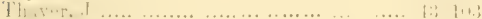

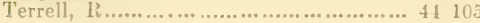

do. ............................................ it 105

à

Thayer, J.......................................... 53126

do. ........................................ 58,137
T.

Page. Plate.

Tweedale, f ................................ 59 140

Turek, H ..................................... 63 -

Tulleston, J.A............................. it 14 is

Tildesley, M.................................. if 17

Terrell, R........................................... it 96

U.

Page. Plate,

Ulmer, C $17 \quad 33$

V.

Page. Plate.

..... 19 37 37

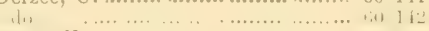

Victury, C. H ...................................... ul 1 1.

Van Hess, R............................... 64148

W.

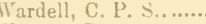

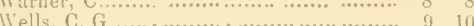

Widrig, G. I .................................... 99

Wailey, C. IV. ............................ 1010

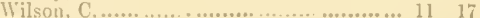

Wailey, C. W $\ldots \ldots \ldots \ldots \ldots \ldots \ldots \ldots \ldots \ldots \ldots \ldots$ I3 22

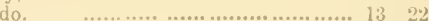

do.

Wallis. J. S ................................ 2.2 4.5

IVheelock, J ....................................... 22 42

IVatkins, F................................ 25 52

Walker, I. S................................... 29 29 65

Weil, I..................................... $31 \quad 79$

IVhiteman, E. W ............................ 35 8:

IV right, Y. F....................................... 3898

IVoodbury, (). D. \& E. C.................... $39 \quad 92$

Ward, C. A .................................... tis 99

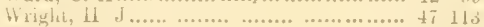

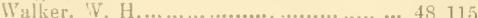

IVilkinson, W ................................... is 1 iso

Wheeler, F. G...................................... 59139

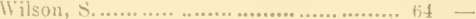

Wilson, R..................................... 6505

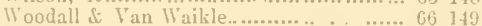

Wailey, C. W................................ $666^{\circ} \quad 22$

II ilson, S........................................ 60 -

Wailey, C. W ...................................... 67 $67 \quad 22$

Wrallis, J. S................................... $69 \quad 45$

Th hitaker \& Bradbury............................. 69 -

Watkins, F.................................... 70 -

Wialher, X. ................................ it th 1..

$\bar{Y}$.

Yardley, I. T.

Page. l'ate.

Young, H. Z. 


$$
\mathrm{H} 28484
$$






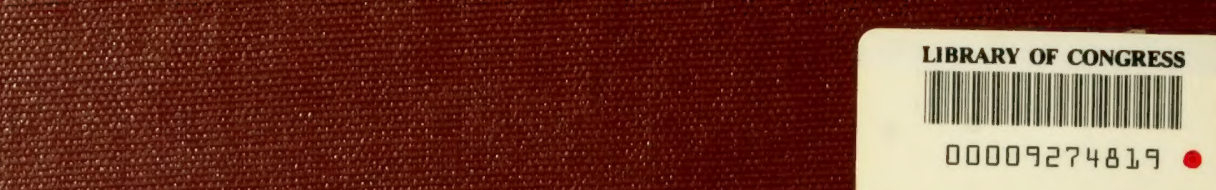

